\title{
Light Vehicle - Heavy Vehicle Interactions: A Critical Preliminary Assessment Using Critical Incident Analysis
}
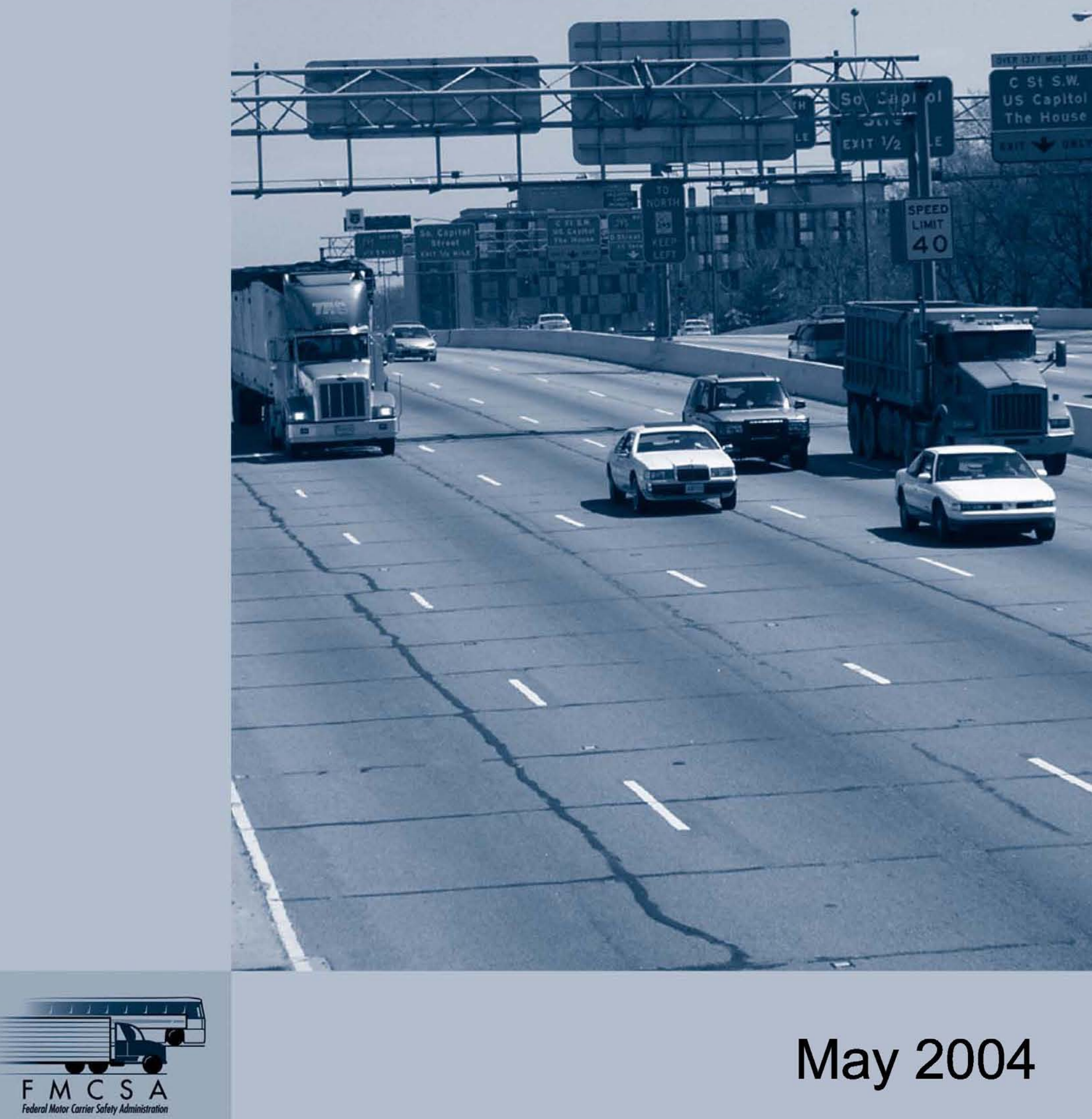

May 2004 


\section{Foreword}

The purpose of this study was to investigate driving behaviors that lead to critical events (e.g., near misses) when trucks and light vehicles interact on the highway. The results suggest that efforts at addressing light vehicle-heavy vehicle (LV-HV) interaction incidents should focus on the driving behaviors of the light vehicle drivers, as well as heavy vehicle drivers. Further, it is recommended that heavy vehicle drivers may also benefit from improved driver training that includes instruction on defensive driving.

Specific to this report, the Virginia Tech Transportation Institute (VTTI) was tasked by the Federal Motor Carriers Safety Administration (FMCSA) to conduct an in-depth investigation on what was termed "Light Vehicle-Heavy Vehicle Interactions: A Preliminary Assessment Using Critical Incident Analysis.”

Archived videotape recordings collected during each on-road data collection effort were retrieved and re-examined. Critical incidents that involved LV-HV interactions were separated and studied in detail, with 78 percent attributed to light vehicle drivers.

A taxonomy was then developed as part of the effort, which aided in characterizing the recorded incidents. In addition to identifying the initiator of each incident and categorizing the type of incidents recorded, analyses involved assessing the primary maneuver, general contributing factor, and specific contributing factor associated with each incident.

Members of the general public will find this report interesting and informative, as will anyone interested in the study of light vehicle-heavy vehicle interactions. This report is considered final in that it fully documents the results of the aforementioned study, and that the information provided herein is not superceded by other research.

\section{Notice}

This document is disseminated under the sponsorship of the Department of Transportation in the interest of information exchange. The United States Government assumes no liability for its contents or use thereof.

The contents of this report reflect the views of the contractor (and the individuals interviewed) who is responsible for the accuracy of the data presented herein. The contents do not necessarily reflect the official policy of the Department of Transportation.

The United States Government does not endorse products or manufacturers. Trademarks or manufacturers' names appear herein only if they are considered essential to the objectives of the document. This document does not constitute a standard, specification, or regulation. 
Technical Report Documentation Page

\begin{tabular}{|c|c|c|c|}
\hline $\begin{array}{l}\text { 1. Report No. } \\
\text { FMCSA-RT-04-004 }\end{array}$ & $\begin{array}{l}\text { 2. Government Accession No. } \\
\text { PB2004-105922 }\end{array}$ & \multicolumn{2}{|c|}{ 3. Recipient's Catalog No. } \\
\hline \multirow{2}{*}{\multicolumn{2}{|c|}{$\begin{array}{l}\text { 4. Title and Subtitle: } \\
\text { Light Vehicle-Heavy Vehicle Interactions: A Preliminary Assessment } \\
\text { Using Critical Incident Analysis }\end{array}$}} & \multicolumn{2}{|c|}{ 5. Report Date: May 2004} \\
\hline & & \multicolumn{2}{|c|}{ 6. Performing Organization Code } \\
\hline \multicolumn{2}{|c|}{$\begin{array}{l}\text { 7. Author(s): } \\
\text { Hanowski, Richard, J., Keisler, Aysha, Wierwille, Walter, W. }\end{array}$} & \multicolumn{2}{|c|}{ 8. Performing Organization Report No. } \\
\hline \multirow{2}{*}{\multicolumn{2}{|c|}{$\begin{array}{l}\text { 9. Performing Organization Name and Address } \\
\text { Virginia Tech Transportation Institute } \\
3500 \text { Transportation Research Plaza } \\
\text { Blacksburg, VA } 24061\end{array}$}} & \multicolumn{2}{|c|}{ 10. Work Unit No. (TRAIS) } \\
\hline & & \multicolumn{2}{|c|}{$\begin{array}{l}\text { 11. Contract or Grant No. } \\
\text { DTFH61-96-C-00105 }\end{array}$} \\
\hline \multirow{2}{*}{\multicolumn{2}{|c|}{$\begin{array}{l}\text { 12. Sponsoring Agency Name and Address } \\
\text { Federal Motor Carrier Safety Administration, USDOT } \\
400 \text { Virginia Ave., SW } \\
\text { Washington, DC } 20024\end{array}$}} & \multicolumn{2}{|c|}{$\begin{array}{l}\text { 13. Type of Report and Period Covered } \\
\text { Final Report }\end{array}$} \\
\hline & & \multicolumn{2}{|c|}{ 14. Sponsoring Agency Code } \\
\hline \multicolumn{4}{|c|}{$\begin{array}{l}\text { 15. Supplementary Notes } \\
\text { Robert J. Carroll was the FMCSA COTR for this project. }\end{array}$} \\
\hline \multicolumn{4}{|c|}{$\begin{array}{l}\text { 16. Abstract: Two recently completed on-road, in situ data collection efforts provided a large data set in which to conduct } \\
\text { an examination of near-crashes and crashes (critical incidents) that occurred between light vehicles (LV) and heavy } \\
\text { vehicles (HV). Video and other sensor data collected during the two studies were used to characterize critical incidents } \\
\text { that were recorded between LV and HV drivers. Across both studies, } 210 \mathrm{LV}-\mathrm{HV} \text { critical incidents were recorded. Of } \\
\text { these, } 78 \text { percent were initiated by the light vehicle driver. Aggressive driving, on the part of the LV driver, was found to } \\
\text { be the primary contributing factor for LV driver initiated incidents. For HV driver initiated incidents, the primary } \\
\text { contributing factor was poor driving technique. The results suggest that efforts at addressing LV-HV interaction incidents } \\
\text { should focus on aggressive light vehicle drivers. Additionally, it is recommended that HV drivers might benefit from } \\
\text { improved driver training that includes instruction on defensive driving. }\end{array}$} \\
\hline \multicolumn{2}{|c|}{$\begin{array}{l}\text { 17. Key Words } \\
\text { Truck, interaction, crash, critical incident, aggressive driving }\end{array}$} & \multicolumn{2}{|c|}{$\begin{array}{l}\text { 18. Distribution Statement } \\
\text { No restrictions. This document is available } \\
\text { to the public through the National } \\
\text { Technical Information Service, Springfield, } \\
\text { VA } 22161 \text {. }\end{array}$} \\
\hline $\begin{array}{l}\text { 19. Security Classif. (of this report) } \\
\text { Unclassified }\end{array}$ & $\begin{array}{l}\text { 20. Security Classif. (of this page) } \\
\text { Unclassified }\end{array}$ & $\begin{array}{c}\text { 21. No. of Pages } \\
200\end{array}$ & 22. Price \\
\hline
\end{tabular}




\section{ACKNOWLEDGMENTS}

This research was funded under an addendum to Federal Motor Carrier Safety Administration (formerly the Federal Highway Administration, Office of Motor Carrier Research and Standards) Contract Number DTFH-61-96-C-00105. Robert Carroll of FMCSA served as the Contracting Officer's Technical Representative. Thanks are due to Mr. Carroll for facilitating and advising on this project. The authors also wish to thank the following individuals for their help with this project:

- Dr. Ron Knipling of FMCSA for helpful technical suggestions.

- Dr. Tom Dingus of VTTI for ensuring that the necessary facilities and personnel were made available.

- Sheila Garness of VTTI for providing technical assistance regarding the Sleeper Berth project methodology.

- Eryn Perry of VTTI for editorial assistance and document production. 


\section{EXECUTIVE SUMMARY}

Data from a number of independent research efforts indicate that the interaction between light vehicles $(\mathrm{LV})$ and heavy vehicles $(\mathrm{HV})$ on the roadway is a serious problem. Focus groups conducted with Local/Short Haul drivers (Hanowski, Wierwille, Gellatly, Early, and Dingus, 2000) and Long Haul drivers (Neale, Robinson, Belz, Christian, Casali, and Dingus, 1998) found that heavy vehicle drivers believe light vehicle drivers are a primary safety concern. These findings are consistent with results of other published research efforts. For example, data from a recent report on large truck crashes (Federal Motor Carriers Safety Administration, 2000) indicate that in 1998, 4 percent of all roadway fatalities involved large trucks and "most victims [in these crashes] were people in the other vehicles, on bicycles, or pedestrians" (page 5). Given the consistent findings from various studies, the Virginia Tech Transportation Institute (VTTI) was tasked by the Federal Motor Carriers Safety Administration (FMCSA) to conduct an indepth investigation on what was termed "Light Vehicle/ Heavy Vehicle (LV-HV) Interaction."

There were two phases to this project. In the first phase, the critical incident interactions between light vehicles and Local/Short Haul (L/SH) vehicles were studied. The on-road data to conduct the first phase were taken from the FMCSA-sponsored project entitled "The Impact of Local/Short Haul Operations on Driver Fatigue" (DTFH-61-96-C-00105). In the second phase, the light vehicle-heavy vehicle (LV-HV) critical incident interactions captured in the FMCSAsponsored project entitled "The Impact of Sleeper Berth Usage on Driver Fatigue” (DTFH-6196-C-00068) were studied. For both phases, archived videotape recordings collected during each on-road data collection effort were retrieved and re-examined. Critical incidents that involved LV-HV interactions were separated and studied in detail. Video cameras recorded multiple views both inside and outside the HV. These multiple views were combined in a composite image and provided good coverage of the external vehicle environment as well as the driver's face and eye glance positions. The tapes also included audio from a microphone in the cab of the heavy vehicle.

A total of $142 \mathrm{LV}-\mathrm{HV}$ interaction critical incidents were identified in the L/SH data. Of these, 117 (82.4 percent) were initiated by (attributed to) light vehicle drivers, while 25 (17.6 percent) events were initiated by L/SH drivers. Further analysis showed that the types of incidents differed between the two driver classes. For incidents attributable to light vehicle drivers, the three most prevalent types were: 1) lane change without sufficient gap, 2) entering roadway without sufficient clearance, and 3) left turn without clearance. All of these categories confirm what L/SH drivers stated in focus groups: that they were often "cut off" by light vehicle drivers, and that they have a problem with light vehicles. For incidents attributable to L/SH drivers, the three most prevalent types were: 1) entering roadway without sufficient clearance, 2) backing in roadway (in presence of through traffic), and 3) late braking for stopped/stopping traffic, tied with wide turn into adjacent lane.

Similar results were found in the analysis of the LV-HV incidents in the Sleeper Berth data set. Of the 68 interaction incidents identified, 47 were initiated by a light vehicle driver. The most prominent type of incident for light vehicle drivers was "lane change without sufficient gap." This particular incident type accounted for 32 percent of all light vehicle driver-initiated 
incidents. For incidents caused by heavy vehicle drivers, the most common classification type was "late braking for stopped/stopping traffic," occurring in 48 percent of the HV driver-initiated incidents.

In addition to identifying the initiator of each incident and categorizing the type of incidents recorded, analyses involved assessing the primary maneuver, general contributing factor, and specific contributing factor associated with each incident. A taxonomy was developed as part of the effort, which aided in characterizing the recorded incidents.

The results from this study indicate that LV-HV interactions represent a serious problem. The detailed analyses that were conducted provide insight into how this problem might be addressed. The following are several concrete ideas that might be considered for reducing LV-HV interactions:

- Addressing the LV-HV interaction problem must focus on the light vehicle driver. The light vehicle driver was the initiator in 78 percent of the LV-HV interaction incidents recorded.

- The primary area for light vehicle drivers that should be addressed involves Aggressive Driving. The majority of light vehicle driver-initiated critical incidents that were captured in both the $\mathrm{L} / \mathrm{SH}$ and sleeper berth data collection efforts were due to Aggressive Driving.

- The primary area for heavy vehicle drivers that should be addressed involves Driving Techniques. Improved truck driver training programs should be implemented. Consideration should be given to ongoing (e.g., yearly) training courses. Given the high incidence of Aggressive Driving on the part of light vehicle drivers, one of the primary areas of focus for a truck driving training program should be on defensive driving.

- Infrastructure was found to play a role in L/SH driver-initiated incidents. Drivers and/or company dispatchers should be cognizant of problematic sections of routes, and avoid such locations to the greatest extent possible.

- In situ data collection is an effective way in which to study a wide range of safety-related issues in a naturalistic environment. The video and performance/behavior data collected from the L/SH and Sleeper Berth studies have been archived and provide a rich source of information that can be used for studying critical incidents, as was the case in the current effort, or other issues that might be identified at a later time. 


\section{TABLE OF CONTENTS}

CHAPTER 1: LOCAL/SHORT HAUL INTERACTIONS .................................................................................

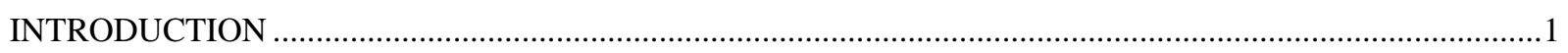

Overview of the Light Vehicle-Heavy Vehicle Interaction Problem ...............................................................

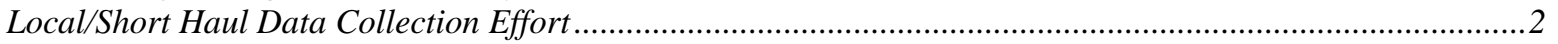

Defining Local/Short Haul Operations.................................................................................................................

Phase I: Focus Groups Conducted Nationwide ..................................................................................................... 2

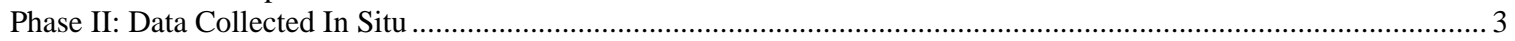

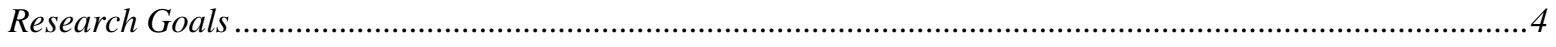

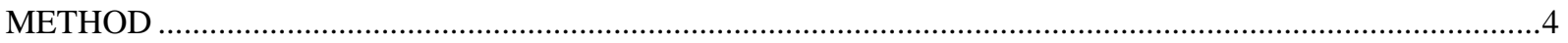

Data Collection Methodology for the L/SH Driver Fatigue Study .................................................................

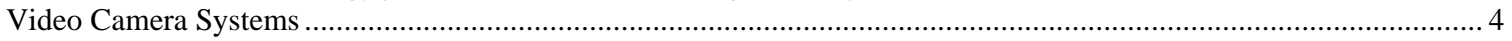

Video Recording Operation ........................................................................................................................... 6

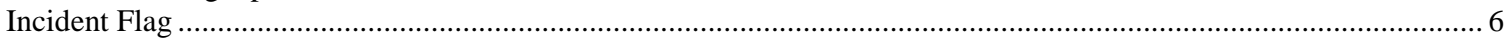

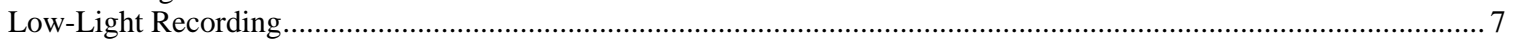

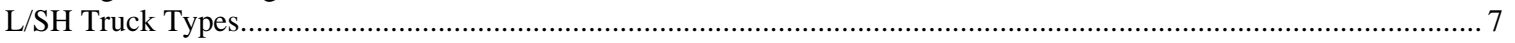

Re-analysis of Archived Incidents .........................................................................................................

Strengths and Limitations of the Methodology Used .................................................................................10

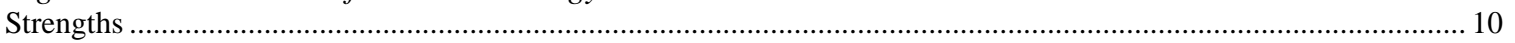

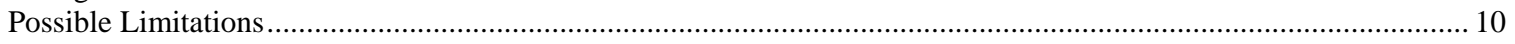

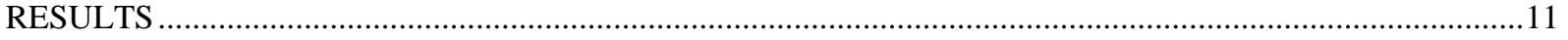

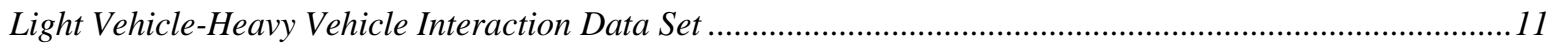

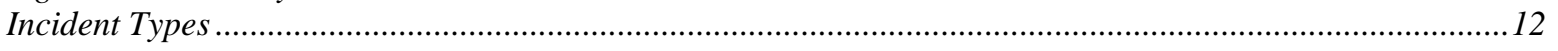

Primary Maneuvers, Secondary Maneuvers, and Conflict Types .................................................................28

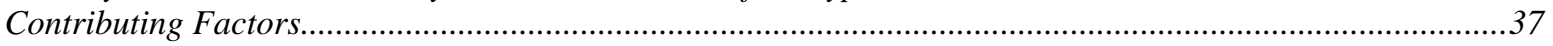

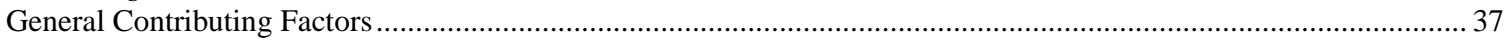

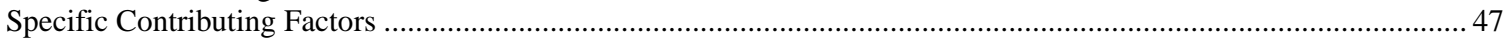

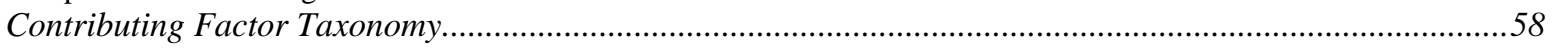

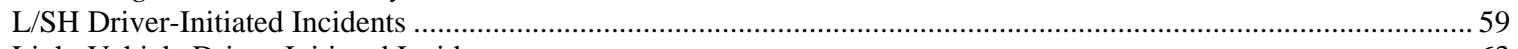

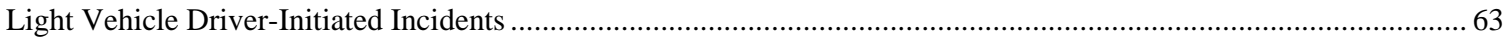

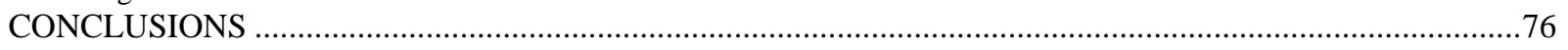

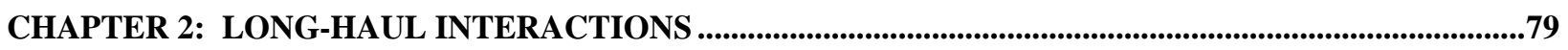

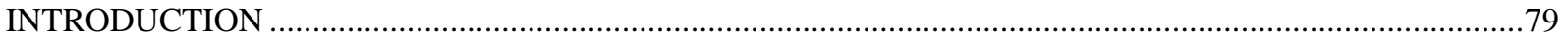

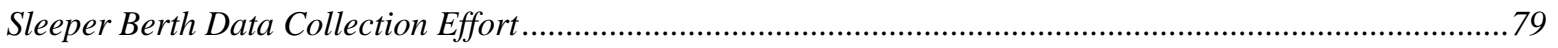

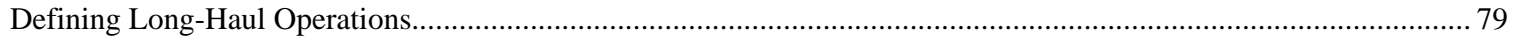

Phase I: Long-Haul Focus Groups ………………………………………………………………………….... 79

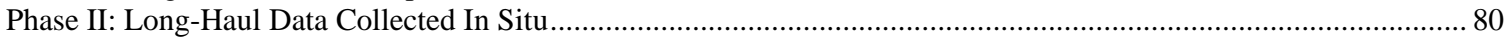

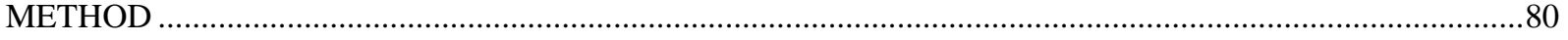

Data Collection Methodology for the Sleeper Berth Study ..........................................................................8

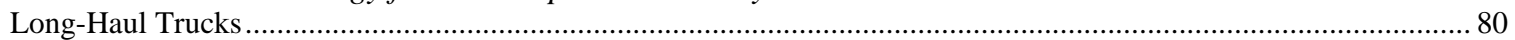

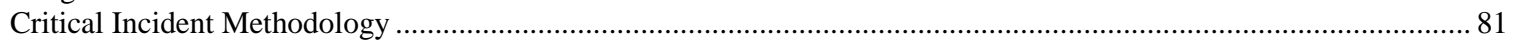

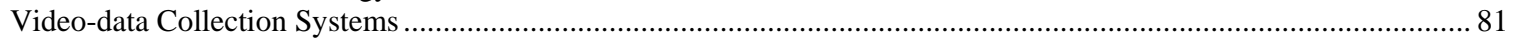

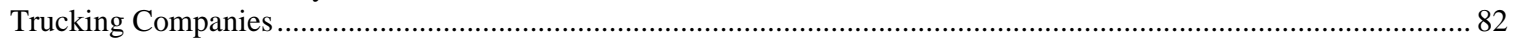

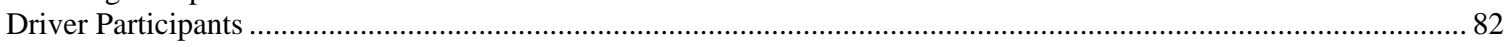

Strengths and Limitations of the Methodology Used ……...........................................................................83

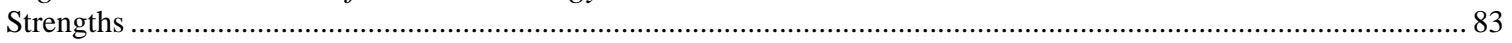

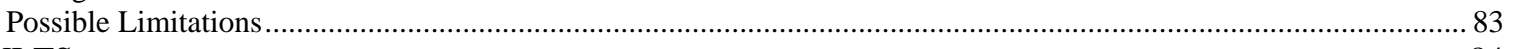

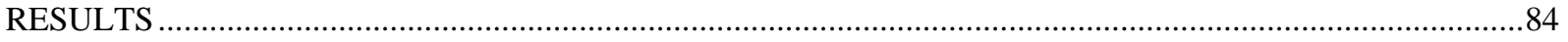

Light Vehicle-Heavy Vehicle Interaction Data Set ……........................................................................84

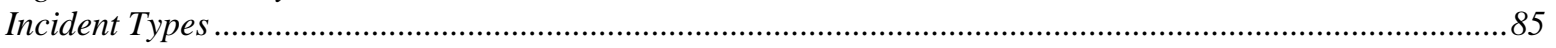

Primary Maneuvers, Secondary Maneuvers, and Conflict Types ................................................................94

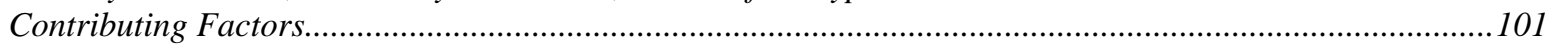

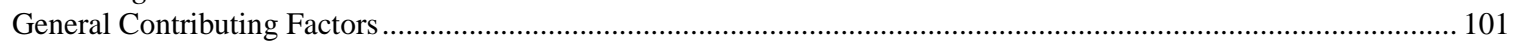

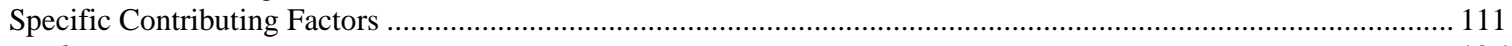

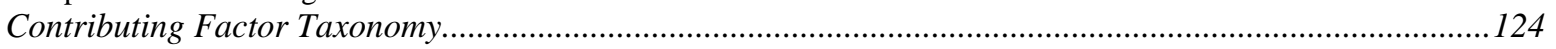




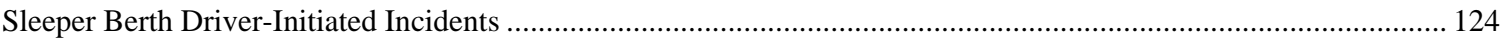

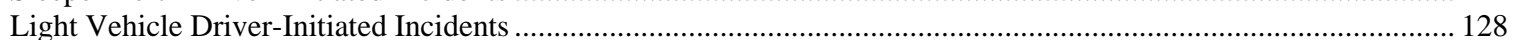

DISCUSSION OF THE RESULTS FROM LIGHT VEHICLE-HEAVY VEHICLE ANALYSIS USING THE

SLEEPER BERTH DATA SET .

CHAPTER 3: COMPARISON OF THE RESULTS FROM THE ANALYSES CONDUCTED WITH THE

LOCAL/SHORT HAUL DATA AND THE SLEEPER BERTH DATA ....................................................139

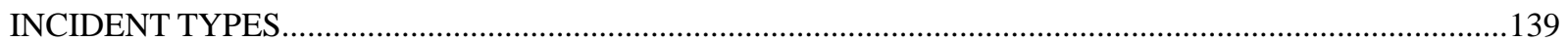

Primary Maneuvers, General Contributing Factors, and Secondary Contributing Factors ..........................149

Differences Due to Data Collection Methods ......................................................................................166

DISCUSSION OF THE RESULTS COMPARING THE L/SH AND SLEEPER BERTH ANALYSES ..............175

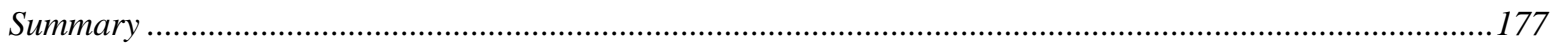

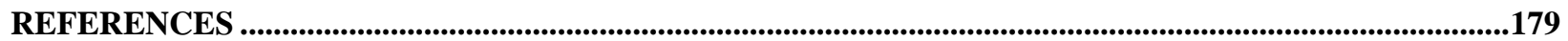




\section{LIST OF FIGURES}

FIGURE 1. CAMERA DIRECTIONS AND APPROXIMATE FIELDS OF VIEW. …….........................................................

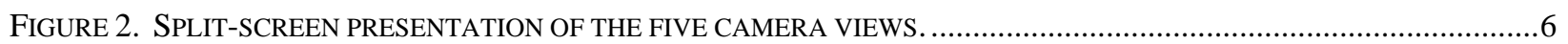

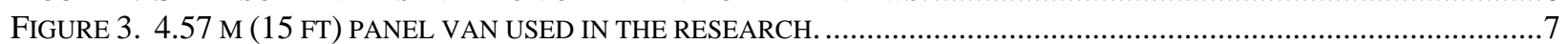

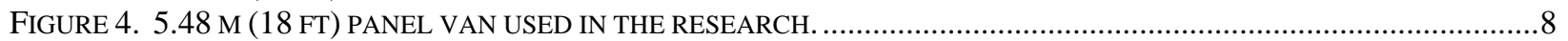

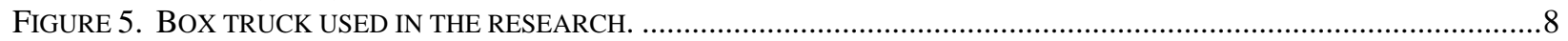

FIGURE 6. CLASS B STRAIGHT TRUCK USED IN THE RESEARCH. .............................................................................

FIGURE 7. INTERACTION BREAKDOWN OF THE 249 CRITICAL INCIDENTS CAPTURED IN THE ORIGINAL L/SH STUDY....12

FIGURE 8. FREQUENCY OF INCIDENT TYPES; ALL INCIDENTS INCLUDED...............................................................20

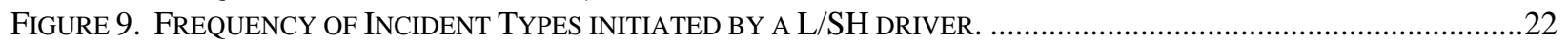

FIGURE 10. FREQUENCY OF INCIDENT TYPES INITIATED BY A LIGHT VEHICLE DRIVER. ...........................................24

FIGURE 11. FREQUENCY OF INCIDENT TYPES; ALL INCIDENTS INCLUDED WHERE $\mathrm{N}_{\text {LIGHT VeHICLE }}=117$ AND $\mathrm{N}_{\mathrm{L} / S \mathrm{SH}}=25 . \ldots . .27$

FIGURE 12. FREQUENCY OF PRIMARY MANEUVERS; ALL INCIDENTS INCLUDED.......................................................32

FigURE 13. FREQUENCY OF PRIMARY MANEUVERS INVOLVING L/SH DRIVER-INITIATED INCIDENTS. ........................34

FIGURE 14. FREQUENCY OF PRIMARY MANEUVERS INVOLVING LIGHT VEHICLE DRIVER-INITIATED INCIDENTS...........36

Figure 15. FREQUENCY OF PRIMARY MANEUVERS; ALL INCIDENTS INCLUDED WHERE $\mathrm{N}_{\text {LIGHT Vehicle }}=117$

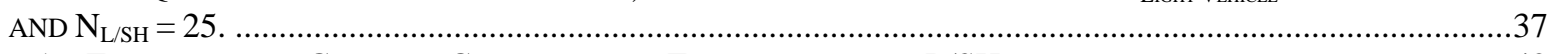

FIGURE 16. FREQUENCY OF GENERAL CONTRIBUTING FACTORS FOR THE L/SH DRIVER-INITIATED INCIDENTS............42

FIGURE 17. FREQUENCY OF GENERAL CONTRIBUTING FACTORS FOR THE LIGHT VEHICLE DRIVER-INITIATED INCIDENTS

FIGURE 18. FREQUENCY OF GENERAL CONTRIBUTING FACTORS; ALL INCIDENTS INCLUDED WHERE

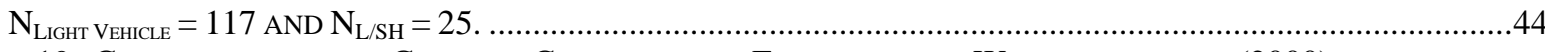

FiguRE 19. COMPARISON OF THE GENERAL CONTRIBUTING FACTORS FROM WIERWILLE ET AL. (2000) AND ALL (DETERMINABLE) DATA IN THE CURRENT RESEARCH.

FigURE 20. GENERAL CONTRIBUTING FACTORS COMPARISON OF THE WIERWILLE ET AL. (2000) DATA AND DETERMINABLE DATA FROM THE LIGHT VEHICLE DRIVER-INITIATED INCIDENTS CAPTURED IN THE CURRENT

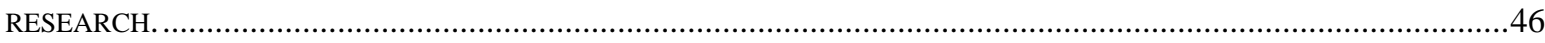

FIGURE 21. FREQUENCY OF SPECIFIC CONTRIBUTING FACTORS; ALL INCIDENTS INCLUDED WHERE

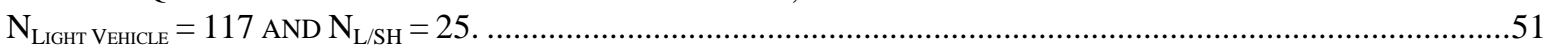

FIGURE 22. FREQUENCY OF SPECIFIC CONTRIBUTING FACTORS FOR THE L/SH DRIVER-INITIATED INCIDENTS.............54

FIGURE 23. FREQUENCY OF SPECIFIC CONTRIBUTING FACTORS FOR THE LIGHT VEHICLE DRIVER-INITIATED

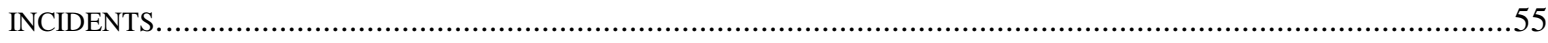

FIGURE 24. OUTLINE TAXONOMY OF THE CONTRIBUTING FACTORS FOR THE INCIDENTS INITIATED BY THE L/SH

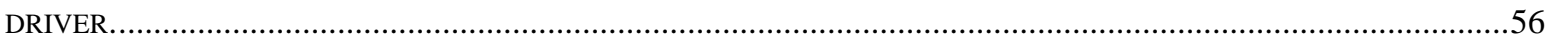

FIGURE 25. OUTLINE TAXONOMY OF THE CONTRIBUTING FACTORS FOR THE INCIDENTS INITIATED BY THE LIGHT

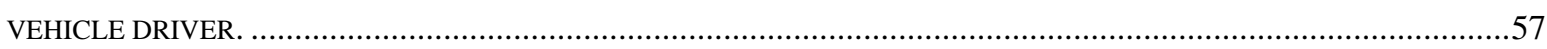

FIGURE 26. TAXONOMY STRUCTURE USED TO CHARACTERIZE THE 142 INTERACTION INCIDENTS...............................59

FIGURE 27. CONTRIBUTING FACTOR TAXONOMY: INCIDENTS INITIATED BY THE L/SH DRIVER. ................................60

FIGURE 28. CONTRIBUTING FACTOR TAXONOMY: INCIDENTS INITIATED BY THE LIGHT VEHICLE DRIVER....................64

FiguRE 29. VTTI'S TWO CLASS 8 HEAVY TRUCKS; 1997 VOLVO L4 VN-SERIES TRACTOR (LEFT) AND 1995 PETERBILT 379 TRACTOR (RIGHT).

FigURE 30. MULTIPLEXED IMAGE SHOWING THE SCENES OBSERVED BY THE FOUR STRATEGICALLY-LOCATED VIDEO CAMERAS (CLOCKWISE FROM UPPER LEFT): FORWARD ROAD SCENE, DRIVER'S FACE (OBSCURED TO PRESERVE ANONYMITY), LEFT-SIDE/REARWARD SCENE, RIGHT-SIDE/REARWARD SCENE. EVENT FLAGS AND RUNNING TIME ARE ALSO DISPLAYED.

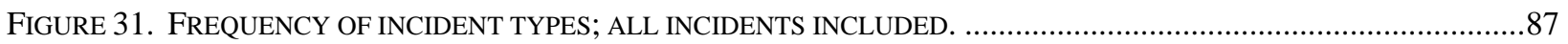

FIGURE 32. FREQUENCY OF INCIDENT TYPES AS A FUNCTION OF THE INITIATING DRIVER. ........................................8

FIGURE 33. FREQUENCY OF INCIDENT TYPES INITIATED BY A LIGHT VEHICLE DRIVER...............................................89

FIGURE 34. FREQUENCY OF INCIDENT TYPES INITIATED BY A SLEEPER BERTH DRIVER. .........................................90

FIGURE 35. FREQUENCY OF INCIDENT TYPES AS A FUNCTION OF DRIVER TYPE. .........................................................91

FIGURE 36. FREQUENCY OF INCIDENT TYPES INVOLVING TEAM AND SINGLE DRIVERS FOR INCIDENTS INITIATED BY A LIGHT VEHICLE DRIVER. .92

FIGURE 37. FREQUENCY OF INCIDENT TYPES INVOLVING TEAM AND SINGLE DRIVERS FOR INCIDENTS INITIATED BY A SLEEPER BERTH DRIVER. 
FIGURE 38. FREQUENCY OF PRIMARY MANEUVERS FOR ALL INCIDENTS. ......................................................................95

FIGURE 39. FREQUENCY OF PRIMARY MANEUVERS AS A FUNCTION OF INITIATING DRIVER. .....................................96

FIGURE 40. FREQUENCY OF PRIMARY MANEUVERS FOR THE LIGHT VEHICLE DRIVER-INITIATED INCIDENTS. ...............97

FigURE 41. FREQUENCY OF PRIMARY MANEUVERS FOR THE SLEEPER BERTH DRIVER-INITIATED INCIDENTS...............98

FIGURE 42. FREQUENCY OF PRIMARY MANEUVERS AS A FUNCTION OF DRIVER TYPE. ..............................................99

FIGURE 43. FREQUENCY OF INCIDENT TYPES INVOLVING TEAM AND SINGLE DRIVERS FOR INCIDENTS INITIATED

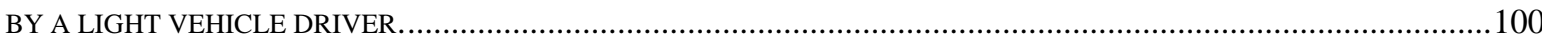

FIGURE 44. FREQUENCY OF INCIDENT TYPES INVOLVING TEAM AND SINGLE DRIVERS FOR INCIDENTS INITIATED

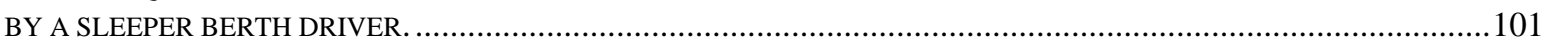

FIGURE 45. FREQUENCY OF GENERAL CONTRIBUTING FACTORS FOR ALL INCIDENTS. .............................................103

FigURE 46. FREQUENCY OF GENERAL CONTRIBUTING FACTOR AS A FUNCTION OF INITIATING DRIVER. ....................104

FIGURE 47. FREQUENCY OF GENERAL CONTRIBUTING FACTOR FOR THE LIGHT VEHICLE DRIVER INITIATED

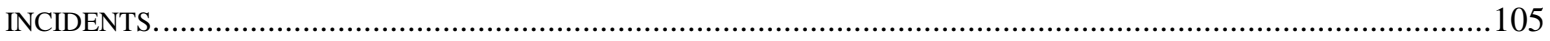

FIGURE 48. FREQUENCY OF GENERAL CONTRIBUTING FACTOR FOR THE SLEEPER BERTH DRIVER INITIATED

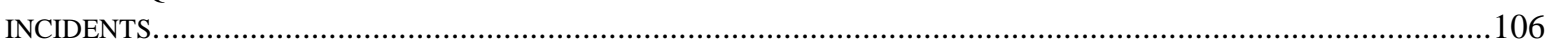

FiguRE 49. FREQUENCY OF GENERAL CONTRIBUTING FACTORS AS A FUNCTION OF DRIVER TYPE............................107

FIGURE 50. FREQUENCY OF GENERAL CONTRIBUTING FACTORS INVOLVING TEAM AND SINGLE DRIVERS FOR INCIDENTS INITIATED BY A LIGHT VEHICLE DRIVER. ............................................................................... 108

FIGURE 51. FREQUENCY OF GENERAL CONTRIBUTING FACTORS INVOLVING TEAM AND SINGLE DRIVERS FOR INCIDENTS INITIATED BY A SLEEPER BERTH DRIVER.

FiguRE 52. COMPARISON OF GENERAL CONTRIBUTING FACTORS WIERWILLE ET AL. (2000) AND ALL DETERMINABLE DATA FROM THE CURRENT RESEARCH.

FiguRE 53. COMPARISON OF GENERAL CONTRIBUTING FACTORS WIERWILLE ET AL. (2000) AND THE DETERMINABLE DATA FROM THE LIGHT VEHICLE DRIVER-INITIATED INCIDENTS CAPTURED IN THE CURRENT RESEARCH.

FigURE 54. FREQUENCY OF SPECIFIC CONTRIBUTING FACTORS FOR ALL INCIDENTS.

FiguRE 55. FREQUENCY OF SPECIFIC CONTRIBUTING FACTORS AS A FUNCTION OF INITIATING DRIVER.

FIGURE 56. FREQUENCY OF SPECIFIC CONTRIBUTING FACTORS FOR THE LIGHT VEHICLE DRIVER INITIATED INCIDENTS

FIGURE 57. FREQUENCY OF SPECIFIC CONTRIBUTING FACTORS FOR THE SLEEPER BERTH DRIVER INITIATED INCIDENTS

FiguRE 58. FREQUENCY OF SPECIFIC CONTRIBUTING FACTORS AS A FUNCTION OF HV DRIVER TYPE.

Figure 59. FREQUENCY OF SPECIFIC CONTRIBUTING FACTORS INVOLVING HV TEAM AND HV SINGLE DRIVERS FOR INCIDENTS INITIATED BY A LIGHT VEHICLE DRIVER.

FiguRE 60. FREQUENCY OF SPECIFIC CONTRIBUTING FACTORS INVOLVING HV TEAM AND HV SINGLE DRIVERS FOR INCIDENTS INITIATED BY A SLEEPER BERTH DRIVER.

FIGURE 61. OUTLINE TAXONOMY OF THE CONTRIBUTING FACTORS FOR THE INCIDENTS INITIATED BY THE SLEEPER BERTH DRIVER.

FIGURE 62. OUTLINE TAXONOMY OF THE CONTRIBUTING FACTORS FOR THE INCIDENTS INITIATED BY THE LIGHT VEHICLE DRIVER.

FIGURE 63. TAXONOMY STRUCTURE USED TO CHARACTERIZE THE 68 INTERACTION INCIDENTS...............................124

FIGURE 64. CONTRIBUTING FACTOR TAXONOMY: INCIDENTS INITIATED BY THE SLEEPER BERTH DRIVER. .................125

FIGURE 65. CONTRIBUTING FACTOR TAXONOMY: INCIDENTS INITIATED BY THE LIGHT VEHICLE DRIVER..................129

FiguRE 66. PERCENTAGE OF INCIDENT OCCURRENCE AS A FUNCTION OF INCIDENT TYPE; ALL INCIDENTS FROM BOTH DATA SETS INCLUDED.

FiguRE 67. PERCENTAGE OF INCIDENT OCCURRENCE AS A FUNCTION OF INCIDENT TYPE FOR THE HEAVY VEHICLE DRIVER-INITIATED INCIDENTS.

Figure 68. PERCENTAGE OF INCIDENT OCCURRENCE AS A FUNCTION OF ROAD TYPE AND TRUCKING OPERATION.

Figure 69. PERCENTAGE OF INCIDENT OCCURRENCE AS A FUNCTION OF INCIDENT TYPE FOR THE LIGHT VEHICLE DRIVER-INITIATED INCIDENTS.

Figure 70. Percentage of InCident OCCURRENCE AS A FUnCTION OF THE PRIMARY MANEUVERS; ALL INCIDENTS FROM BOTH DATA SETS INCLUDED.

Figure 71. PERCENTAGE OF INCIDENT OCCURRENCE AS A FUNCTION OF THE PRIMARY MANEUVERS FOR HEAVY VEHICLE DRIVER-INITIATED INCIDENTS. 
Figure 72. PERCENTAge OF INCIDENT OCCURRENCE AS A FUNCTION OF THE PRIMARY MANEUVERS FOR LIGHT

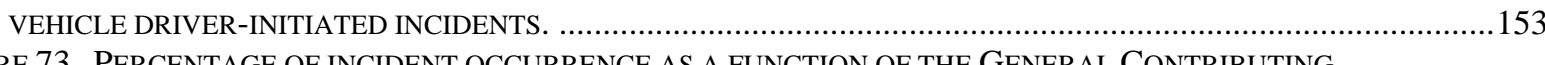

Figure 73. PERCENTAGE OF INCIDENT OCCURRENCE AS A FUNCTION OF THE GENERAL CONTRIBUTING

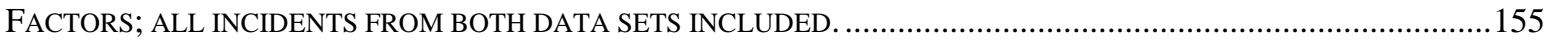

Figure 74. PERCENTAGE OF INCIDENT OCCURRENCE AS A FUNCTION OF THE GENERAL CONTRIBUTING

FACTORS FOR HEAVY VEHICLE DRIVER-INITIATED INCIDENTS. ..........................................................156

FIGURE 75. PERCENTAGE OF INCIDENT OCCURRENCE AS A FUNCTION OF THE GENERAL CONTRIBUTING

FACTORS FOR HEAVY VEHICLE DRIVER-INITIATED INCIDENTS. .............................................................157

Figure 76. PERCENTAGE OF INCIDENT OCCURRENCE AS A FUNCTION OF THE SPECIFIC CONTRIBUTING

FACTORS; ALL INCIDENTS FROM BOTH DATA SETS INCLUDED, .................................................................161

Figure 77. PERCENTAGE OF INCIDENT OCCURRENCE AS A FUNCTION OF THE SPECIFIC CONTRIBUTING

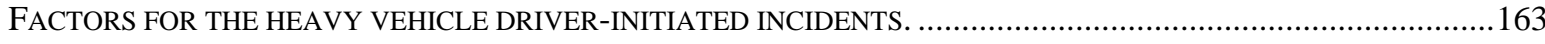

Figure 78. PERCENTAGE OF INCIDENT OCCURRENCE AS A FUNCTION OF THE SPECIFIC CONTRIBUTING

FACTORS FOR THE LIGHT VEHICLE DRIVER-INITIATED INCIDENTS ............................................................165

FIGURE 79. INCIDENT TYPE PERCENTAGE FREQUENCY IN TRIGGERED AND NON-TRIGGERED EVENTS IN

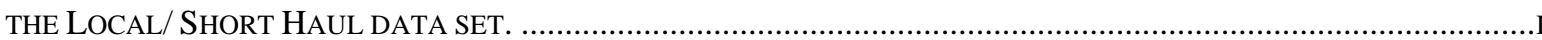

Figure 80. PERCENTAGE OF INCIDENT OCCURRENCE AS A FUNCTION OF INCIDENT TYPE; ONLY TRIGGERED

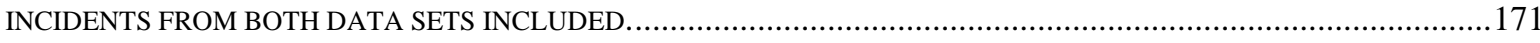

FIgURE 81. PERCENTAGE OF INCIDENT OCCURRENCE AS A FUNCTION OF INCIDENT TYPE; ALL INCIDENTS

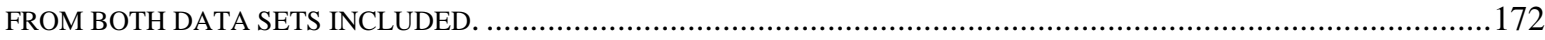

FIGURE 82. RATE OF INCIDENT OCCURRENCE AS A FUNCTION OF INCIDENT TYPE; ONLY TRIGGERED EVENTS FROM BOTH DATA SETS INCLUDED. 


\section{LIST OF TABLES}

TABLE 1. DESCRIPTION OF THE INCIDENT TYPES THAT WERE IDENTIFIED IN THIS EFFORT......................................13

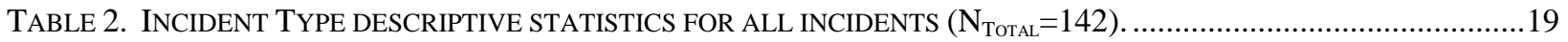

TABLE 3. INCIDENT TYPE DESCRIPTIVE STATISTICS FOR INCIDENTS INITIATED BY A L/SH DRIVER $\left(\mathrm{N}_{\mathrm{L} / \mathrm{SH}}=25\right) . . . . . . . . .21$

TABLE 4. INCIDENT TYPE DESCRIPTIVE STATISTICS FOR INCIDENTS INITIATED BY A LV DRIVER

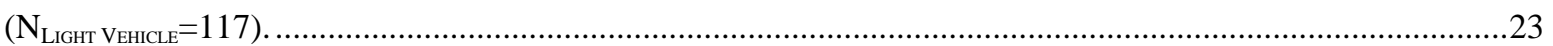

TABLE 5. LIST AND DEFINITION OF PRIMARY MANEUVER TYPES......................................................................28

TABLE 6. THIRTY-SEVEN CONFLICT TYPES IDENTIFIED FOR THE 142 INTERACTION INCIDENTS................................29

TABLE 7. PRIMARY MANEUVER DESCRIPTIVE STATISTICS; ALL INCIDENTS INCLUDED $\left(\mathrm{N}_{\text {Total }}=142\right) \ldots . . . . . . . . . . . . . . . . . . . .31$

TABLE 8. PRIMARY MANEUVER DESCRIPTIVE STATISTICS FOR INCIDENTS INITIATED BY A L/SH DRIVER

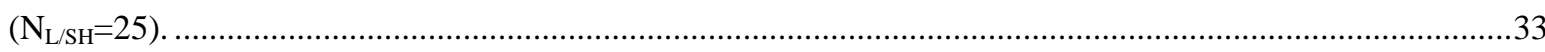

TABLE 9. PRIMARY MANEUVER DESCRIPTIVE STATISTICS FOR INCIDENTS INITIATED BY AN LV DRIVER

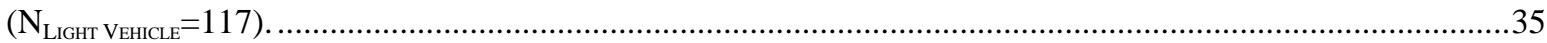

TABLE 10. GENERAL CONTRIBUTING FACTORS USED TO IDENTIFY THE PRIMARY CAUSE OF THE INCIDENT. ...............38

TABLE 11. GENERAL CONTRIBUTING FACTOR OCCURRENCE DATA FOR ALL INCIDENTS. ........................................39

TABLE 12. GENERAL CONTRIBUTING FACTOR OCCURRENCE FOR INCIDENTS INITIATED BY A L/SH DRIVER...............41

TABLE 13. GENERAL CONTRIBUTING FACTOR OCCURRENCE FOR INCIDENTS INITIATED BY A LIGHT

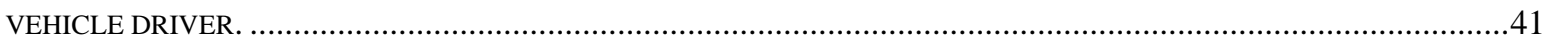

TABLE 14. SPECIFIC CONTRIBUTING FACTORS USED TO IDENTIFY THE PRIMARY CAUSE OF THE INCIDENT..................48

TABLE 15. SPECIFIC CONTRIBUTING FACTORS; ALL INCIDENTS INCLUDED........................................................50

TABLE 16. SPECIFIC CONTRIBUTING FACTORS FOR THE L/SH DRIVER-INITIATED INCIDENTS..................................52

TABLE 17. SPECIFIC CONTRIBUTING FACTORS FOR THE LIGHT VEHICLE DRIVER-INITIATED INCIDENTS. ....................53

TABLE 18. BREAKDOWN OF THE 68 LV-HV CRITICAL INCIDENT INTERACTIONS CAPTURED IN THIS STUDY...............84

TABLE 19. SCALE USED TO RANK THE SEVERITY OF AN INCIDENT. RIGHTMOST COLUMN SHOWS THE

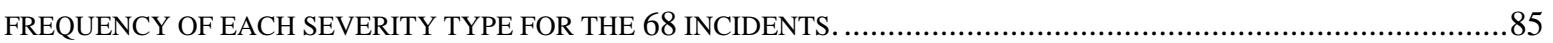

TABLE 20. INCIDENT TYPE DESCRIPTIVE STATISTICS FOR INCIDENTS AS A FUNCTION OF INITIATING DRIVER. ............86

TABLE 21. INCIDENT TYPE DESCRIPTIVE STATISTICS FOR INCIDENTS AS A FUNCTION OF DRIVER TYPE. ....................86

TABLE 22. PRIMARY MANEUVER DESCRIPTIVE STATISTICS AS A FUNCTION OF INITIATING DRIVER.........................94

TABLE 23. PRIMARY MANEUVER DESCRIPTIVE STATISTICS AS A FUNCTION OF DRIVER TYPE.................................95

TABLE 24. GENERAL CONTRIBUTING FACTORS DESCRIPTIVE STATISTICS AS A FUNCTION OF INITIATING DRIVER. ...102

TABLE 25. GENERAL CONTRIBUTING FACTORS DESCRIPTIVE STATISTICS AS A FUNCTION OF DRIVER TYPE. .............102

TABLE 26. SPECIFIC CONTRIBUTING FACTORS DESCRIPTIVE STATISTICS AS A FUNCTION OF INITIATING DRIVER......113

TABLE 27. SPECIFIC CONTRIBUTING FACTORS DESCRIPTIVE STATISTICS AS A FUNCTION OF DRIVER TYPE..............114

TABLE 28. INCIDENT TYPE DESCRIPTIVE STATISTICS FOR THE L/SH AND SLEEPER BERTH DATA SETS.....................140

TABLE 29. PRIMARY MANEUVER DESCRIPTIVE STATISTICS FOR L/SH AND SLEEPER BERTH DATA SETS..................149

TABle 30. GENERAL CONTRIBUTING FACTOR DESCRIPTIVE STATISTICS FOR THE L/SH AND SLEEPER

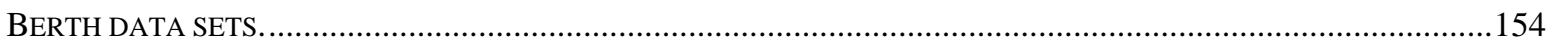

TABLE 31. SPECIFIC CONTRIBUTING FACTOR DESCRIPTIVE STATISTICS FOR THE L/SH AND SLEEPER

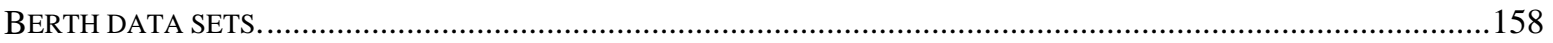

TABLE 32. TRIGGER TYPES UTILIZED IN THE LOCAL/ SHORT HAUL STUDY. .....................................................166

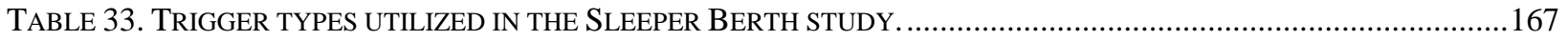




\section{CHAPTER 1: LOCAL/SHORT HAUL INTERACTIONS}

\section{INTRODUCTION}

\section{Overview of the Light Vehicle-Heavy Vehicle Interaction Problem}

Cars and trucks differ greatly in their handling, size, ability to accelerate and brake, visibility, and use. Both types of vehicles use the highway system in the U.S. and therefore must necessarily interact with one another. While there are proposals to separate light and heavy vehicles on high-volume travel routes, the likelihood that this will occur in most cases is small. The costs and other difficulties associated with new or modified road construction are of such a magnitude that the two types of vehicles will have to continue to share the road for the foreseeable future. Thus, a better understanding of light vehicle-heavy vehicle (LV-HV) interaction is needed and would serve as a necessary foundation for countermeasures to relieve or eliminate problems.

Focus group results obtained in a recent study, to be described in more detail later, showed that local/short haul truck drivers rank "problems with light vehicles" as their most important problem, thereby lending credence to the idea that LV-HV interaction problems should be further studied (Hanowski, Wierwille, Gellatly, Early, and Dingus, 1998). This finding was supported by several other research efforts. For example, data from a recent report on large truck crashes (FMCSA, 2000) indicates that in 1998, 4 percent of all roadway fatalities involved large trucks and "most victims [in these crashes] were people in the other vehicles, on bicycles, or pedestrians" (page 5). In addition, data from focus groups conducted with long-haul drivers (Neale et al., 1998) indicate that a safety concern exists with regard to the interaction of light and heavy vehicles. Given the consistent findings from these various studies, VTTI was tasked by FMCSA to conduct an in-depth investigation on what was termed "Light Vehicle-Heavy Vehicle (LV-HV) Interaction.”

Of course, the most serious problems in LV-HV interaction can be studied by examining accident databases. This approach has been tried and does shed light on occurrences of severe problems. However, the accident database approach does not necessarily shed light on the full variety of interaction problems, and it may not be particularly helpful in gaining an understanding of the reasons for interaction problems. Accident databases may tell what happened, but not necessarily why.

An alternative approach is to study the occurrence of incidents. An "incident" does not have a precise definition, but generally involves an unexpected event resulting in a close call or requiring fast action on the part of a driver to avoid a crash. Incidents often require emergency steering or braking, or both, by at least one of the drivers involved. Incidents are far more numerous than crashes, but they are believed to be related to crashes. One might think of a crash as an incident in which the drivers could not avoid a collision through their emergency actions. Because incidents are far more numerous than crashes, the study of incidents is much more feasible.

There are two types of problems occurring on our highways with regard to car/truck interaction: unintentional incidents and intentional incidents. Unintentional incidents are those that occur 
largely as a result of inattention, ignorance, or chance. An example of an unintentional incident is a car that remains in the mirror blind spot of an HV, causing problems when the trucker wishes to change lanes. Assuming the driver of the car does not understand the problem this creates for the trucker, this is an unintentional incident. An example of an intentional incident is a car that pulls in front of a truck and then decelerates rapidly. This is an intentional incident assuming the driver of the car understands the problem this causes for the trucker.

Incidents may be initiated by either the LV driver or the trucker. However, preliminary indications are that $\mathrm{LV}$ drivers are more often the initiators by a ratio of between two-to-one and three-to-one (Wang, Knipling, and Blincoe, 1999). Nevertheless, to obtain a full understanding of incidents, both types should be studied. It is possible that countermeasures could eventually be developed for both types of incidents.

\section{Local/Short Haul Data Collection Effort}

The current project is an extension of a recently completed project entitled "The Impact of Local/Short Haul (L/SH) Operations on Driver Fatigue" (Hanowski, Wierwille, Garness, and Dingus, 2000). The project involved two phases of research. In Phase I, 11 focus groups were held nationwide to assess L/SH drivers' opinions on safety issues in their jobs. In Phase II, performance data were gathered from L/SH drivers as they operated their trucks and worked their normal delivery routes. Because the current effort is a follow-on to the original L/SH study, a brief overview of the original project follows and provides background information that will be useful in understanding the impetus for the current research.

\section{Defining Local/Short Haul Operations}

$\mathrm{L} / \mathrm{SH}$ operations are defined as those that primarily engage in trips (deliveries) of $160 \mathrm{~km}$ (100 mi) or less from the truck's home base. The U.S. Department of Commerce (1994) indicates that L/SH operations comprise the largest segment of the trucking industry. Massie, Blower, and Campbell (1997) estimated that local haul, or short range, trucks (i.e., those that make trips of 80 $\mathrm{km}(50 \mathrm{mi})$ or less from the home base) comprise 58 percent of the trucking industry (light trucks, such as pick-up trucks, are excluded). Thus, the majority of trucking operations in the U.S. are of the L/SH variety.

\section{Phase I: Focus Groups Conducted Nationwide}

A two-phase research effort was conducted to investigate safety issues in $\mathrm{L} / \mathrm{SH}$ operations. Phase I of this research involved conducting focus groups with L/SH drivers (Hanowski et al., 1998). The goal of these focus groups was to determine driver opinions on safety issues in the $\mathrm{L} / \mathrm{SH}$ industry. Eleven focus groups were held in eight cities, across five states. Eighty-two $\mathrm{L} / \mathrm{SH}$ drivers participated. One of the purposes was to generate a list of causal factors that would highlight safety-critical issues in the L/SH industry. Across all sessions, the top five critical issues, ranked in order of importance, were:

1. Problems caused by drivers of light vehicles.

2. Stress due to time pressure.

3. Inattention.

4. Problems caused by roadway and/or dock design.

5. Fatigue. 
As can be seen, and of particular relevance to the current research, the drivers' top safety issue was "problems caused by drivers of light vehicles." In fact, "problems caused by drivers of light vehicles" was the only safety issue that was consistently mentioned in all 11 focus groups. Drivers commented that the problems they have with LV drivers stem from two sources. The first source is the "poor attitude" these drivers have, in that LV drivers tend to be discourteous to truck drivers and show them little respect. The second source of the problem is that LV drivers are not well trained with regard to how to interact with trucks. That is, driver education and training includes little or no mention of how to safely interact with HVs.

Based on the consensus opinions of the truck drivers who participated in the focus groups, it is apparent that there is a strong need to conduct further research into the interactions that truckers have with LV drivers. A greater understanding of these interactions might lead to the development of countermeasures aimed at reducing the negative, safety-critical interactions that occur between LV drivers and truck drivers.

\section{Phase II: Data Collected In Situ}

The second phase of the original L/SH study involved collecting driver performance and behavior data as drivers drove their trucks and worked their normal delivery routes. The information obtained from the focus groups was used to help develop the Phase II data collection methodology. For example, because drivers in the focus groups indicated that LV drivers were their top safety concern, five video cameras were installed on the trucks so that there was nearly complete coverage around, and inside, the truck. Careful positioning of the video cameras provided a comprehensive indication of the interactions that the L/SH trucks had with other vehicles and of the truck drivers' facial expressions and eye glance patterns during the interactions. With regard to the current effort, this video coverage allowed for detailed analysis of the LV-HV interactions.

In Phase II, two L/SH trucking companies participated in the on-road data collection effort. In total, $42 \mathrm{~L} / \mathrm{SH}$ drivers participated. Each driver drove an instrumented data collection truck for approximately two weeks. The focus of the data collection was on critical incidents (i.e., near crash scenarios) experienced by the drivers.

The video approach used in the study's methodology served to capture 249 critical incidents. Of these 249 critical incidents, 137 were initiated by "other drivers," and 77 were initiated by L/SH drivers. (Note that the ratio of incidents initiated by LV drivers to incidents initiated by $\mathrm{L} / \mathrm{SH}$ drivers was nearly two-to-one and is, therefore, consistent with the earlier presented findings of Wang et al., 1999). Based on these data, it can be seen that "other drivers" were the instigators of the majority of critical incidents in which the L/SH drivers were involved. This finding supports the contention made by L/SH drivers in the focus group: the most important safety issue for truck drivers is "problems caused by drivers of light vehicles."

Based on the results of the Phase I focus groups and the Phase II on-road study, it is clear that $\mathrm{LV}-\mathrm{HV}$ interactions is an important area for further study. Because LV-HV interactions were not the main thrust of the original project, a follow-on effort (the current project) was undertaken. 


\section{Research Goals}

The data from the original L/SH study were archived in such a way that it could easily be retrieved and examined further. Thus, it was unnecessary to gather new experimental data to study the problem of LV/L/SH vehicle interaction. The archived data could be efficiently reexamined for purposes of studying this interaction.

There were three general goals of the current effort:

- Gain a better understanding of incidents occurring when light vehicles and heavy vehicles interact on roadways.

- Develop a classification scheme and corresponding contributing factors list for incidents occurring between light vehicles and heavy vehicles.

- Provide background information that would serve as a necessary prerequisite to the development of countermeasures for interaction problems.

To achieve these goals, the current project was divided into two research phases. In Phase A, the effort was focused on the data that were collected in the original L/SH study. The method and results of this project are detailed in the remainder of this chapter. The second phase of research, Phase B, was directed at the LV-HV interactions captured in long-haul trucking and is the subject of Chapter 2.

\section{METHOD}

\section{Data Collection Methodology for the L/SH Driver Fatigue Study}

A full description of the research methodology used in the on-road portion (Phase II) of the original L/SH study can be found in Hanowski et al. (2000). An overview of this method was briefly highlighted in an earlier section of this report (Phase II: Data Collected In Situ). Because the data used in the current effort consisted of the video recordings of critical incidents, the most important methodological considerations to be described are those related to the video systems. Details of the methodology related to the video recordings, abstracted from Hanowski et al., are presented here.

Video Camera Systems

As shown in Figure 1, five video cameras were used in the video recording system: (1) a forward-looking camera that captured the forward roadway scene, traffic situation, and possible incidents, (2) a driver's face camera that was used to record facial expressions, eyelid closure, glance position, and head turns, (3) left-side and (4) right-side cameras that were mounted on the side mirrors and aimed toward the rear, and (5) a rear camera that was intended to capture the situation behind the vehicle. 


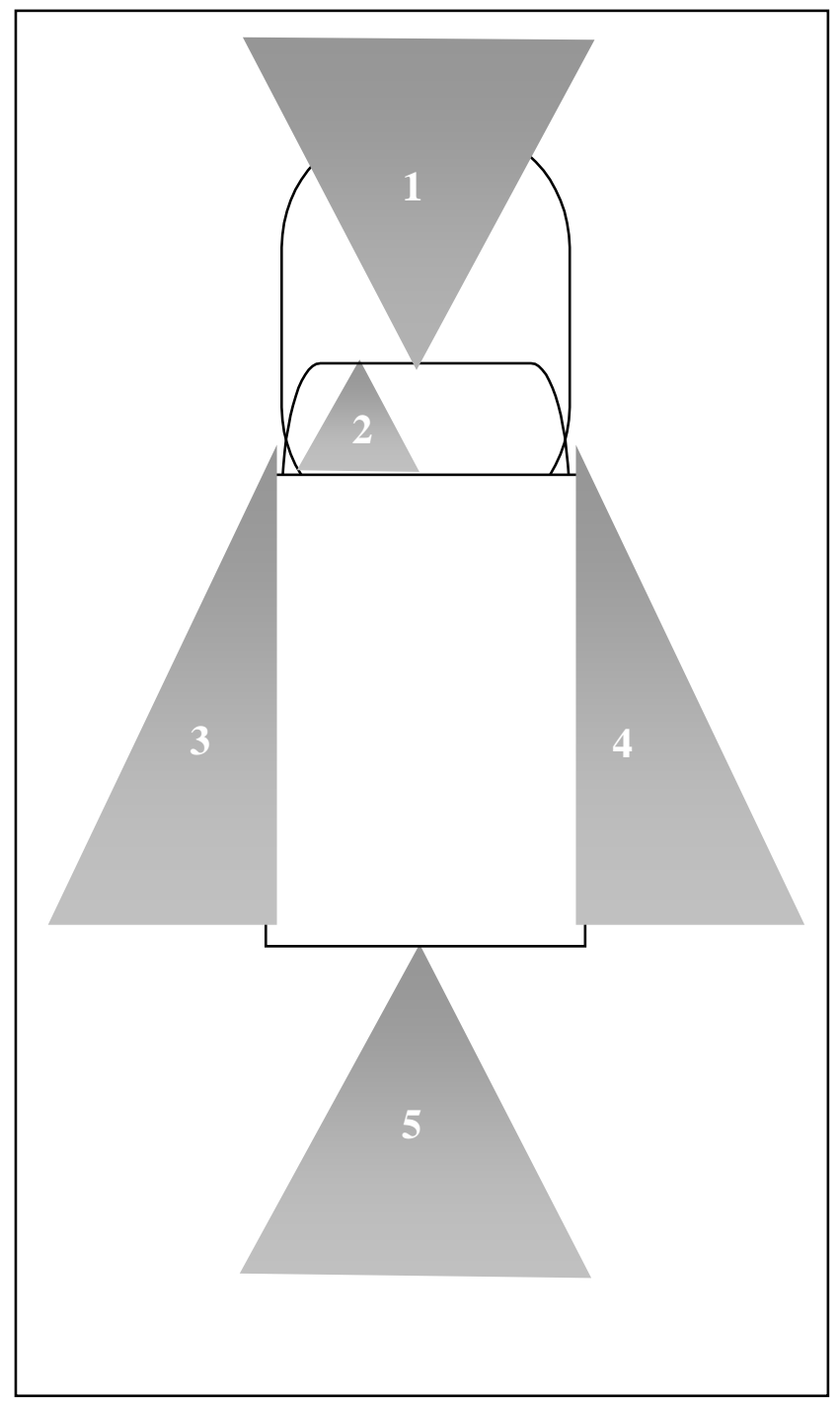

Figure 1. Camera directions and approximate fields of view.

The video camera arrangement shown in Figure 1 had several advantages. First, it provided good coverage around the vehicle so that incidents could be captured as they developed. Second, the driver's facial expression, approximate glance direction, and approximate level of eye closure were also captured. And third, the arrangement provided appropriate views, whether moving forward or backward.

The five camera images were multiplexed into a single image as shown in Figure 2. Note in particular that the two side cameras used a single quadrant (lower right) in a split arrangement. This format was selected so that all five camera views could be included on a single image. To aid in the videotape analysis, a timestamp legend ("sync" number) was also included in the video frame. 


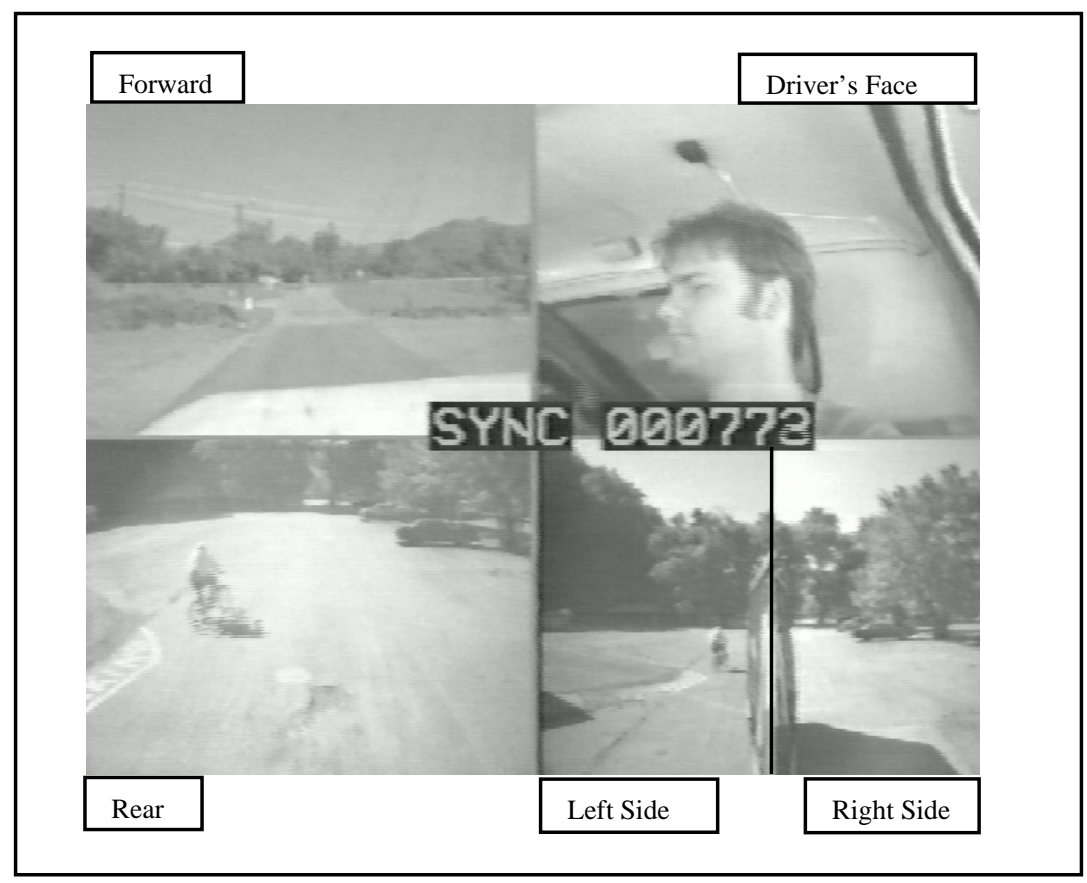

Figure 2. Split-screen presentation of the five camera views.

\section{Video Recording Operation}

Video recording was tied to the booting/powering system and it began to operate 15 seconds after the ignition was on. It also shut down in an orderly manner when the ignition was turned off. It was desired for the recording system to record for as long as possible without requiring technician/researcher attention. Therefore, multiple recorders designed to operate in sequence were used. The recording system operated for 18 hours of ignition-on time without needing to have tapes exchanged. The video recorded continuously while the ignition was on. This allowed laboratory review and selection of the video without losses of any kind.

The videotaped episodes/incidents were selected and keyed to digitally recorded data. In some cases, the videotape timestamp was used to access the corresponding digital data. In other cases, the incident flags in the digital data were used to access the corresponding video. Therefore, there was a straightforward keying procedure to allow both kinds of access to take place efficiently.

\section{Incident Flag}

As indicated previously, a critical incident involves an unexpected event resulting in a close call or requiring fast action on the part of a driver to avoid a crash. Incidents were detected by one of three methods. The first method involved flagging events where the L/SH truck sensors exceeded a specified value. Two examples of this include: (1) a braking response of $0.5 \mathrm{~g}$ or more would be recorded as a potential incident where the L/SH driver may have braked in a panic, and (2) absolute lateral acceleration above $0.25 \mathrm{~g}$ and longitudinal speed above 32.19 $\mathrm{km} / \mathrm{h}$ where the L/SH driver may have made an evasive steering maneuver. The second method occurred when the driver pressed an incident pushbutton located on the dashboard. Drivers were trained to press a button on the dashboard (after the event, not during the event) if they witnessed 
an incident or were involved in an incident. Finally, the third method of detecting incidents was through an analyst's judgment when reviewing the videotapes. Note that the video systems were operational as long as the ignition was turned on. In identifying incidents, the analysts looked through all of the video recordings from the 42 drivers and tagged those events that were critical incidents.

The incident flags (associated with the first and second methods described above) were computed and detected on-line (as well as stored) with the flag appearing in the video. Since the entire video recording was reviewed, the presence of flags served as an indicator to the analyst of the high likelihood of an incident occurrence. However, the analyst was also mindful of the possibility of incidents without flags and reviewed the tapes accordingly.

\section{Low-Light Recording}

The L/SH operations studied in this research were performed primarily on a daytime (daylight hours) schedule. Nevertheless, the data collection systems were designed so that video data could be collected in low (or no) light. In particular, infrared illumination was used for the interior camera. Low light levels generally occurred at the beginning and end of the shifts.

\section{L/SH Truck Types}

The data that were collected for this effort came from four types of L/SH trucks: two panel vans of different lengths, a box truck, and a Class B straight truck. The trucks that were instrumented

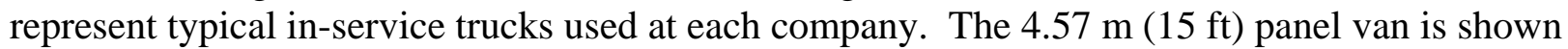
in Figure 3. It should be pointed out that it is the load-area, not including the driver's cab area, that measures approximately $4.57 \mathrm{~m}$. The Gross Vehicle Weight Rating (GVWR) of this van is 9,000 lbs. Four of the study participants drove this van. The $5.48 \mathrm{~m}(18 \mathrm{ft})$ panel van is shown in Figure 4. This truck has a GVWR of 10,000 lbs. Eight of the study participants drove this van. No special permit or special drivers' license is required to operate a panel van. The pictures have been modified to obscure the identifying markings.

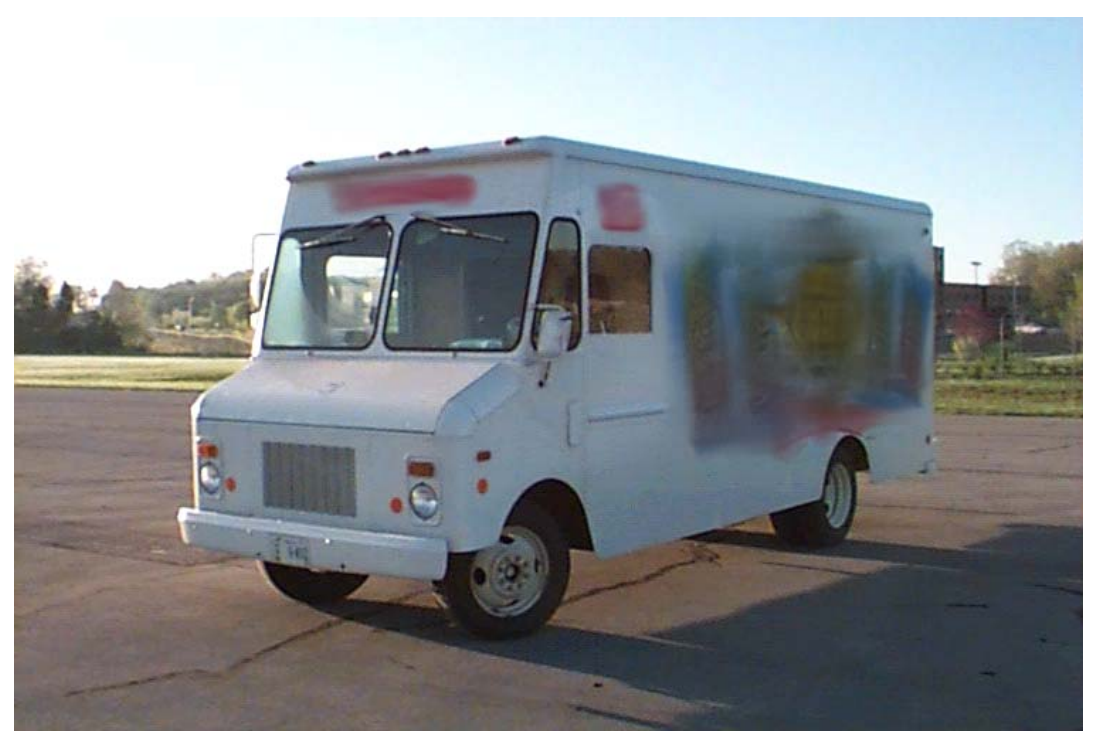

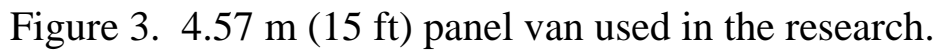




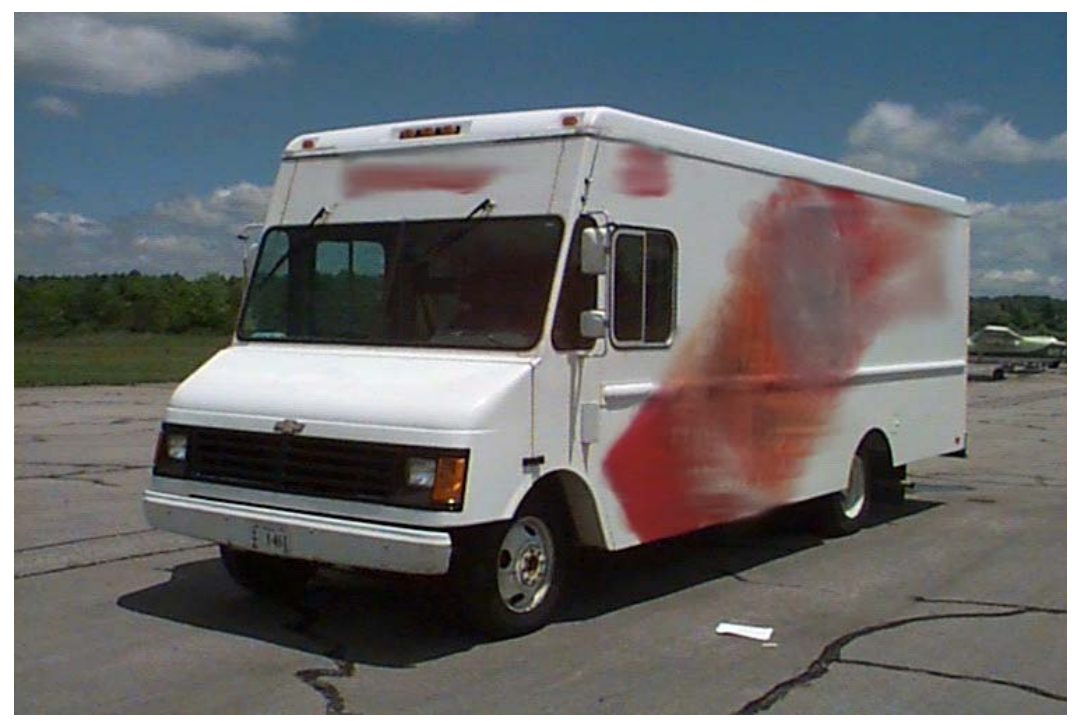

Figure 4. $5.48 \mathrm{~m}$ (18 ft) panel van used in the research.

A box truck was the third type of truck that was instrumented. As shown in Figure 5, the cab area is separate from the load area. Access to the load is from the rear of the vehicle. This particular box truck had one "roll-door" in the back, compared to other trucks that might have "swing doors." The truck had an approximate length of 24'3" and a GVWR of 15,000 lbs. Eighteen of the study participants drove this truck. As with the panel vans, no special permit or drivers' license is required to operate a box truck.

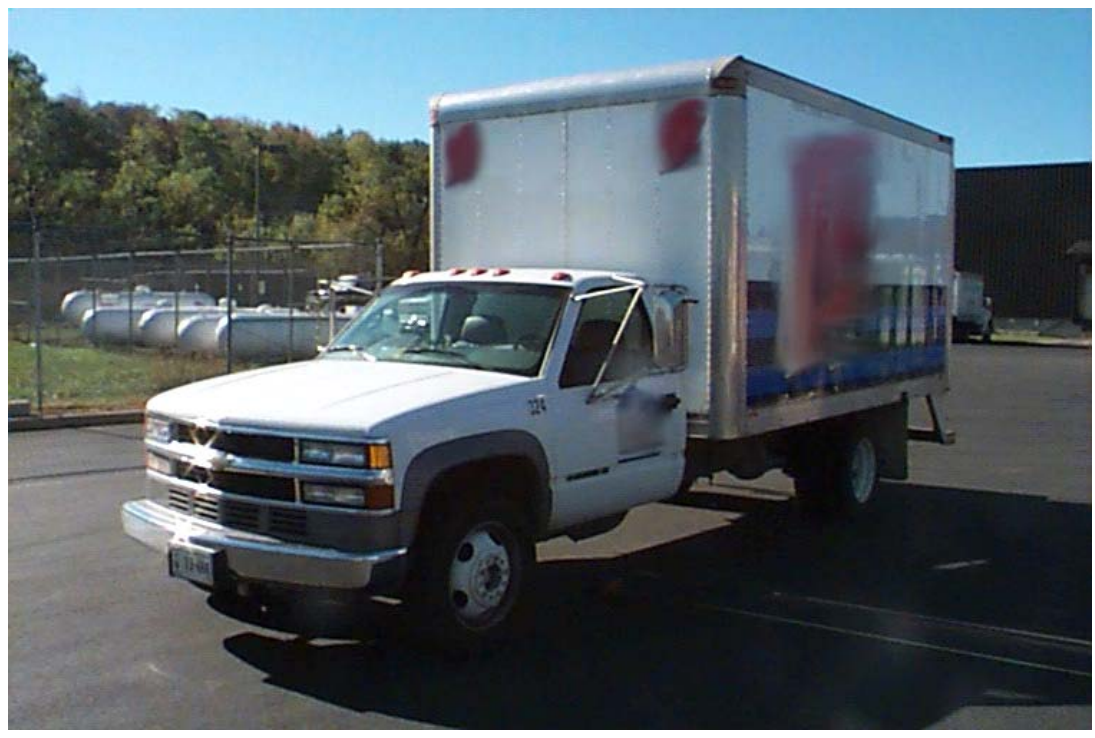

Figure 5. Box truck used in the research.

The fourth type of truck that was instrumented for this project was a Class B straight truck (Figure 6). This was the largest of the four trucks instrumented with a total length of 
approximately 30'3" (GVWR of 27,040 lbs.). Unlike the box truck, where entry was from the rear, entry to the load on this truck was from side roll-doors. Also, unlike the panel vans and the box truck, a Class B license is required to operate this type of truck. Twelve of the study participants drove this truck.

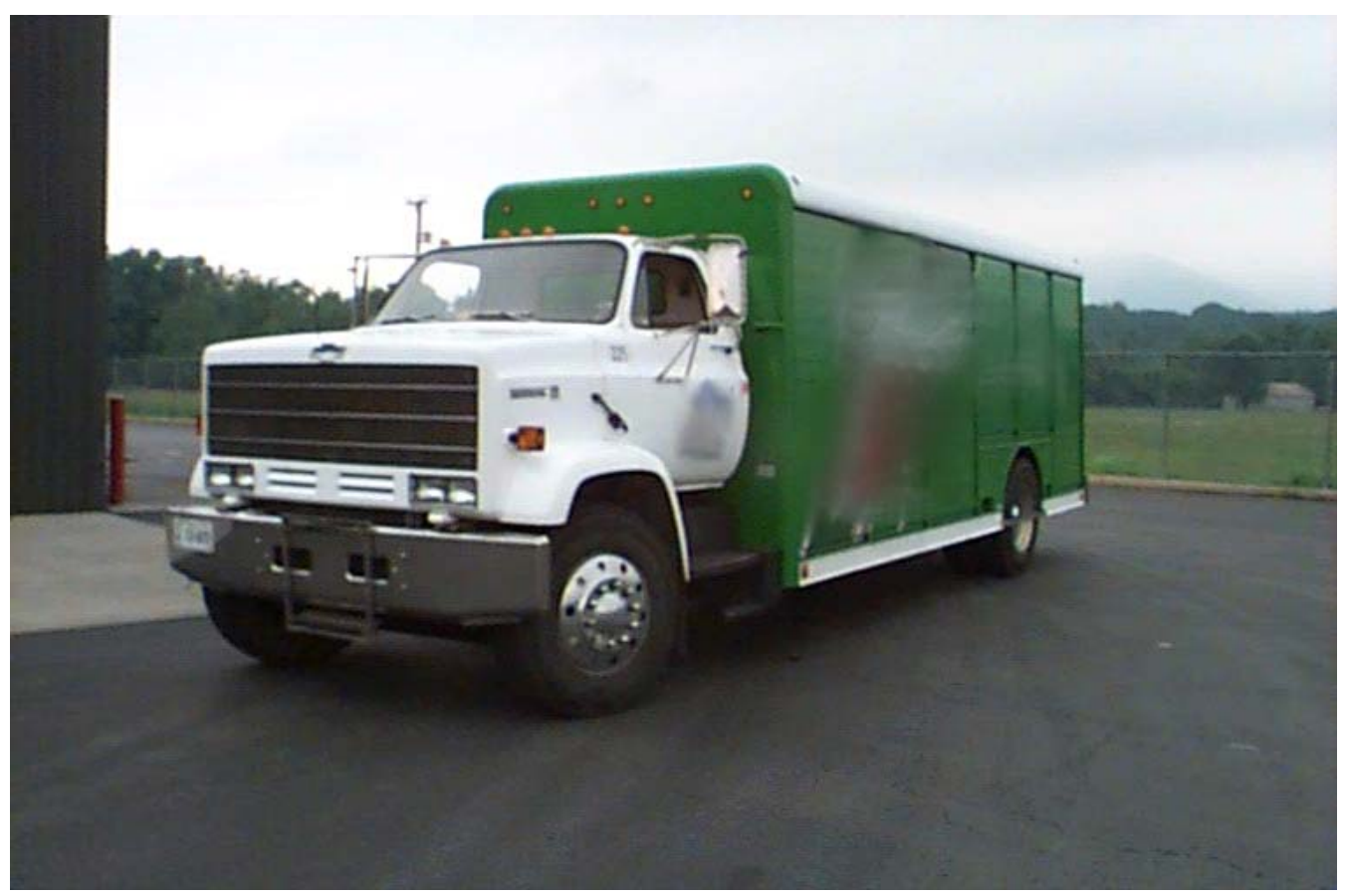

Figure 6. Class B straight truck used in the research.

It is acknowledged that other truck types, which were not included in this research, can be involved in L/SH operations. For example, tractor-trailer units were not included in the study but are involved in $\mathrm{L} / \mathrm{SH}$ operations. This should be considered when examining the results and conclusions from the L/SH phase of the study. To address this shortcoming, the sleeper berth study data, described in Chapter 2, does include tractor-trailer units.

\section{Re-analysis of Archived Incidents}

Two-hundred-and-forty-nine critical incidents were captured in the original L/SH study. In addition to being stored on the original videotape, each incident was digitized on the computer. For the current effort, the incidents from the videotapes were reviewed and those involving LVHV interactions were re-recorded onto a single videotape. This new "master" videotape was then used in the analysis process. It was decided to conduct the analysis from videotape because of the superior resolution as compared to the digitized incident files. The master videotape provided the analyst with the clearest and most complete images of the events leading up to the incident and the incident itself.

The critical incidents on the master videotape were re-analyzed for the current effort. The goals of this re-analysis, as described previously, were to (1) gain a better understanding of incidents occurring when light vehicles and heavy vehicles interact on roadways, (2) develop a 
classification scheme and corresponding contributing factors list for incidents occurring between light vehicles and heavy vehicles, and (3) provide background information that will serve as a necessary prerequisite to development of countermeasures for interaction problems.

\section{Strengths and Limitations of the Methodology Used}

As with any experimental approach, there are corresponding strengths, limitations, and tradeoffs. Using the video recording of the critical incidents captured in the original L/SH study is no exception.

\section{$\underline{\text { Strengths }}$}

One of the strengths of this approach is that using the videotape recordings of the critical incidents captured in the original L/SH study provided a good understanding of the incident, the events leading up to the incident, and the aftermath of the incident from the L/SH driver's viewpoint. The video camera arrangement described previously allowed the researchers to watch the critical incidents unfold from multiple camera views. The five video camera system that was used provided an understanding of not only what happened, but in many cases why it happened.

A second advantage of this approach was that using multiple cameras helped insure that any critical incidents involving the L/SH driver that did occur were captured and available for analysis.

\section{Possible Limitations}

There were two possible limitations of the approach that was used. The first was that because the video cameras were installed in the L/SH trucks and not in light vehicles, critical incidents could only be captured from the L/SH driver's perspective. It is possible that incidents involving interactions between light vehicles and the L/SH truck, which may have only been apparent from the LV driver's viewpoint, were not recorded. However, because there was fairly complete video recording coverage around the entire truck, it is likely that the great majority of $\mathrm{LV}-\mathrm{HV}$ interactions were recorded.

The second possible limitation, similar to the previous one, is that because there were no cameras mounted in any light vehicles, it is difficult to have a complete understanding of the LV driver's behavior during the incident. The video camera that was directed at the L/SH driver's face, along with the verbal utterances of the driver, provided the researchers with fairly complete understanding of the L/SH driver's behavior before, during, and after each incident. However, this was not the case regarding the behavior of the LV driver. The absence of video footage of the LV driver's face meant that the LV driver's behavior had to be surmised based on the video of the LV collected from the L/SH trucks, and the comments and facial expressions made by the L/SH driver.

For a complete picture of the LV-HV interaction problem, video cameras also could have been installed on light vehicles. However, because there are many more LVs than HVs, the frequency of LV-HV interactions captured from this latter approach would not be as high as from the approach that was used. It is believed that the approach used provided the most efficient data 
collection procedure for achieving the stated research goal, albeit subject to the possible limitations mentioned here.

\section{RESULTS}

\section{Light Vehicle-Heavy Vehicle Interaction Data Set}

As indicated, the on-road L/SH study captured 249 critical incidents. These 249 incidents were originally divided into four categories: (1) events in which the L/SH driver was at fault, (2) events in which the driver of the other vehicle was at fault, (3) events in which the L/SH driver was not involved (i.e., the driver reported an incident in which he was not involved), and (4) events in which the L/SH driver reacted to a situation, but no other driver(s) were involved (e.g., driver swerves to miss an animal in the road).

The data set used for the current effort was comprised of a subset of incidents from the 249 described above. The 249 incidents were carefully reviewed and only those that involved a LV$\mathrm{HV}$ interaction were included. (It should be noted that "light vehicles" were defined as passenger cars and light trucks (i.e., pickup trucks), while "heavy vehicles" referred to L/SH trucks.) Figure 7 shows a breakdown of the 249 critical incidents as a function of the vehicles involved and whether or not the incident was an interaction between vehicles. As can be seen, of the 249 incidents, 140 (56 percent) involved a LV-HV interaction. 


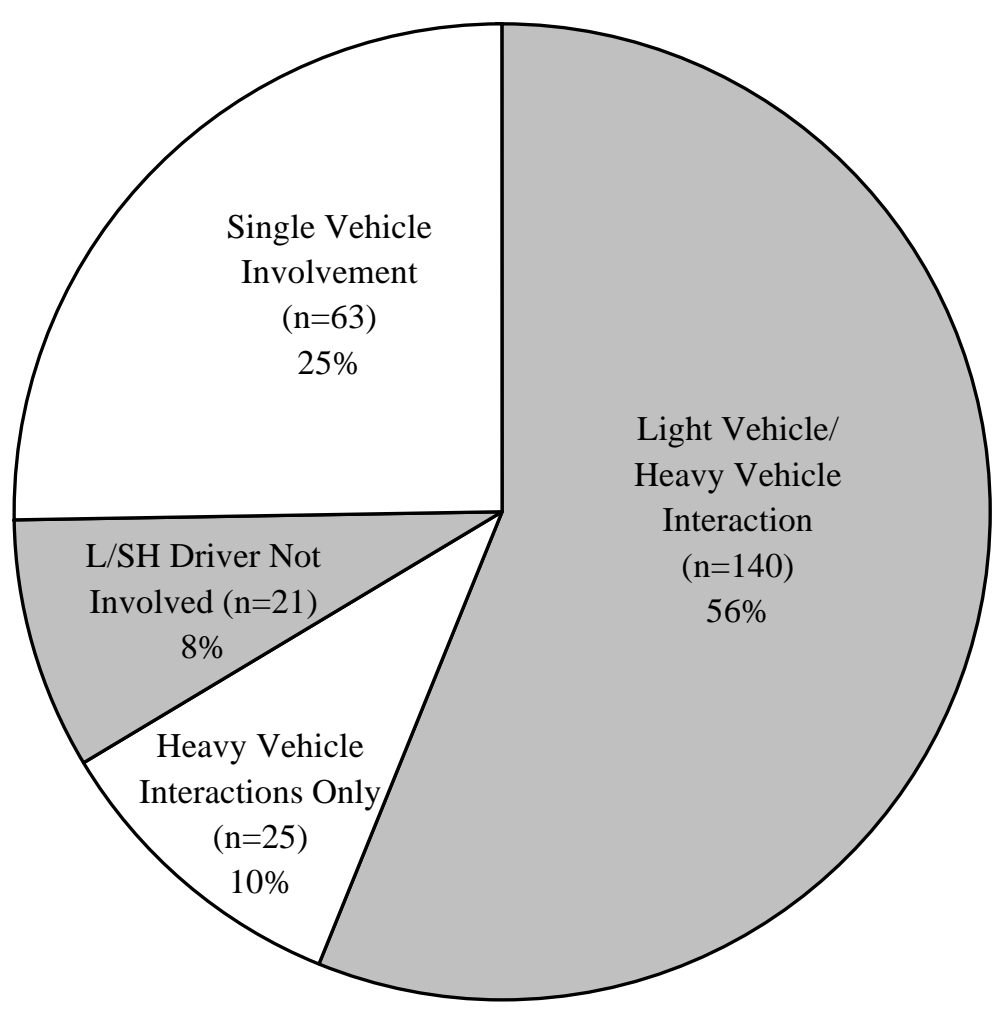

Figure 7. Interaction breakdown of the 249 critical incidents captured in the original L/SH study.

Upon closer inspection of these $140 \mathrm{LV}-\mathrm{HV}$ interactions, it was determined that two of the incidents involved a "double interaction" (i.e., the L/SH truck had a distinct interaction with two different light vehicles). Thus, in counting each individual incident, a total of $142 \mathrm{LV}-\mathrm{HV}$ interactions were identified. Of these 142 incidents, the breakdown regarding which driver initiated the incident was as follows: L/SH driver $=25$ (18 percent), LV driver $=117$ (82 percent).

\section{Incident Types}

Given that the data set was comprised of $142 \mathrm{LV}-\mathrm{HV}$ interactions, the next step in the analysis was to determine the action (i.e., primary contributing factor or what happened) for each incident. To this end, the video and relevant data for each incident were carefully reviewed and then classified into an "Incident Type." Twenty different Incident Types were identified, and a detailed description of each is presented in Table 1. It should be noted that the 20 Incident Types listed do not necessarily comprise the entire universe of all types of LV-HV interaction incidents. Rather, the 20 Incident Types listed comprise those that were identified in the data set $(\mathrm{N}=142)$. The shaded vehicle in each illustration represents the driver who initiated the incident; the Incident Types are written in such a way as to be interchangeable regarding light vehicles and $\mathrm{L} / \mathrm{SH}$ vehicles. 
Table 1. Description of the Incident Types that were identified in this effort.

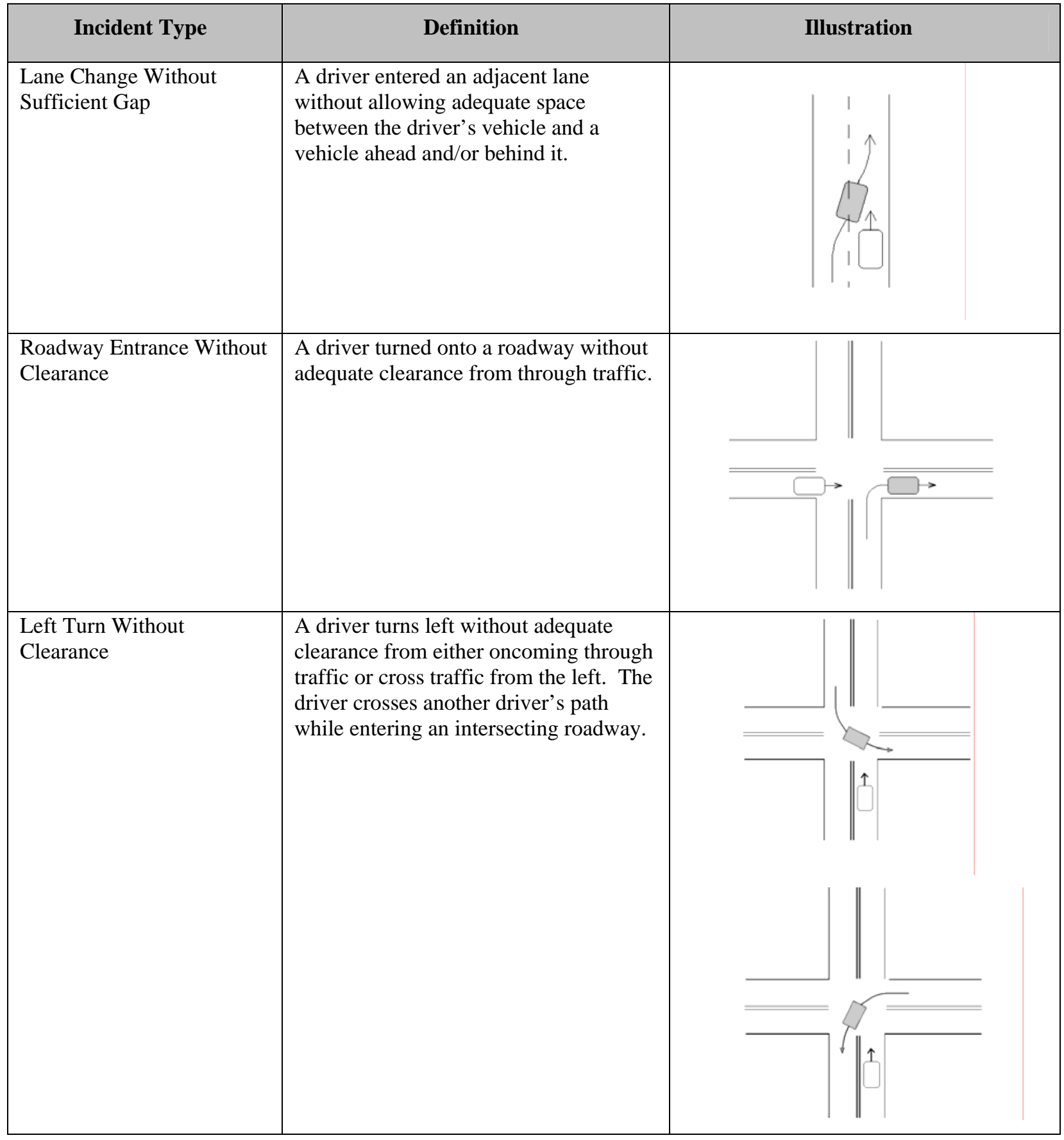


Table 1. Continued.

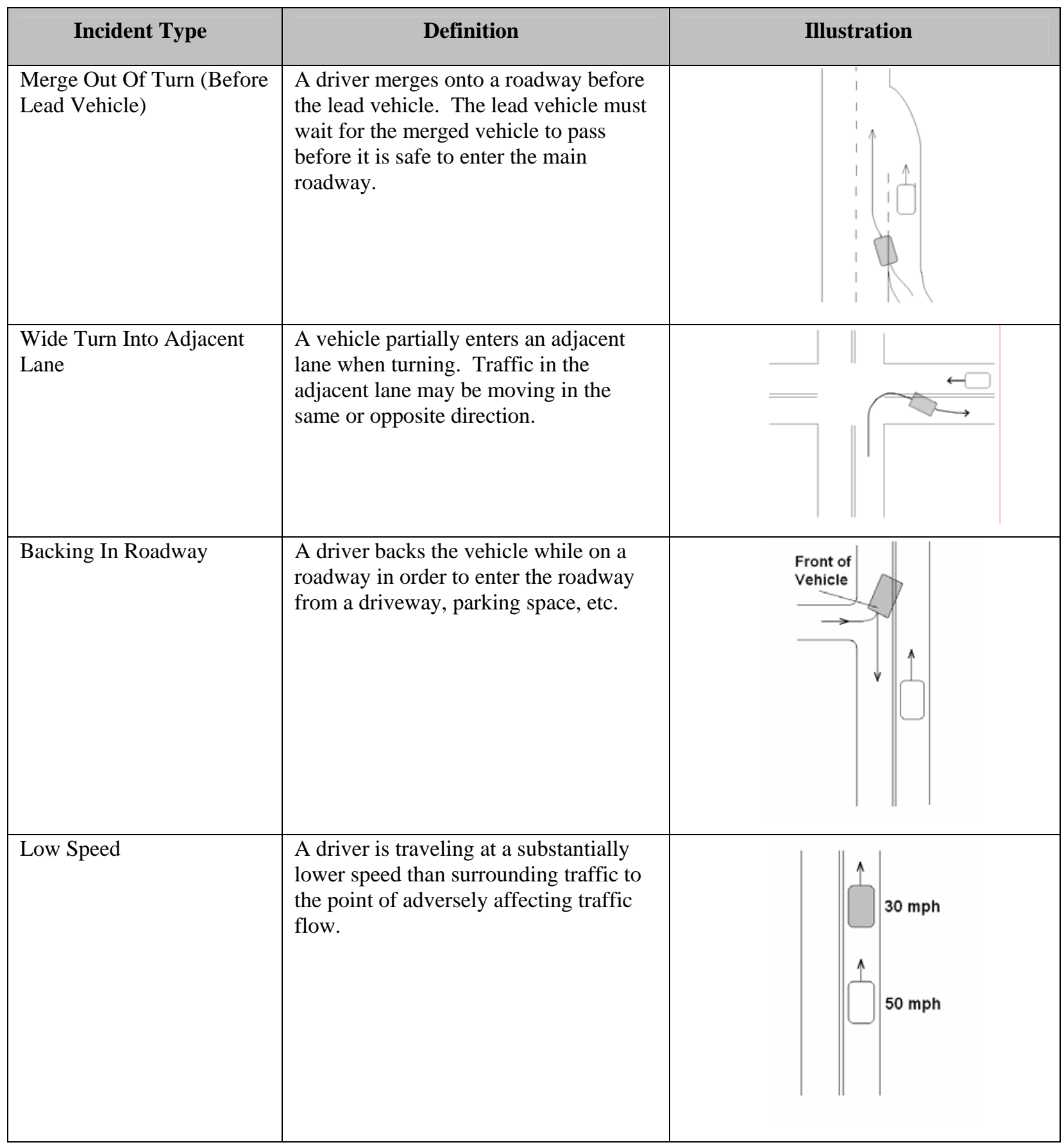


Table 1. Continued.

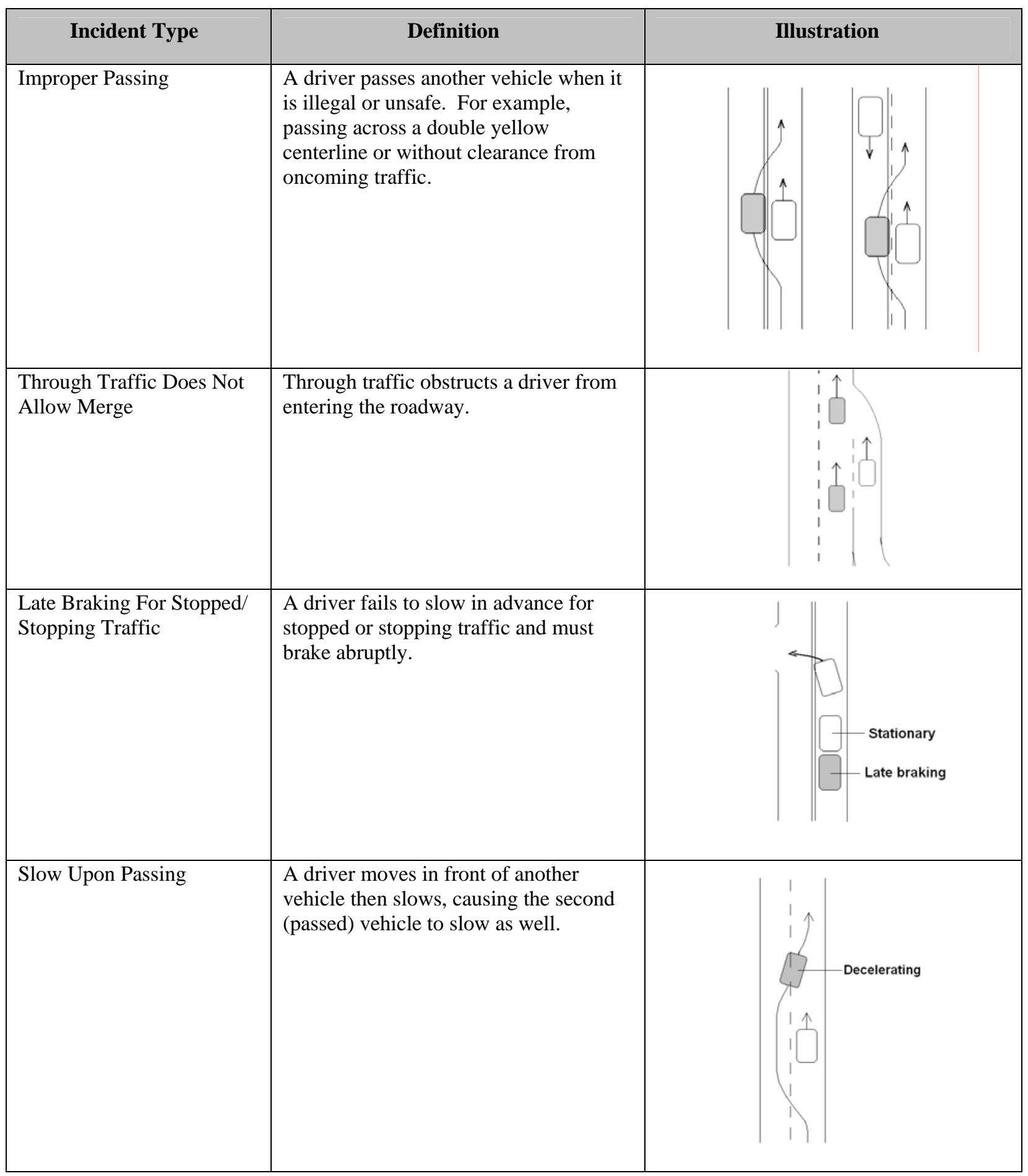


Table 1. Continued.

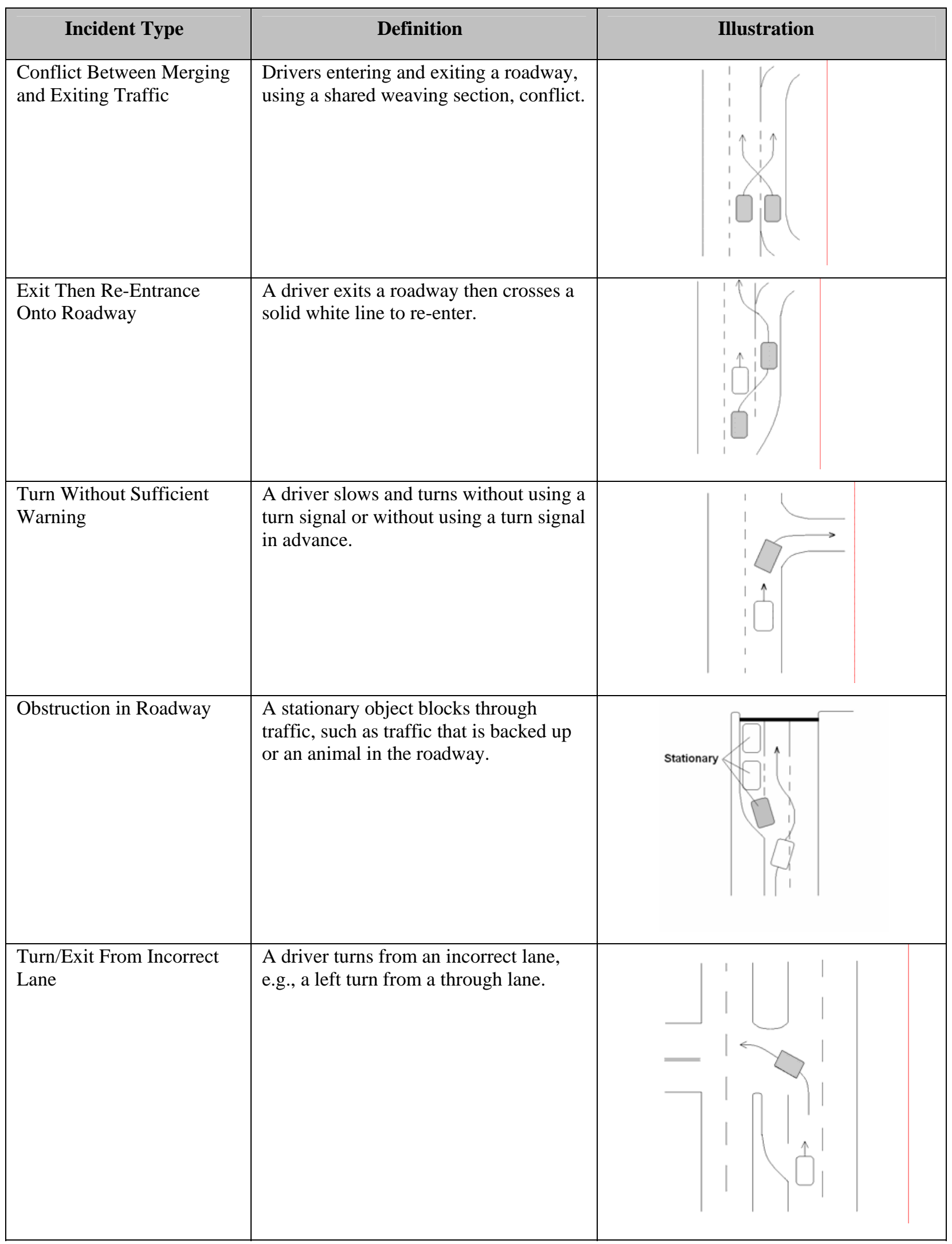


Table 1. Continued and concluded.

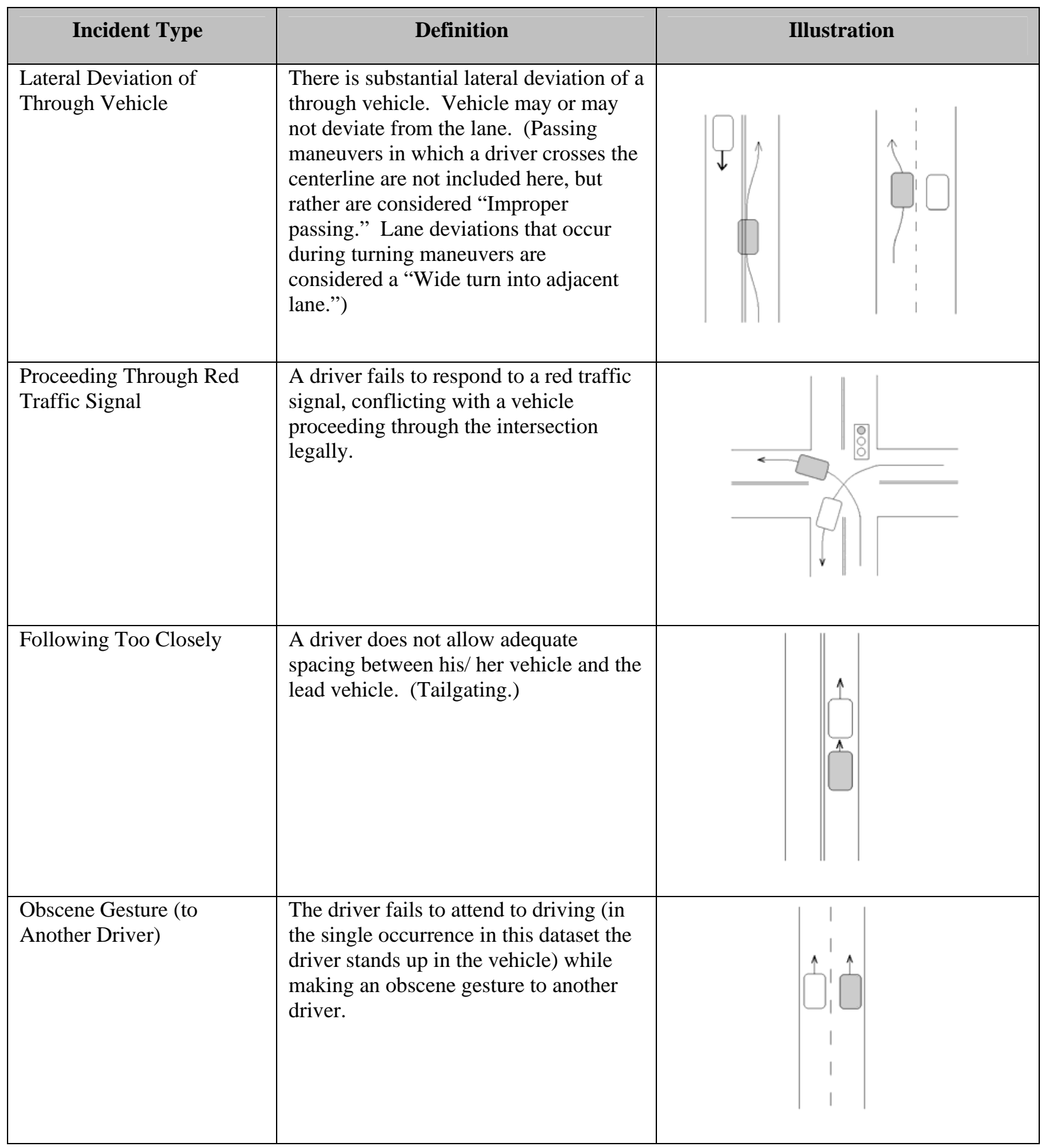

Table 2 shows the Incident Type descriptive statistics for the entire data set. The rank ordering highlights the frequency of Incident Types from most frequently occurring (ranked as a low number, "1") to least frequently occurring (ranked as a high number, "19"). Incident Types that had an equal number of occurrences were ranked as a "tie" and the mean of the rankings was assigned. For example, "Backing in Roadway in the Presence of Through Traffic" and "Improper Passing" occurred equally with a frequency of "7." Because their order in the ranking 
would consist of the fifth and sixth positions, a mean ranking of "5.5" was assigned to both Incident Types.

As can be seen from the data presented in Table 2, the most commonly occurring Incident Type, that involved an interaction between an LV and an L/SH truck, was Lane Change Without Sufficient Gap. Across all 142 incidents, this particular Incident Type occurred 30 times and accounted for 21.1 percent of the incidents captured. A histogram, shown in Figure 8, provides a clear image of the occurrences for each Incident Type. As can be seen from Figure 8, the majority of the incidents (54.2 percent) were of three Incident Types: (1) Lane Change Without Sufficient Gap, (2) Roadway Entrance Without Clearance, and (3) Left Turn Without Clearance. 


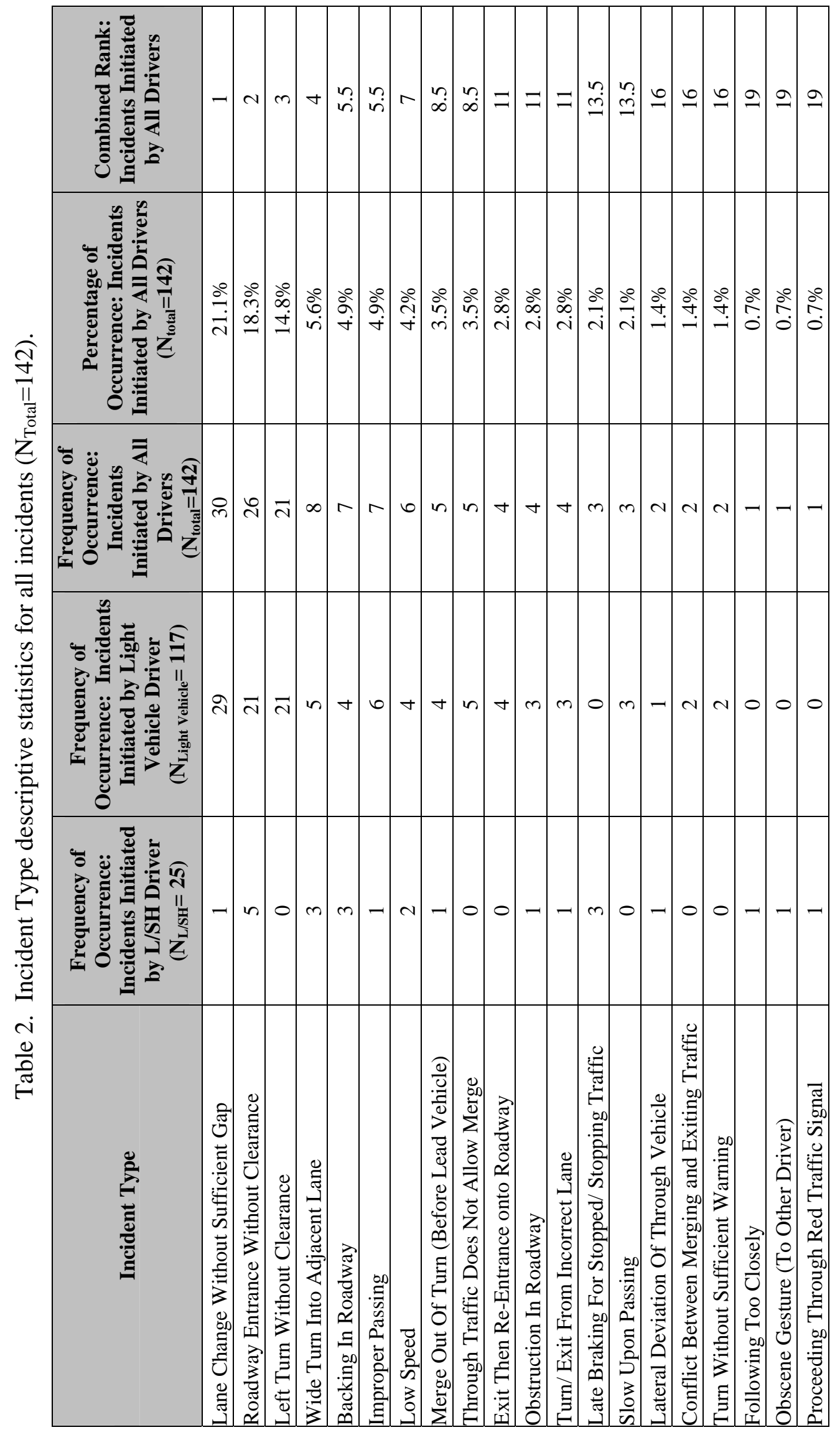




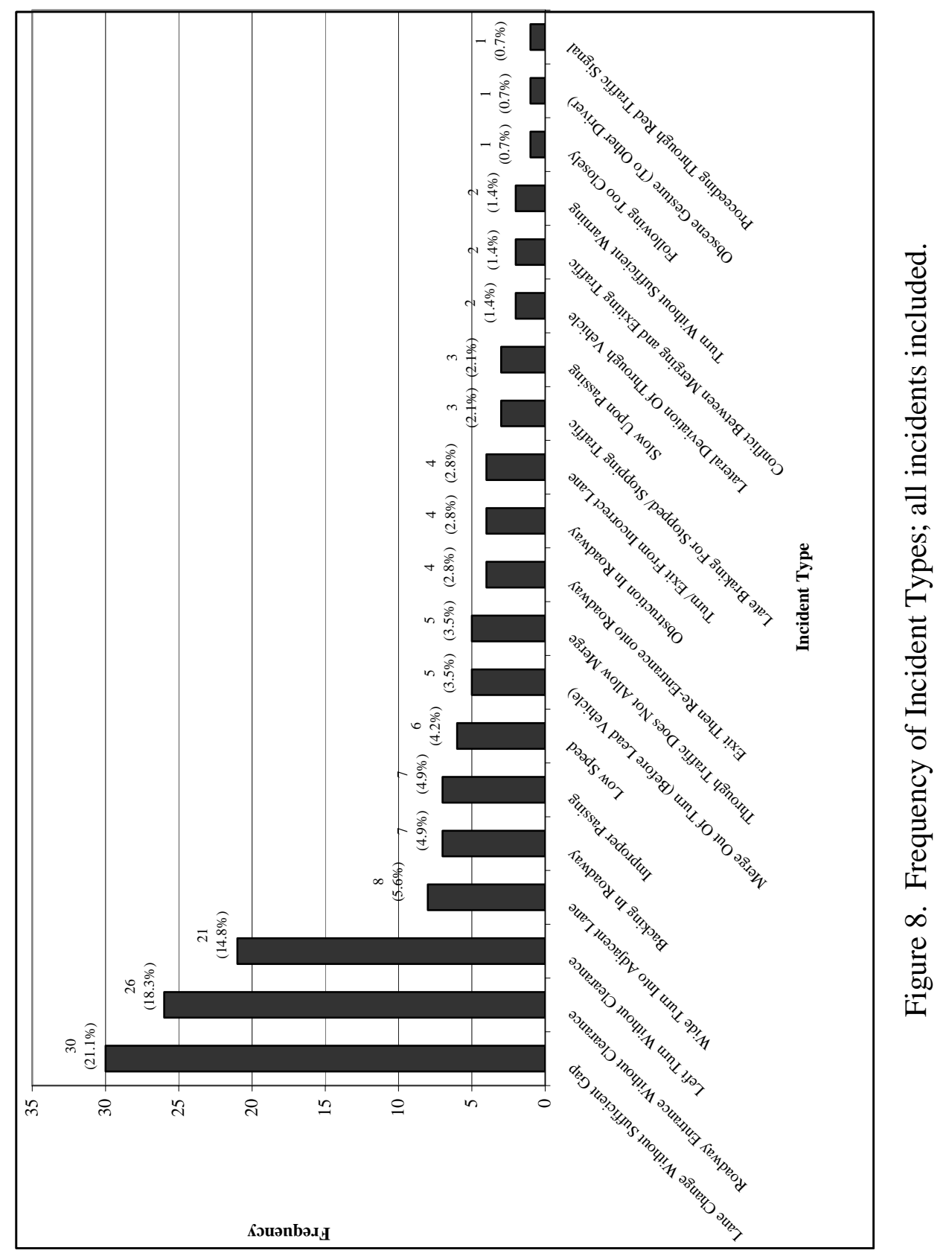


Descriptive statistics for the Incident Types were also calculated for incidents as a function of the initiating driver. Table 3 shows the incident frequency, percentage of occurrence, and rank for the Incident Types initiated by the L/SH driver. As can be seen, the most frequently occurring Incident Type for L/SH drivers was Entered Roadway Without Clearance. Figure 9 shows a histogram of the $25 \mathrm{~L} / \mathrm{SH}$ driver-initiated incidents as a function of Incident Type. The Incident Types that were most prevalent for L/SH drivers were: (1) Entered Roadway Without Clearance, (2) Backing in Roadway in the Presence of Through Traffic, (3) Late Braking for Stopped/Stopping Traffic, (4) Wide Turn into Adjacent Lane, and (5) Low Speed. These five Incident Types accounted for 64 percent of the L/SH driver-initiated critical incidents.

Table 3. Incident Type descriptive statistics for incidents initiated by a $\mathrm{L} / \mathrm{SH}$ driver $\left(\mathrm{N}_{\mathrm{L} / \mathrm{SH}}=25\right)$.

\begin{tabular}{|c|c|c|c|}
\hline Incident Type & $\begin{array}{c}\text { Frequency of } \\
\text { Occurrence: Incidents } \\
\text { Initiated by } \mathrm{L} / \mathrm{SH} \text { Driver } \\
\left(\mathrm{N}_{\mathrm{L} / \mathrm{SH}}=25\right)\end{array}$ & $\begin{array}{l}\text { Percentage of Occurrence: } \\
\text { Incidents Initiated by } \\
\text { L/SH Driver } \\
\left(\mathrm{N}_{\mathrm{L} / \mathrm{SH}}=25\right)\end{array}$ & Rank \\
\hline Roadway Entrance Without Clearance & 5 & $20.0 \%$ & 1 \\
\hline Backing In Roadway & 3 & $12.0 \%$ & 3 \\
\hline Late Braking For Stopped/ Stopping Traffic & 3 & $12.0 \%$ & 3 \\
\hline Wide Turn Into Adjacent Lane & 3 & $12.0 \%$ & 3 \\
\hline Low Speed & 2 & $8.0 \%$ & 5 \\
\hline Following Too Closely & 1 & $4.0 \%$ & 10 \\
\hline Improper Passing & 1 & $4.0 \%$ & 10 \\
\hline Lane Change Without Sufficient Gap & 1 & $4.0 \%$ & 10 \\
\hline Lateral Deviation Of Through Vehicle & 1 & $4.0 \%$ & 10 \\
\hline Merge Out Of Turn (Before Lead Vehicle) & 1 & $4.0 \%$ & 10 \\
\hline Obscene Gesture (To Other Driver) & 1 & $4.0 \%$ & 10 \\
\hline Obstruction In Roadway & 1 & $4.0 \%$ & 10 \\
\hline Proceeding Through Red Traffic Signal & 1 & $4.0 \%$ & 10 \\
\hline Turn/ Exit From Incorrect Lane & 1 & $4.0 \%$ & 10 \\
\hline
\end{tabular}




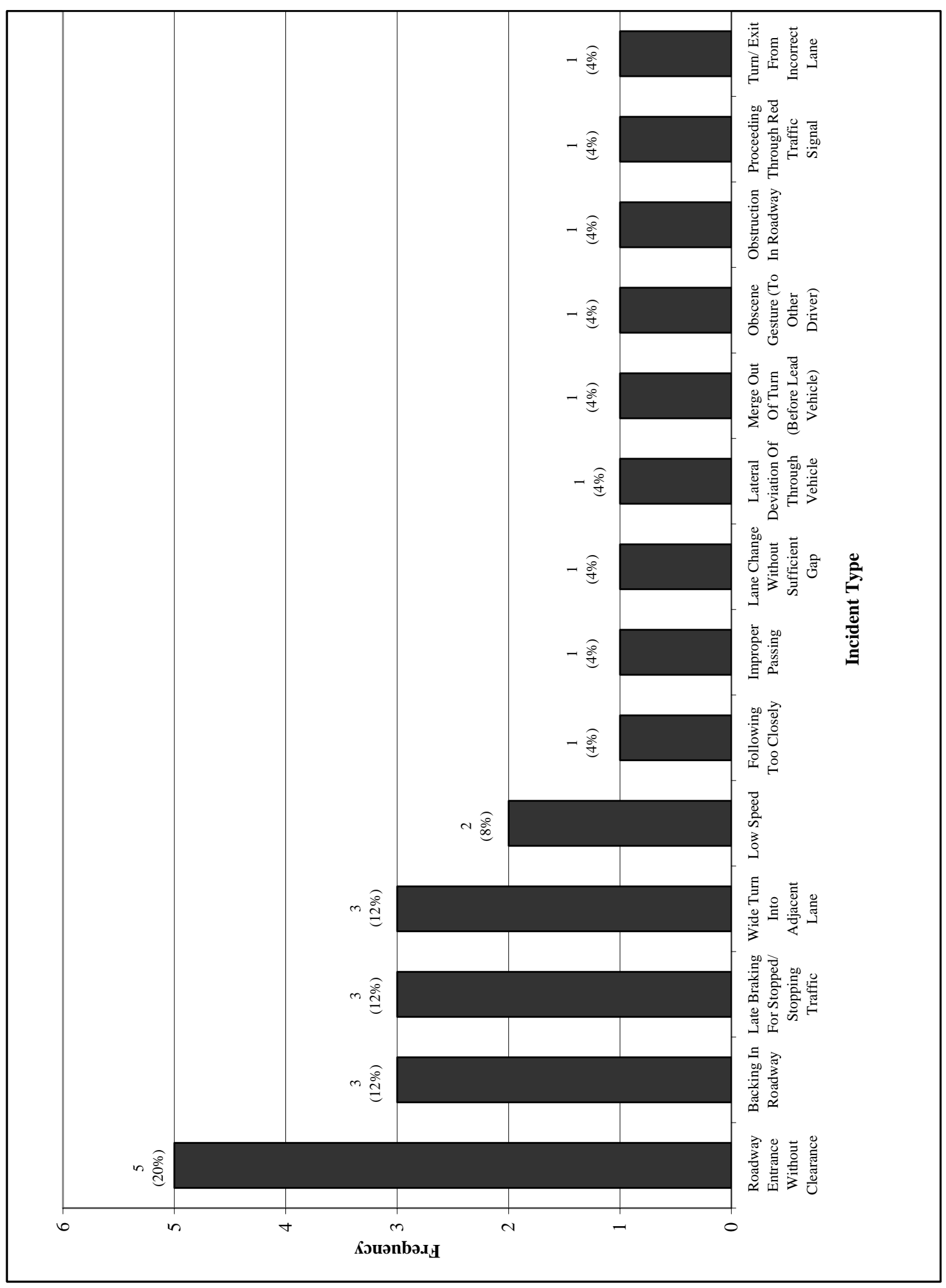

告 N 
Table 4 shows the incident frequency, percentage of occurrence, and rank for the Incident Types initiated by the LV driver. The most frequently occurring incident type was Lane Change Without Sufficient Gap. Figure 10 shows a histogram of these data. The majority (60.6 percent) of the LV driver-initiated incidents were of three types: (1) Lane Change Without Sufficient Gap, (2) Entered Roadway Without Clearance, and (3) Left Turn Without Clearance.

Table 4. Incident Type descriptive statistics for incidents initiated by a LV driver ( $\mathrm{N}_{\text {Light }}$ Vehicle=117).

\begin{tabular}{|l|c|c|c|}
\hline \multicolumn{1}{|c|}{ Incident Type } & $\begin{array}{c}\text { Frequency of } \\
\text { Occurrence: } \\
\text { Incidents Initiated by } \\
\text { Light Vehicle Driver } \\
\text { (N }_{\text {Light Vehicle 117) }}\end{array}$ & $\begin{array}{c}\text { Percentage of } \\
\text { Occurrence: } \\
\text { Incidents Initiated by } \\
\text { Light Vehicle Driver } \\
\text { ( }_{\text {Light Vehicle 117) }}\end{array}$ & Rank \\
\hline Lane Change Without Sufficient Gap & 29 & $24.8 \%$ & 1 \\
\hline Roadway Entrance Without Clearance & 21 & $17.9 \%$ & 2.5 \\
\hline Left Turn Without Clearance & 21 & $17.9 \%$ & 2.5 \\
\hline Improper Passing & 6 & $5.1 \%$ & 4 \\
\hline Through Traffic Does Not Allow Merge & 5 & $4.3 \%$ & 5.5 \\
\hline Wide Turn Into Adjacent Lane & 5 & $4.3 \%$ & 5.5 \\
\hline Backing In Roadway & 4 & $3.4 \%$ & 8.5 \\
\hline Exit Then Re-Entrance onto Roadway & 4 & $3.4 \%$ & 8.5 \\
\hline Low Speed & 4 & $3.4 \%$ & 8.5 \\
\hline Merge Out Of Turn (Before Lead Vehicle) & 4 & $3.4 \%$ & 8.5 \\
\hline Obstruction In Roadway & 3 & $2.6 \%$ & 12 \\
\hline Slow Upon Passing & 3 & $2.6 \%$ & 12 \\
\hline Turn/ Exit From Incorrect Lane & 3 & $2.6 \%$ & 12 \\
\hline Conflict Between Merging and Exiting & 2 & $1.7 \%$ & 14.5 \\
\hline Traffic & 2 & $0.9 \%$ & 16 \\
\hline Turn Without Sufficient Warning & 2 & & \\
\hline Lateral Deviation Of Through Vehicle & 2 & & \\
\hline
\end{tabular}




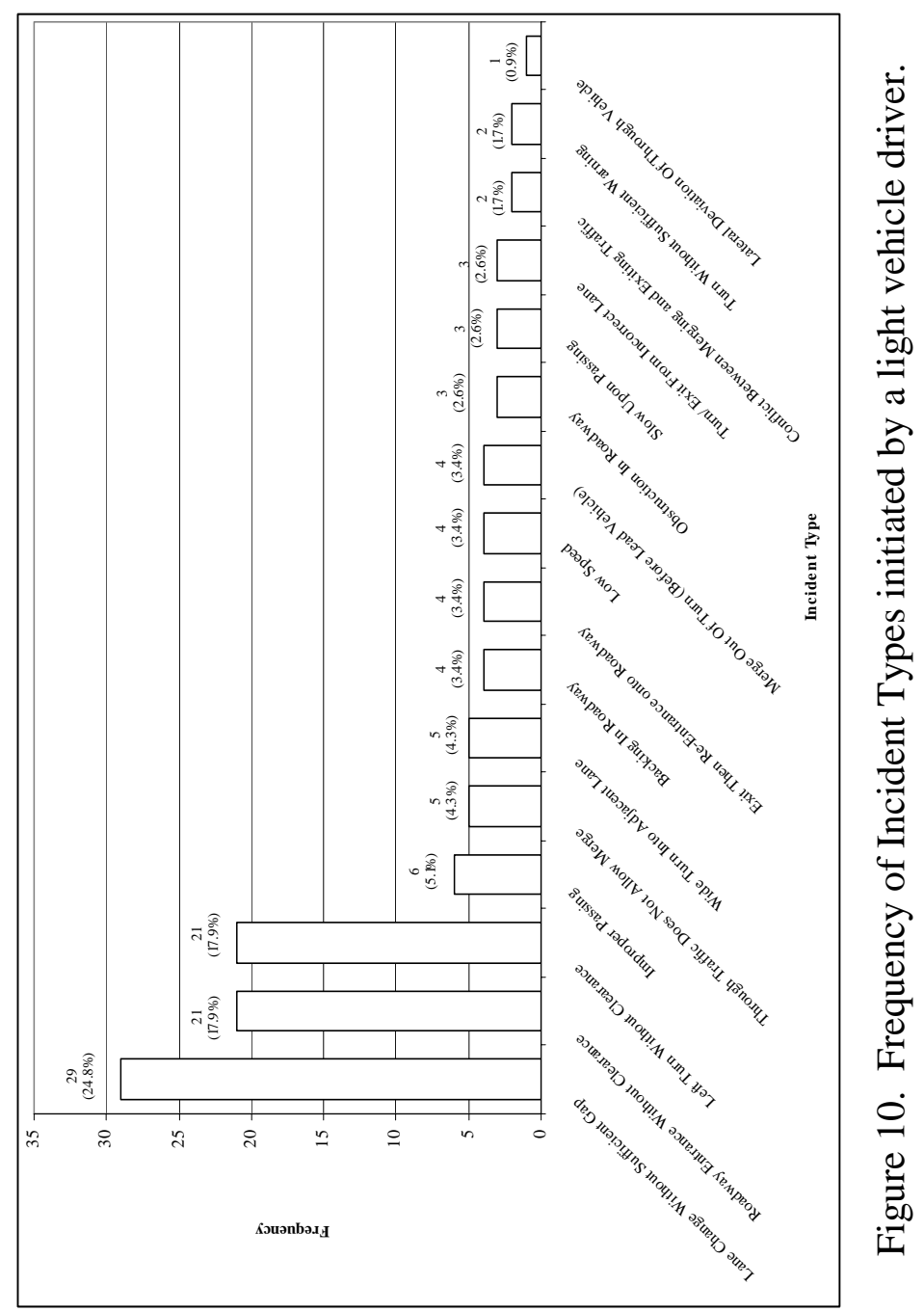


A histogram comparing the Incident Types initiated by the two groups of drivers (L/SH and LV) is shown in Figure 11. The figure shows that the individual types differ substantially depending on whether the LV driver or the L/SH driver was at fault. The most commonly occurring incident type was the Lane Change Without Sufficient Gap, followed by Roadway Entrance Without Clearance, and then Left Turn Without Clearance. The great majority of these were attributable to LV drivers.

Looking back at Figures 9 and 10, the second Incident Type, Roadway Entrance Without Clearance, represents 20 percent of incidents attributable to L/SH drivers and, similarly, 21 percent of incidents attributable to LV drivers. Other than this similarity, Figure 11 in combination with Figures 9 and 10 suggests that the pattern of incidents attributable to the two classes of drivers differs markedly.

In terms of some of the differences observable from Figures 9, 10, and 11, there are several interesting findings. L/SH drivers appear to have greater difficulty maneuvering their vehicles. The Wide Turn into Adjacent Lane, Backing in Roadway, and Low Speed categories are represented in much larger proportions for the $\mathrm{L} / \mathrm{SH}$ drivers than for the LV drivers. Also, no L/SH drivers initiated any Left Turn Without Clearance incidents, suggesting that L/SH drivers may take a cautious approach to left turns at intersections owing to the reduced maneuverability of their vehicles. In regard to the category entitled Late Braking for Stopped/Stopping Traffic, incidents were only initiated by the L/SH drivers. This result may be biased and may have been obtained because of the lack of instrumentation in light vehicles. Without such instrumentation, it would be difficult to discern late braking for the LV class. Finally, in regard to the previously mentioned category of Lane Change Without Sufficient Gap, LV drivers performed this maneuver far more often than did L/SH drivers. This finding echoes the reports made by $\mathrm{L} / \mathrm{SH}$ drivers in the focus groups as reported by Hanowski et al. (1998), where drivers told of the problems they face in frequently being "cut-off" by LV drivers. 


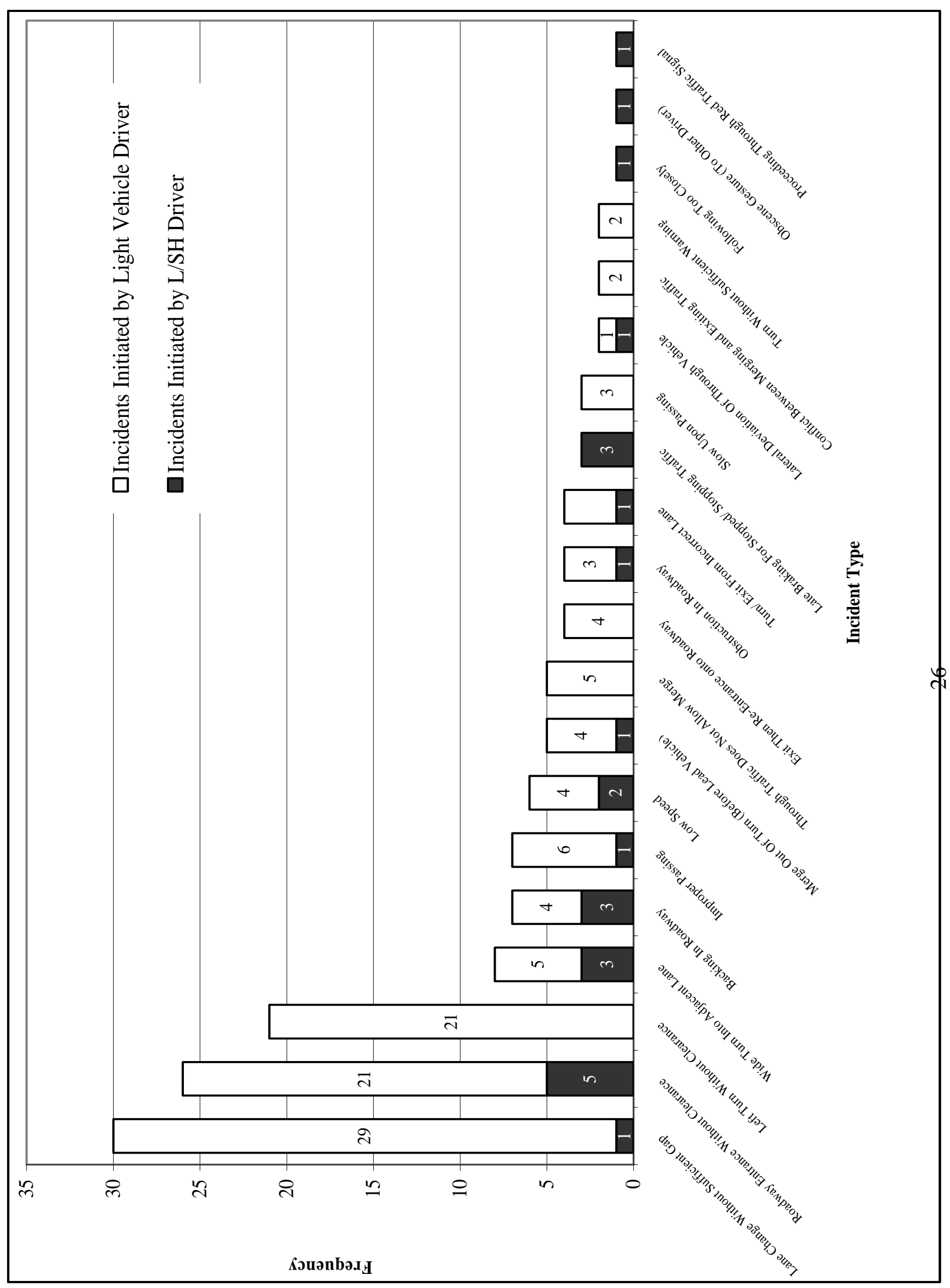




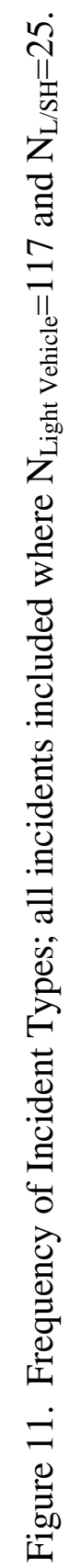




\section{Primary Maneuvers, Secondary Maneuvers, and Conflict Types}

After each of the 142 incidents was given an Incident Type classification, the next step in the analysis was to identify the "Primary Maneuvers," "Secondary Maneuvers," and "Conflict Types" involved in each incident. The Primary Maneuver refers to the maneuver of the driver who initiated the incident (i.e., the at-fault driver). As listed and defined in Table 5, across the 142 interaction incidents, 10 Primary Maneuvers were identified.

Table 5. List and definition of Primary Maneuver types.

\begin{tabular}{|c|c|}
\hline Primary Maneuver & Definition \\
\hline Backing & $\begin{array}{l}\text { From a parking space or driveway, or to complete a maneuver (i.e., while } \\
\text { maneuvering a tight turn). }\end{array}$ \\
\hline $\begin{array}{l}\text { Roadway Entrance From } \\
\text { Shoulder or Parking Space }\end{array}$ & $\begin{array}{l}\text { Stationary vehicle that enters the roadway from a parallel parking space or the } \\
\text { shoulder of the roadway. }\end{array}$ \\
\hline Through: & Vehicles traveling forward on a roadway or straight through an intersection. \\
\hline Oncoming & Another vehicle traveling in the opposite direction of at-fault vehicle. \\
\hline Following & Another vehicle traveling behind the at-fault vehicle. \\
\hline Lead & Another vehicle traveling ahead of the at-fault vehicle. \\
\hline Merge Onto Roadway: & From a merge lane. \\
\hline Lead & Another vehicle in the merge lane, ahead of the at-fault vehicle. \\
\hline Following & Another vehicle in the merge lane, behind the at-fault vehicle. \\
\hline Left Turn & $\begin{array}{l}\text { Relative to turning vehicle's direction of forward motion (not necessarily relative } \\
\text { to at-fault vehicle). May take place at an intersection or the entrance of a } \\
\text { driveway or parking lot. }\end{array}$ \\
\hline Right Turn & $\begin{array}{l}\text { Relative to turning vehicle's direction of forward motion (not necessarily relative } \\
\text { to at-fault vehicle). May take place at an intersection or the entrance of a } \\
\text { driveway or parking lot. }\end{array}$ \\
\hline Lane Change: & A through vehicle moves from one lane to another. \\
\hline To right & The driver moves into the adjacent right lane. \\
\hline To left & The driver moves into the adjacent left lane. \\
\hline From exit into though lane & $\begin{array}{l}\text { A driver moves from an exit lane into a through lane. Refers to cases in which a } \\
\text { driver moves into an exit lane then re-enters the through lane; this maneuver is } \\
\text { treated as a lane change rather than a roadway merge. }\end{array}$ \\
\hline U-turn & Driver turns into an opposing lane of traffic. \\
\hline Stopped & $\begin{array}{l}\text { Vehicle has stopped for reasons other than traffic and traffic signals. (Refers to a } \\
\text { vehicle stopped in a merge lane with hazard lights on.) }\end{array}$ \\
\hline Roadway Exit & Vehicle moves from a through lane into an exit lane. \\
\hline
\end{tabular}


In addition to identifying the Primary Maneuver for each incident, the Secondary Maneuver, or the maneuver of the responding driver (i.e., driver of the second vehicle involved in the interaction), was also classified. Considering the maneuvers of both vehicles involved in the incident, a clear picture of the conflict, or Conflict Type, could be determined. Table 6 shows the Conflict Types that were identified in the 142 interaction incidents that were analyzed. As can be seen, Table 6 consists of 37 Conflict Types (i.e., Primary Maneuver and Secondary Maneuver combinations).

Table 6. Thirty-seven Conflict Types identified for the 142 interaction incidents.

\begin{tabular}{|c|c|c|c|}
\hline Primary Maneuver & $\begin{array}{c}\text { Conflict Type } \\
\text { Number }\end{array}$ & $\begin{array}{l}\text { Detailed Primary Maneuver } \\
\text { (Maneuver of At-Fault Driver) }\end{array}$ & $\begin{array}{c}\text { Detailed Secondary Maneuver } \\
\text { (Maneuver of Responding Driver) }\end{array}$ \\
\hline \multirow[t]{2}{*}{ Backing } & 1 & Backing into roadway & $\begin{array}{l}\text { Oncoming through traffic (in } \\
\text { adjacent lane) }\end{array}$ \\
\hline & 2 & Backing into roadway & Same direction through traffic \\
\hline \multirow{2}{*}{$\begin{array}{l}\text { Roadway Entrance } \\
\text { From Shoulder or } \\
\text { Parking Space }\end{array}$} & 3 & $\begin{array}{l}\text { Roadway Entrance From } \\
\text { Shoulder of Parking Space }\end{array}$ & Merging traffic \\
\hline & 4 & $\begin{array}{l}\text { Roadway Entrance From } \\
\text { Shoulder of Parking Space }\end{array}$ & Through traffic \\
\hline \multirow[t]{2}{*}{ Roadway Exit } & 5 & Roadway Exit (proper) & Traffic already in exit lane \\
\hline & 6 & $\begin{array}{l}\text { Roadway Exit (from far left lane } \\
\text { into right exit lane) }\end{array}$ & Through traffic (in right lane) \\
\hline \multirow[t]{5}{*}{ Lane change } & 7 & Lane change (from exit lane) & Through traffic \\
\hline & 8 & $\begin{array}{l}\text { Lane change (from far left lane } \\
\text { into right turn lane) }\end{array}$ & Through traffic in right lane \\
\hline & 9 & Lane change (to left) & Through traffic in left lane \\
\hline & 10 & Lane change (to right) & Through traffic in right lane \\
\hline & 11 & Lane change (to right) & $\begin{array}{l}\text { Entering traffic from right (to the } \\
\text { rear) }\end{array}$ \\
\hline \multirow[t]{6}{*}{ Left turn } & 12 & Left turn & Cross traffic from left \\
\hline & 13 & Left turn & Cross traffic from right \\
\hline & 14 & Left turn & Following through traffic \\
\hline & 15 & Left turn & Oncoming through traffic \\
\hline & 16 & Left turn & $\begin{array}{l}\text { Oncoming through traffic (in parking } \\
\text { lot) }\end{array}$ \\
\hline & 17 & Left turn & Left turn traffic from right \\
\hline \multirow[t]{5}{*}{ Right turn } & 18 & Right turn & Cross traffic from left \\
\hline & 19 & Right turn & Cross traffic from right \\
\hline & 20 & Right turn & Following through traffic \\
\hline & 21 & Right turn & Left turn cross traffic from right \\
\hline & 22 & Right turn & Oncoming left turn traffic \\
\hline \multirow[t]{3}{*}{ Merge Onto Roadway } & 23 & Merge Onto Roadway & Lead merge traffic \\
\hline & 24 & Merge Onto Roadway & Following merge traffic \\
\hline & 25 & Merge Onto Roadway & Through traffic \\
\hline
\end{tabular}


Table 6. Continued and concluded.

\begin{tabular}{|l|c|l|l|}
\hline Primary Maneuver & $\begin{array}{c}\text { Conflict Type } \\
\text { Number }\end{array}$ & $\begin{array}{c}\text { Detailed Primary Maneuver } \\
\text { (Maneuver of At-Fault Driver) }\end{array}$ & $\begin{array}{c}\text { Detailed Secondary Maneuver } \\
\text { (Maneuver of Responding Driver) }\end{array}$ \\
\hline \multirow{4}{*}{ Stopped in Roadway } & 26 & $\begin{array}{l}\text { Merge Onto Roadway (from } \\
\text { shared auxiliary lane) }\end{array}$ & $\begin{array}{l}\text { Exiting traffic (onto shared auxiliary } \\
\text { lane) }\end{array}$ \\
\hline Through & 28 & Stopped vehicle in merge lane & Merge traffic \\
\cline { 2 - 4 } & 29 & Through & Adjacent through traffic \\
\cline { 2 - 4 } & 30 & Through & Cross-traffic from left \\
\cline { 2 - 4 } & 31 & Through & Following through traffic \\
\cline { 2 - 4 } & 32 & Through & Lead through traffic \\
\cline { 2 - 4 } & 33 & Through & Lead turning traffic \\
\cline { 2 - 4 } & 34 & Through & Merging traffic \\
\cline { 2 - 4 } & 35 & Through & Oncoming through traffic \\
\hline \multirow{3}{*}{ U-turn } & 36 & U-turn & Following through \\
\cline { 2 - 4 } & 37 & U-turn & Oncoming through traffic \\
\hline
\end{tabular}

Table 7 shows a set of descriptive statistics of the Primary Maneuvers for all of the incidents in the data set. Figure 12 shows a histogram of the cumulative frequency data for all of the Primary Maneuvers. As can be seen in Figure 12, the three most common Primary Maneuvers across all incidents were: (1) Lane Change, n=32, (2) Left Turn, n=29, and (3) Through, n=27. 


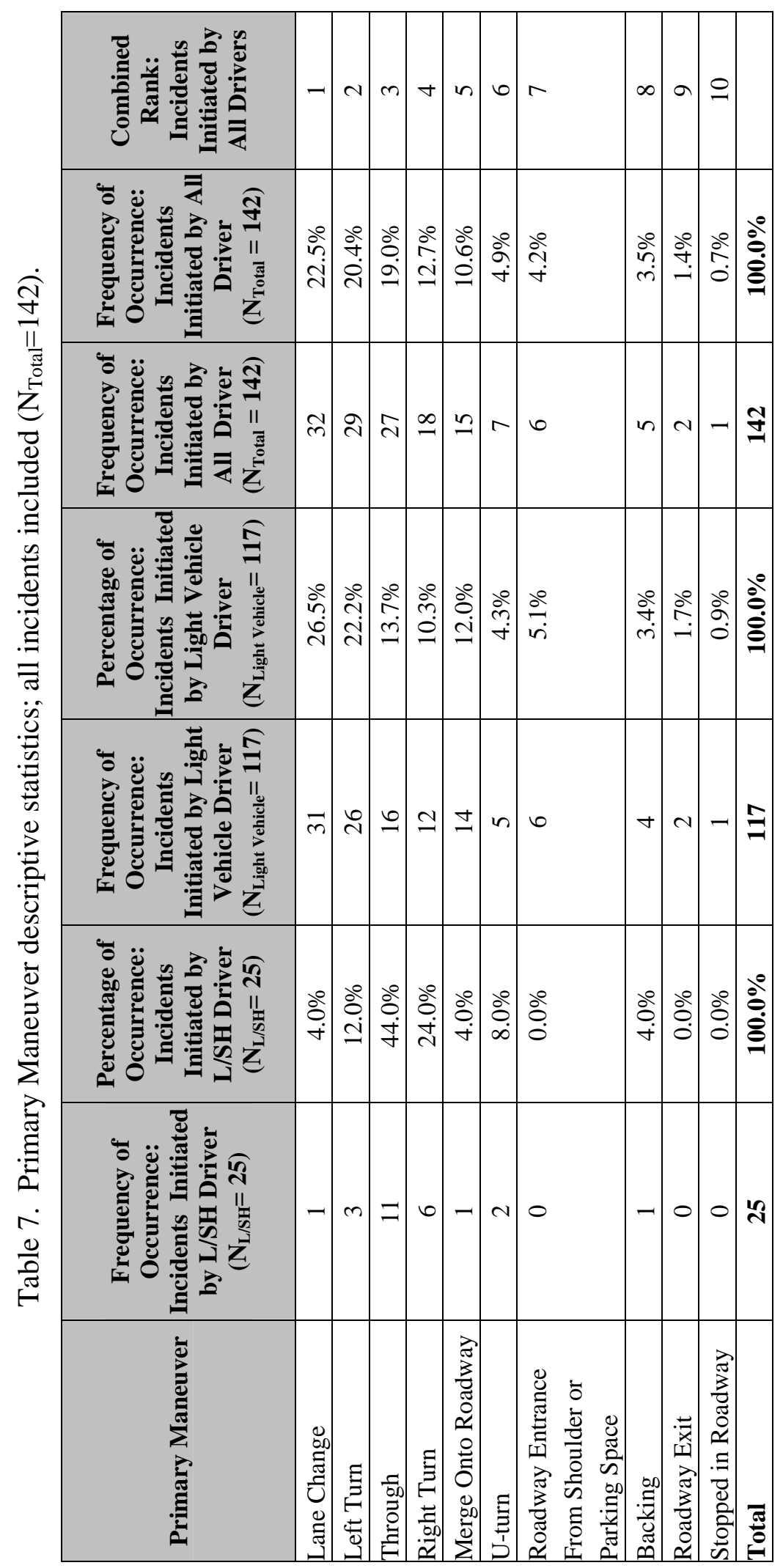




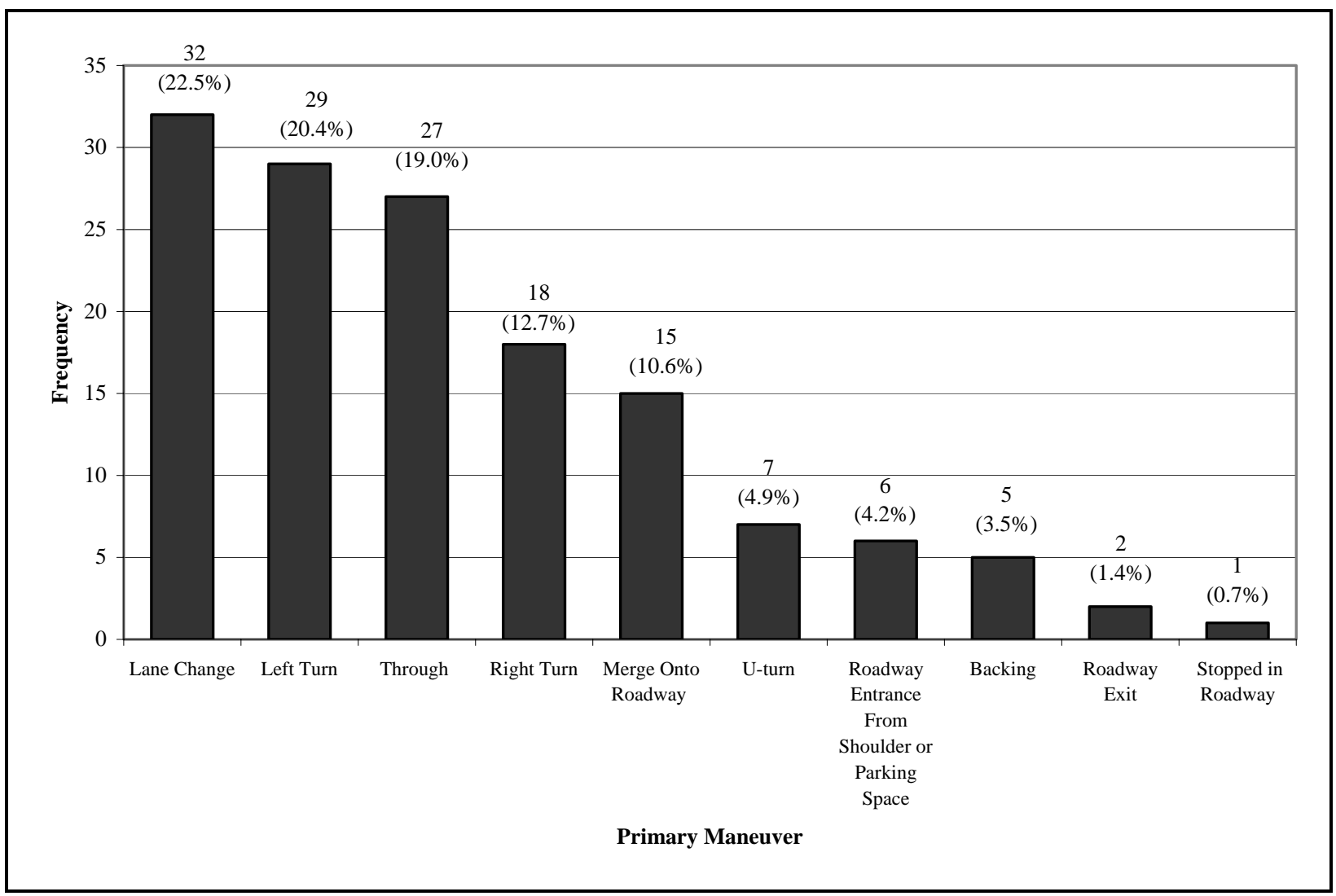

Figure 12. Frequency of Primary Maneuvers; all incidents included.

The Primary Maneuvers for incidents that were initiated by the L/SH driver are highlighted in Table 8. Specifically, Table 8 shows the frequency of occurrence, percentage of occurrence, and frequency rank for each Primary Maneuver. The frequency of occurrence and percentage of occurrence are also shown in Figure 13. For incidents initiated by L/SH drivers, the most common Primary Maneuver, “Through,” involved the driver driving forward on a roadway or straight through an intersection. 
Table 8. Primary Maneuver descriptive statistics for incidents initiated by a L/SH driver $\left(\mathrm{N}_{\mathrm{L} / \mathrm{SH}}=25\right)$.

\begin{tabular}{|c|c|c|c|}
\hline Primary Maneuver & $\begin{array}{c}\text { Frequency of } \\
\text { Occurrence: } \\
\text { Incidents Initiated } \\
\text { by } \mathrm{L} / \mathrm{SH} \text { Driver } \\
\left(\mathrm{N}_{\mathrm{L} / \mathrm{SH}}=25\right) \\
\end{array}$ & $\begin{array}{c}\text { Percentage of } \\
\text { Occurrence: Incidents } \\
\text { Initiated by } \mathrm{L} / \mathrm{SH} \\
\text { Driver }\left(\mathrm{N}_{\mathrm{L} / \mathrm{SH}}=25\right)\end{array}$ & $\begin{array}{c}\text { Rank: Incidents } \\
\text { Initiated by } \mathrm{L} / \mathrm{SH} \\
\text { Driver } \\
\left(\mathrm{N}_{\mathrm{L} / \mathrm{SH}}=25\right)\end{array}$ \\
\hline \begin{tabular}{|l} 
Through \\
\end{tabular} & 11 & $44.0 \%$ & 1 \\
\hline Right Turn & 6 & $24.0 \%$ & 2 \\
\hline Left Turn & 3 & $12.0 \%$ & 3 \\
\hline U-turn & 2 & $8.0 \%$ & 4 \\
\hline Backing & 1 & $4.0 \%$ & 6 \\
\hline Lane Change & 1 & $4.0 \%$ & 6 \\
\hline Merge Onto Roadway & 1 & $4.0 \%$ & 6 \\
\hline Stopped in Roadway & 0 & $0.0 \%$ & 9 \\
\hline $\begin{array}{l}\text { Roadway Entrance From } \\
\text { Shoulder or Parking Space }\end{array}$ & 0 & $0.0 \%$ & 9 \\
\hline Roadway Exit & 0 & $0.0 \%$ & 9 \\
\hline Total & 25 & $100.0 \%$ & \\
\hline
\end{tabular}




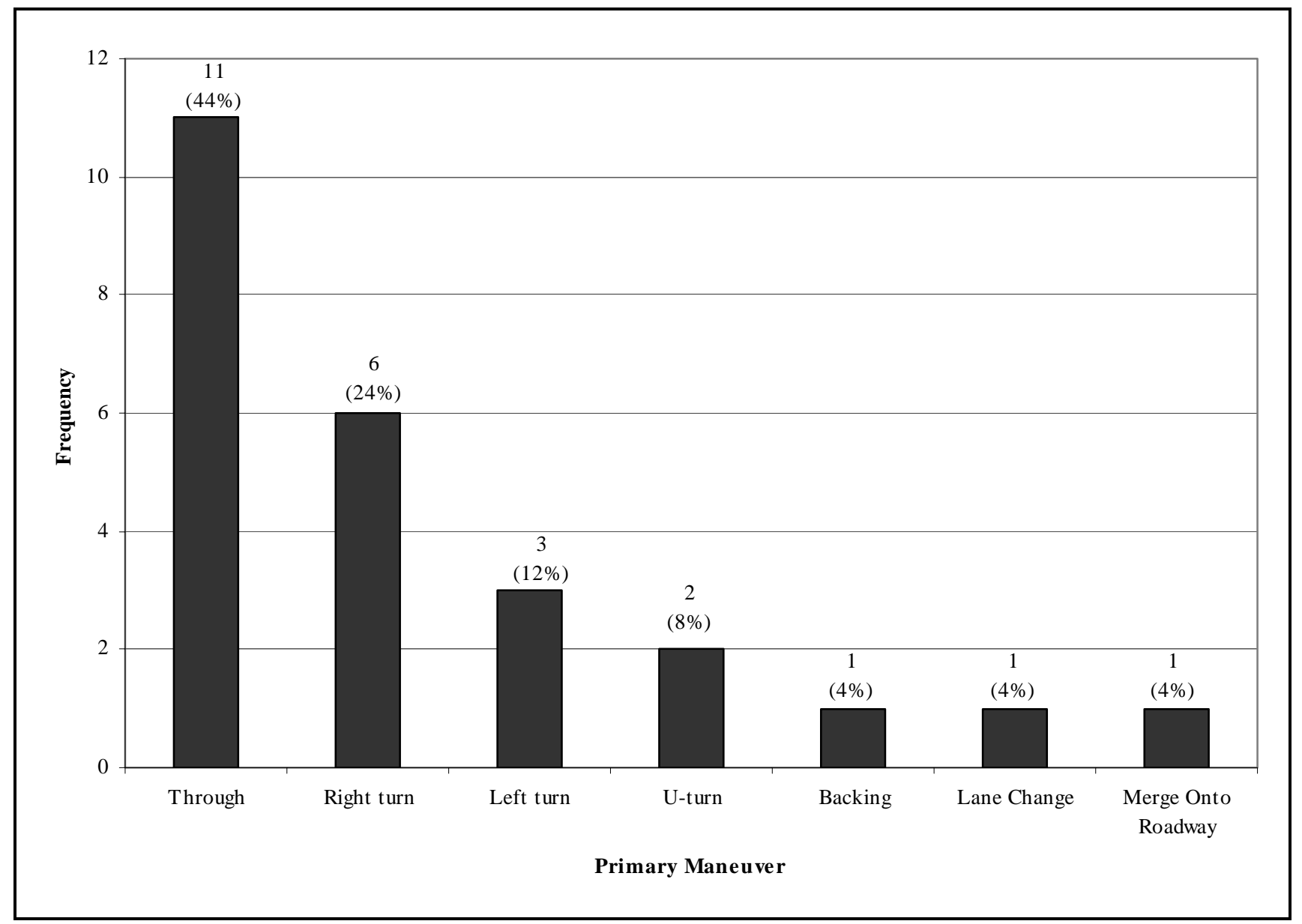

Figure 13. Frequency of Primary Maneuvers involving L/SH driver-initiated incidents.

The Primary Maneuver occurrence data for incidents initiated by LV drivers is shown in Table 9. The Primary Maneuver frequency data for these incidents are presented in Figure 14. As shown, the two most common Primary Maneuvers for LV driver-initiated incidents were Lane Change $(n=31)$ and Left Turn $(n=26)$. 
Table 9. Primary Maneuver descriptive statistics for incidents initiated by an LV driver $\left(\mathrm{N}_{\text {Light }}\right.$ Vehicle=117).

\begin{tabular}{|c|c|c|c|}
\hline Primary Maneuver & $\begin{array}{c}\text { Frequency of } \\
\text { Occurrence: } \\
\text { Incidents Initiated } \\
\text { by Light Vehicle } \\
\text { Driver } \\
\left(\mathrm{N}_{\text {Light Vehicle }}=117\right)\end{array}$ & $\begin{array}{l}\text { Percentage of } \\
\text { Occurrence: Incidents } \\
\text { Initiated by Light } \\
\text { Vehicle Driver } \\
\left(\mathrm{N}_{\text {Light Vehicle }}=117\right)\end{array}$ & $\begin{array}{l}\text { Rank: Incidents } \\
\text { Initiated by Light } \\
\text { Vehicle Driver }\end{array}$ \\
\hline Lane Change & 31 & $26.5 \%$ & 1 \\
\hline Left Turn & 26 & $22.2 \%$ & 2 \\
\hline Through & 16 & $13.7 \%$ & 3 \\
\hline Merge Onto Roadway & 14 & $12.0 \%$ & 4 \\
\hline Right Turn & 12 & $10.3 \%$ & 5 \\
\hline $\begin{array}{l}\text { Roadway Entrance From } \\
\text { Shoulder or Parking Space }\end{array}$ & 6 & $5.1 \%$ & 6 \\
\hline U-turn & 5 & $4.3 \%$ & 7 \\
\hline Backing & 4 & $3.4 \%$ & 8 \\
\hline Roadway Exit & 2 & $1.7 \%$ & 9 \\
\hline Stopped in Roadway & 1 & $0.9 \%$ & 10 \\
\hline Total & 117 & $100.0 \%$ & \\
\hline
\end{tabular}




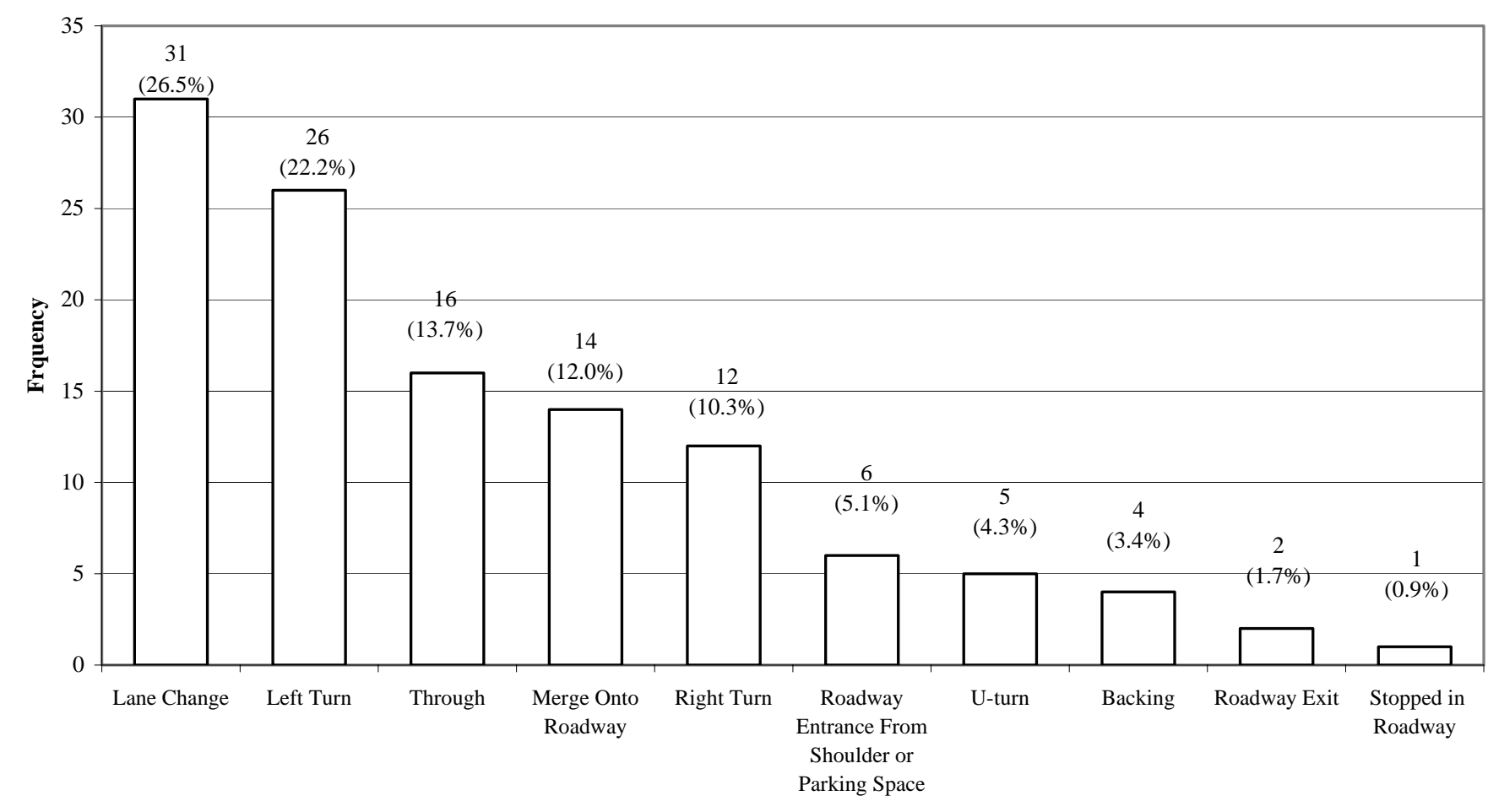

Primary Maneuver

Figure 14. Frequency of Primary Maneuvers involving light vehicle driver-initiated incidents.

As in the case of Incident Types initiated by L/SH drivers and those initiated by LV drivers, a comparison was made for the Primary Maneuvers of the two groups of drivers. The results of this comparison are shown in Figure 15. When Figures 13, 14, and 15 are examined, it once again becomes apparent that there are large differences between L/SH driver initiated incidents and LV driver initiated incidents. Lane Change, Left Turn, and Merging onto Roadway occur substantially more often for LV drivers than for L/SH drivers. In contrast, Through, Right Turn, and U-Turn maneuvers occur more frequently for $\mathrm{L} / \mathrm{SH}$ drivers than for $\mathrm{LV}$ drivers. 


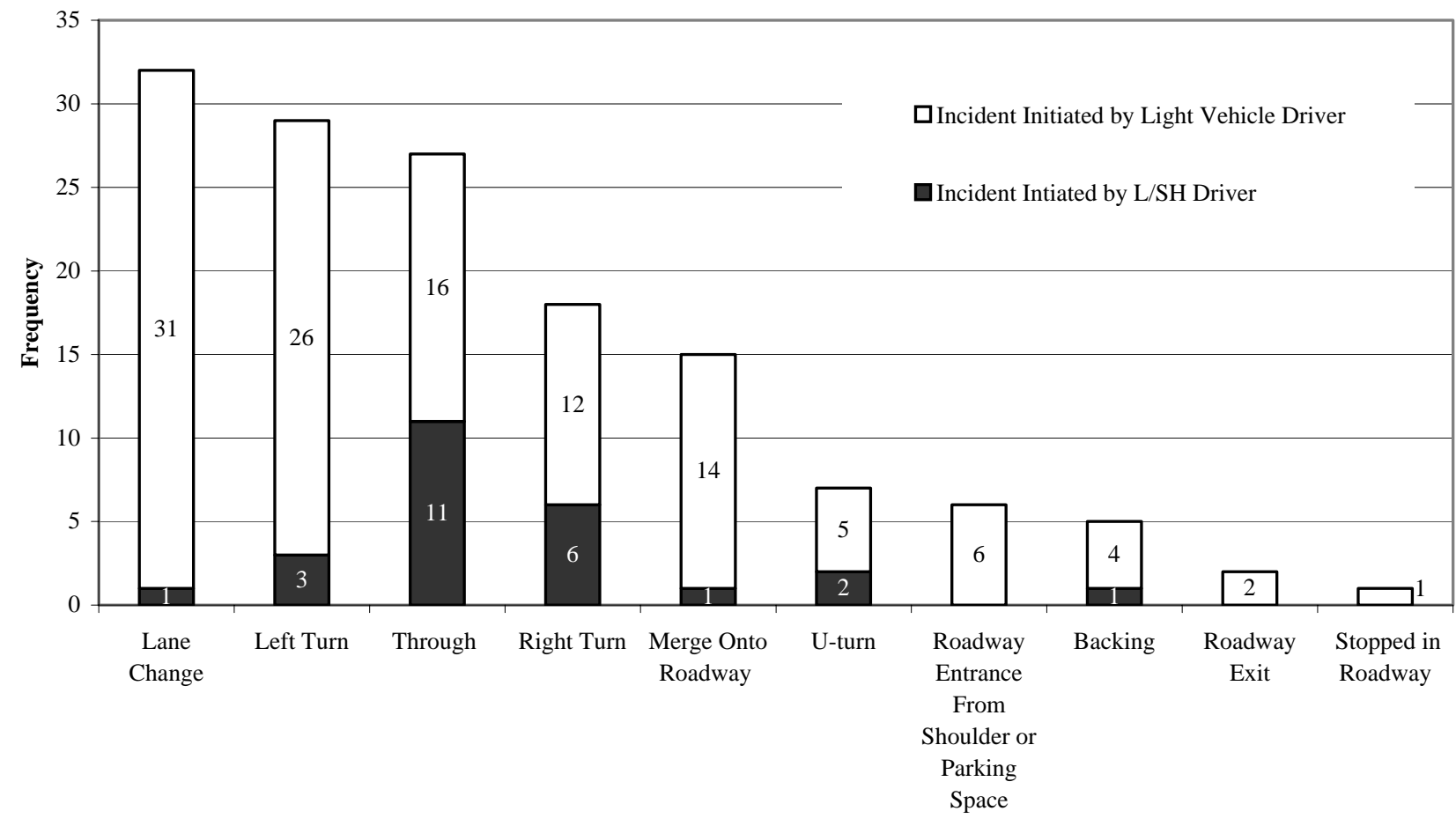

Primary Maneuver

Figure 15. Frequency of Primary Maneuvers; all incidents included where $\mathrm{N}_{\text {Light Vehicle }}=117$ and $\mathrm{N}_{\mathrm{L} / \mathrm{SH}}=25$.

\section{Contributing Factors}

Just as the Incident Types describe the action or what happened during an incident, contributing factors provide likely reasons why an incident occurred. For each incident that was analyzed, a number of contributing factors were identified. The "but for" test was applied to this list of contributing factors for each incident; that is, "but for , the incident would not have happened." The result of this filtering was a single contributing factor that was judged to be of primary importance to the incident occurrence.

General Contributing Factors

The term "General Contributing Factor" was used because the factors included were very general in nature. Table 10 outlines the General Contributing Factors and shows that four such factors were used: (1) Impairment, (2) Willful Behavior, (3) Infrastructure, and (4) Driver Proficiency. It should be pointed out that these factors are the same as those used by Wierwille, Kieliszewski, Hanowski, Keisler, and Olsen (2000). 
Table 10. General Contributing Factors used to identify the primary cause of the incident.

\begin{tabular}{|l|l|}
\hline General Contributing Factor & \multicolumn{1}{c|}{ Definition } \\
\hline Impairment & The driver's behavior, judgment or driving ability is altered or hindered. \\
\hline Willful Behavior & $\begin{array}{l}\text { The driver knowingly and purposefully drives in an unsafe or } \\
\text { inappropriate manner. }\end{array}$ \\
\hline Infrastructure & $\begin{array}{l}\text { The driver's physical surroundings hinder his/her ability to drive safely } \\
\text { and appropriately or confuse the driver. }\end{array}$ \\
\hline Driver Proficiency & An individual's driving skills, abilities, or knowledge are inadequate. \\
\hline
\end{tabular}

Table 11 provides General Contributing Factors occurrence data for the 142 incidents. Frequency and percentage of occurrence are provided for all General Contributing Factors for each driver group. In addition, the overall ranking based on frequency of occurrence for all 142 incidents is provided. Table 12 shows the occurrence data for the L/SH driver-initiated incidents, and Table 13 shows the occurrence data for LV driver-initiated incidents. The top three General Contributing Factors (not including the "Undeterminable" category) for each driver group were the same, although in a different order. 


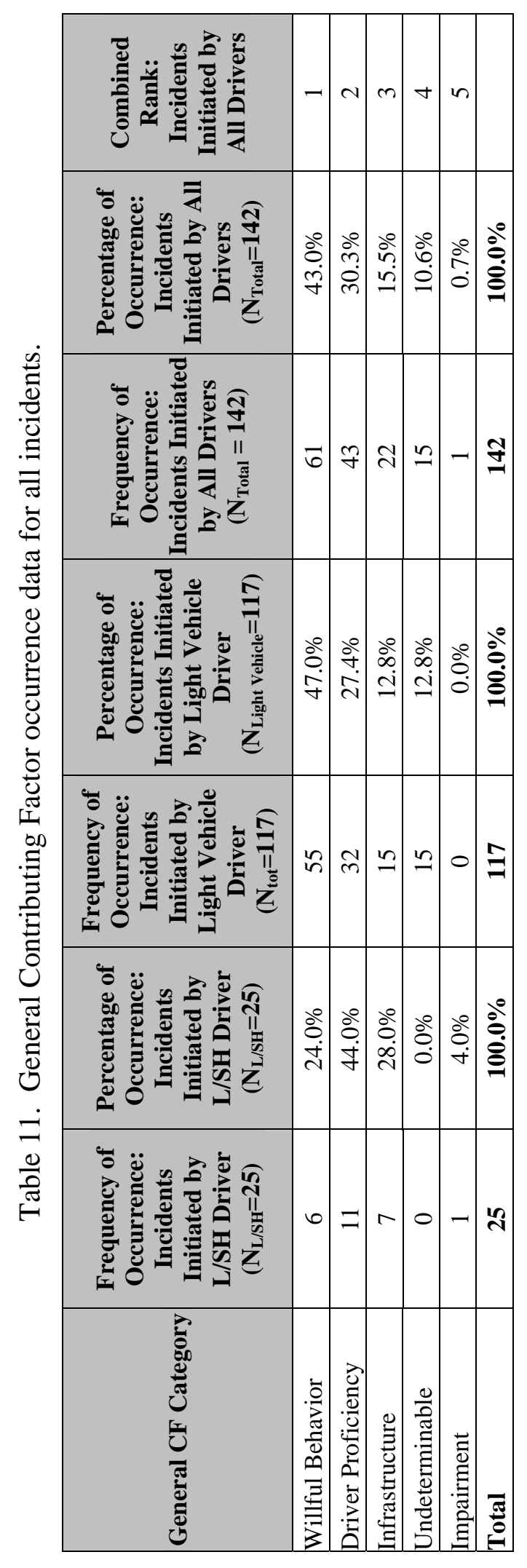



Table 12. General Contributing Factor occurrence for incidents initiated by a L/SH driver.

\begin{tabular}{|l|c|c|c|}
\hline $\begin{array}{c}\text { General CF } \\
\text { Category }\end{array}$ & $\begin{array}{c}\text { Frequency of Occurrence: } \\
\text { Incidents Initiated by L/SH } \\
\left.\text { Driver } \mathbf{( N}_{\mathbf{L} / \mathbf{S H}}=\mathbf{2 5}\right)\end{array}$ & $\begin{array}{c}\text { Percentage of Occurrence: } \\
\text { Incidents Initiated by L/SH } \\
\text { Driver } \mathbf{~ ( N / S H ~}_{\mathbf{L} / \mathbf{2 5})}\end{array}$ & $\begin{array}{c}\text { Rank: Incidents } \\
\text { Initiated by L/SH } \\
\text { Driver }\end{array}$ \\
\hline Driver Proficiency & 11 & $44.0 \%$ & 2 \\
\hline Infrastructure & 7 & $28.0 \%$ & 3 \\
\hline Willful Behavior & 6 & $24.0 \%$ & 4 \\
\hline Impairment & 1 & $4.0 \%$ & 5 \\
\hline Undeterminable & 0 & $0.0 \%$ & \\
\hline Total & $\mathbf{2 5}$ & $\mathbf{1 0 0 . 0 \%}$ & 2 \\
\hline
\end{tabular}

Table 13. General Contributing Factor occurrence for incidents initiated by a light vehicle driver.

\begin{tabular}{|c|c|c|c|}
\hline General CF Category & $\begin{array}{l}\text { Frequency of Occurrence: } \\
\text { Incidents Initiated by } \\
\text { Light Vehicle Driver } \\
\left(\mathbf{N}_{\text {tot }}=117\right)\end{array}$ & $\begin{array}{l}\text { Percentage of Occurrence: } \\
\text { Incidents Initiated by } \\
\text { Light Vehicle Driver } \\
\left(\mathrm{N}_{\text {Light Vehicle }}=117\right)\end{array}$ & $\begin{array}{l}\text { Rank: Incidents } \\
\text { Initiated by Light } \\
\text { Vehicle Driver }\end{array}$ \\
\hline Willful Behavior & 55 & $47.0 \%$ & 1 \\
\hline Driver Proficiency & 32 & $27.4 \%$ & 2 \\
\hline Infrastructure & 15 & $12.8 \%$ & 3.5 \\
\hline Undeterminable & 15 & $12.8 \%$ & 3.5 \\
\hline Impairment & 0 & $0.0 \%$ & 5 \\
\hline Total & 117 & $100.0 \%$ & \\
\hline
\end{tabular}


Figure 16 shows a histogram for the General Contributing Factors of L/SH driverinitiated incidents. Note that the Undeterminable category was created to include incidents in which the General Contributing Factors could not be determined from the videotape. As can be seen, the top three factors from highest frequency to lowest frequency were: (1) Driver Proficiency, (2) Infrastructure, and (3) Willful Behavior.

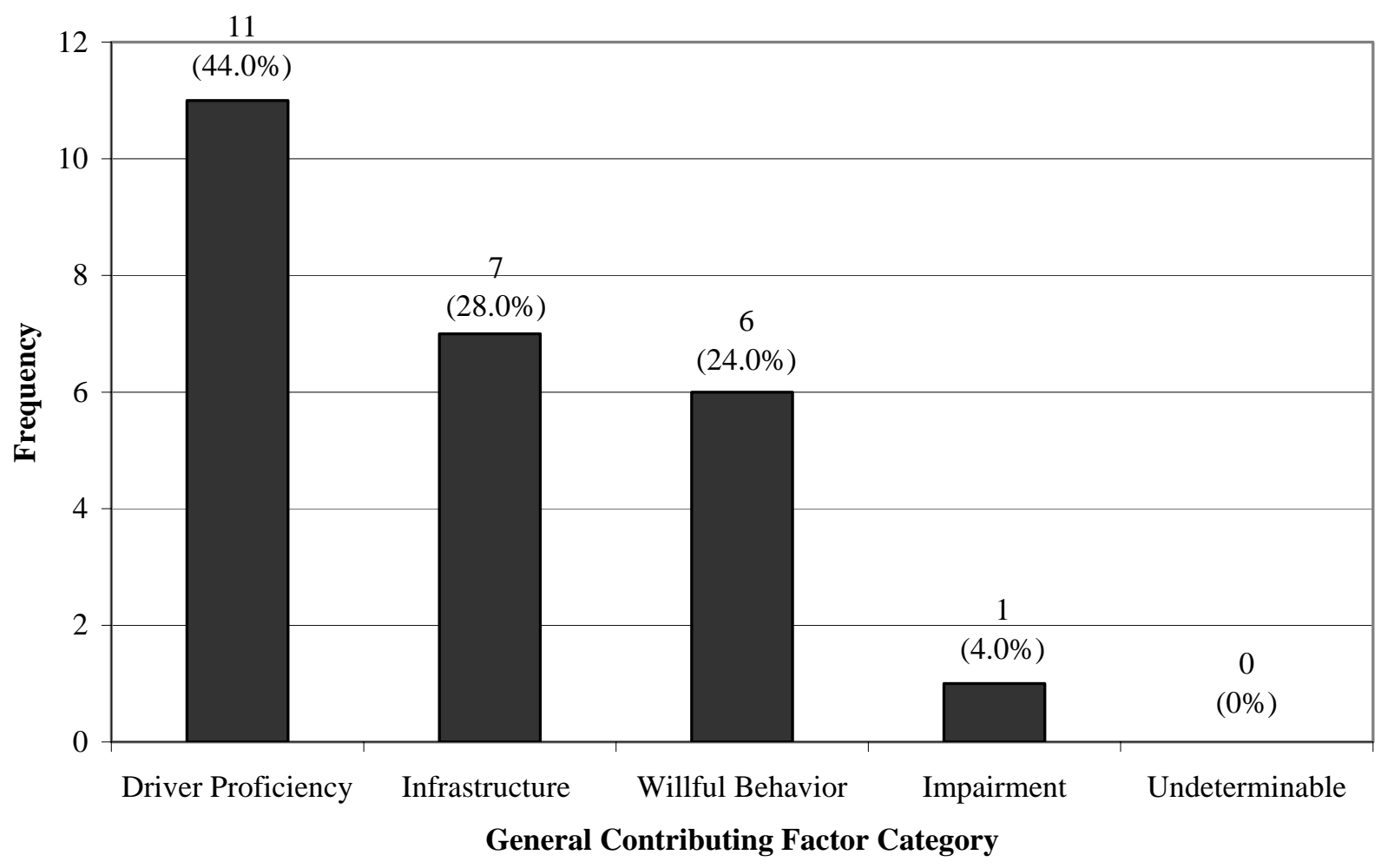

Figure 16. Frequency of General Contributing Factors for the L/SH driver-initiated incidents. 
Figure 17 shows a histogram of the General Contributing Factors of LV driver-initiated incidents. The top three factors from highest to lowest frequency were: (1) Willful Behavior, (2) Driver Proficiency, and (3) Infrastructure (tied with Undeterminable).

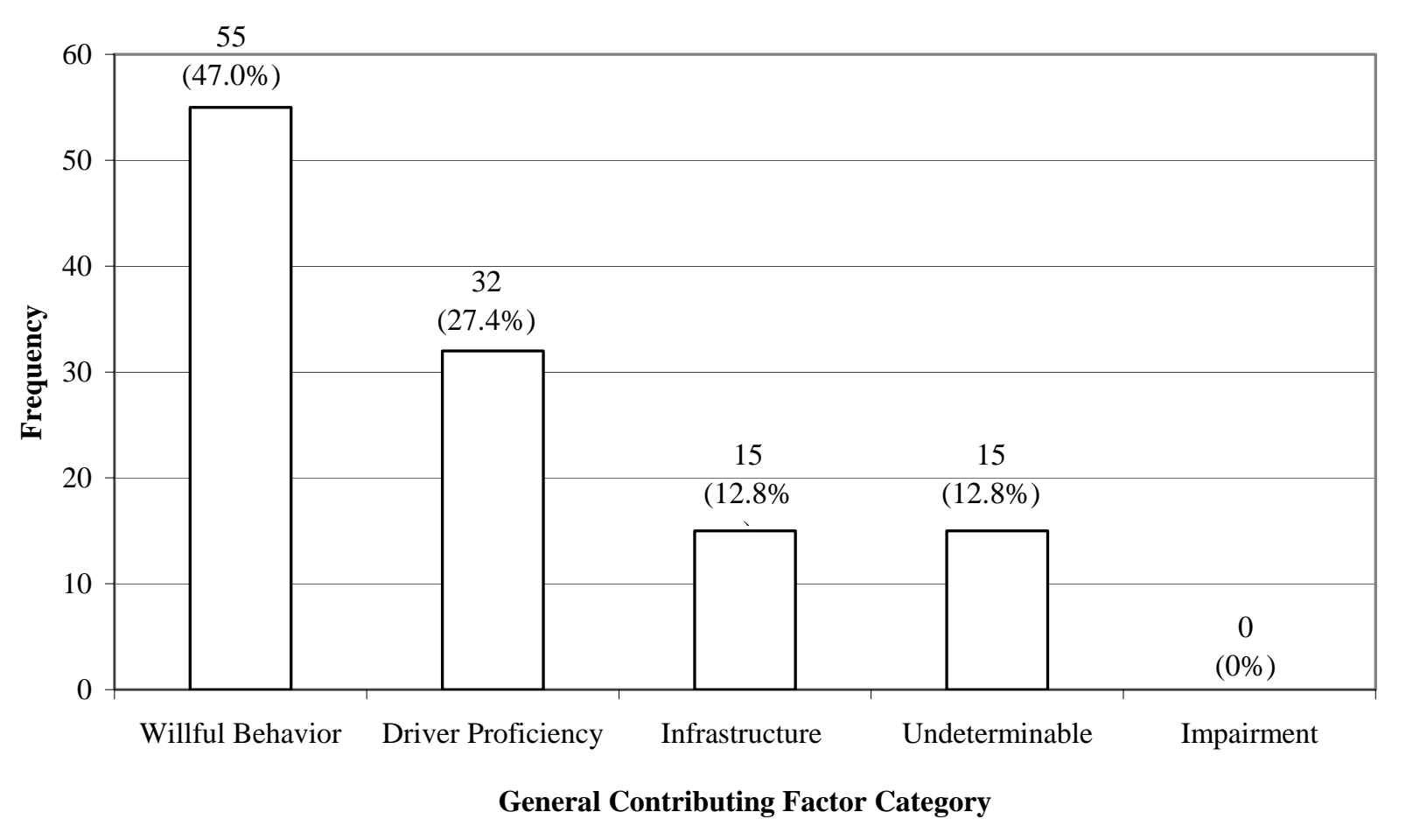

Figure 17. Frequency of General Contributing Factors for the light vehicle driver-initiated incidents. 
A comparison was made between the General Contributing Factors for incidents initiated by the $\mathrm{L} / \mathrm{SH}$ driver and those initiated by the LV driver, as is shown in Figure 18. The histogram in this figure shows that L/SH drivers had difficulty with Infrastructure and Driver Proficiency, while incidents initiated by LV drivers involved Willful Behavior most frequently.

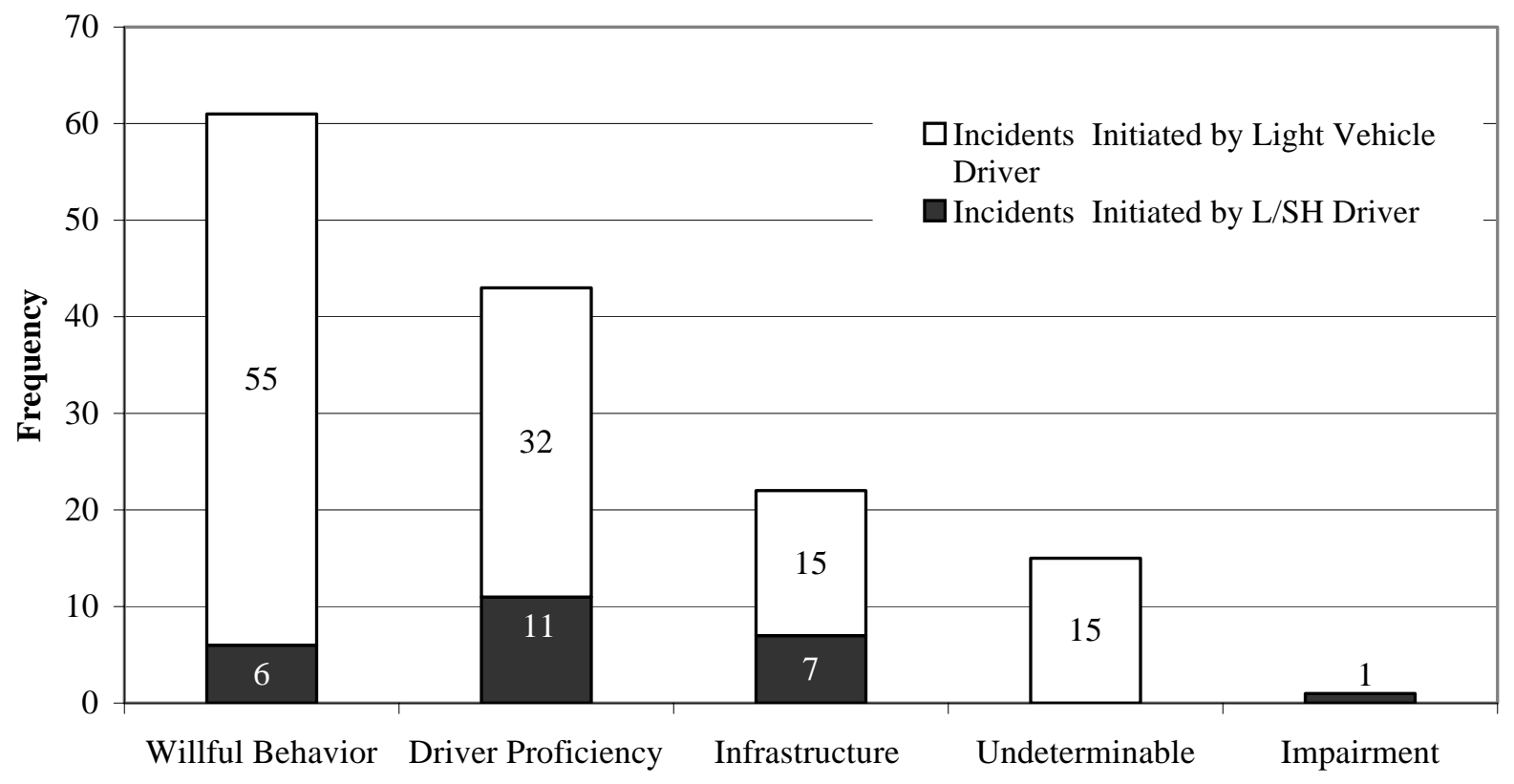

General Contributing Factor Category

Figure 18. Frequency of General Contributing Factors; all incidents included where $\mathrm{N}_{\text {Light Vehicle }}$ $=117$ and $\mathrm{N}_{\mathrm{L} / \mathrm{SH}}=25$. 
As pointed out earlier, the General Contributing Factors categories used in the present research were the same as those outlined in Wierwille et al. (2000). In the Wierwille et al. research, video cameras were mounted in stationary positions to capture incidents at various roadway sites (primarily intersections). The incidents captured were analyzed in a manner similar to the analysis conducted for the present effort. One of the analyses conducted by Wierwille et al. included an assessment of the General (or Principle) Contributing Factors for "serious" incidents (very close calls). Fifty-two serious incidents were captured and analyzed. Of these, 30 (57.7 percent) were attributed to Willful Behavior; 12 (23.1 percent) to Driver Proficiency; and 10 (19.2 percent) to Infrastructure. Figure 19 compares the General Contributing Factors data from Wierwille et al. and the current effort. Note that to make a meaningful comparison with the Wierwille et al. data, the Undeterminable category used in the current effort was not included. The data from the two research efforts are quite similar, and, as illustrated in Figure 20, the results show even greater correspondence when a comparison is made using only LV driverinitiated incidents (incidents that were typical in the Wierwille et al. data).

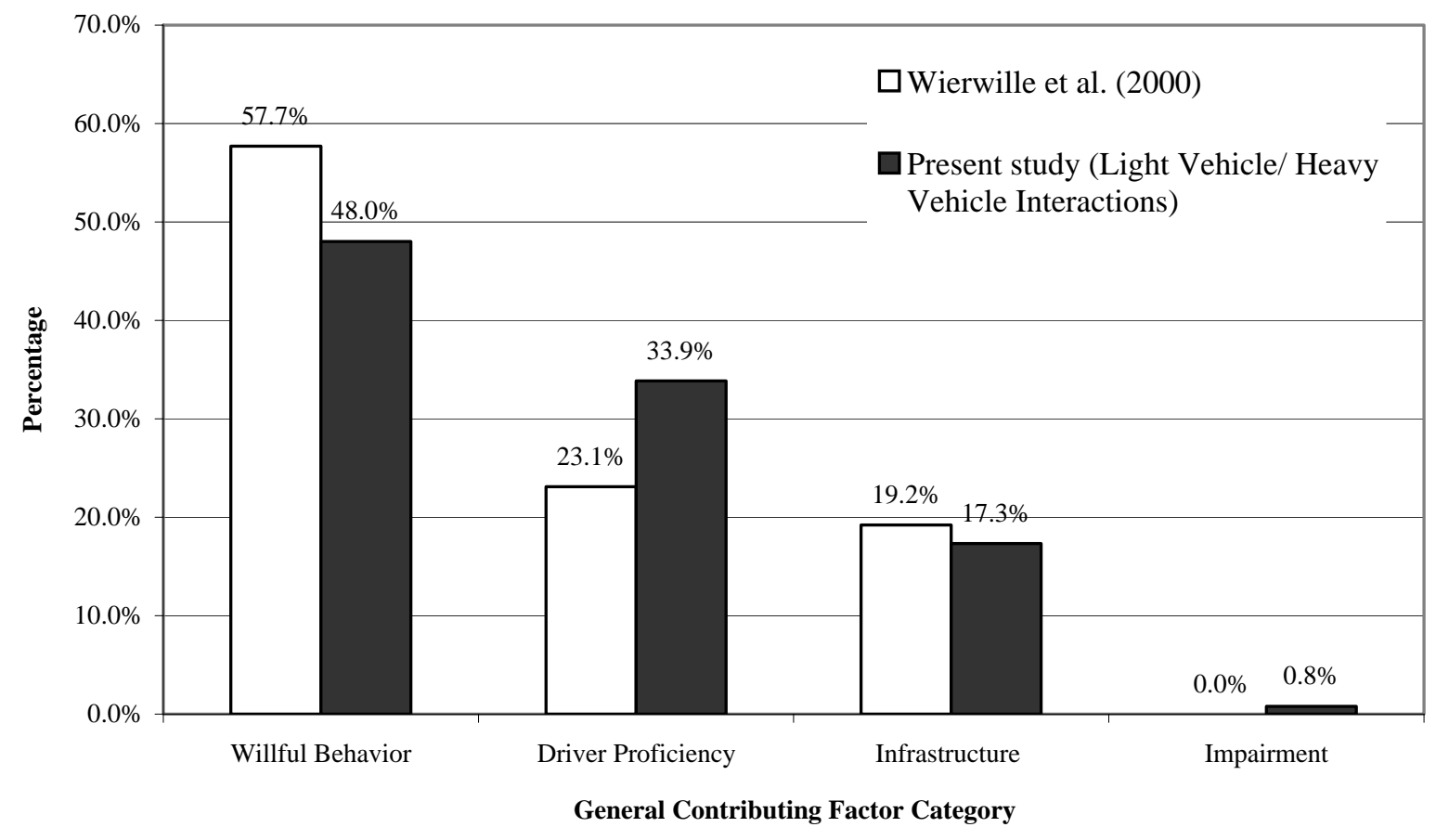

Figure 19. Comparison of the General Contributing Factors from Wierwille et al. (2000) and all (determinable) data in the current research. 


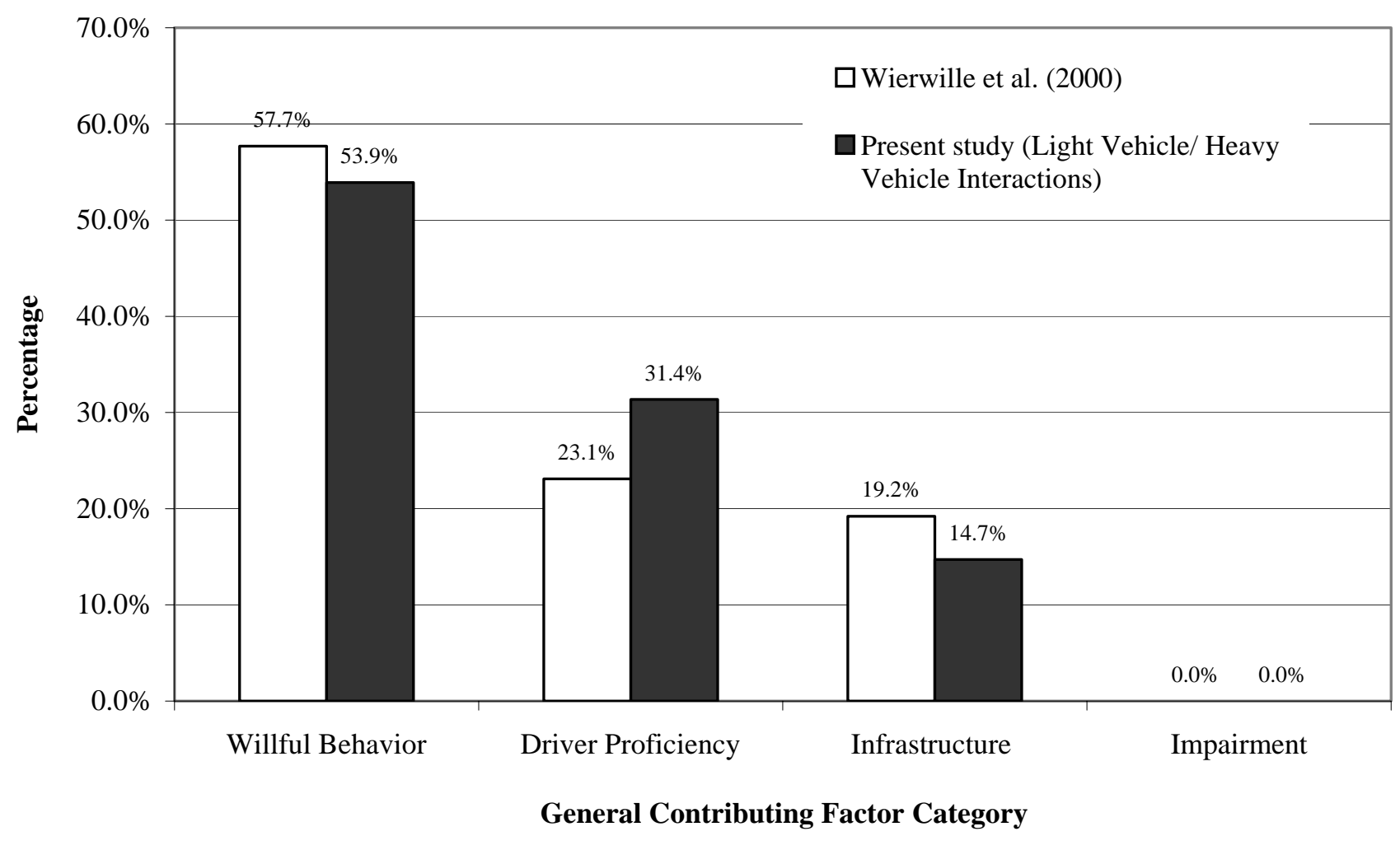

Figure 20. General Contributing Factors comparison of the Wierwille et al. (2000) data and determinable data from the light vehicle driver-initiated incidents captured in the current research. 
Specific Contributing Factors

After a General Contributing Factor was identified for each incident, a more detailed assessment was made to determine the "Specific Contributing Factors" associated with the incident. As shown in Table 14, which is similar to categorizations in Wierwille et al. (2000), each General Contributing Factor is subdivided into several Specific Contributing Factors. In the same way as a single General Contributing Factor was assessed for each incident, the single most relevant Specific Contributing Factor was also determined for each incident. By reading the definitions of the Specific Contributing Factors in Table 14, these factors help provide a clear indication as to why the incident occurred. 
Table 14. Specific Contributing Factors used to identify the primary cause of the incident.

\begin{tabular}{|c|c|}
\hline Specific Contributing Factor & Definition \\
\hline \multicolumn{2}{|l|}{ Impairment } \\
\hline Fatigue and Drowsiness & Impairs the driver's attention and/or judgment. \\
\hline Use of Drugs, Alcohol & $\begin{array}{l}\text { Alter the driver's judgment and/or behavior, as evidenced by erratic or } \\
\text { extreme driving. }\end{array}$ \\
\hline Illness & Impairs the driver's attention and/or judgment. \\
\hline $\begin{array}{l}\text { Lack of Use, Incorrect Use of } \\
\text { Medication }\end{array}$ & Impairs the driver's attention and/or judgment. \\
\hline Disability, Uncorrected Disability & $\begin{array}{l}\text { Impairs the driver's ability to drive safely (e.g., uncorrected vision or } \\
\text { hearing problem). }\end{array}$ \\
\hline \multicolumn{2}{|l|}{ Willful Behavior } \\
\hline Aggressive Driving & $\begin{array}{l}\text { The driver intentionally drives unsafely or inappropriately, usually } \\
\text { due to impatience (e.g., quickly passes another vehicle just before a } \\
\text { turn, fails to remain a safe distance from another vehicle, excessive } \\
\text { speed). }\end{array}$ \\
\hline $\begin{array}{l}\text { Purposeful Violation of Traffic Laws, } \\
\text { Regulations }\end{array}$ & $\begin{array}{l}\text { The driver knowingly violates a traffic law (e.g., fails to respond to a } \\
\text { traffic signal or stop sign). }\end{array}$ \\
\hline $\begin{array}{l}\text { Use of Vehicle for Improper Purposes } \\
\text { (Intimidation) }\end{array}$ & $\begin{array}{l}\text { A driver intentionally attempts to intimidate or provoke another driver } \\
\text { (e.g., purposefully slows in retaliation to another driver following too } \\
\text { closely). }\end{array}$ \\
\hline $\begin{array}{l}\text { Use of Vehicle for Improper Purposes } \\
\text { (As a Weapon) }\end{array}$ & $\begin{array}{l}\text { A driver intentionally causes harm or attempts to cause harm to } \\
\text { another driver (e.g., forces another driver off the road). }\end{array}$ \\
\hline \multicolumn{2}{|l|}{ Infrastructure } \\
\hline Roadway Alinement & $\begin{array}{l}\text { It is difficult for the driver to maneuver due to the geometry of a } \\
\text { roadway or intersection (e.g., a narrow roadway or sharp turn). }\end{array}$ \\
\hline Roadway Sight Distance & The driver is unable to see an adequate distance ahead. \\
\hline Traffic Control Device & $\begin{array}{l}\text { Lack of, poor positioning of, or poor visibility of traffic control } \\
\text { devices. }\end{array}$ \\
\hline Roadway Delineation & $\begin{array}{l}\text { Poor visibility (e.g., faded paint) or positioning of roadway or lane } \\
\text { borders. }\end{array}$ \\
\hline Weather, Visibility & May limit maneuverability (poor traction) or visibility. \\
\hline \multicolumn{2}{|l|}{ Driver Proficiency } \\
\hline Traffic Laws & $\begin{array}{l}\text { Driver appears unaware of a traffic law (e.g., right-of-way } \\
\text { convention). }\end{array}$ \\
\hline Driving Techniques & $\begin{array}{l}\text { Driver appears unsure or incompetent as to how to safely perform a } \\
\text { driving maneuver (e.g., failing to check for traffic before proceeding } \\
\text { onto a roadway). }\end{array}$ \\
\hline Vehicle Kinematics, Physics & $\begin{array}{l}\text { The driver appears unsure or incompetent handling the vehicle. (e.g., } \\
\text { unaware of the turning radius of a large vehicle. ) }\end{array}$ \\
\hline Driver Capabilities, Limitations & $\begin{array}{l}\text { The driver performs a maneuver under the incorrect assumption that it } \\
\text { is safe and appropriate to do so (e.g., a driver believes he/she can use a } \\
\text { cell phone while driving but cannot safely attend to both tasks). }\end{array}$ \\
\hline
\end{tabular}


Table 15 shows the frequency of occurrence data for the Specific Contributing Factors across all 142 incidents. A histogram of the combined data is presented in Figure 21. As can be seen across all incidents, Aggressive Driving and Driving Techniques are the Specific Contributing Factors that occur most frequently. 


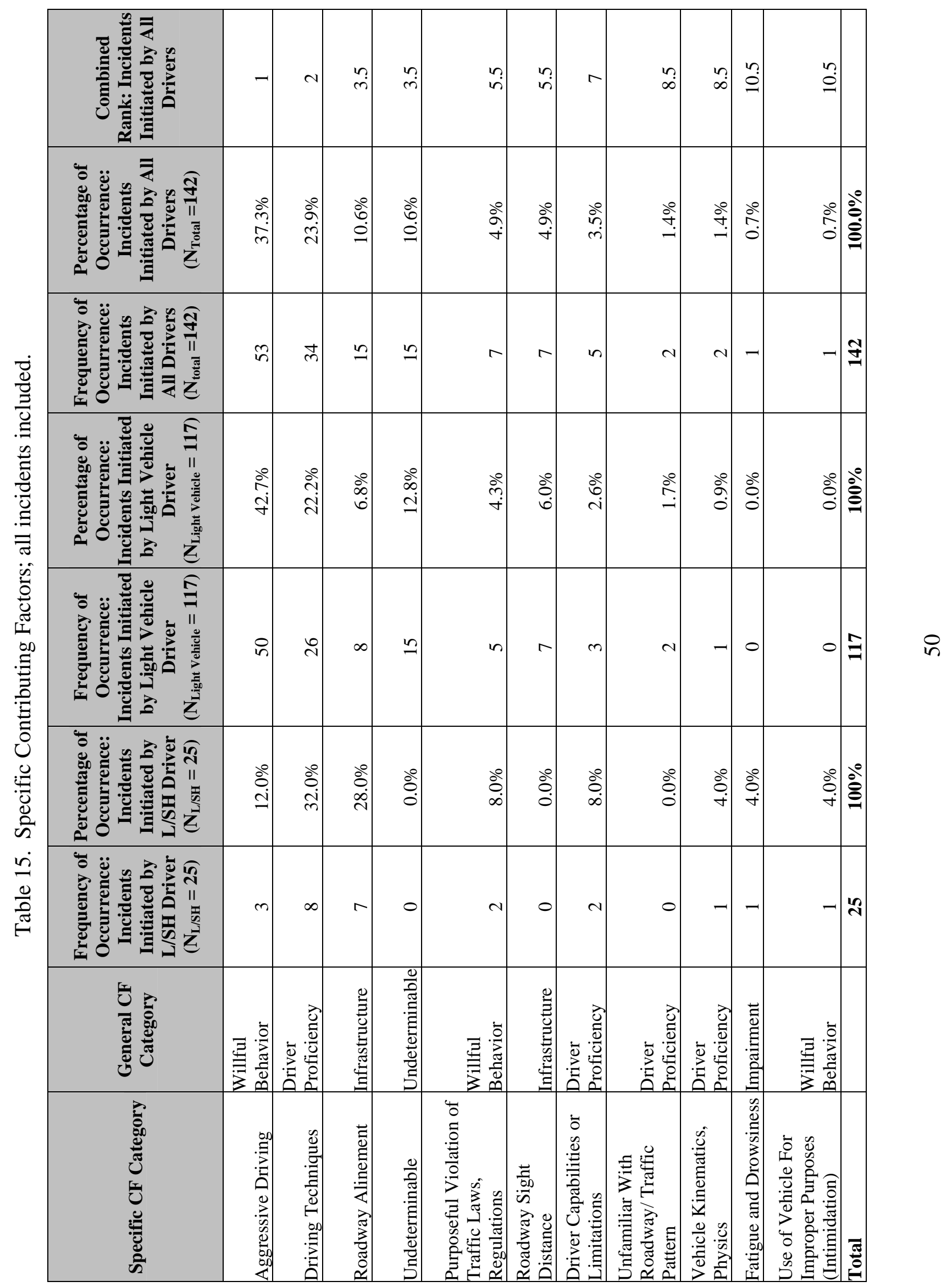




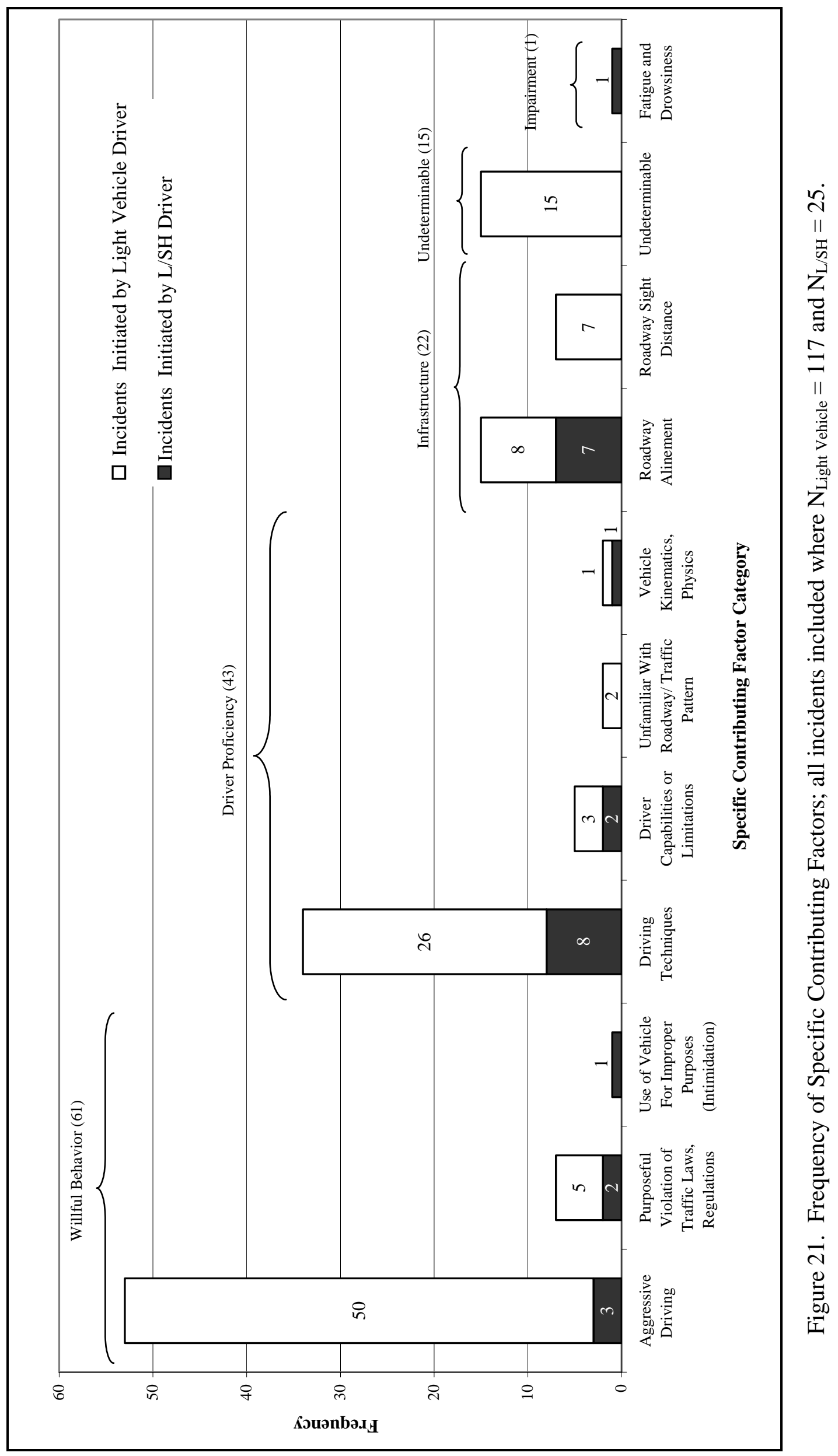


Tables 16 and 17 break out the frequency of occurrence data, for the Specific Contributing Factors, for incidents initiated by the L/SH driver and LV driver respectively. The frequency data are presented as histograms in Figures 22 and 23. Perhaps the most striking contrast in Figures 21, 22, and 23 is the substantial number of incidents initiated by the LV driver that are due to Aggressive Driving, and the relatively large number of $\mathrm{L} / \mathrm{SH}$ driver-initiated incidents caused by Roadway Alinement.

Table 16. Specific Contributing Factors for the L/SH driver-initiated incidents.

\begin{tabular}{|c|c|c|c|c|}
\hline Specific CF Category & $\begin{array}{l}\text { General CF } \\
\text { Category }\end{array}$ & $\begin{array}{c}\text { Frequency of } \\
\text { Occurrence: } \\
\text { Incidents Initiated } \\
\text { by } \mathrm{L} / \mathrm{SH} \text { Driver } \\
\left(\mathrm{N}_{\mathrm{L} / \mathrm{SH}}=25\right) \\
\end{array}$ & $\begin{array}{c}\text { Percentage of } \\
\text { Occurrence: } \\
\text { Incidents Initiated } \\
\text { by } \mathrm{L} / \mathrm{SH} \text { Driver } \\
\left(\mathrm{N}_{\mathrm{L} / \mathrm{SH}}=25\right) \\
\end{array}$ & $\begin{array}{c}\text { Rank: } \\
\text { Incidents } \\
\text { Initiated by } \\
\text { L/SH Driver }\end{array}$ \\
\hline Driving Techniques & Driver Proficiency & 8 & $32.0 \%$ & 1 \\
\hline Roadway Alinement & Infrastructure & 7 & $28.0 \%$ & 2 \\
\hline Aggressive Driving & Willful Behavior & 3 & $12.0 \%$ & 3 \\
\hline $\begin{array}{l}\text { Driver Capabilities or } \\
\text { Limitations } \\
\end{array}$ & Driver Proficiency & 2 & $8.0 \%$ & 4.5 \\
\hline $\begin{array}{l}\text { Purposeful Violation of } \\
\text { Traffic Laws, } \\
\text { Regulations } \\
\end{array}$ & Willful Behavior & 2 & $8.0 \%$ & 4.5 \\
\hline $\begin{array}{l}\text { Vehicle Kinematics, } \\
\text { Physics }\end{array}$ & Driver Proficiency & 1 & $4.0 \%$ & 7 \\
\hline Fatigue and Drowsiness & Impairment & 1 & $4.0 \%$ & 7 \\
\hline $\begin{array}{l}\text { Use of Vehicle For } \\
\text { Improper Purposes } \\
\text { (Intimidation) }\end{array}$ & Willful Behavior & 1 & $4.0 \%$ & 7 \\
\hline $\begin{array}{l}\text { Unfamiliar With } \\
\text { Roadway/Traffic Pattern }\end{array}$ & Driver Proficiency & 0 & $0.0 \%$ & 10 \\
\hline Roadway Sight Distance & Infrastructure & 0 & $0.0 \%$ & 10 \\
\hline Undeterminable & Undeterminable & 0 & $0.0 \%$ & 10 \\
\hline Total & & 25 & $100 \%$ & \\
\hline
\end{tabular}


Table 17. Specific Contributing Factors for the light vehicle driver-initiated incidents.

\begin{tabular}{|c|c|c|c|c|}
\hline Specific CF Category & $\begin{array}{l}\text { General CF } \\
\text { Category }\end{array}$ & $\begin{array}{c}\text { Frequency of } \\
\text { Occurrence: } \\
\text { Incidents Initiated by } \\
\text { Light Vehicle Driver } \\
\left(\mathbf{N}_{\text {Light Vehicle }}=117\right)\end{array}$ & $\begin{array}{c}\text { Percentage of } \\
\text { Occurrence: } \\
\text { Incidents Initiated } \\
\text { by Light Vehicle } \\
\text { Driver } \\
\left(\mathrm{N}_{\text {Light Vehicle }}=117\right)\end{array}$ & Rank \\
\hline Aggressive Driving & Willful Behavior & 50 & $42.7 \%$ & 1 \\
\hline Driving Techniques & Driver Proficiency & 26 & $22.2 \%$ & 2 \\
\hline Undeterminable & Undeterminable & 15 & $12.8 \%$ & 3 \\
\hline Roadway Alinement & Infrastructure & 8 & $6.8 \%$ & 4.5 \\
\hline Roadway Sight Distance & Infrastructure & 7 & $6.0 \%$ & 4.5 \\
\hline $\begin{array}{l}\text { Purposeful Violation of } \\
\text { Traffic Laws, } \\
\text { Regulations } \\
\end{array}$ & Willful Behavior & 5 & $4.3 \%$ & 6 \\
\hline $\begin{array}{l}\text { Driver Capabilities or } \\
\text { Limitations }\end{array}$ & Driver Proficiency & 3 & $2.6 \%$ & 7 \\
\hline \begin{tabular}{|l|} 
Unfamiliar With \\
Roadway/Traffic Pattern \\
\end{tabular} & Driver Proficiency & 2 & $1.7 \%$ & 8 \\
\hline $\begin{array}{l}\text { Vehicle Kinematics, } \\
\text { Physics }\end{array}$ & Driver Proficiency & 1 & $0.9 \%$ & 9 \\
\hline Fatigue and Drowsiness & Impairment & 0 & $0.0 \%$ & 10.5 \\
\hline $\begin{array}{l}\text { Use of Vehicle For } \\
\text { Improper Purposes } \\
\text { (Intimidation) }\end{array}$ & Willful Behavior & 0 & $0.0 \%$ & 10.5 \\
\hline Total & & 117 & $100 \%$ & \\
\hline
\end{tabular}




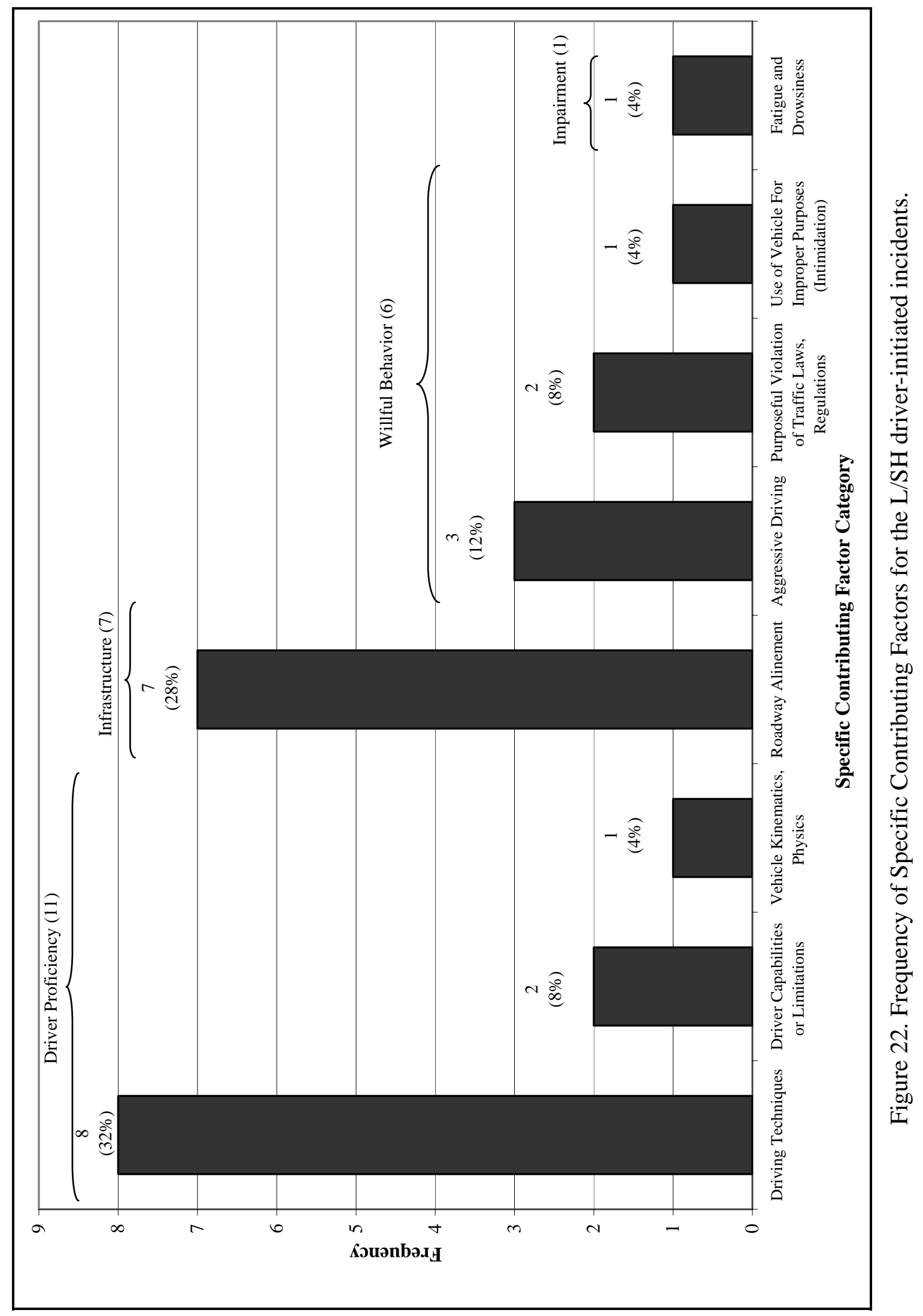

เั 


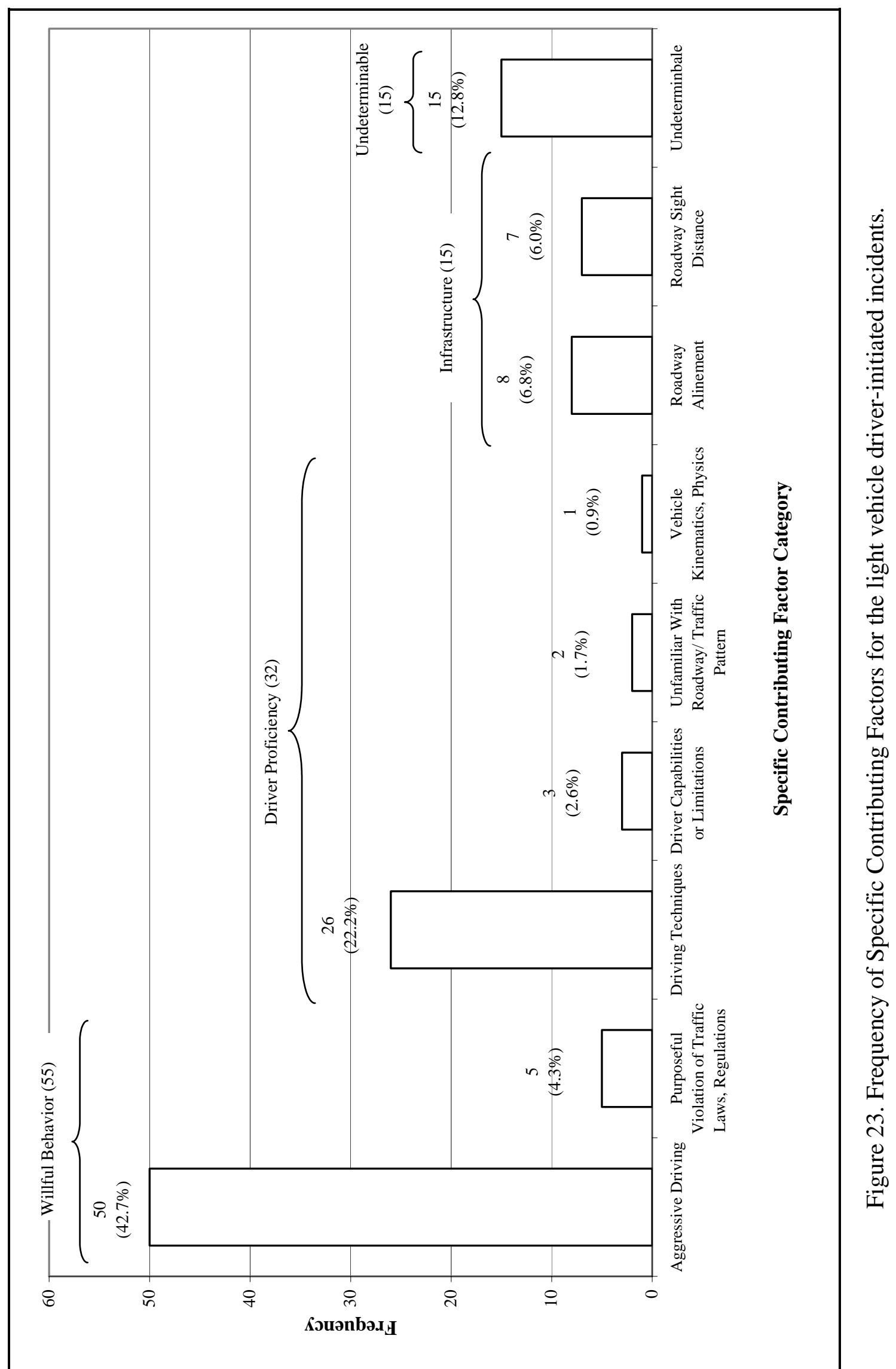


Figure 24 provides an outline (tree) taxonomy of the General and Specific Contributing Factors for the 25 incidents initiated by the L/SH driver, while Figure 25 similarly provides an outline taxonomy of the contributing factors for the 117 incidents initiated by the LV driver. These figures are another way of viewing the data in Figures 22 and 23 but with emphasis on the taxonomic structure.

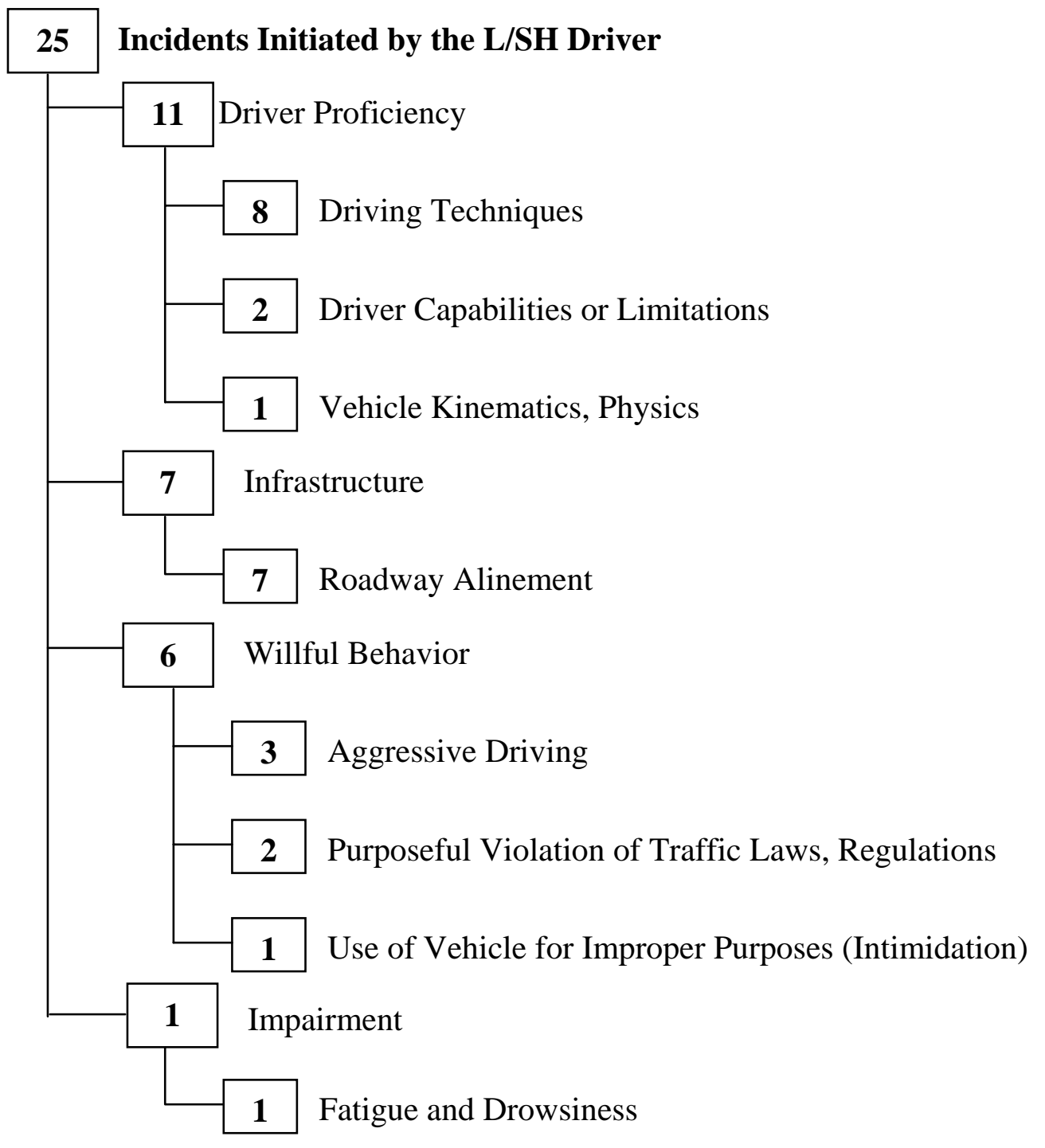

Figure 24. Outline taxonomy of the contributing factors for the incidents initiated by the L/SH driver. 


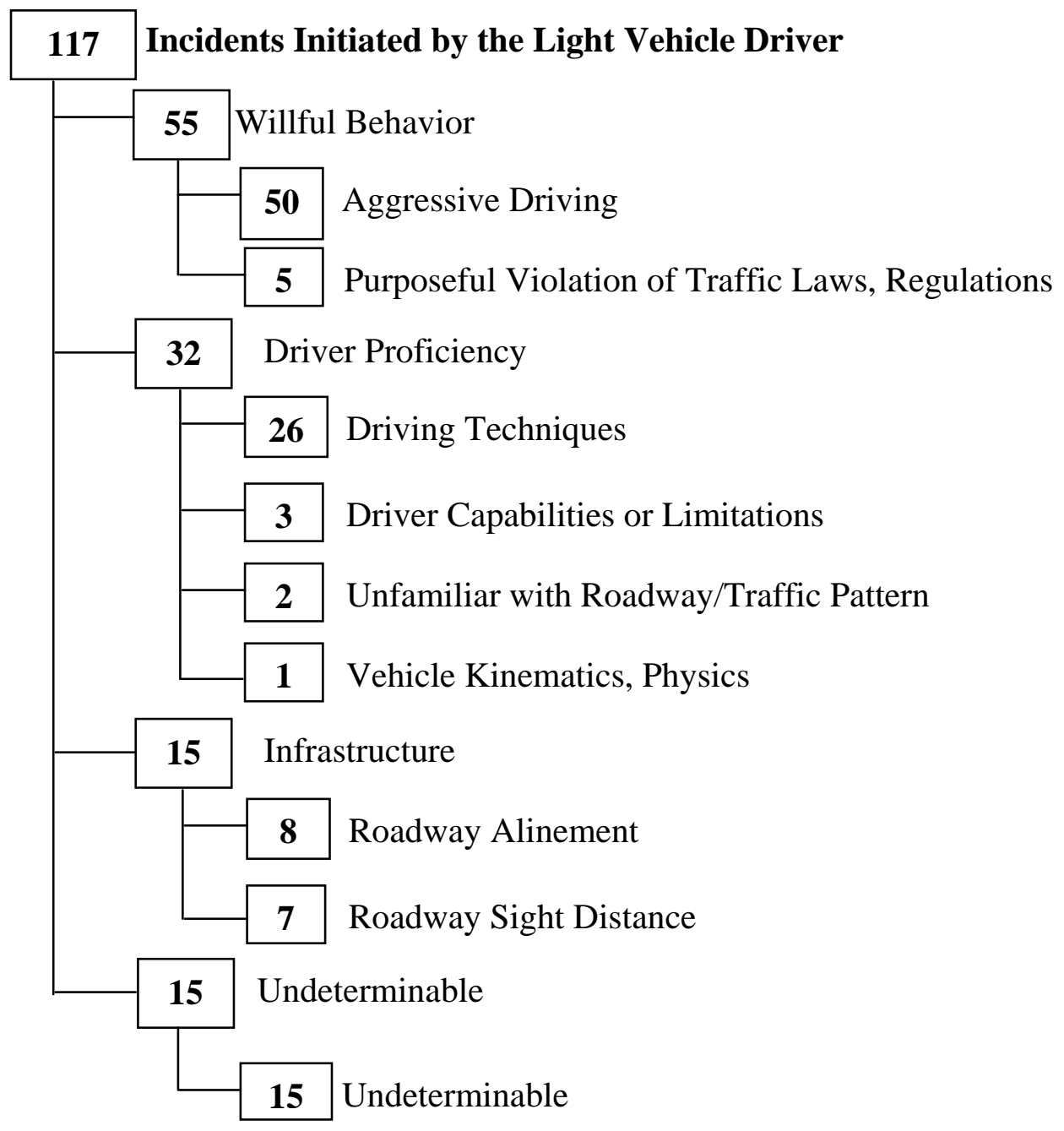

Figure 25. Outline taxonomy of the contributing factors for the incidents initiated by the light vehicle driver.

Hankey et al. (1999) conducted an accident database analysis using crash data from the state of Pennsylvania. One finding from the Pennsylvania database analysis that supports the data from the current effort is in regard to the Specific Contributing Factors associated with the incidents. Note that "incidents" in the current research refer to near-crashes while "incidents" from the Pennsylvania database analysis refer to crashes. It was found in the Pennsylvania database that 77 percent of crashes occurring in 1995 and 1996 had "Human Error" as a direct cause. To compare the results of the current research to this finding, the Specific Contributing Factors associated with Human Error in Figures 24 and 25 were grouped and tallied. (Summing over the categories of Driver Proficiency and Willful Behavior yields 104 such “error" incidents out of the total of 142.) The result of this was that 73 percent of the LV-HV interactions were determined to have Human Error as a direct cause, a result that is fairly consistent with the Pennsylvania database result. 
Hankey et al. (1999) also conducted a database analysis using the 1996 Fatality Analysis Reporting System (FARS). In this analysis, "Aggressive Driving" was found to be a factor in 31.1 percent of the accidents in the FARS database. In the current research, Aggressive Driving accounted for 37.3 percent of all incidents.

\section{Contributing Factor Taxonomy}

A taxonomy to highlight the characteristics of the incidents was developed. The Incident Types, Contributing Factor Categories, and brief incident descriptions were hierarchically arranged to create two taxonomies: one consisting of events initiated by the L/SH driver and another consisting of events initiated by the LV driver. At the highest level of the taxonomy, the events are grouped by the driver who initiated the event (i.e., L/SH driver or LV driver). The second highest level in the taxonomy is the Incident Type, followed by the General Contributing Factor Category, Specific Contributing Factor Category, and finally by the incident description. The incident descriptions outline the basic cause and result of the events. The taxonomy structure is shown in Figure 26. 

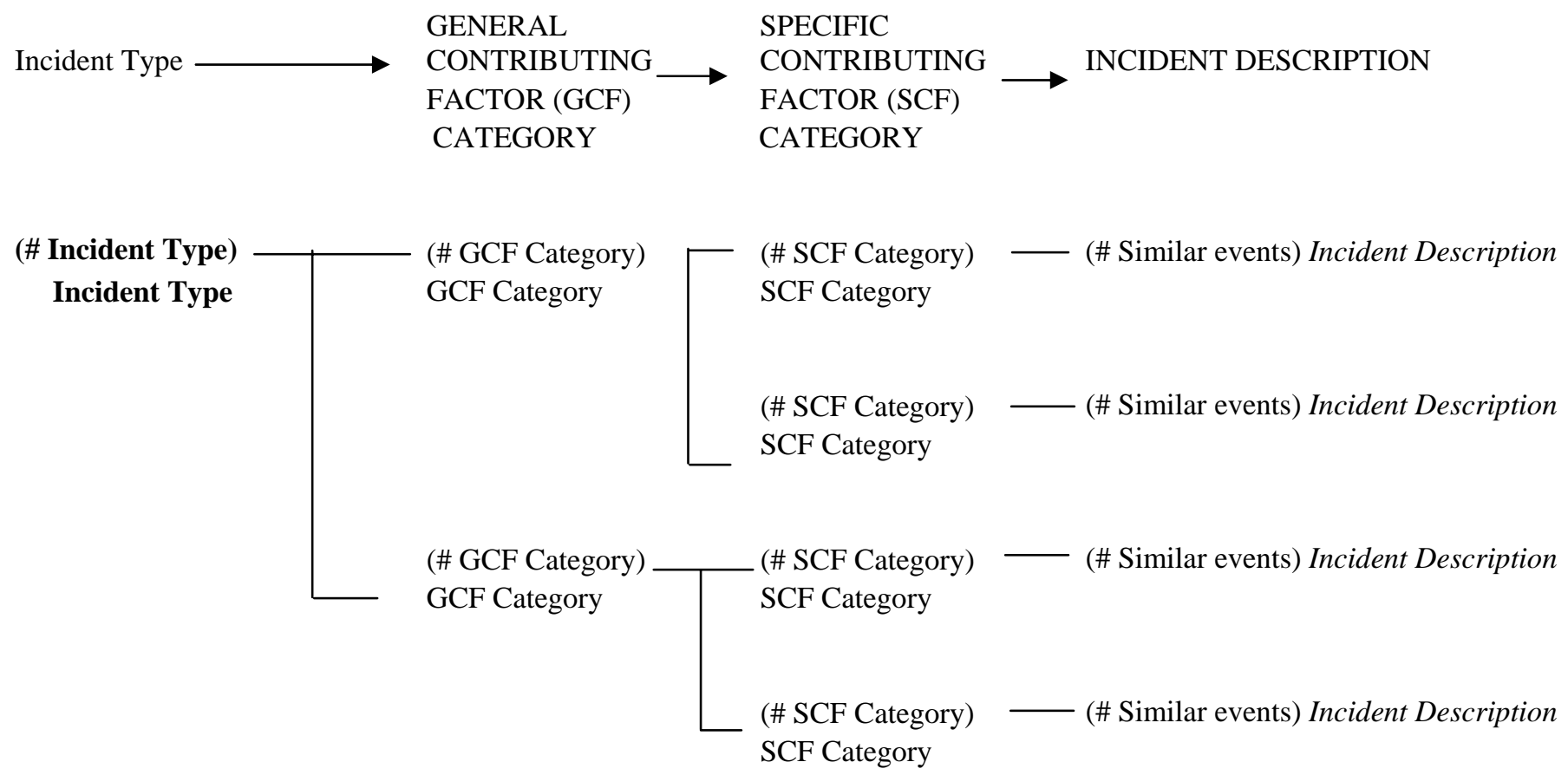

Figure 26. Taxonomy structure used to characterize the 142 interaction incidents.

\section{L/SH Driver-Initiated Incidents}

The taxonomy for the incidents initiated by the L/SH driver is presented in Figure 27, which is several pages long. As indicated previously, the taxonomy describes what happened (Incident Type), why it happened (General and Specific Contributing Factors), and details of the incident (Incident Description). 


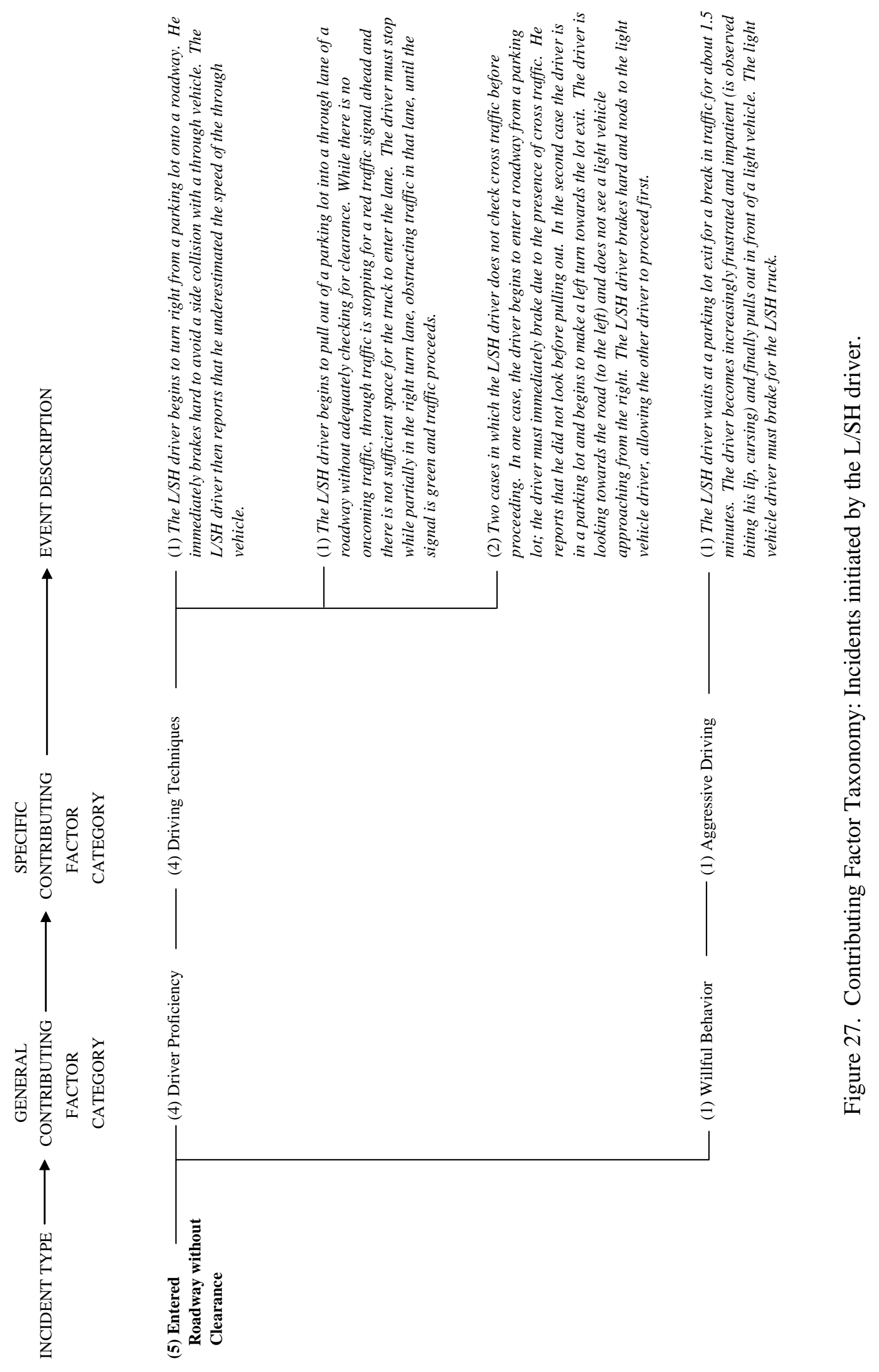




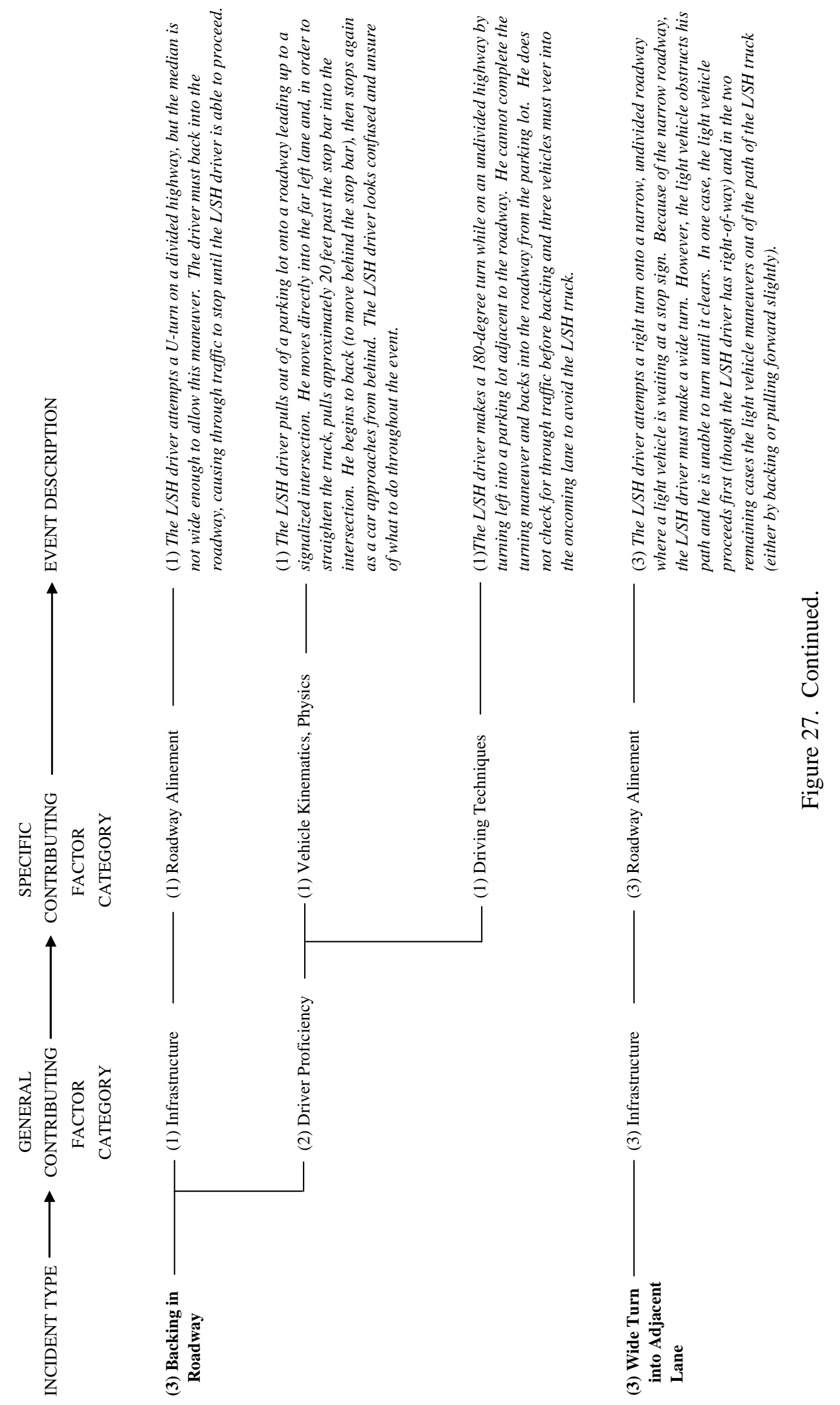




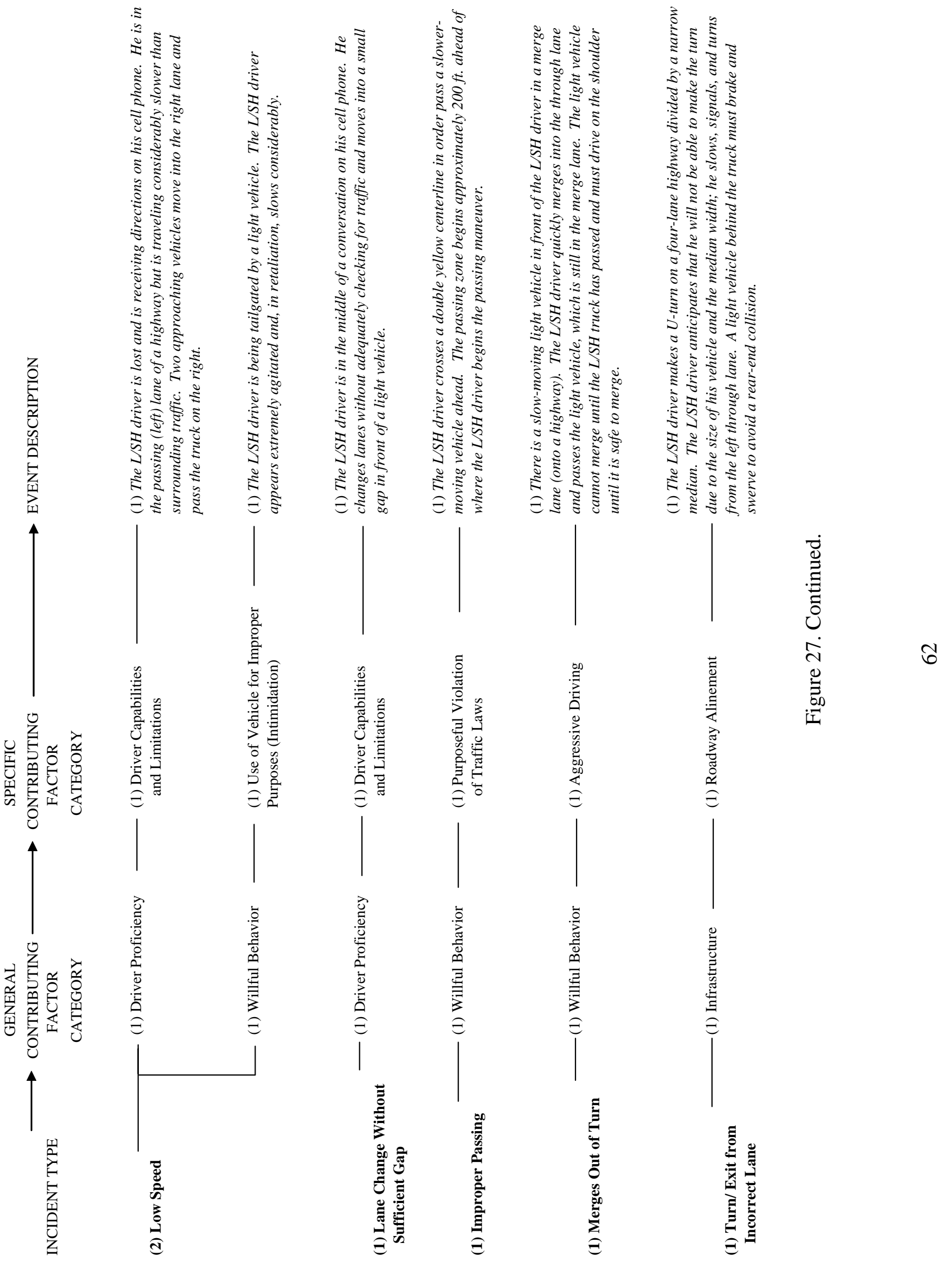




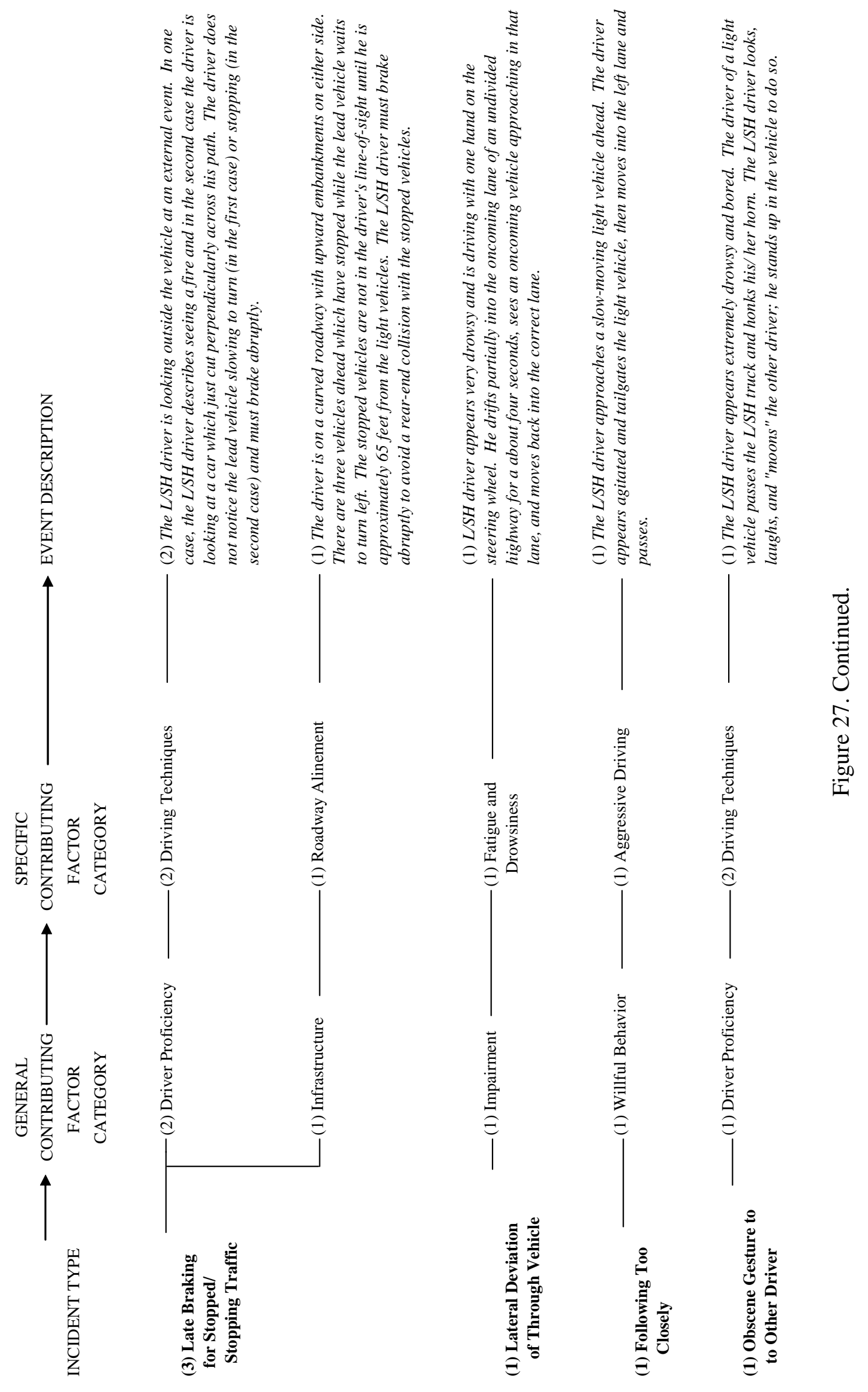




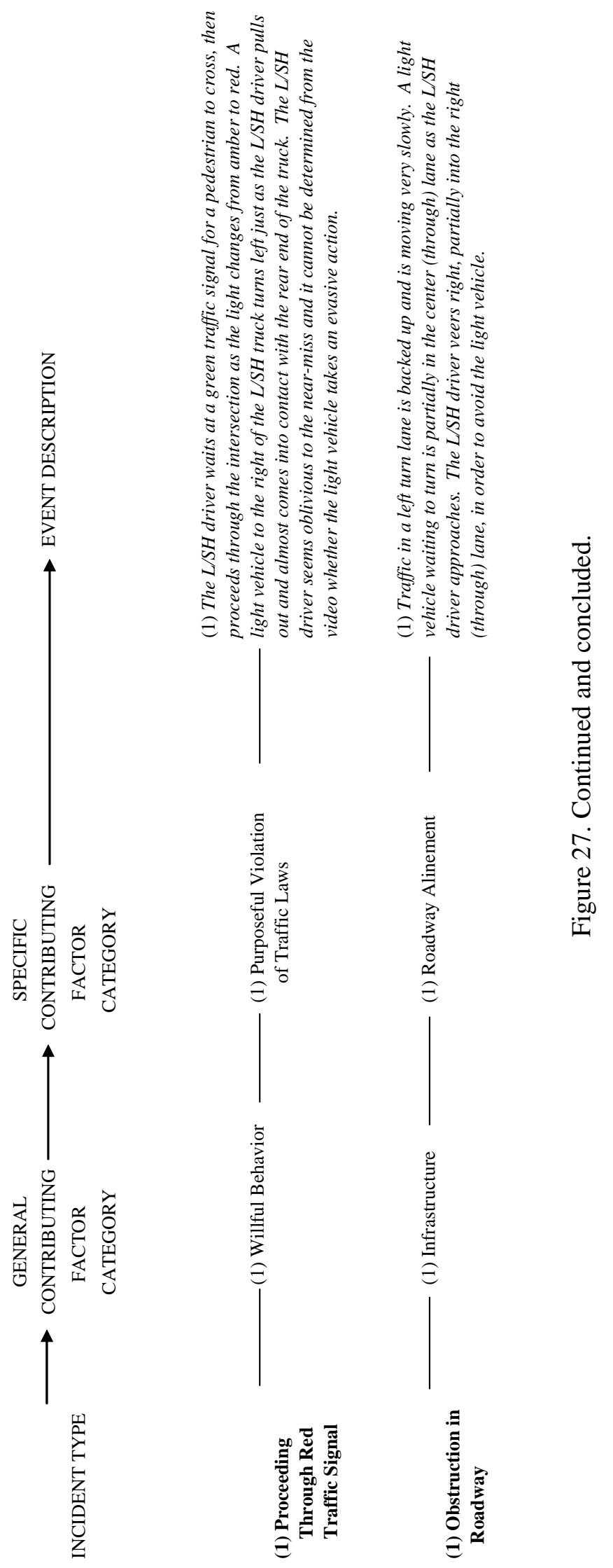




\section{Light Vehicle Driver-Initiated Incidents}

The contributing factor taxonomy for the LV driver-initiated incidents is presented in Figure 28 and continues over the next several pages. The taxonomy is identical in format to the L/SH driver-initiated incident taxonomy in the previous table. 


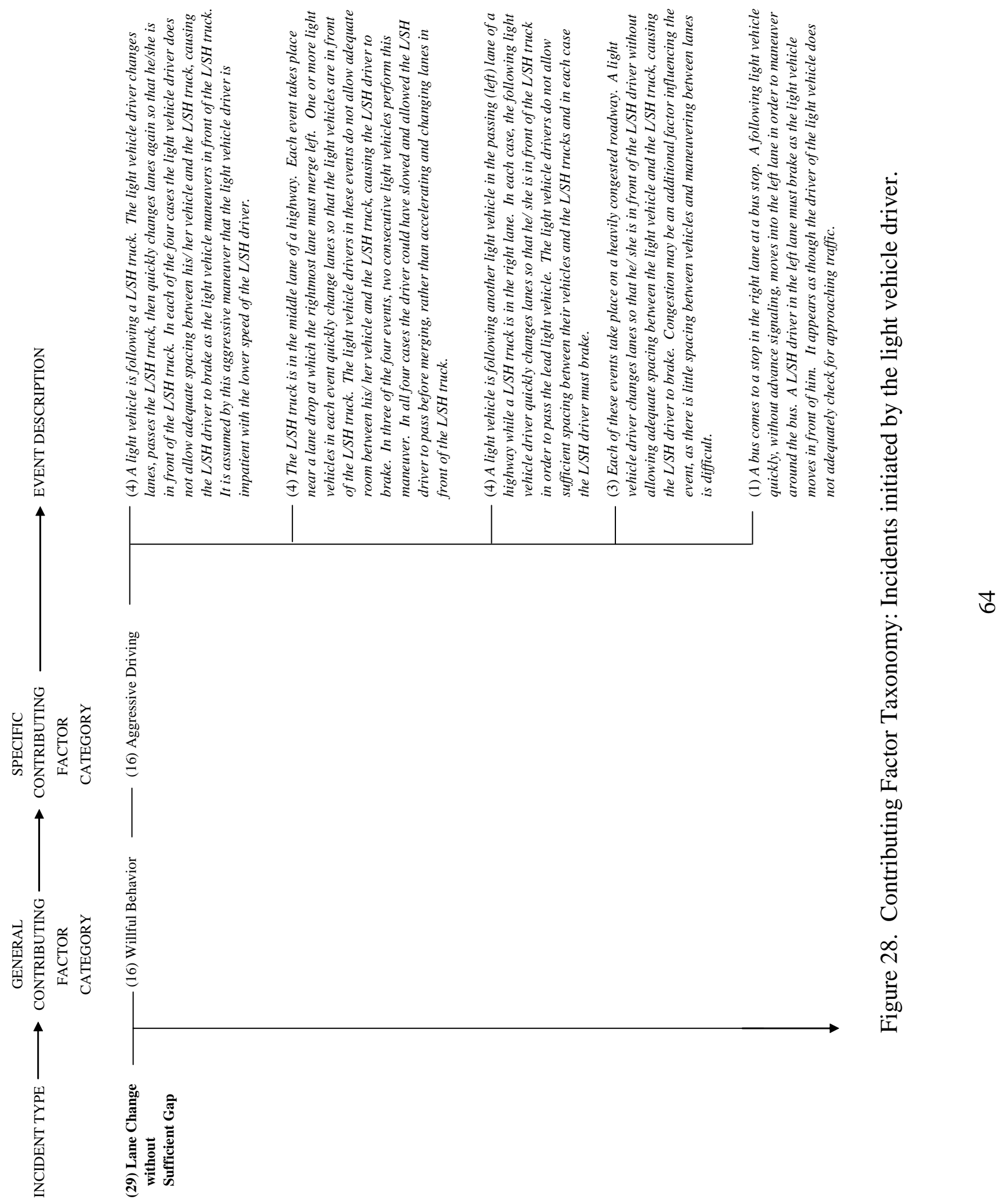




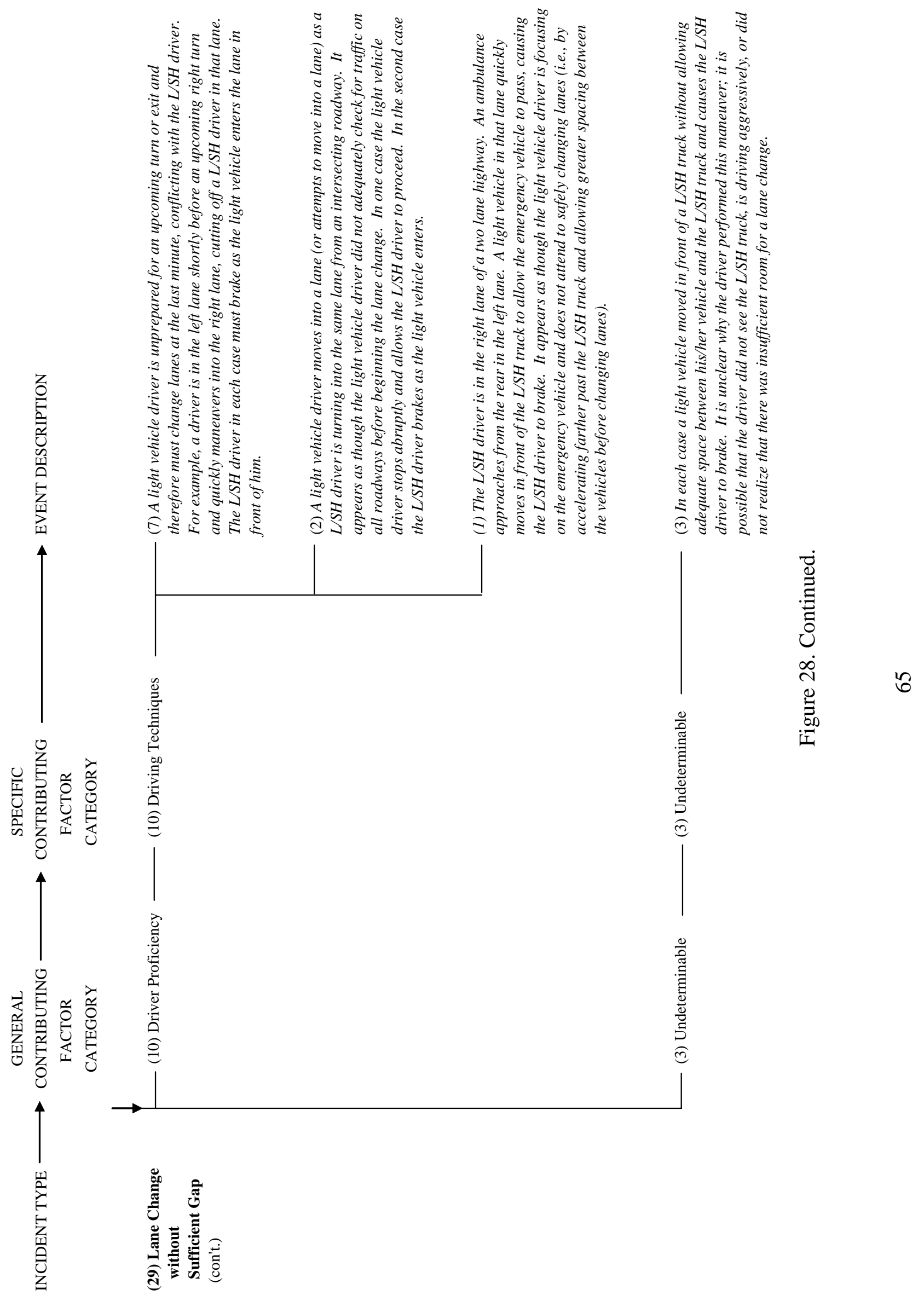




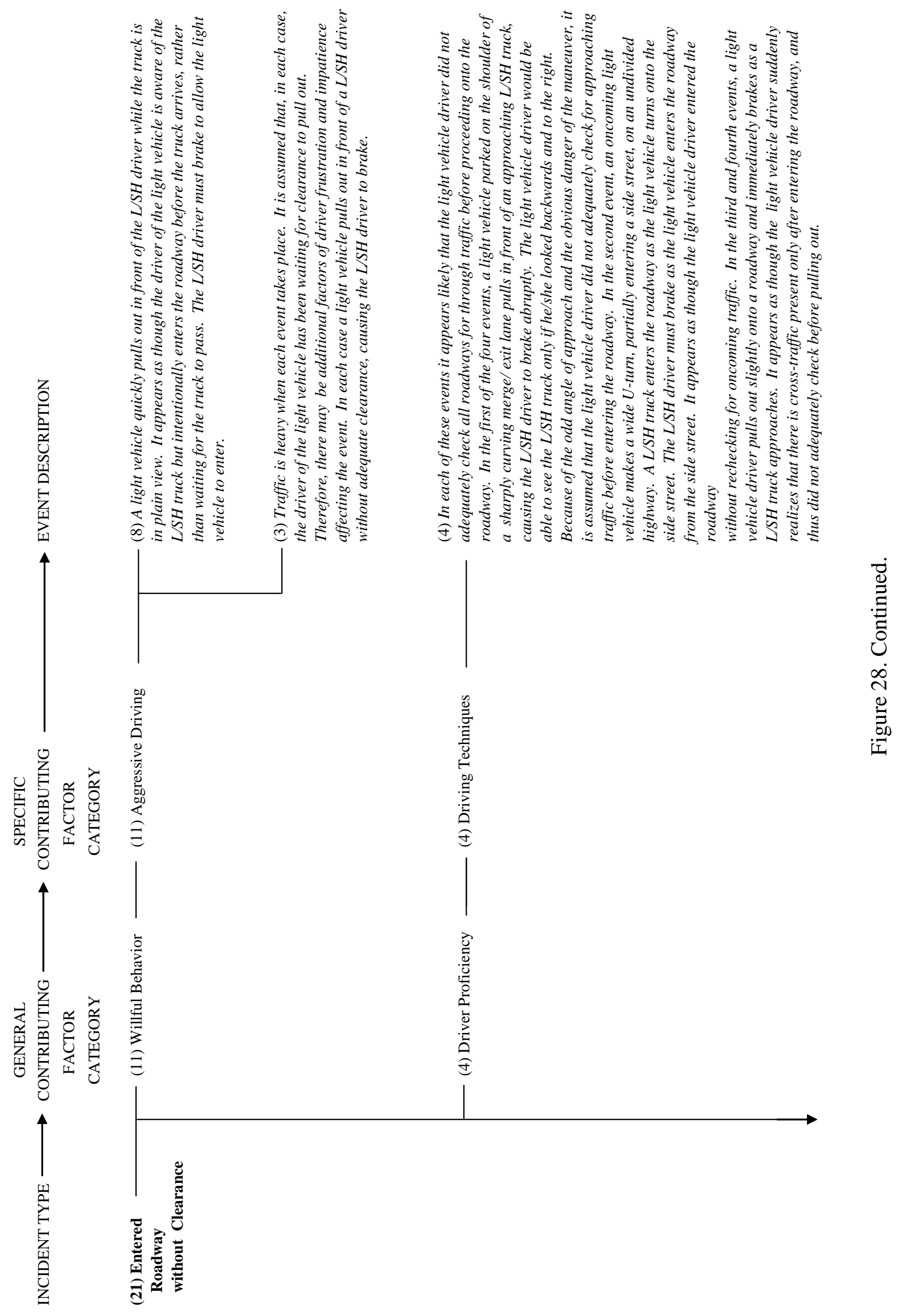

ต 


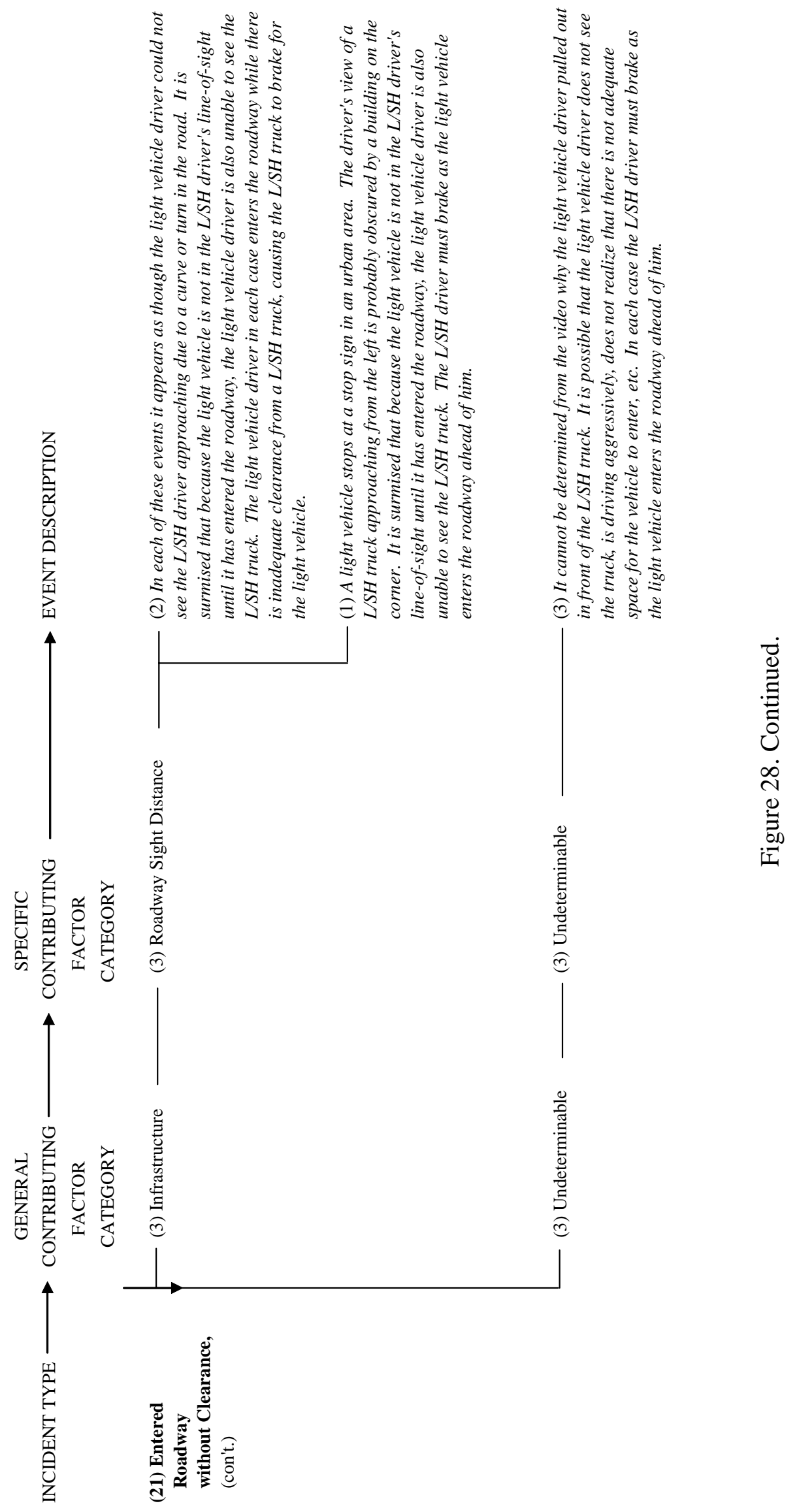

气 


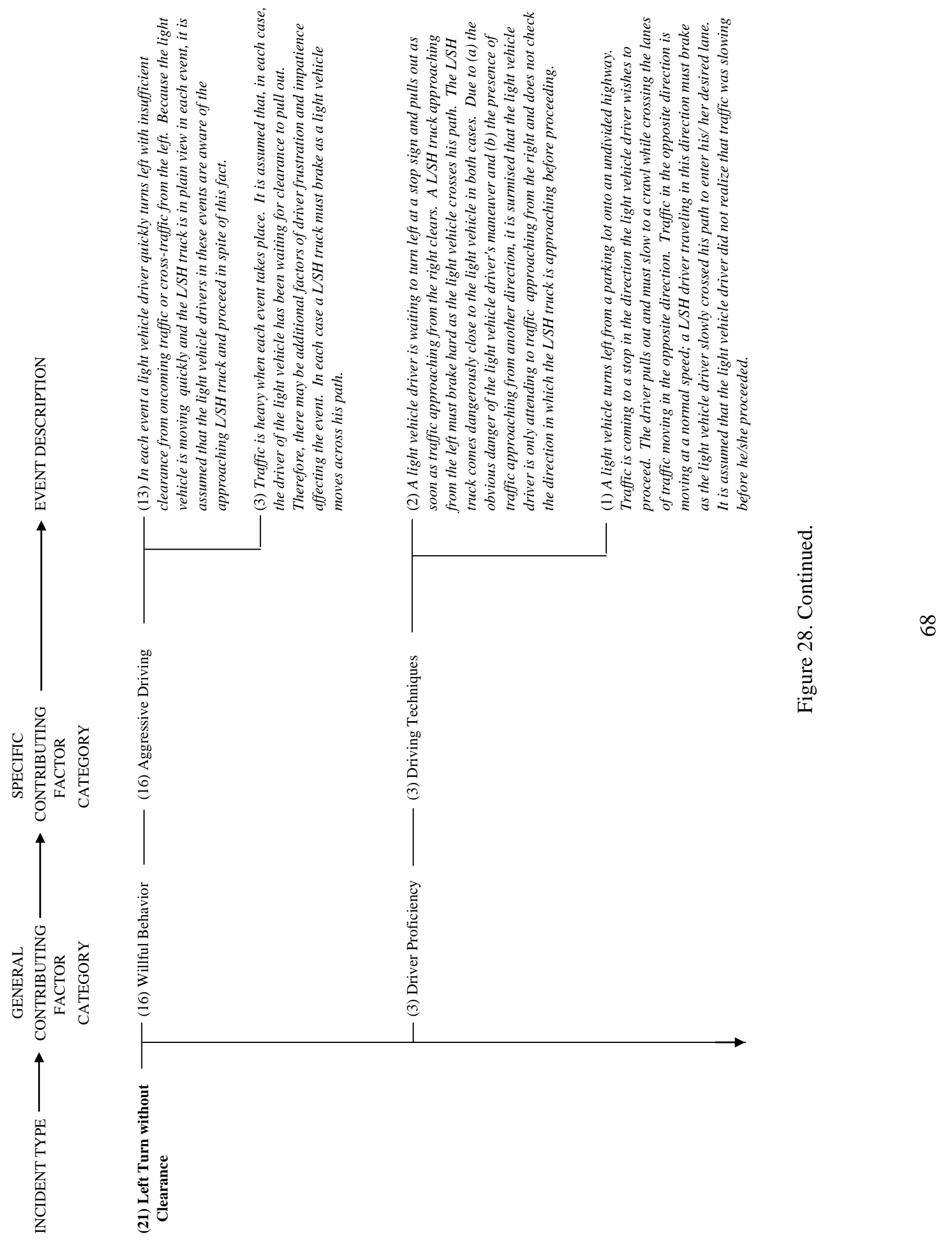




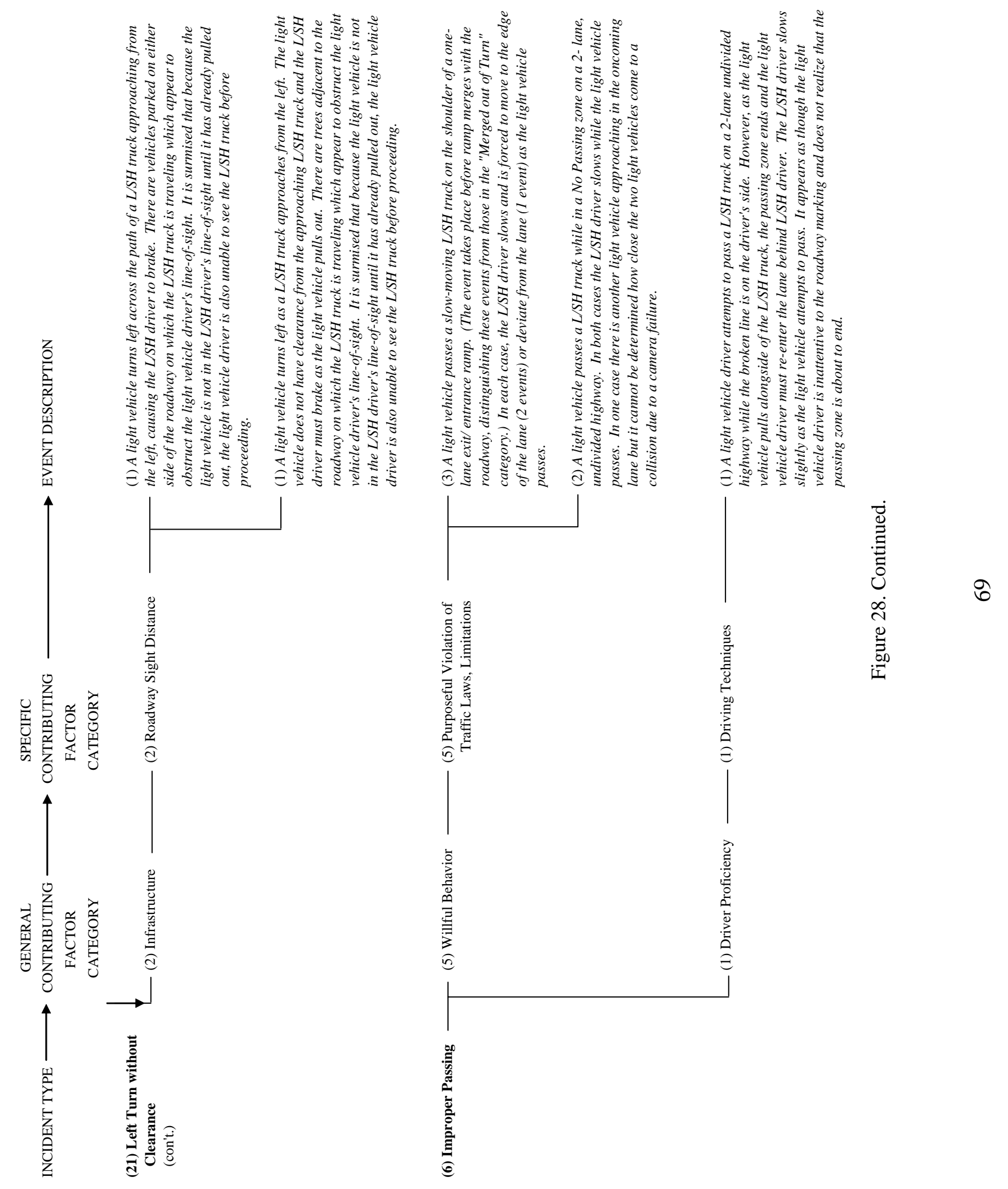




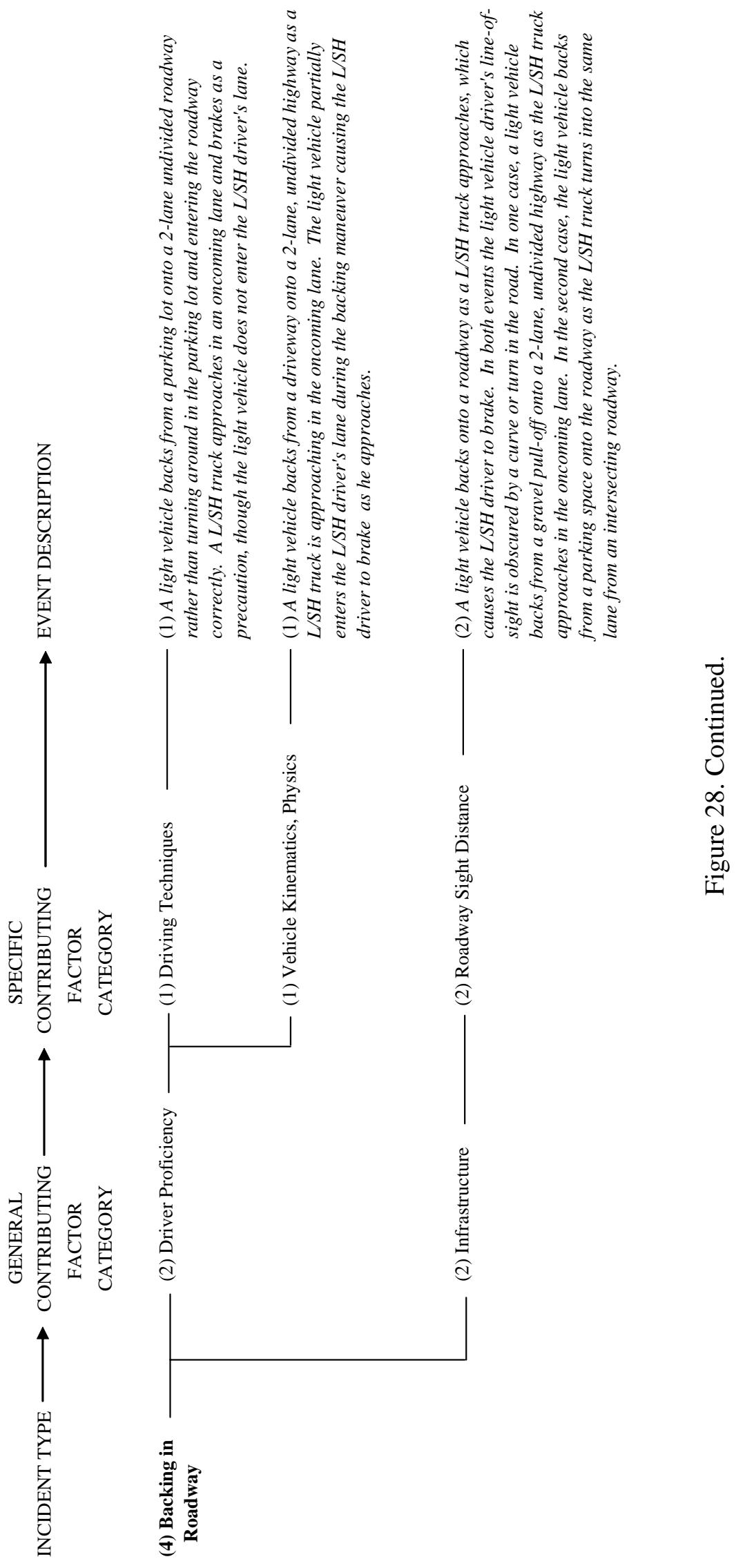




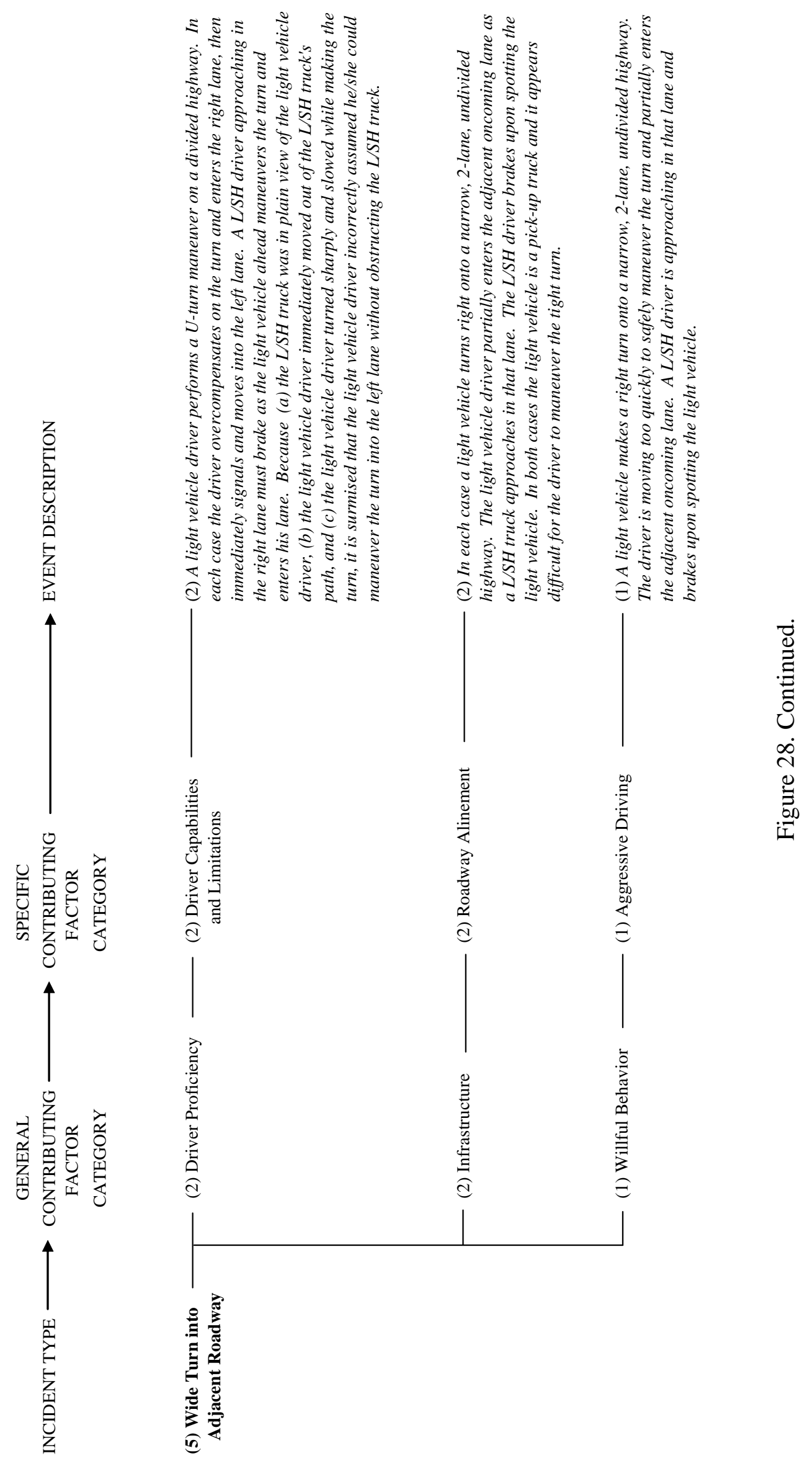



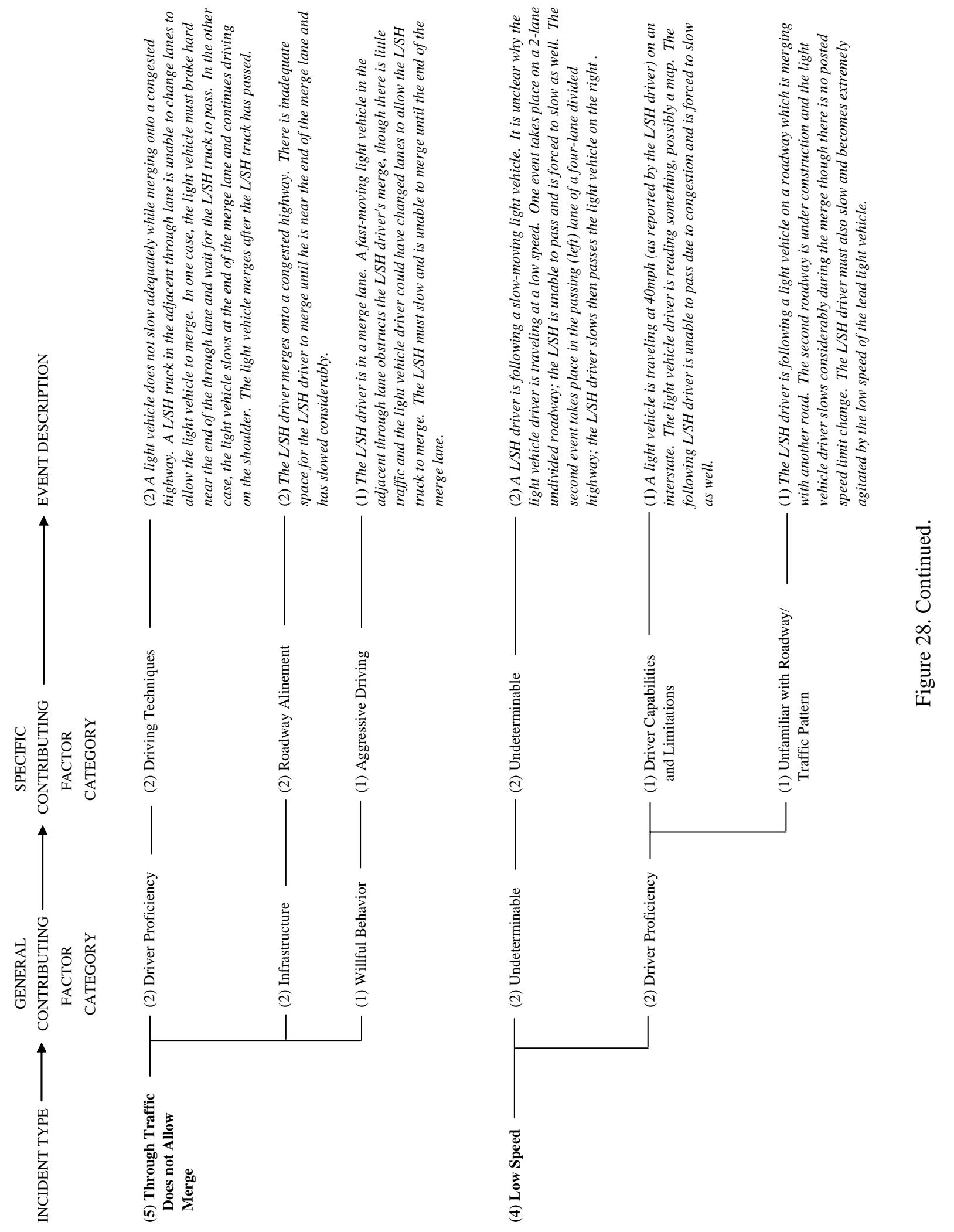

N 


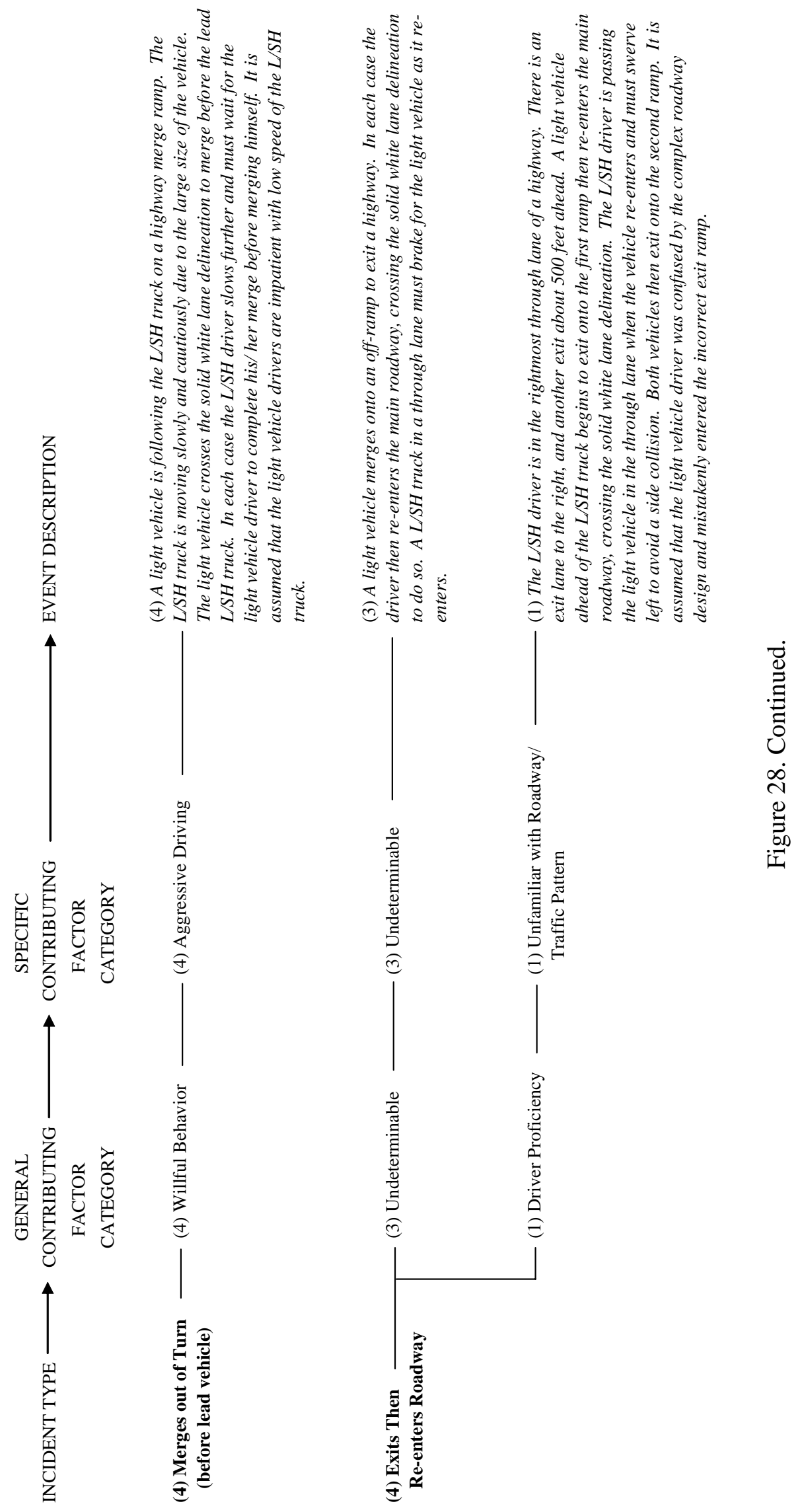




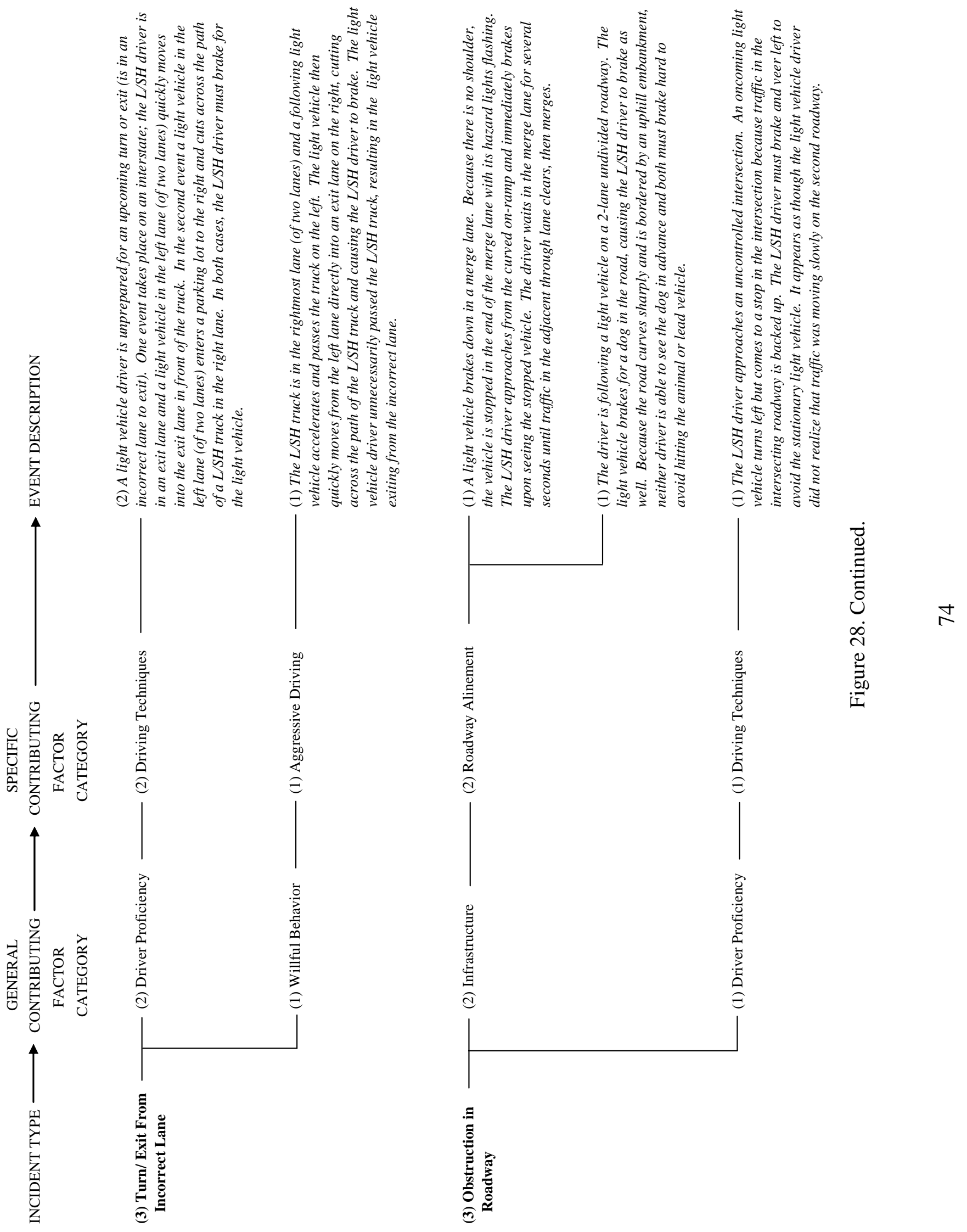




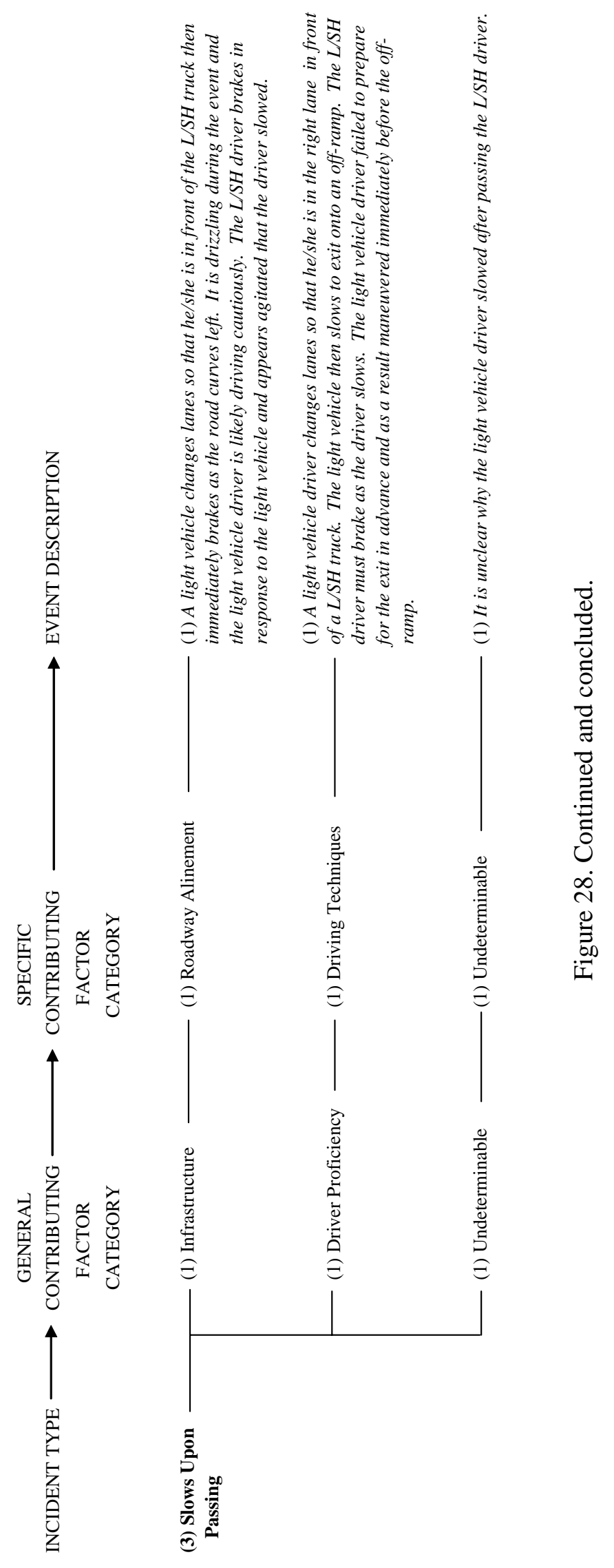




\section{CONCLUSIONS}

The analyses that were conducted with the LV-HV interactions captured in the original L/SH study provide compelling evidence to support the contention that $\mathrm{LV}-\mathrm{HV}$ interactions are a serious problem. Consider that of the 249 (revised to 251) critical incidents captured in the original L/SH study, $142 \mathrm{LV}-\mathrm{HV}$ interactions were identified. Put another way, of the large critical incident data set that was obtained in the original L/SH study, 57 percent of these incidents involved a LV-HV interaction.

There are five important findings that stem from the analyses conducted on the interactions between LVs and L/SH trucks. First, of the 142 interactions that were analyzed, it was determined that 117, or 82 percent, were initiated by the driver of an LV. Drivers of L/SH trucks were judged to have initiated only 25 incidents, or just 18 percent. This finding supports what the drivers in the Hanowski et al. (1998) focus groups said about drivers of light vehicles being their most important safety concern. Based on this finding, it is suggested that the group that must be targeted when addressing the LV-HV interaction problem is the LV driver group. While a program aimed at L/SH drivers would probably be effective in reducing LV-HV incidents, it appears that the "biggest bang for the buck" would be achieved by focusing on the group that initiates the majority of these incidents (i.e., LV drivers).

The second important finding from the analyses that were conducted was with regard to the different Incident Types that were most common in each driver group. For LV drivers, the most prevalent Incident Types were: Lane Change Without Sufficient Gap (24.8 percent), Entered Roadway Without Clearance (17.9 percent), and Left Turn Without Clearance (17.9 percent). These particular Incident Types are indicative of aggressive driving. Once again, the objective data support the sentiment of the L/SH drivers in the Hanowski et al. (1998) focus group who indicated that during their daily drives they were often "cut-off” by LV drivers. In contrast to the Incident Types prevalent for LV drivers, the Incident Types common for L/SH drivers were: Entered Roadway Without Clearance (20 percent), Wide Turn into Adjacent Lane (12 percent), Backing in Roadway (12 percent), and Late Braking for Stopped/Stopping Traffic (12 percent). Note that there are substantial differences in the most common Incident Types as a function of driver group. As will be highlighted later, unlike LV drivers, the typical Incident Types initiated by L/SH drivers do not appear to be related to aggressive driving.

The third result is the difference in the Primary Maneuvers for the two groups of drivers. The most prevalent Primary Maneuvers for LV drivers were: Lane Change (26.5 percent) and Left Turn (22.5 percent). Both of these maneuver types involve the LV cutting in front of, or across the path of, an HV. In contrast, the Primary Maneuvers that were most common for incidents initiated by L/SH drivers were: Through (44 percent) and Right Turn ( 24 percent). With regard to the Through incidents, drivers were driving in a forward direction in their established lane and were not generally involved in cutting-off another vehicle. Many of the Right Turn incidents were attributed to a lack of a sharp steering radius of the truck and/or narrow lanes. It appears that the Primary Maneuvers that were prominent for the L/SH drivers were fundamentally different and less aggressive as compared to the prominent LV driver maneuvers. Also, it is important to point out that just as in the Incident Types, there was no prevalent Primary 
Maneuver that was common across driver groups. This finding also highlights the fundamental differences in the characteristics of incidents that were initiated by the two driver groups.

The fourth important finding is related to the General Contributing Factors that were common to each driver group. For LV drivers, the most common General Contributing Factor was Willful Behavior (47 percent). In contrast, for L/SH drivers, the most common General Contributing Factor was Driver Proficiency (44 percent). These results further demonstrate that the incidents initiated by the different driver groups were fundamentally different.

The fifth noteworthy result from this research is in terms of the Specific Contributing Factors that were prominent for the driver groups. For LV drivers, it was determined that 42.7 percent of the incidents they initiated were a result of Aggressive Driving. This was approximately four times the proportion of incidents in which Aggressive Driving was attributed to L/SH driverinitiated incidents. That is, Aggressive Driving was attributed to only 12 percent of the L/SH driver-initiated incidents. The two most prevalent Specific Contributing Factors for L/SH driverinitiated incidents were Driving Techniques (32 percent) and Roadway Alinement (28 percent).

Phase A of this research has provided reasonably objective data to indicate that a serious problem does indeed exists in LV-HV interactions. From this research, it is not only clear that there is a problem, but it is also clear as to what factors contribute to the problem. As shown, these contributing factors differ markedly between LV drivers and L/SH drivers. Any effort to ameliorate this problem must take these differences into account.

Though the data from Phase A represent data collected with typical L/SH trucks, the results do not include tractor-trailers. Phase B of the project, discussed in the next chapter, examines whether Incident Type and Contributing Factor differences exist between LV drivers and longhaul drivers (driving tractor-trailer rigs). Following the discussion of the Phase B effort, Chapter 3 provides a comparison between the results of Phase A and Phase B. Note that one of the goals of this project was to develop suggestions, based on the analysis results, aimed at ameliorating LV-HV incidents; these suggestions are also presented in Chapter 3. 
THIS PAGE INTENTIONALLY LEFT BLANK 


\section{CHAPTER 2: LONG-HAUL INTERACTIONS}

\section{INTRODUCTION}

\section{Sleeper Berth Data Collection Effort}

As outlined in Chapter 1, Phase A involved analyzing the LV-HV interactions that were captured in the L/SH study. This chapter focuses on Phase B, which involved analyzing incidents occurring between light vehicles and long-haul heavy vehicles. The data used to conduct the analyses was collected during the FMCSA-sponsored project entitled "The Impact of Sleeper Berth Usage on Driver Fatigue" (Dingus et al., in press). It should be noted that in addition to detailing the Phase B effort, this chapter also provides a comparison of the findings from the L/SH and long-haul analyses.

As with the L/SH study, the Sleeper Berth project involved two data collection phases: (1) focus groups, and (2) data collected in situ. A detailed description of the focus group effort can be found in Neale et al. (1998). A description of the on-road study can be found in Dingus et al. (in press). Highlights of each research phase of the Sleeper Berth project are presented in the next sections. However, before presenting these highlights, it is important to define what is meant by "long-haul operations."

\section{Defining Long-Haul Operations}

Long-haul operations are defined by the U.S. Department of Commerce (1994) as those that primarily engage in trips of $804.6 \mathrm{~km}(500 \mathrm{mi})$ or more from the truck's home base. Also termed "over-the-road" trucks, Massie et al. (1997) note that these operations comprise 36 percent of registered large trucks in the U.S. In contrast, L/SH operations (those studied in Phase A) are defined as those that primarily engage in trips of $160 \mathrm{~km}(100 \mathrm{mi})$ or less from the truck's home base. Also, local service trucks represent approximately 58 percent of the large truck population (Massie et al. 1997). Based on these definitions, it can be seen that a large segment (94 percent) of the trucking population was represented in the approach that was used for the current study (i.e., where both L/SH, Phase A, and long-haul, Phase B, trucks were investigated).

\section{Phase I: Long-Haul Focus Groups}

Ten focus groups were held in eight cities, across seven states, between September 1997 and February 1998. Seventy-four drivers (61 men and 13 women) participated. One of the goals of this effort was to gain an understanding, from the long-haul drivers' perspective, of the issues affecting the quality and quantity of sleep drivers' receive, as well as other issues that may affect driver fatigue. Topics discussed by drivers during the sessions included: team driving, equipment issues, facilities, enforcement issues, private driver education, terminus issues, company and dispatcher issues, and training issues. With regard to the LV-HV interaction problem studied in the current effort, truck drivers indicated that the interaction between these two vehicle types is a problem and that an education program is needed to instruct drivers of LVs on how to interact with HVs. Based on this focus group finding and as outlined in the L/SH focus group description presented in the Phase A report, the notion that LV drivers are problematic for truck drivers seems to be an opinion shared by both long-haul and L/SH drivers. 


\section{Phase II: Long-Haul Data Collected In Situ}

The second phase of the Sleeper Berth project involved collecting driver performance and behavior data as drivers drove their trucks and worked their normal delivery routes. The information obtained from the focus groups was used to develop the Phase II data collection methodology. For example, candidate independent and dependent variables were selected based on the issues raised during the focus groups.

The purpose of the Phase II field study was to investigate the relationship between driving performance and fatigue in long-haul operations. As in the L/SH field study described in Chapter 1, a critical incident data collection approach was used. That is, the focus of the data analysis was on critical incidents (or near crashes) in which long-haul drivers were involved. As will be detailed later, $68 \mathrm{LV}$-HV critical incidents were captured in this effort; 47 of these incidents were judged to have been caused by the LV driver, while the long-haul driver caused the other 21. As in the L/SH field study, these results indicated that LV drivers were responsible for the majority of incidents captured in this study. Taking into account the focus group findings from both the long-haul and L/SH studies, and the field studies from both of these efforts, it seems clear that an important area for further study is LV-HV interactions.

\section{METHOD}

\section{Data Collection Methodology for the Sleeper Berth Study}

A full description of the data collection hardware that was used in the Sleeper Berth study can be found in Dingus et al. (in press); sections from the Dingus et al. document have been summarized and are presented below. Because the data used in the current effort consisted of the video recordings of incidents, the most important methodological considerations to be described are those related to the video systems.

\section{Long-Haul Trucks}

Drivers employed by two long-haul trucking companies used two VTTI-owned tractors while hauling their normal cargo on regularly-scheduled revenue-producing runs. Shown in Figure 29, these tractors were a 1997 Volvo L4 VN-series unit and a 1995 Peterbilt 379. Functionally identical instrumentation packages and data collection systems were installed in the two trucks. 

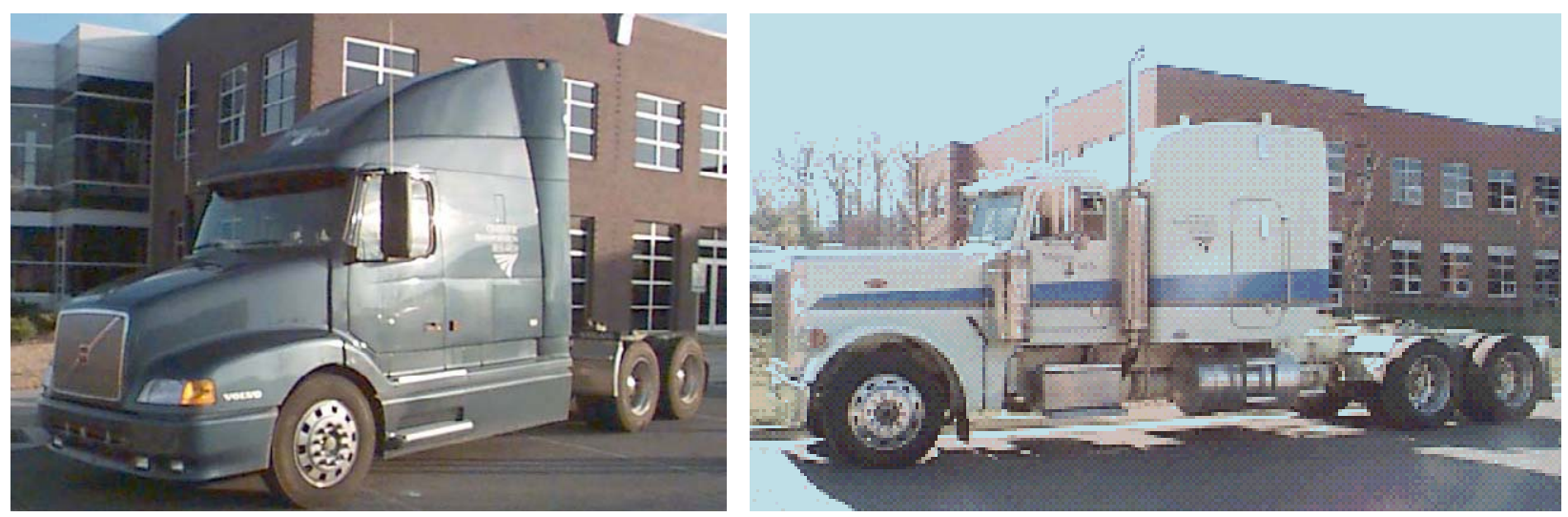

Figure 29. VTTI's two Class 8 heavy trucks; 1997 Volvo L4 VN-series tractor (left) and 1995 Peterbilt 379 tractor (right).

\section{Critical Incident Methodology}

Instrumentation systems implemented in other VTTI research vehicles (Collins, Neale, and Dingus, 1999; Hanowski, Dingus, Gallagher, Kieliszewski, and Neale, 1999; Wierwille and Hanowski, 1998), and in the Volvo tractor (Winters, 1998) for various research projects recorded data continuously throughout the experimental trials. Such trials typically have been on the order of 15 minutes to 10 hours in length. Because the data collection runs conducted in the Sleeper Berth project were 6 to 10 days long (up to 240 hours), recording data continuously was not feasible. Thus, a method of reducing the bulk of the data without losing relevant information was developed. This method consisted of implementing a data collection system based on the occurrence of critical incidents. Vehicle and driver performance data were only collected when specific trigger events occurred. Details on the parameters of the event triggers that were used can be found in Robinson et al., (1999). For the analyses conducted in the present effort, the video-data were filtered such that the final data set was comprised of only those incidents that involved an interaction between an LV and an HV.

\section{Video-data Collection Systems}

Four cameras were installed in the trucks. These four cameras recorded the drivers' face, the driver's forward view, the driver's side view through the left-hand rear-view mirror, and the view through the passenger's side rear-view mirror. These four views were recorded simultaneously through a quad-splitter so that trained data analysts could process all four images simultaneously. Figure 30 shows the camera views and the four video images. 


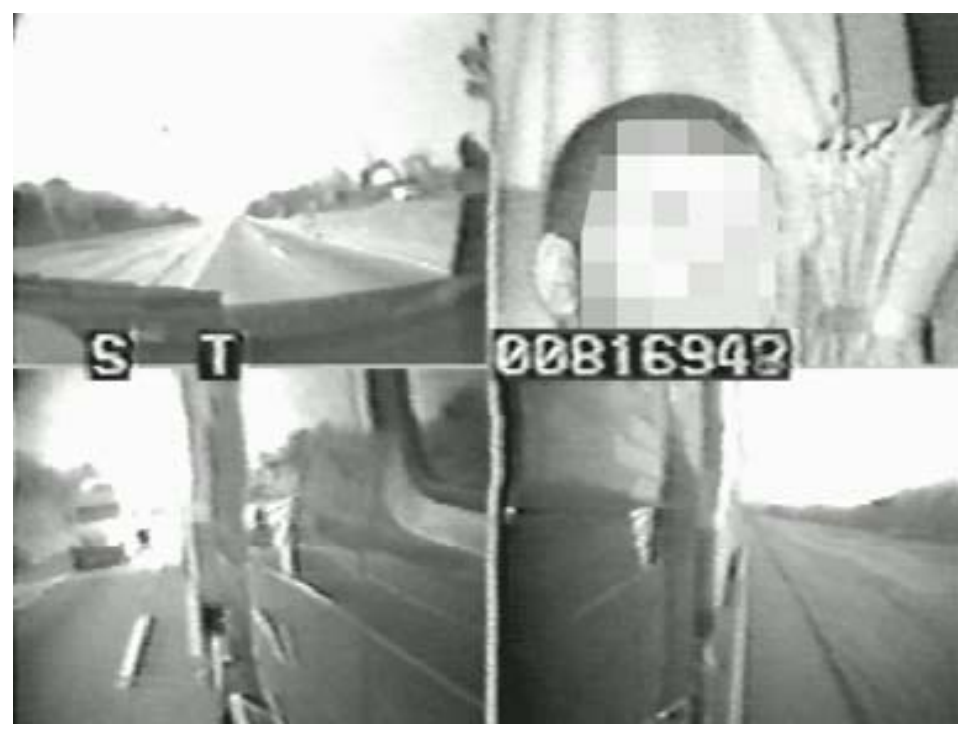

Figure 30. Multiplexed image showing the scenes observed by the four strategically-located video cameras (clockwise from upper left): forward road scene, driver's face (obscured to preserve anonymity), left-side/rearward scene, right-side/rearward scene. Event flags and running time are also displayed.

Sensors were installed on the truck to monitor driving performance. A variety of measures were collected including steering wheel angle, lateral/longitudinal acceleration, lane deviation, timeto-collision, eyelid closure, and the drivers' subjective alertness rating. When an incident was detected, data from the sensors were stored along with the video of the incident. Sensor and video data were recorded for two minutes prior to the start of the incident and for one minute following the incident. ${ }^{1}$

The data collection system operated automatically with minimal driver intervention. The triggerbased data collection system allowed the experimenters to obtain the driving performance and driver alertness data that would be important for analysis without recording hours of video that was not relevant for this study.

\section{Trucking Companies}

As previously stated, two long-haul companies participated in the study. One company hauled dry goods and the other company hauled refrigerated foods. Trip locations varied, but spanned the U.S. The companies' compensation for participating was the free use of the tractor. VTTI was responsible for truck maintenance; however, the trucking companies paid for the fuel and freight taxes.

\section{Driver Participants}

Twenty-four single drivers and 12 two-driver teams (24 drivers) were recruited for the Sleeper Berth study (48 drivers total). Because data were still being collected at the time the current LV$\mathrm{HV}$ analysis was performed, the data for LV-HV incident analyses presented here involved 20

\footnotetext{
${ }^{1}$ The technique of continuous loop recording and automatic transfer was used to obtain data prior to the trigger.
} 
single drivers and 7 teams of drivers (34 drivers total). All drivers volunteered and were paid for their participation in the study. The mean age was 44 years. Each driver was expected to drive for a minimum of 6 continuous days; however, drivers generally drove for 7 to 10 working days. The schedules of drivers varied according to load assignment, truck maintenance, and requirements of the trucking company.

\section{Strengths and Limitations of the Methodology Used}

As indicated in the Chapter 1 , there are corresponding strengths, limitations, and trade-offs with any experimental approach that is used. Using the video recording of the critical incidents captured in the Sleeper Berth study is no exception.

\section{$\underline{\text { Strengths }}$}

As described in the discussion of the L/SH study methodology, one of the strengths of the approach used in the Sleeper Berth study was that the video coverage provided by the camera arrangement allowed researchers to view the incidents as they unfolded. Additionally, the multiple camera approach allowed researchers to gain an understanding of what happened and why it might have happened. Also, using multiple cameras helped insure that any critical incidents involving the long-haul driver that did occur, were captured and were available for analysis.

\section{Possible Limitations}

There were three possible limitations of the approach that was used. The first two limitations are the same as those described with the L/SH study. First, video cameras were installed in the longhaul trucks and not in LVs and, as such, critical incidents could only be captured from the longhaul driver's perspective. Second, because there were no cameras mounted in any LVs, it was difficult to have a complete understanding of the LV driver's behavior during the incident.

A third possible limitation unique to the Sleeper Berth study was that to be recorded, incidents had to meet a pre-set threshold for the sensors (e.g., strong braking maneuver of at least $0.25 \mathrm{~g}$ ). Although this was an efficient way in which to record incident data while not recording irrelevant data, it was possible that incidents that occurred with a more subtle onset (i.e., did not trigger the system) were not recorded as incidents. That is, it is conceivable that incidents occurred that were missed by the system and were, therefore, not recorded (this issue is discussed in detail later in this report). Unfortunately, because the trucks were on the road for six or more days at a time, it would have been extremely difficult to record data continuously (and even more difficult to analyze it later in the lab). As such, though this approach has potential shortcomings, it was considered a reasonable way in which to collect incidents that occurred.

How could this approach have been improved to obtain a more complete picture of the light LVHV interaction problem? First, video cameras also could have been installed on LVs. However, because there are many more LVs than HVs, the frequency of LV-HV interactions captured from this latter approach would not be as high as in the approach that was used. A second possible improvement in the data collection approach may have been to record data continuously. Although this would have provided a more complete picture of the LV-HV interaction problem, filtering the data for valid critical incidents would have taken many months (perhaps years) to 
complete. It is believed that the approach used provided the most efficient data collection procedure for achieving the stated research goal, albeit subject to the possible limitations mentioned here.

\section{RESULTS}

\section{Light Vehicle-Heavy Vehicle Interaction Data Set}

The on-road Sleeper Berth study captured 68 LV-HV critical incident interactions. As shown in Table 18, these 68 incidents were grouped as a function of "Driver Type" (data were collected from a single driver or a team driver) or by "Initiating Driver" (incident caused by driver of LV or HV).

Table 18. Breakdown of the $68 \mathrm{LV}$-HV critical incident interactions captured in this study.

\begin{tabular}{|c|l|c|c|c|}
\hline & \multicolumn{4}{|c|}{ Driver Type } \\
\hline \multirow{4}{*}{$\begin{array}{c}\text { Initiating } \\
\text { Driver }\end{array}$} & $\begin{array}{c}\text { Incidents } \\
\text { involving a } \\
\text { single driver }\end{array}$ & $\begin{array}{c}\text { Incidents } \\
\text { involving a } \\
\text { team driver }\end{array}$ & Total \\
\cline { 2 - 5 } & $\begin{array}{l}\text { LV driver- } \\
\text { initiated }\end{array}$ & 36 & 11 & $\mathbf{4 7}$ \\
\cline { 2 - 5 } & $\begin{array}{l}\text { HV driver- } \\
\text { initiated }\end{array}$ & 19 & 2 & $\mathbf{2 1}$ \\
\cline { 2 - 5 } & Total & $\mathbf{5 5}$ & $\mathbf{1 3}$ & $\mathbf{6 8}$ \\
\hline
\end{tabular}

The data set that was used for the current effort was comprised of a subset of incidents that were captured in the sleeper berth data collection effort. In total, 2,877 critical incidents were recorded for the drivers included in the current study. These were carefully reviewed and only those that involved a LV-HV interaction and had a severity rating of $\geq 3$, were included. (Light vehicles were defined as passenger cars and light trucks [i.e., pickup trucks], while heavy vehicles referred to sleeper berth trucks.) It should be noted that the severity rating scale used, shown in Table 19, was developed during another VTTI project entitled "Identification and Evaluation of Driver Errors" (Wierwille et al., 2001). The column on the far right side shows the frequency of incidents for each severity rating in the Sleeper Berth data set. Of the 111 incidents with a severity rating $\geq 3,68$ involved a $\mathrm{LV}-\mathrm{HV}$ interaction. 
Table 19. Scale used to rank the severity of an incident. Rightmost column shows the frequency of each severity type for the 68 incidents.

\begin{tabular}{|l|l|c|l|c|}
\hline \multicolumn{1}{|c|}{ Hazard Category } & $\begin{array}{c}\text { Conflict } \\
\text { Severity }\end{array}$ & $\begin{array}{c}\text { Severity } \\
\text { Rating }\end{array}$ & \multicolumn{1}{|c|}{ Definition } & $\begin{array}{c}\text { Frequency of } \\
\text { Occurrence in } \\
\text { the Sleeper } \\
\text { Berth Data Set } \\
\text { (N }_{\text {tot }} \text { 2877) }\end{array}$ \\
\hline $\begin{array}{l}\text { Error, no hazard } \\
\text { present }\end{array}$ & Negligible & 1 & $\begin{array}{l}\text { Poor driving behavior that did not cause a } \\
\text { conflict or result in an interaction with } \\
\text { another vehicle or object. Commonly a } \\
\text { single vehicle traffic event. }\end{array}$ & 2636 \\
\hline $\begin{array}{l}\text { Error, hazard } \\
\text { present }\end{array}$ & Marginal & 2 & $\begin{array}{l}\text { Precautionary braking or lane change with } \\
\text { minimal risk of a near-crash, such as } \\
\text { blocking an intersection with very slow } \\
\text { moving or stopped traffic or backing at an } \\
\text { intersection when there is no vehicle to the } \\
\text { rear. }\end{array}$ & 130 \\
\hline $\begin{array}{l}\text { Serious error, hazard } \\
\text { present }\end{array}$ & 3 & $\begin{array}{l}\text { Controlled acceleration, deceleration, lane } \\
\text { change, and/or a warning behavior such as } \\
\text { sounding the horn with slight risk of a near- } \\
\text { crash, such as tailgating. }\end{array}$ & \\
\hline Near-crash & Critical & 4 & $\begin{array}{l}\text { Rapid controlled acceleration, deceleration, } \\
\text { lane change, or stopping to avoid a crash. }\end{array}$ & \\
\hline Serious near-crash & 5 & $\begin{array}{l}\text { Emergency braking or violent swerve to } \\
\text { avoid a crash, resulting in a very near-crash } \\
\text { situation. }\end{array}$ & 13 \\
\hline Non-injury crash & Catastrophic & 6 & Crash resulting in only property damage. & \\
\hline Injury crash & & 7 & $\begin{array}{l}\text { Crash resulting in bodily injury and/or } \\
\text { property damage. }\end{array}$ & 1 \\
\hline Fatality & 8 & $\begin{array}{l}\text { Crash resulting in death and/or severe } \\
\text { property damage. }\end{array}$ & 0 \\
\hline
\end{tabular}

\section{Incident Types}

As noted, of the 2,877 incidents that were captured, 68 of these were LV-HV interactions and had a severity rating of $\geq 3$. The next step in the analysis was to determine the action (i.e., primary contributing factor or what happened) for each incident. To this end, the video and relevant data for each incident were carefully reviewed and then classified into an Incident Type. As indicated in Chapter 1, 20 different Incident Types were identified in the L/SH and Sleeper Berth data sets. It should be reiterated that the 20 Incident Types identified do not necessarily comprise the entire universe of all types of LV-HV interaction incidents. For comparison, the L/SH data set analyzed in Phase A had 142 incidents that were categorized into 20 Incident Types, while the Sleeper Berth data set had 68 incidents categorized into 10 Incident Types. Please refer back to Table 1 for a description of the 20 Incident Types.

Tables 20 and 21 show the Incident Type descriptive statistics for the entire data set, as functions of Initiating Driver and Driver Type. The frequency of occurrence, percentage of occurrence, and rank order is presented for each incident type across Initiating Driver (Table 20) and Driver Type (Table 21). The rank ordering highlights the frequency of Incident Types from most 
frequently occurring (ranked as a low number, "1") to least frequently occurring (ranked as a high number, "10"). Incident Types that had an equal number of occurrences were ranked as a "tie" and the mean of the rankings was assigned. For example, "Roadway Entrance without Clearance" and "Obstruction in Roadway " occurred equally with a frequency of "4." Because their order in the ranking would consist of the sixth and seventh positions, a mean ranking of "6.5" was assigned to both Incident Types.

Table 20. Incident Type descriptive statistics for incidents as a function of Initiating Driver.

\begin{tabular}{|c|c|c|c|c|c|}
\hline Incident Type & $\begin{array}{c}\text { Frequency of } \\
\text { Occurrence: } \\
\text { Incidents } \\
\text { Initiated by } \\
\text { Sleeper Berth } \\
\text { Driver } \\
\left(\mathrm{N}_{\mathrm{SB}}=21\right)\end{array}$ & $\begin{array}{c}\text { Frequency of } \\
\text { Occurrence: } \\
\text { Incidents } \\
\text { Initiated by } \\
\text { Light Vehicle } \\
\text { Driver } \\
\left(\mathrm{N}_{\mathrm{LV}}=47\right)\end{array}$ & $\begin{array}{c}\text { Frequency of } \\
\text { Occurrence: } \\
\text { Incidents } \\
\text { Initiated by } \\
\text { All Drivers } \\
\left(\mathbf{N}_{\text {Total }}=\mathbf{6 8}\right)\end{array}$ & $\begin{array}{l}\text { Percentage of } \\
\text { Occurrence: } \\
\text { Incidents } \\
\text { Initiated by } \\
\text { All Drivers } \\
\left(\mathbf{N}_{\text {Total }}=68\right)\end{array}$ & $\begin{array}{l}\text { Combined } \\
\text { Rank: } \\
\text { Incidents } \\
\text { Initiated by } \\
\text { All Drivers } \\
\left(\mathbf{N}_{\text {Total }}=68\right)\end{array}$ \\
\hline Lane Change Without Sufficient Gap & 2 & 15 & 17 & $25 \%$ & 1 \\
\hline Turn Without Sufficient Warning & 3 & 9 & 12 & $18 \%$ & 2 \\
\hline Late Braking for Stopped/ Stopping Traffic & 10 & 0 & 10 & $15 \%$ & 3 \\
\hline Low Speed & 1 & 8 & 9 & $13 \%$ & 4 \\
\hline Following Too Closely & 5 & 0 & 5 & $7 \%$ & 5 \\
\hline Roadway Entrance Without Clearance & 0 & 4 & 4 & $6 \%$ & 6.5 \\
\hline Obstruction in Roadway & 0 & 4 & 4 & $6 \%$ & 6.5 \\
\hline Lateral Deviation of Through Vehicle & 0 & 3 & 3 & $4 \%$ & 8 \\
\hline Slow Upon Passing & 0 & 2 & 2 & $3 \%$ & 9.5 \\
\hline Improper Passing & 0 & 2 & 2 & $3 \%$ & 9.5 \\
\hline Total & 21 & 47 & 68 & $100 \%$ & \\
\hline
\end{tabular}

Table 21. Incident Type descriptive statistics for incidents as a function of Driver Type.

\begin{tabular}{|l|c|c|c|c|c|}
\hline \multicolumn{1}{|c|}{ Incident Type } & $\begin{array}{c}\text { Frequency of } \\
\text { Occurrence: } \\
\text { Incidents } \\
\text { Involving a } \\
\text { Single Driver } \\
\left.\mathbf{( N}_{\text {Singl }} \mathbf{e}=\mathbf{5 5}\right)\end{array}$ & $\begin{array}{c}\text { Frequency of } \\
\text { Occurrence: } \\
\text { Incidents } \\
\text { Involving a } \\
\text { Team Driver } \\
\left.\mathbf{( N}_{\text {Team }} \mathbf{1 3}\right)\end{array}$ & $\begin{array}{c}\text { Frequency of } \\
\text { Occurrence: } \\
\text { Incidents } \\
\text { Initiated by } \\
\text { All Drivers } \\
\left.\mathbf{( N}_{\text {Total }}=\mathbf{6 8}\right)\end{array}$ & $\begin{array}{c}\text { Percentage of } \\
\text { Occurrence: } \\
\text { Incidents } \\
\text { Involving by } \\
\text { All Drivers } \\
\left.\mathbf{( N}_{\text {Total }}=\mathbf{6 8}\right)\end{array}$ & $\begin{array}{c}\text { Combined } \\
\text { Rank: } \\
\text { Incidents } \\
\text { Involving All } \\
\text { Drivers } \\
\left.\mathbf{( N}_{\text {Total }}=\mathbf{6 8}\right)\end{array}$ \\
\hline Lane Change Without Sufficient Gap & 13 & 4 & 17 & $25 \%$ & 1 \\
\hline Turn Without Sufficient Warning & 10 & 2 & 12 & $18 \%$ & 2 \\
\hline Late Braking for Stopped/ Stopping Traffic & 9 & 1 & 10 & $15 \%$ & 3 \\
\hline Low Speed & 8 & 1 & 9 & $13 \%$ & 4 \\
\hline Following Too Closely & 4 & 1 & 5 & $7 \%$ & 5 \\
\hline Roadway Entrance Without Clearance & 2 & 2 & 4 & $6 \%$ & 6.5 \\
\hline Obstruction in Roadway & 4 & 0 & 4 & $6 \%$ & 6.5 \\
\hline Lateral Deviation of Through Vehicle & 2 & 1 & 3 & $4 \%$ & 8 \\
\hline Slow Upon Passing & 2 & 0 & 2 & $3 \%$ & 9.5 \\
\hline Improper Passing & 1 & 1 & 2 & $3 \%$ & 9.5 \\
\hline Total & $\mathbf{5 5}$ & $\mathbf{1 3}$ & $\mathbf{6 8}$ & $100 \%$ & \\
\hline
\end{tabular}


As can be seen from the data presented in Tables 20 and 21, the most commonly occurring Incident Type involving an interaction between an LV and an SB truck was Lane Change Without Sufficient Gap. Across all 68 incidents, this particular Incident Type occurred 17 times and accounted for 25 percent of the incidents captured. A histogram, shown in Figure 31, provides a clear indication of the frequency of occurrence for each Incident Type. As can be seen from Figure 31, the majority of the incidents (58 percent) were of three Incident Types: (1) Lane Change Without Sufficient Gap, (2) Turn Without Sufficient Warning, and (3) Late Braking for Stopped/Stopping Traffic.

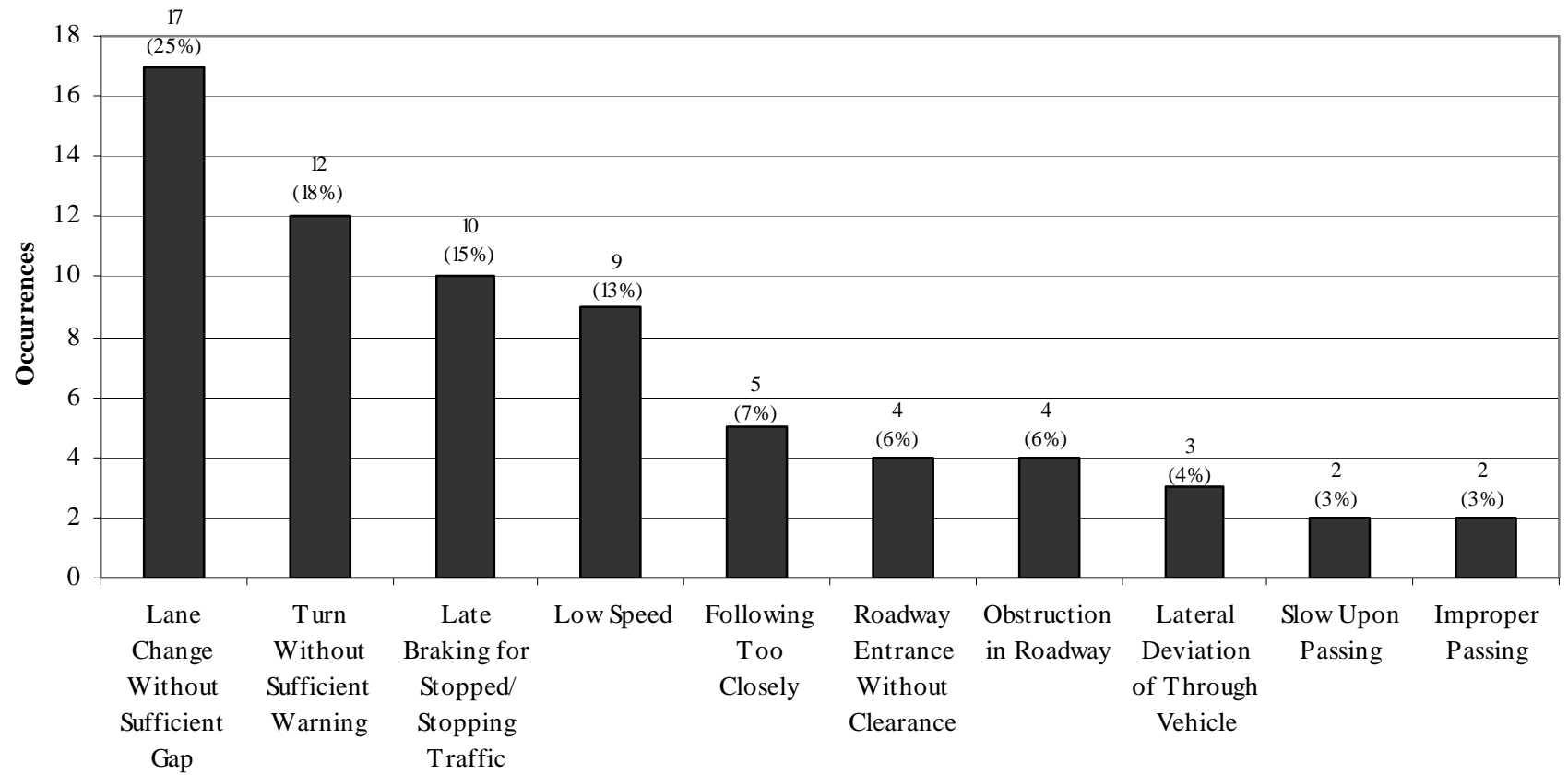

Incident Type

Figure 31. Frequency of incident types; all incidents included. 
Figure 32 shows the incident data as a function of the Initiating Driver. The light bars in Figure 32 represent incidents initiated by the SB driver, while the dark bars represent incidents initiated by the LV driver. As shown, LV drivers initiated over twice as many incidents as SB drivers; the number of LV driver initiated incidents was 47, while the number of SB initiated incidents was 21.

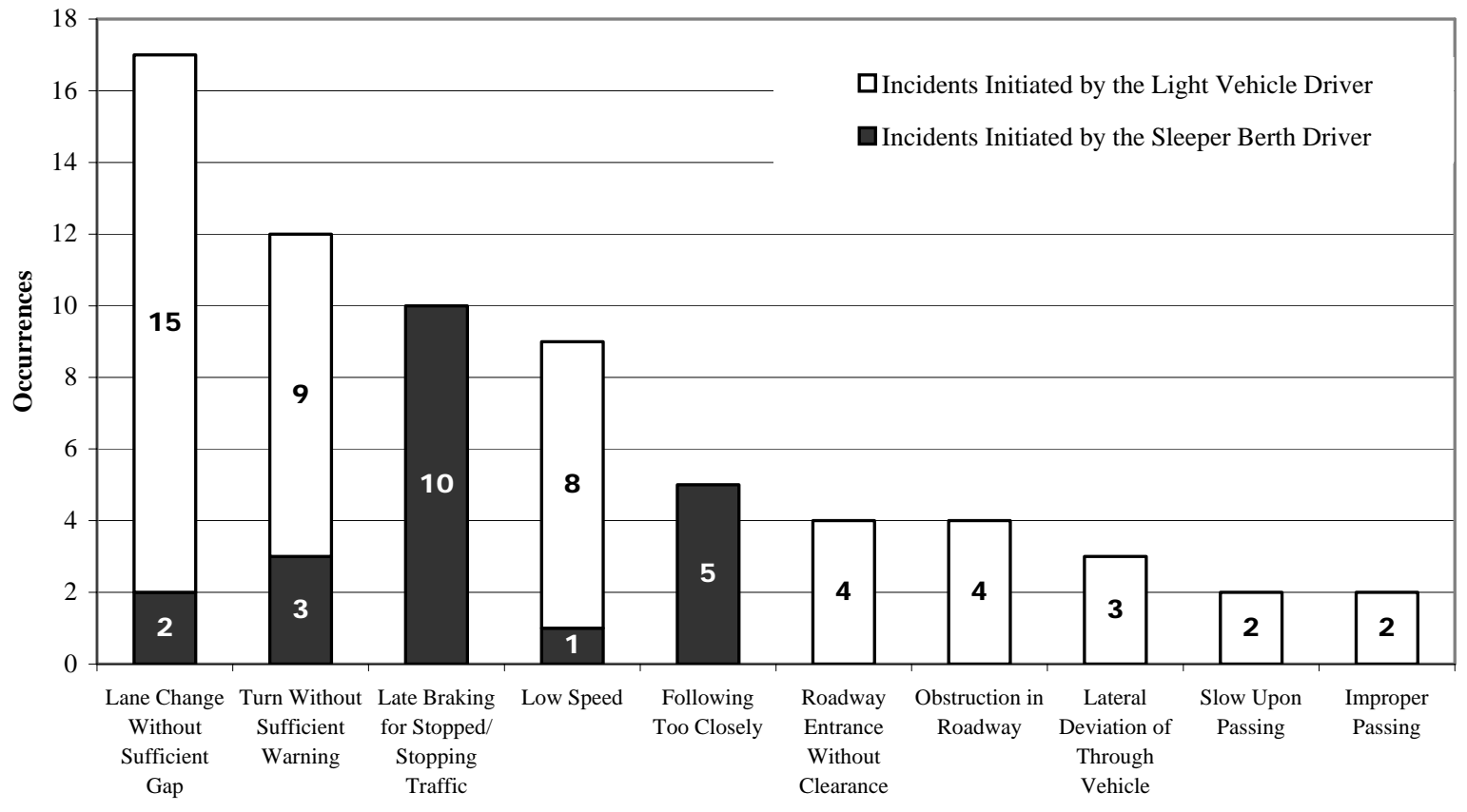

Incident Type

Figure 32. Frequency of incident types as a function of the Initiating Driver 
Figure 33 details the 47 incidents initiated by the LV drivers, while Figure 34 highlights the 21 SB driver initiated incidents. The most frequent incident type initiated by LV drivers was Lane Change Without Sufficient Gap (32 percent), while the most frequent type for SB drivers was Late Braking for Stopped/Stopping Traffic (48 percent).

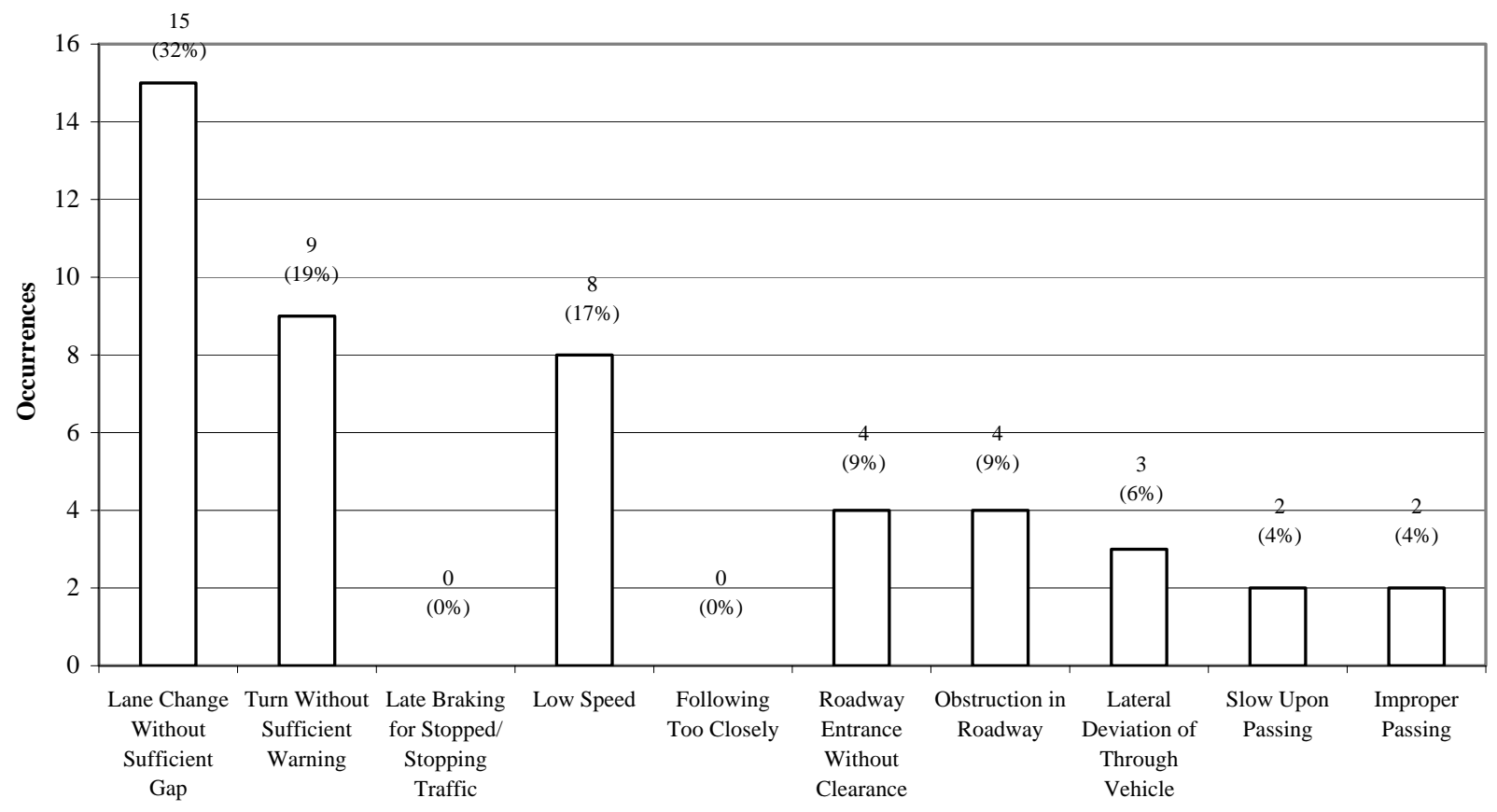

Incident Type

Figure 33. Frequency of incident types initiated by a light vehicle driver. 


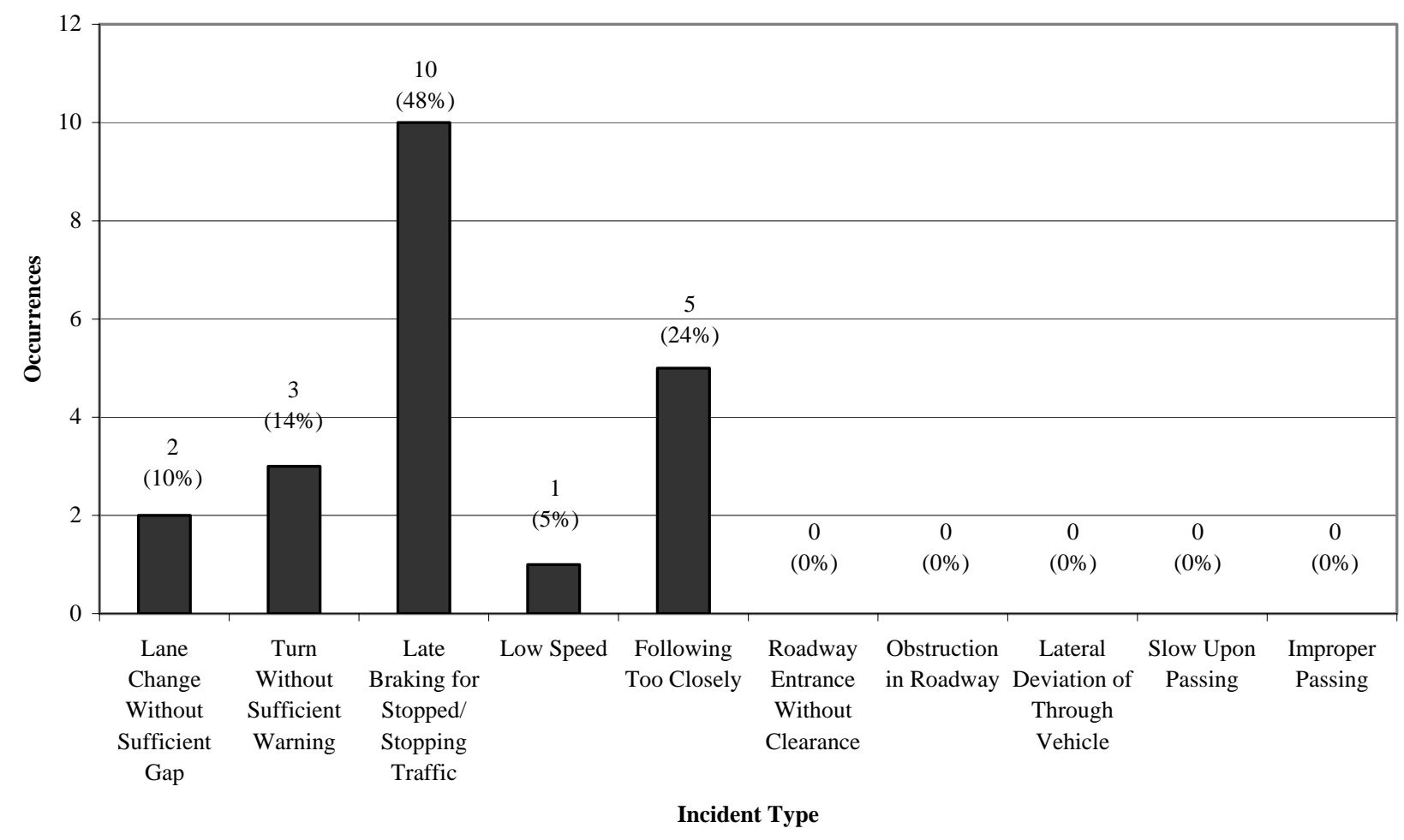

Figure 34. Frequency of incident types initiated by a sleeper berth driver.

There are several interesting findings contained in the incident occurrence data presented. First, in the way of review, LV drivers initiated the majority of incidents. Of the 68 incidents that were recorded, 47 were initiated by LV drivers and 21 were initiated by SB drivers. Put another way, the ratio of incident initiation was 2.2:1, where $2.2 \mathrm{LV}$ driver initiated incidents were recorded for every SB initiated incident. Recall that it was previously mentioned that Wang et al (1999) indicated that the ratio of LV to HV initiated interactions was between 2:1 and 3:1. It must be pointed out that the Wang et al. analysis was not restricted to LV-HV interactions, but rather involved all LV and all HV crashes. Although perhaps not directly comparable, it is noteworthy that the data reported in the current study are, nonetheless, similar to the Wang et al. results. The finding that the majority of incidents were found to have been caused by LV drivers is also consistent with the results of a crash database analysis reported by Craft (1999). In that analysis, Craft examined LV-HV interaction fatality crashes and found that LV drivers were coded more than 4-times as often as being the sole factor in the crash as compared to HV drivers.

A second interesting finding is that the majority of LV initiated incidents were of the type, Lane Change Without Sufficient Gap. This Incident Type accounted for 32 percent of the LV initiated incidents. This finding agrees with the result presented by Hanowski et al. (1998) that suggested truck drivers believe that they are often "cut-off" by LV drivers. For SB initiated incidents, the most frequent type was Late Braking for Stopped/Stopping Traffic. Note that this particular incident type and Lane Change Without Sufficient Gap are similar in that they both refer to an event where an LV is in front of a truck. However, for Lane Change Without Sufficient Gap 
incidents, it is the lead vehicle that is judged to be at fault. For Late Braking for Stopped/Stopping Traffic incidents, it is the following vehicle that is at fault.

Figure 35 shows the incident data as a function of the Driver Type regardless of fault. The crosshatched bars in Figure 35 represent incidents involving an HV team driver, while the dark bars represent incidents involving an HV single driver. ${ }^{2}$ As shown, single drivers were involved in substantially more incidents than team drivers; there were 55 incidents involving single drivers and 13 incidents involving team drivers.

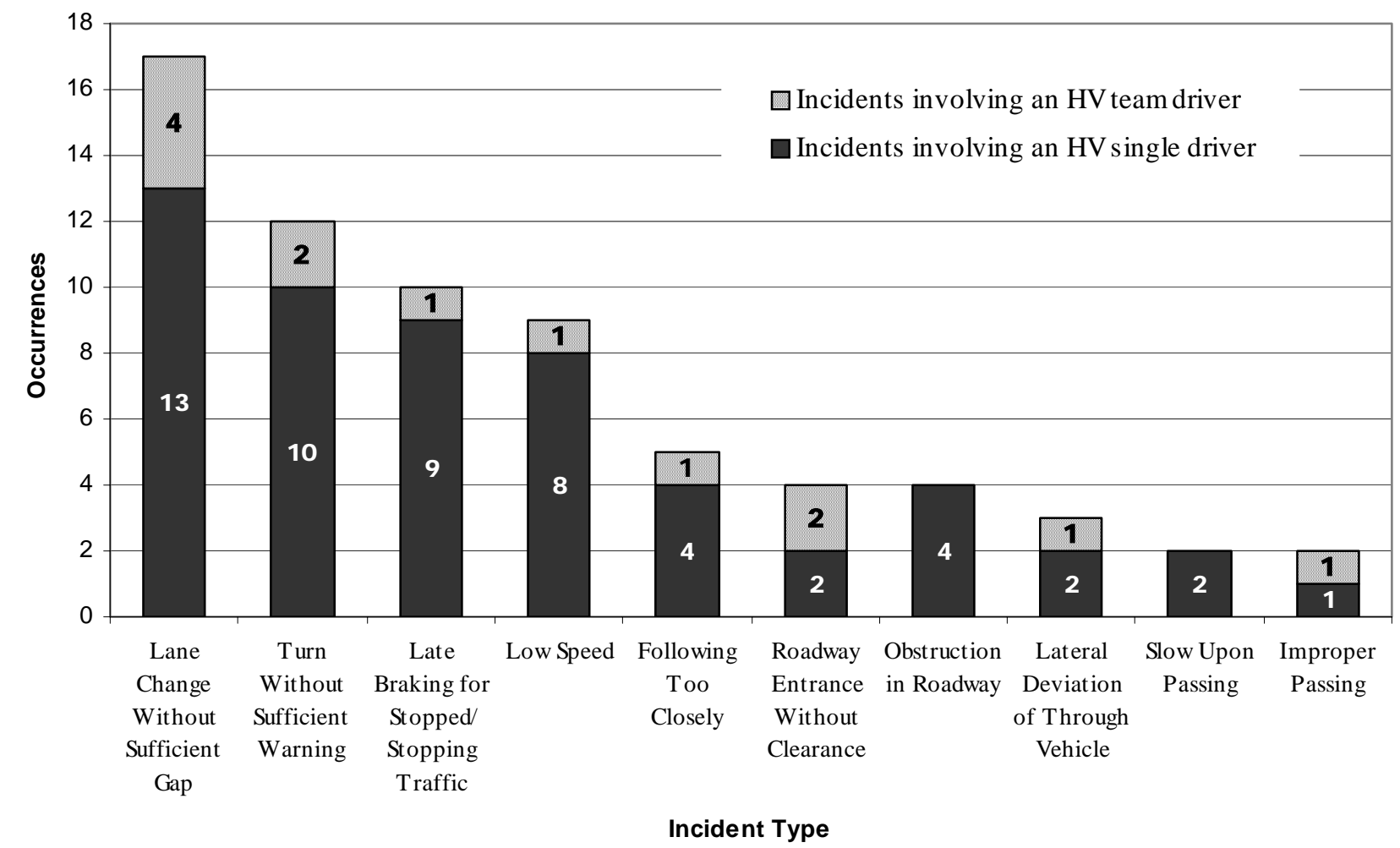

Figure 35. Frequency of incident types as a function of Driver Type.

\footnotetext{
${ }^{2}$ When referring to single and team sleeper berth drivers, the notation HV is used to remind the reader that the single drivers are indeed the sleeper berth vehicle drivers and not the light vehicle (LV) drivers, who in most cases are also single drivers.
} 
Figures 36 and 37 provide a break down of the incidents involving team and single drivers as a function of the Initiating Driver. Figure 36 shows that for LV driver initiated incidents, 11 involved a team driver and 36 involved a single driver. For incidents initiated by the SB driver, Figure 37 shows that a team driver was involved in 2 incidents and a single driver was involved in 19 incidents.

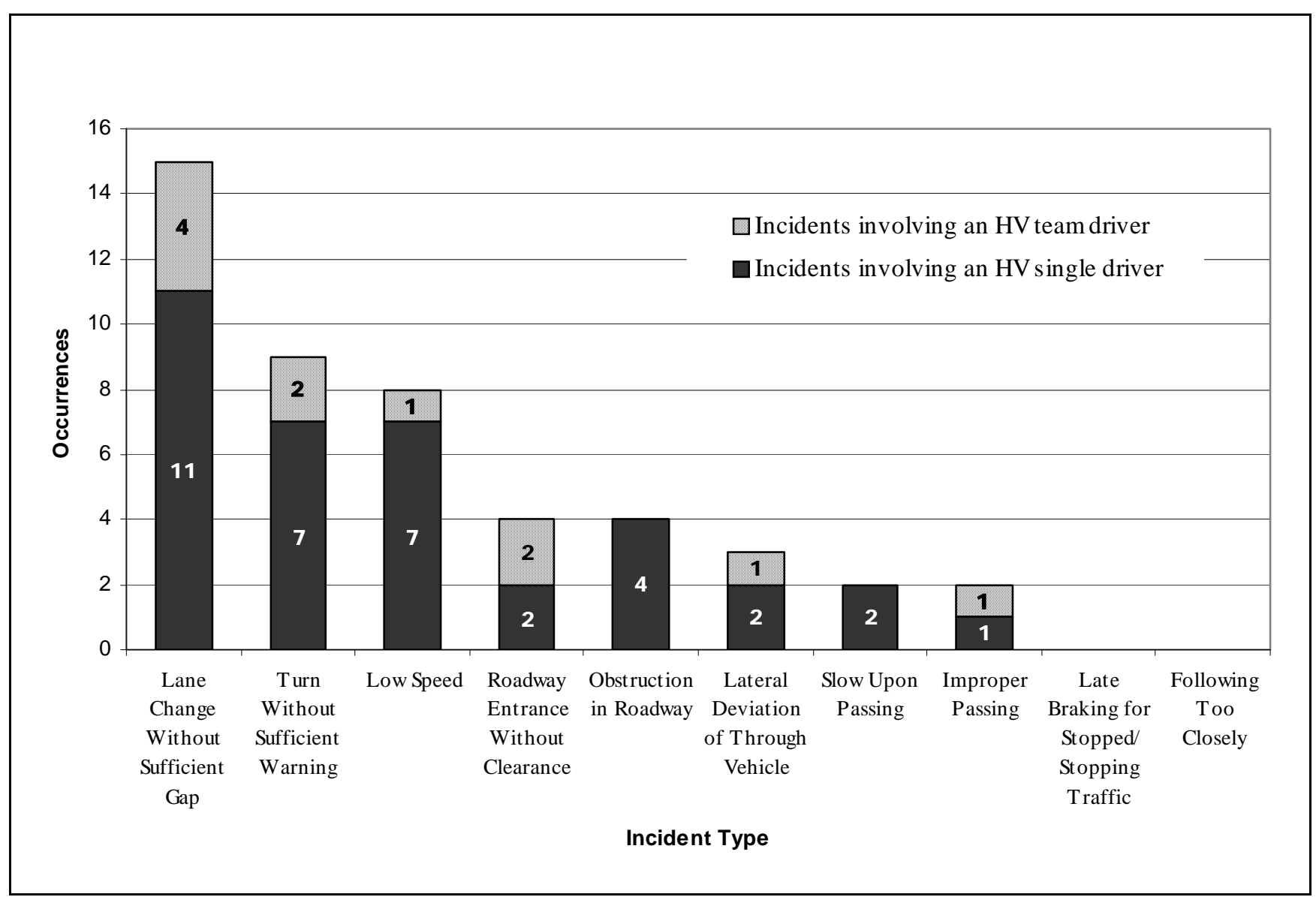

Figure 36. Frequency of incident types involving team and single drivers for incidents initiated by a light vehicle driver. 


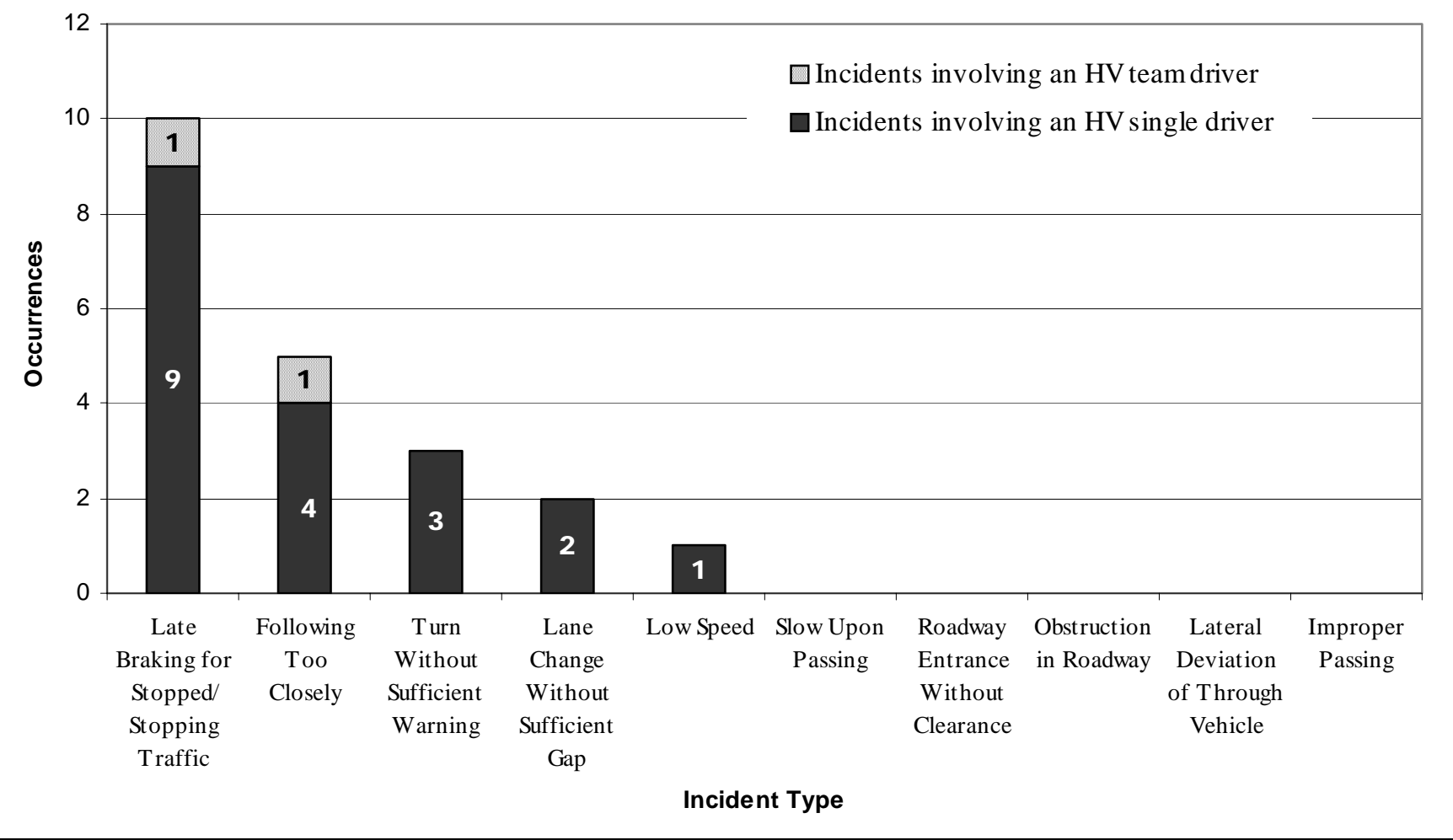

Figure 37. Frequency of incident types involving team and single drivers for incidents initiated by a sleeper berth driver.

As outlined in the Method section, data for this LV-HV study were collected from 20 single drivers and 14 team drivers (7 teams). While more single drivers were included than team drivers, teams averaged greater distances per trip than single drivers. Another way to look at the distribution of drivers is by a ratio of hours on the road. Because video was not recorded continuously in the Sleeper Berth study, the amount of driving time SB drivers drove could not be calculated directly from the data. However, a timed trigger was activated every 90 minutes so that researchers could gather baseline data. Therefore, the number of timed triggers could be used to obtain a rough estimate of the amount of time each subject drove (i.e., number of timed triggers $\mathrm{x} 90 \mathrm{~min}=$ driving time). Using this method, it is estimated that single drivers drove a cumulative 1,385 hours while teams drove a cumulative 867 hours, resulting in a 1.60:1 ratio of time that single drivers were on the road to time that team drivers were on the road. All things being equal, and if incidents occurred randomly, one might expect the same ratio for incidents. However, as shown in the histograms presented previously, there were many more incidents involving single drivers $(\mathrm{N}=55)$ than incidents involving a team driver $(\mathrm{N}=13)$. The ratio for these incidents is 4.23:1; far greater than the 1.60:1 ratio one would have expected. It should be noted that Lane Change Without Sufficient Gap was the most common incident type for both groups of drivers (single and team). 
There are several possible reasons for the differences between the number of incidents between single drivers and team drivers. One such reason is that team drivers are more likely to drive during off-peak hours when incidents with LVs might be expected to be less frequent. A second reason, for those incidents initiated by a sleeper berth driver (see Figure 37), is that team drivers may be less aggressive than single drivers in order to provide a smooth ride for the resting team member. However, this still does not explain the disparity between the single drivers and team drivers for those incidents initiated by the LV driver, shown in Figure 36. Whatever the reasons are for this discrepancy, the large difference in incident occurrence between these two groups of drivers is an important finding.

\section{Primary Maneuvers, Secondary Maneuvers, and Conflict Types}

After each of the 68 incidents was given an Incident Type classification, the next step in the analysis was to identify the Primary Maneuvers, Secondary Maneuvers, and Conflict Types involved in each incident. The Primary Maneuver refers to the maneuver of the driver who initiated the incident (i.e., the at-fault driver). For definitions of the 11 Primary Maneuvers defined in the Phase A and Phase B analyses, please refer back to Table 5.

In addition to identifying the Primary Maneuver for each incident, the Secondary Maneuver, or the maneuver of the responding driver (i.e., driver of the second vehicle involved in the interaction), was also classified. Considering the maneuvers of both vehicles involved in the incident, a clear picture of the conflict, or Conflict Type, could be determined. Please refer back to Table 6 in Chapter 1 for a definition of the 37 Conflict Types.

A set of descriptive statistics for the Primary Maneuvers for all incidents is shown in Tables 22 and 23. Table 22 shows the Primary Maneuvers for the incidents as a function of Initiating Driver, while Table 23 highlights the Primary Maneuvers as a function of Driver Type. Figure 38 shows a histogram of the cumulative frequency data for all of the Primary Maneuvers. As can be seen, the two most common Primary Maneuvers across all incidents were: (1) Through, $n=$ 27, and (2) Lane Change, $\mathrm{n}=22$.

Table 22. Primary Maneuver descriptive statistics as a function of Initiating Driver.

\begin{tabular}{|l|c|c|c|c|c|}
\hline Primary Maneuver & $\begin{array}{c}\text { Frequency of } \\
\text { Occurrence: } \\
\text { Incidents } \\
\text { Initiated by } \\
\text { Sleeper Berth } \\
\text { Driver } \\
\text { (NSB= 21) }\end{array}$ & $\begin{array}{c}\text { Frequency of } \\
\text { Occurrence: } \\
\text { Incidents } \\
\text { Initiated by } \\
\text { Light Vehicle } \\
\text { Driver } \\
\text { (NLV= 47) }\end{array}$ & $\begin{array}{c}\text { Frequency of } \\
\text { Occurrence: } \\
\text { Incidents } \\
\text { Initiated by } \\
\text { All Drivers } \\
\text { (NTotal= 68) }\end{array}$ & $\begin{array}{c}\text { Percentage of } \\
\text { Occurrence: } \\
\text { Incidents } \\
\text { Initiated by } \\
\text { All Drivers } \\
\text { (NTotal= 68) }\end{array}$ & $\begin{array}{c}\text { Combined } \\
\text { Rank: } \\
\text { Incidents } \\
\text { Initiated by } \\
\text { All Drivers } \\
\text { (NTotal = 68) }\end{array}$ \\
\hline Through & 15 & 12 & 27 & $40 \%$ & 1 \\
\hline Lane Change & 2 & 20 & 22 & $32 \%$ & 2 \\
\hline Roadway Exit & 1 & 5 & 6 & $9 \%$ & 3.5 \\
\hline Left Turn & 2 & 4 & 6 & $9 \%$ & 3.5 \\
\hline Merge Onto Roadway & 0 & 4 & 4 & $6 \%$ & 5 \\
\hline Right Turn & 1 & 1 & 2 & $3 \%$ & 6 \\
\hline Stopped in Roadway & 0 & 1 & 1 & $1 \%$ & 7 \\
\hline Total & $\mathbf{2 1}$ & $\mathbf{4 7}$ & $\mathbf{6 8}$ & $\mathbf{1 0 0 \%}$ & \\
\hline
\end{tabular}


Table 23. Primary Maneuver descriptive statistics as a function of Driver Type.

\begin{tabular}{|c|c|c|c|c|c|}
\hline Primary Maneuver & $\begin{array}{l}\text { Frequency of } \\
\text { Occurrence: } \\
\text { Incidents } \\
\text { Involving a } \\
\text { Single Driver } \\
\left(\mathrm{N}_{\text {Single }}=55\right)\end{array}$ & $\begin{array}{l}\text { Frequency of } \\
\text { Occurrence: } \\
\text { Incidents } \\
\text { Involving a } \\
\text { Team Driver } \\
\left(\mathrm{N}_{\text {Team }}=13\right)\end{array}$ & $\begin{array}{l}\text { Frequency of } \\
\text { Occurrence: } \\
\text { Incidents } \\
\text { Initiated by } \\
\text { All Drivers } \\
\left(\mathbf{N}_{\text {Total }}=68\right)\end{array}$ & $\begin{array}{l}\text { Percentage of } \\
\text { Occurrence: } \\
\text { Incidents } \\
\text { Initiated by } \\
\text { All Drivers } \\
\left(\mathbf{N}_{\text {Total }}=68\right)\end{array}$ & $\begin{array}{c}\text { Combined } \\
\text { Rank: Incidents } \\
\text { Involving } \\
\text { All Drivers } \\
\left(\mathbf{N}_{\text {Total }}=\mathbf{6 8}\right)\end{array}$ \\
\hline Through & 23 & 4 & 27 & $40 \%$ & 1 \\
\hline Lane Change & 18 & 4 & 22 & $32 \%$ & 2 \\
\hline Roadway Exit & 4 & 2 & 6 & $9 \%$ & 3.5 \\
\hline Left Turn & 6 & 0 & 6 & $9 \%$ & 3.5 \\
\hline Merge Onto Roadway & 1 & 3 & 4 & $6 \%$ & 5 \\
\hline Right Turn & 2 & 0 & 2 & $3 \%$ & 6 \\
\hline Stopped in Roadway & 1 & 0 & 1 & $1 \%$ & 7 \\
\hline TOTAL & 55 & 13 & 68 & $100 \%$ & \\
\hline
\end{tabular}

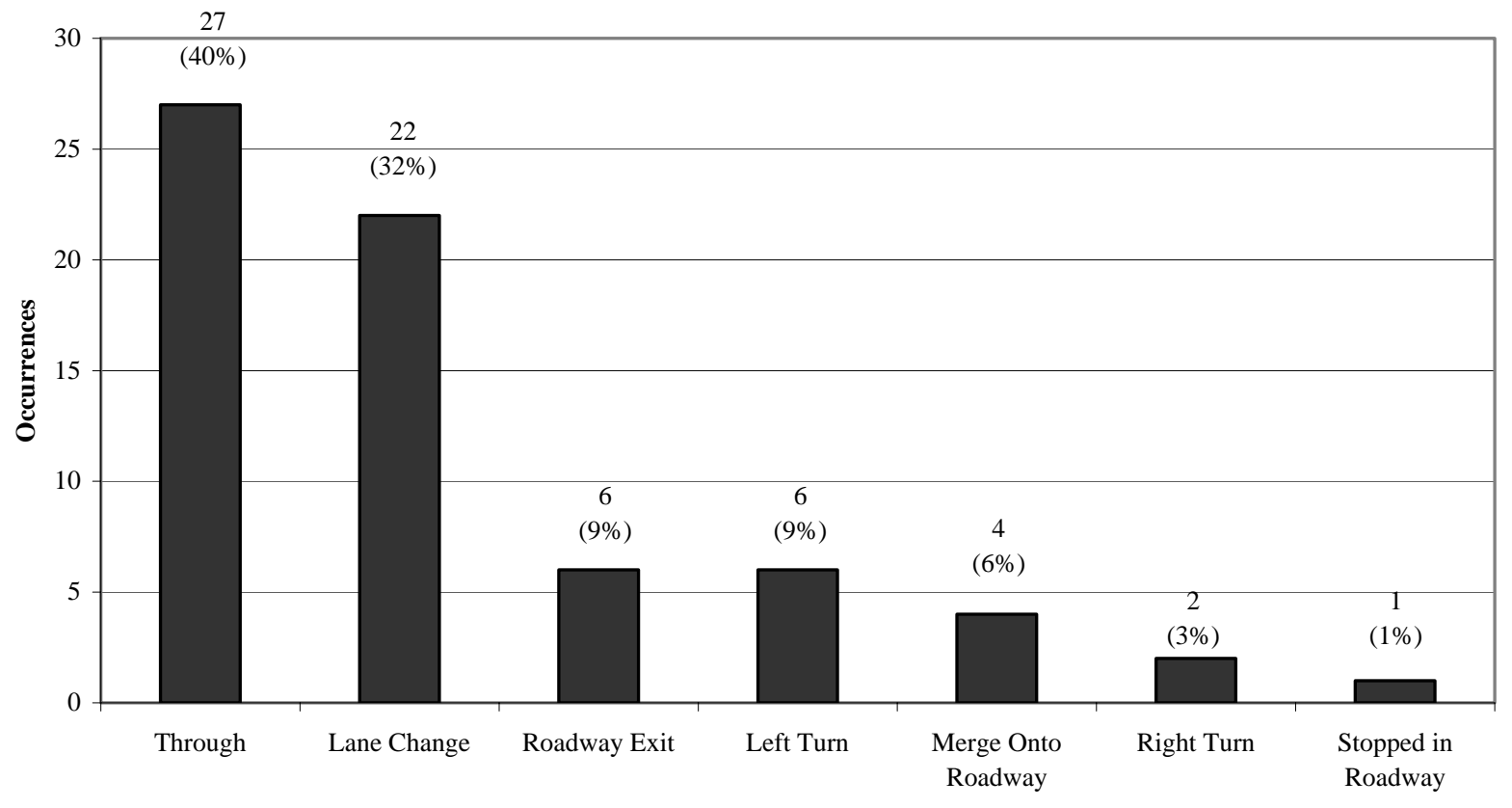

Primary Maneuver

Figure 38. Frequency of Primary Maneuvers for all incidents. 
A histogram of the Primary Maneuvers as a function of the Initiating Driver is shown in Figure 39. The most frequent Primary Maneuver for incidents initiated by LV drivers was Lane Change. The most frequent Primary Maneuver for incidents initiated by SB drivers was Through. This result is highlighted in Figures 40 and 41 . In Figure 40 it can be seen that both Through (26 percent) and Lane Change (43 percent) accounted for the majority of maneuvers for LV driver initiated incidents. In comparison, Figure 41 shows that the Through Primary Maneuver occurred in 71 percent of incidents initiated by SB drivers.

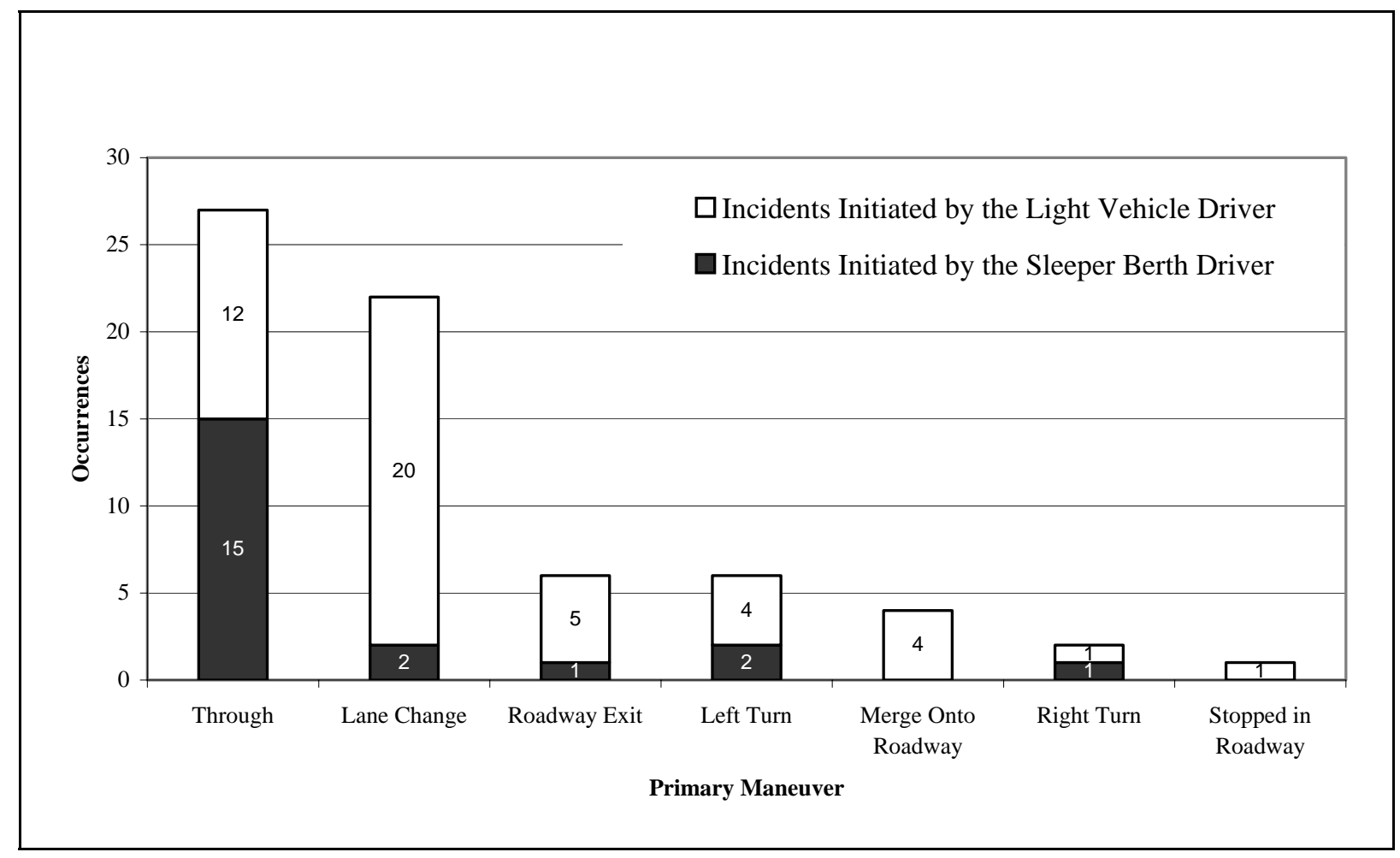

Figure 39. Frequency of Primary Maneuvers as a function of Initiating Driver. 


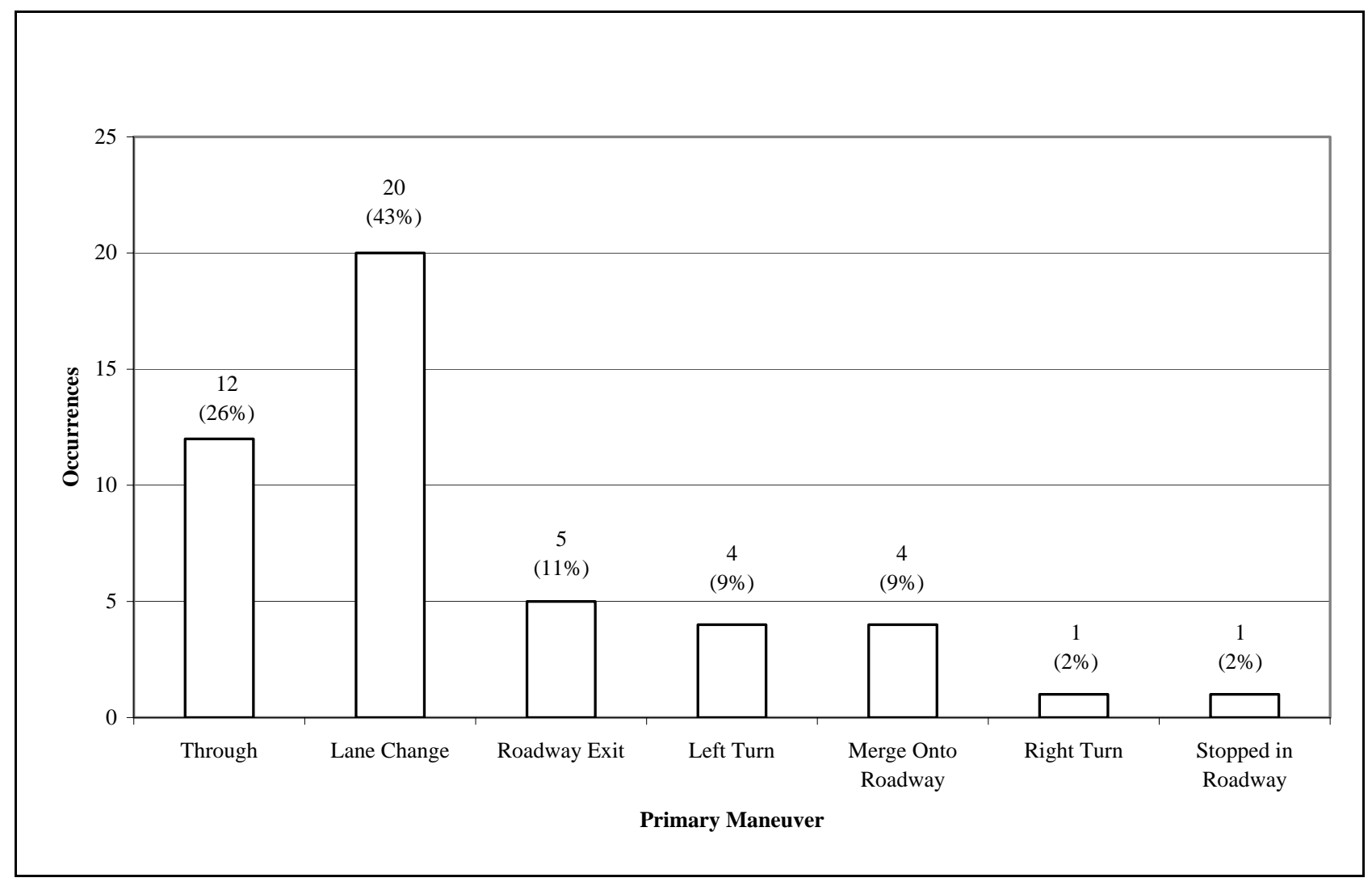

Figure 40. Frequency of Primary Maneuvers for the light vehicle driver-initiated incidents. 


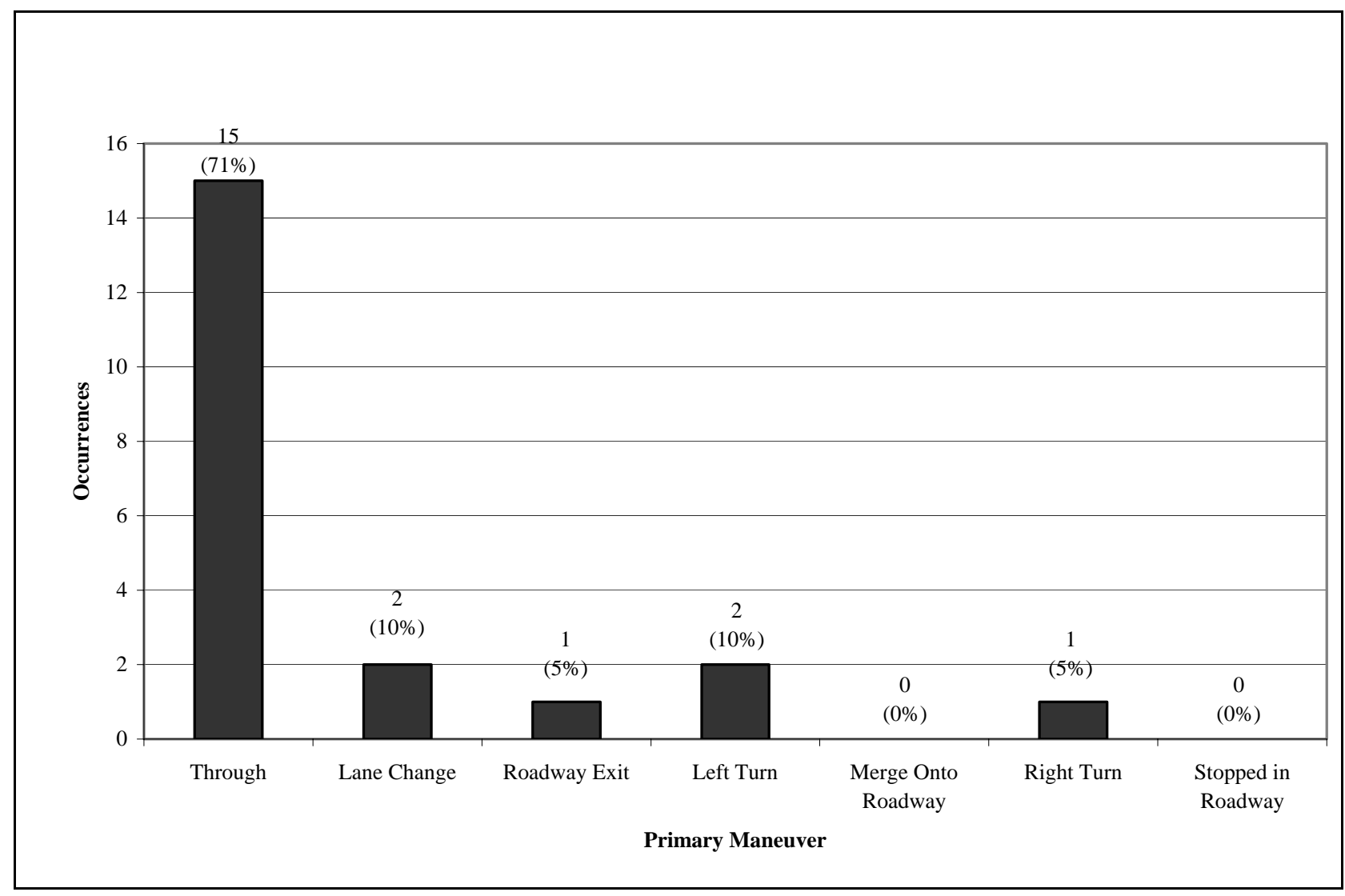

Figure 41. Frequency of Primary Maneuvers for the sleeper berth driver-initiated incidents. 
Figure 42 presents a histogram of the Primary Maneuvers as a function of the HV Driver Type. As shown, the most frequent Primary Maneuver for both groups of drivers was Through and Lane Change.

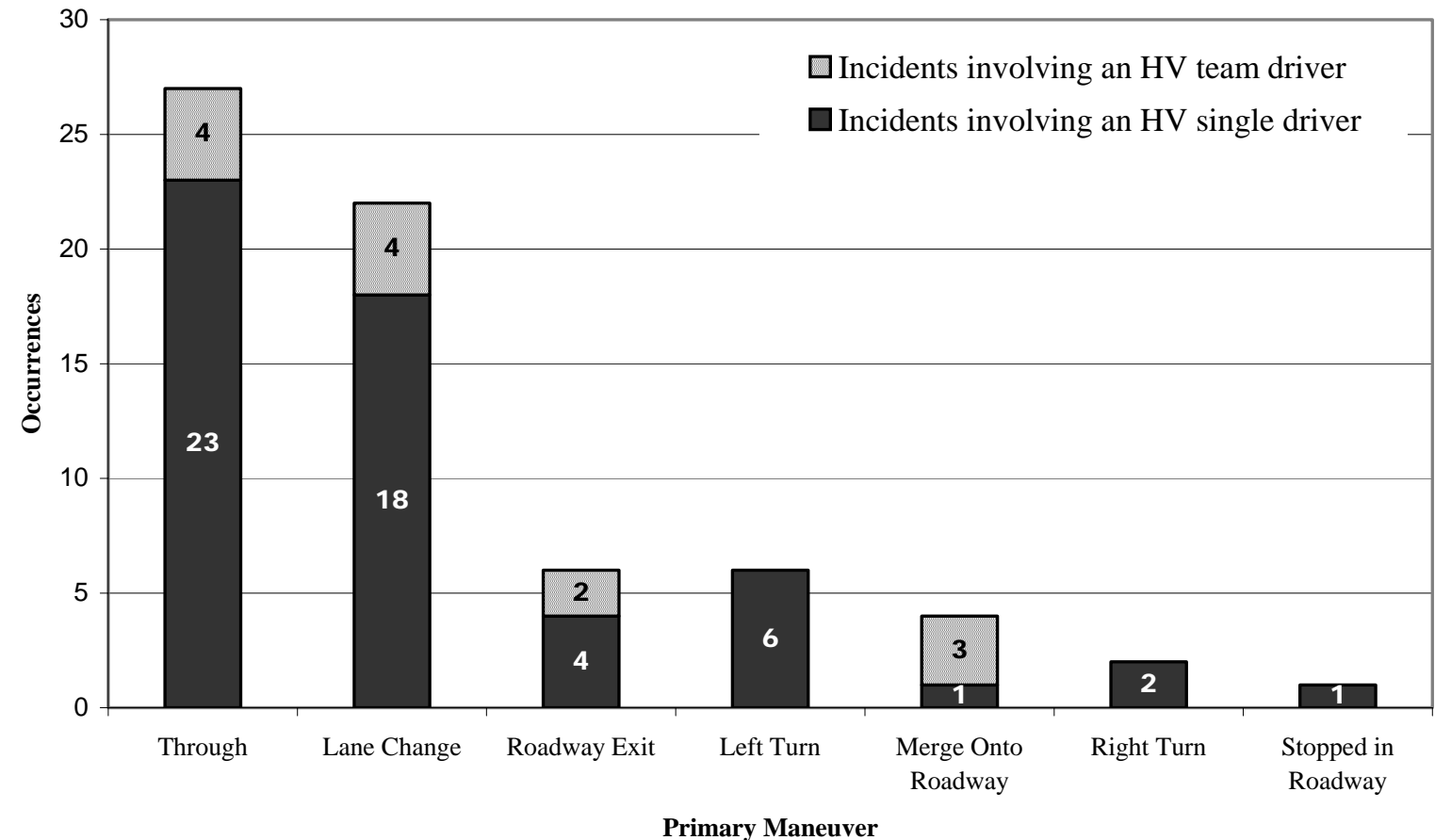

Figure 42. Frequency of Primary Maneuvers as a function of Driver Type. 
Primary Maneuvers for each Driver Type as a function of Initiating Driver are shown in Figures 43 and 44. Figure 43 shows a break down of the Primary Maneuvers for team and single drivers for all LV driver initiated incidents. For team drivers, Through and Lane Change were the most common Primary Maneuvers and were equally frequent. For single drivers, Through and Lane Change were the most frequent Primary Maneuvers. For SB initiated incidents, Figure 44 shows that Through incidents were most common for both single drivers and team drivers. Notice, as presented previously, only two incidents were captured that were SB driver-initiated and involved a team driver

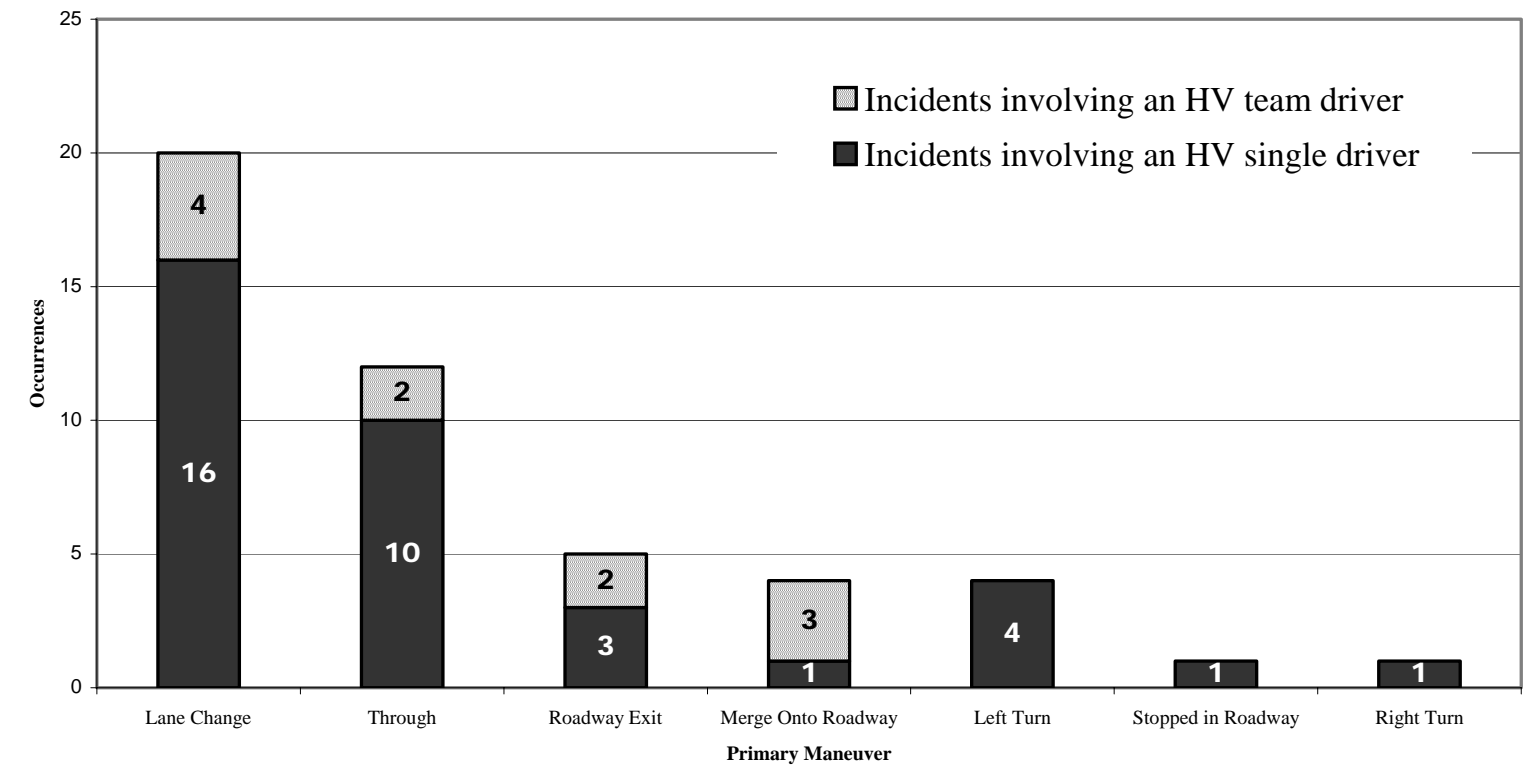

Figure 43. Frequency of incident types involving team and single drivers for incidents initiated by a light vehicle driver. 


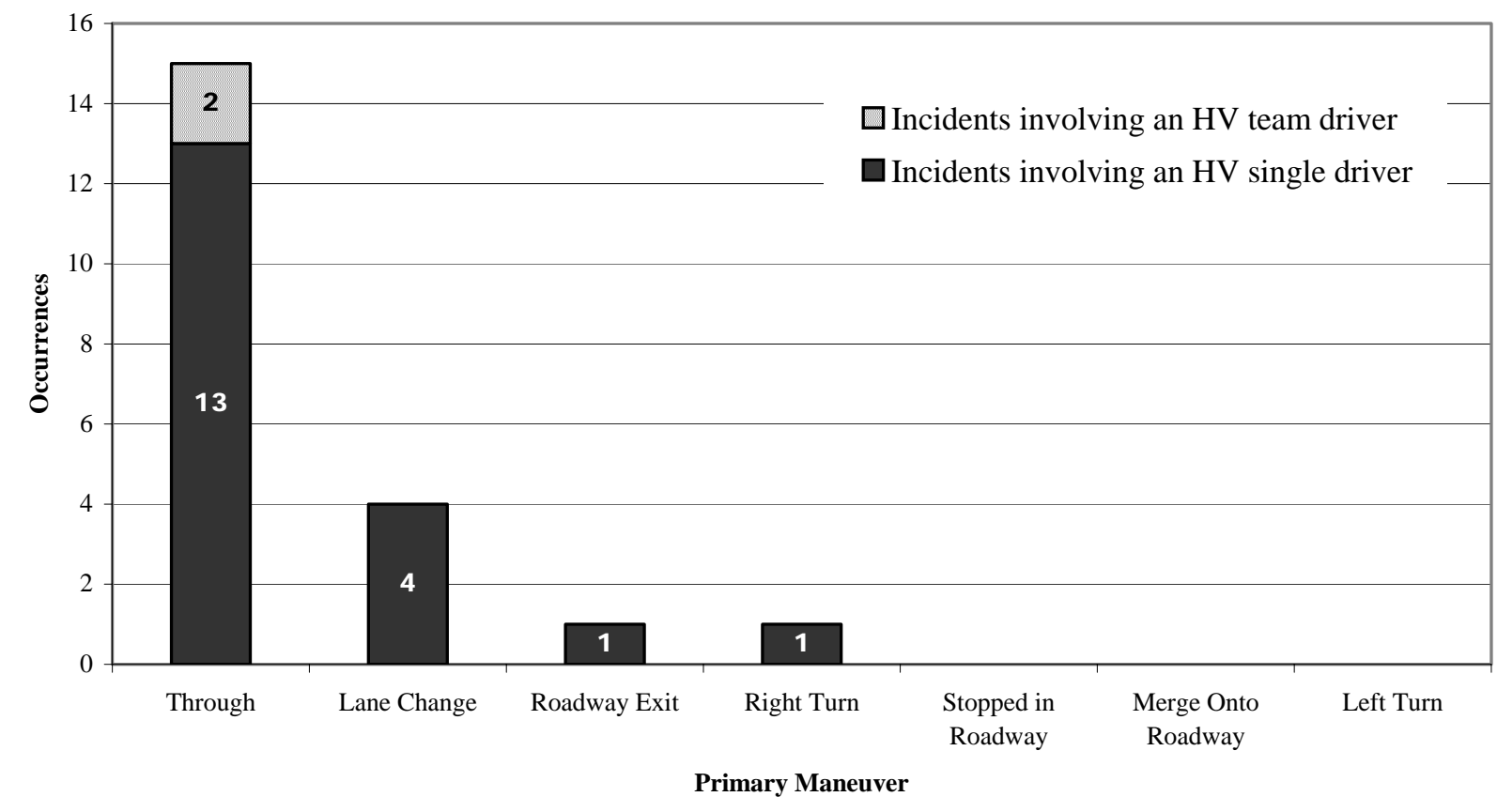

Figure 44. Frequency of incident types involving team and single drivers for incidents initiated by a sleeper berth driver.

\section{Contributing Factors}

Just as the Incident Types describe the action or what happened during an incident, contributing factors provide likely reasons why an incident occurred. For each incident analyzed, a number of contributing factors were identified. As described in Chapter 1, the "but for" test was applied to this list of contributing factors for each incident; that is, "but for , the incident would not have happened." The result of this filtering was a single contributing factor that was judged to be of primary importance to the incident occurrence.

\section{General Contributing Factors}

The term "General Contributing Factor" was used because the factors included were very general in nature. The General Contributing Factors can be seen in Table 10. As can be seen, four factors were identified: (1) Impairment, (2) Willful Behavior, (3) Infrastructure, and (4) Driver Proficiency. It should be pointed out that these factors are the same as those used by Wierwille et al. (2000). In addition to these four categories, a category termed Undeterminable was also used (i.e., incidents where the General Contributing Factor could not be determined).

Table 24 provides General Contributing Factors occurrence data as a function of the Initiating Driver, while Table 25 provides the data as a function of the Driver Type. In both tables, frequency and percentage of occurrence are provided for all General Contributing Factors for each driver group. In addition, the overall ranking based on frequency of occurrence for all 68 
incidents is provided. Figure 45 provides a histogram of the General Contributing Factors for all incidents. As can be seen, the top two factors were Driver Proficiency (51 percent) and Willful Behavior (35 percent).

Table 24. General Contributing Factors descriptive statistics as a function of Initiating Driver.

\begin{tabular}{|l|c|c|c|c|c|}
\hline $\begin{array}{c}\text { General Contributing } \\
\text { Factor }\end{array}$ & $\begin{array}{c}\text { Frequency of } \\
\text { Occurrence: } \\
\text { Incidents } \\
\text { Initiated by } \\
\text { Sleeper Berth } \\
\text { Driver } \\
\left.\mathbf{( N}_{\mathbf{S B}}=\mathbf{2 1}\right)\end{array}$ & $\begin{array}{c}\text { Frequency of } \\
\text { Occurrence: } \\
\text { Incidents } \\
\text { Initiated by } \\
\text { Light Vehicle } \\
\text { Driver } \\
\mathbf{( N}_{\mathbf{L V}}=\mathbf{4 7 )}\end{array}$ & $\begin{array}{c}\text { Frequency of } \\
\text { Occurrence: } \\
\text { Incidents } \\
\text { Initiated by } \\
\text { All Drivers } \\
\left.\mathbf{( N}_{\text {Total }}=\mathbf{6 8}\right)\end{array}$ & $\begin{array}{c}\text { Percentage of } \\
\text { Occurrence: } \\
\text { Incidents } \\
\text { Initiated by } \\
\text { All Drivers } \\
\left.\mathbf{( N}_{\text {Total }}=\mathbf{6 8}\right)\end{array}$ & $\begin{array}{c}\text { Combined } \\
\text { Rank: } \\
\text { Incidents } \\
\text { Initiated by } \\
\text { All Drivers } \\
\left.\mathbf{( N}_{\text {Total }}=\mathbf{6 8}\right)\end{array}$ \\
\hline Driver Proficiency & 15 & 20 & 35 & $51 \%$ & 1 \\
\hline Willful Behavior & 5 & 19 & 24 & $35 \%$ & 2 \\
\hline Undeterminable & 0 & 4 & 4 & $6 \%$ & 3.5 \\
\hline Infrastructure & 0 & 4 & 4 & $6 \%$ & 3.5 \\
\hline Impairment & 1 & 0 & 1 & $1 \%$ & 5 \\
\hline Total & $\mathbf{2 1}$ & $\mathbf{4 7}$ & $\mathbf{6 8}$ & $\mathbf{1 0 0 \%}$ & \\
\hline
\end{tabular}

Table 25. General Contributing Factors descriptive statistics as a function of Driver Type.

\begin{tabular}{|c|c|c|c|c|c|}
\hline $\begin{array}{c}\text { General } \\
\text { Contributing Factor } \\
\text { Category }\end{array}$ & $\begin{array}{l}\text { Frequency of } \\
\text { Occurrence: } \\
\text { Incidents } \\
\text { Involving a } \mathrm{HV} \\
\text { Single Driver } \\
\left(\mathrm{N}_{\text {Single }}=55\right)\end{array}$ & \begin{tabular}{|} 
Frequency of \\
Occurrence: \\
Incidents \\
Involving a HV \\
Team Driver \\
$\left(\mathrm{N}_{\text {Team }}=13\right)$
\end{tabular} & $\begin{array}{l}\text { Frequency of } \\
\text { Occurrence: } \\
\text { Incidents } \\
\text { Initiated by } \\
\text { All Drivers } \\
\left(\mathbf{N}_{\text {Total }}=68\right)\end{array}$ & $\begin{array}{l}\text { Percentage of } \\
\text { Occurrence: } \\
\text { Incidents } \\
\text { Initiated by } \\
\text { All Drivers } \\
\left(\mathbf{N}_{\text {Total }}=68\right)\end{array}$ & $\begin{array}{c}\text { Combined } \\
\text { Rank: Incidents } \\
\text { Involving } \\
\text { All Drivers } \\
\left(\mathrm{N}_{\text {Total }}=68\right)\end{array}$ \\
\hline Driver Proficiency & 30 & 5 & 35 & $51 \%$ & 1 \\
\hline Willful Behavior & 17 & 7 & 24 & $35 \%$ & 2 \\
\hline Undeterminable & 3 & 1 & 4 & $6 \%$ & 3.5 \\
\hline Infrastructure & 4 & 0 & 4 & $6 \%$ & 3.5 \\
\hline Impairment & 1 & 0 & 1 & $1 \%$ & 5 \\
\hline TOTAL & 55 & 13 & 68 & $100 \%$ & \\
\hline
\end{tabular}




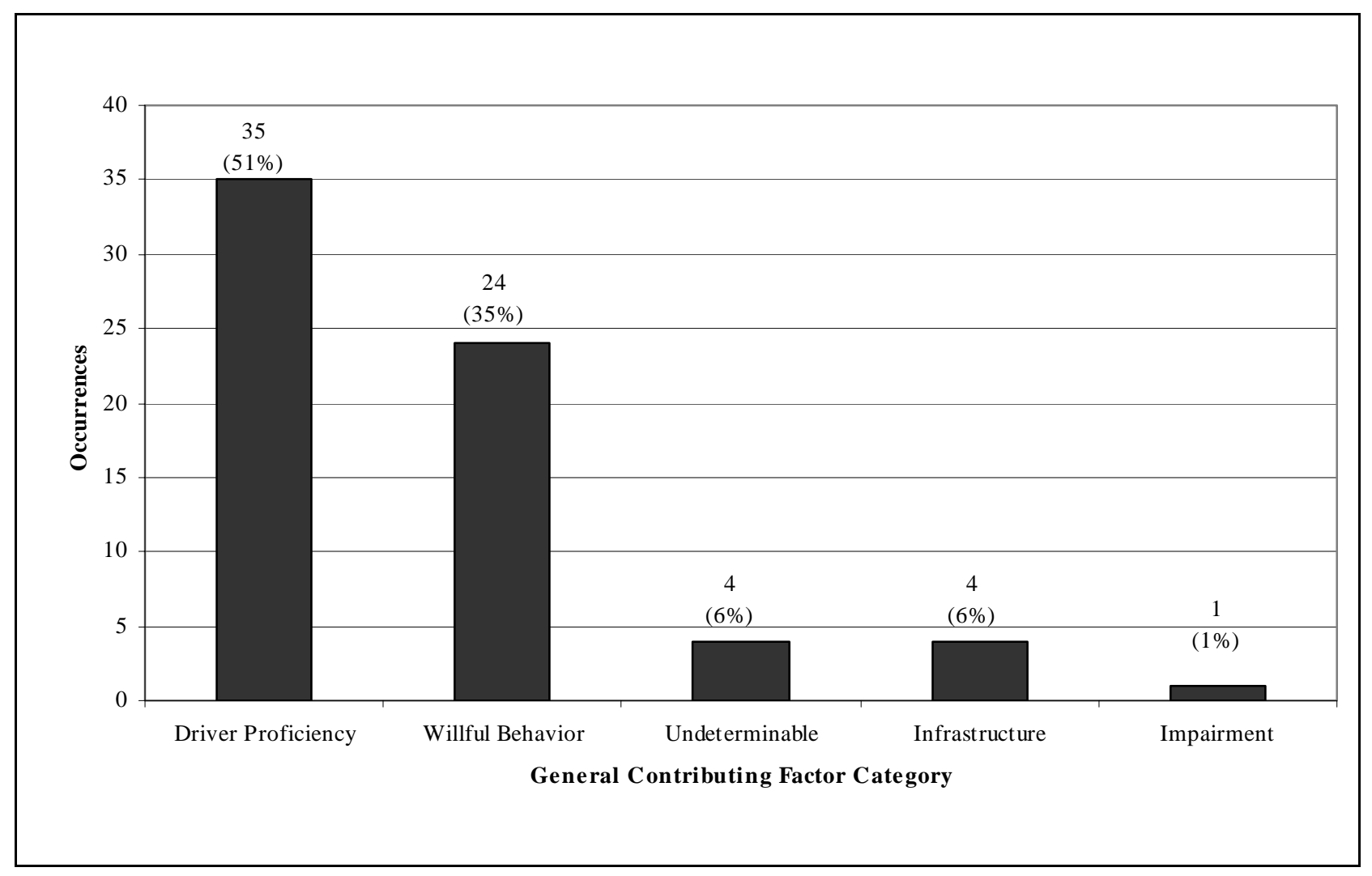

Figure 45. Frequency of General Contributing Factors for all incidents. 
Figure 46 shows the frequency of General Contributing Factors for the 68 incidents as a function of the Initiating Driver. For incidents initiated by a SB driver, the primary factor was Driver Proficiency. For incidents initiated by an LV driver, the primary factors were Driver Proficiency and Willful Behavior. The General Contributing Factor data were also categorized for each driver type. Figure 47 shows the General Contributing Factor frequency data for the LV driver initiated incidents and indicates that both Driver Proficiency (43 percent) and Willful Behavior (40 percent) were the most frequently indicated factors. Figure 48 presents the frequency of General Contributing Factors for the SB driver initiated incidents. As shown, Driver Proficiency was a factor in 71 percent of the incidents that were initiated by the SB driver. Willful Behavior was the second most frequent factor and occurred in 24 percent of the incidents.

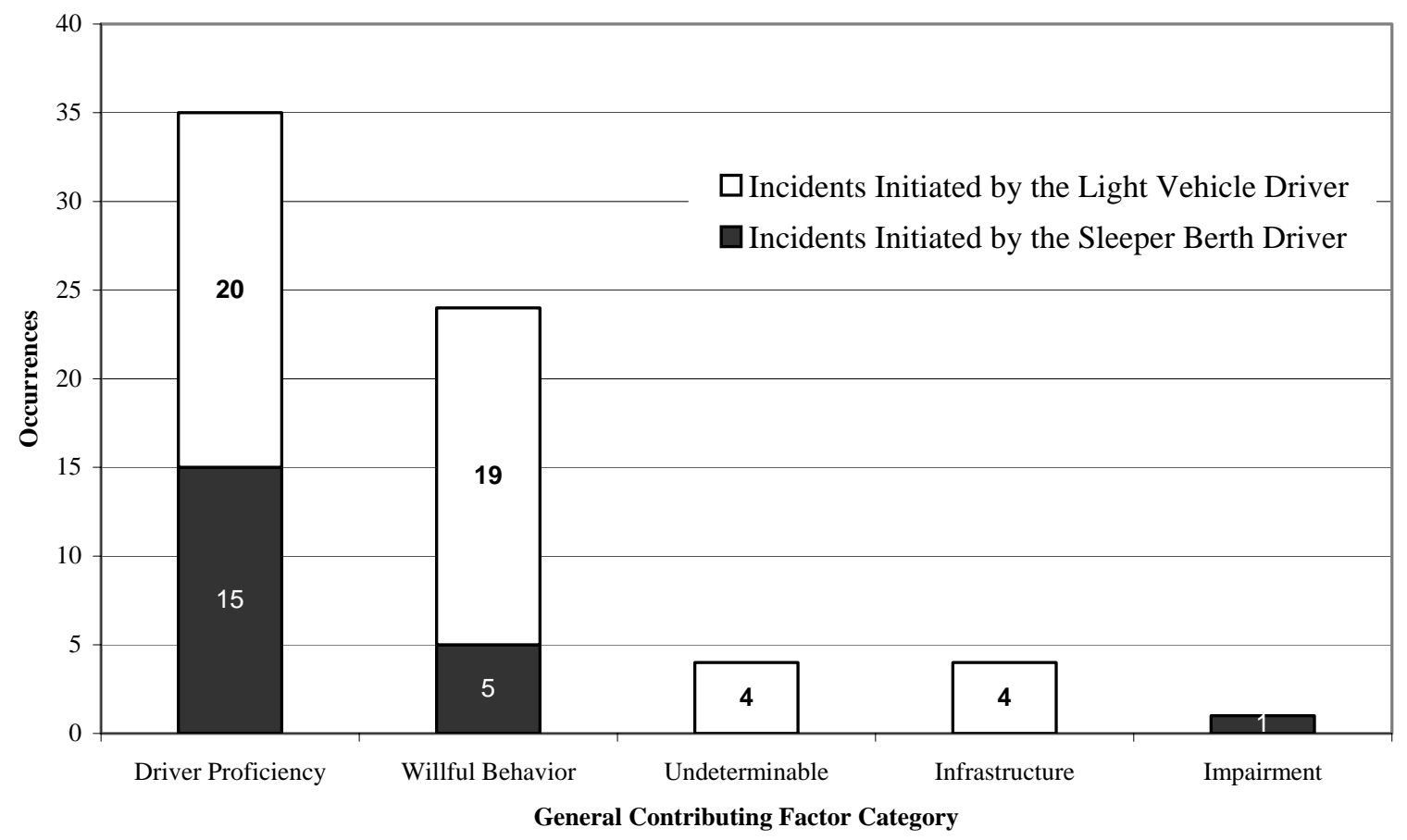

Figure 46. Frequency of General Contributing Factor as a function of Initiating Driver. 


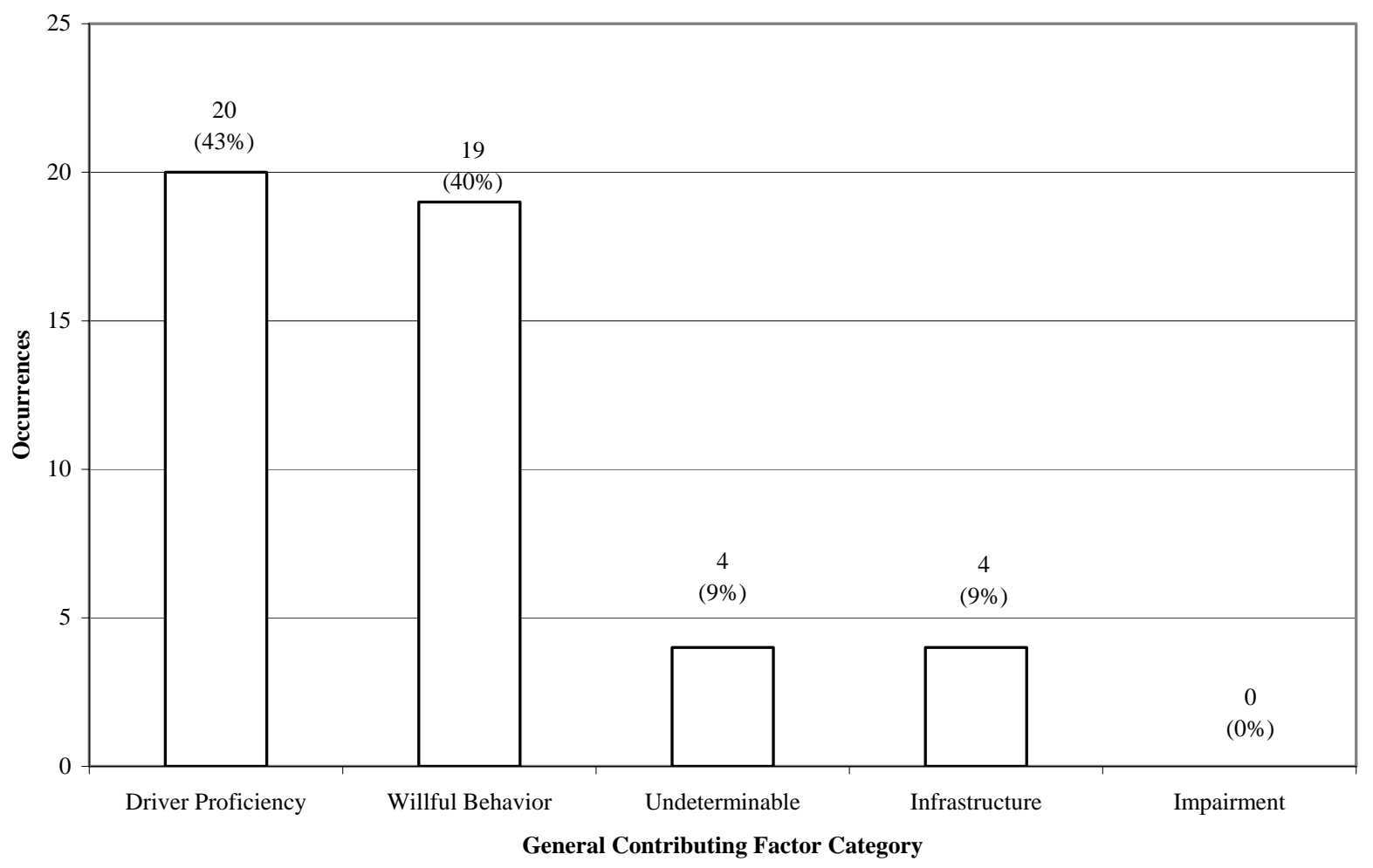

Figure 47. Frequency of General Contributing Factor for the light vehicle driver initiated incidents. 


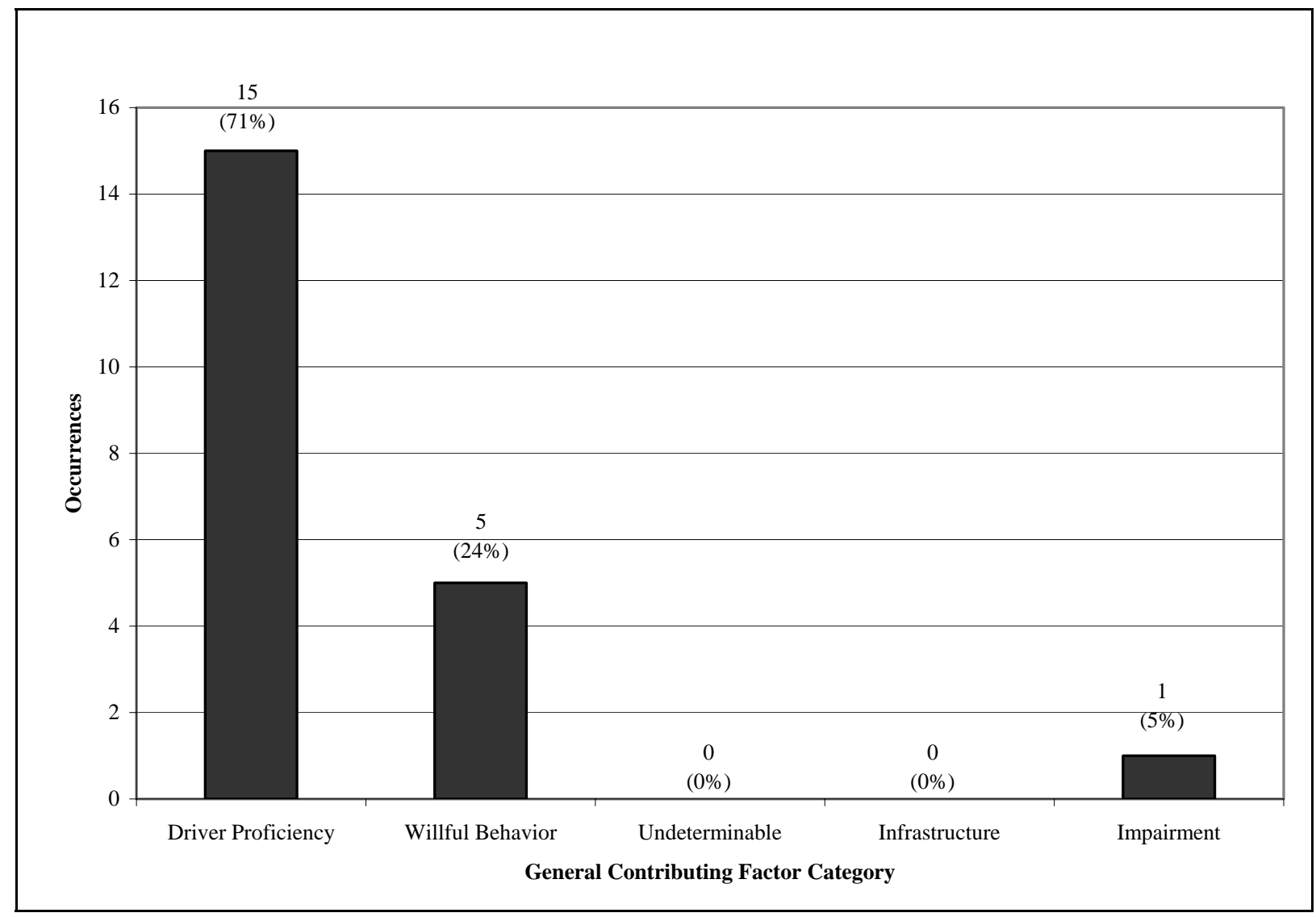

Figure 48. Frequency of General Contributing Factor for the sleeper berth driver initiated incidents. 
A histogram of the General Contributing Factors as a function of the HV Driver Type is shown in Figure 49. For team drivers, the two most prominent factors were Willful Behavior ( $\mathrm{n}=7$ ) and Driver Proficiency $(n=5)$. For single drivers, these same two factors were again found to be most prominent; Driver Proficiency $(n=30)$ and Willful Behavior $(n=17)$, but in reverse order.

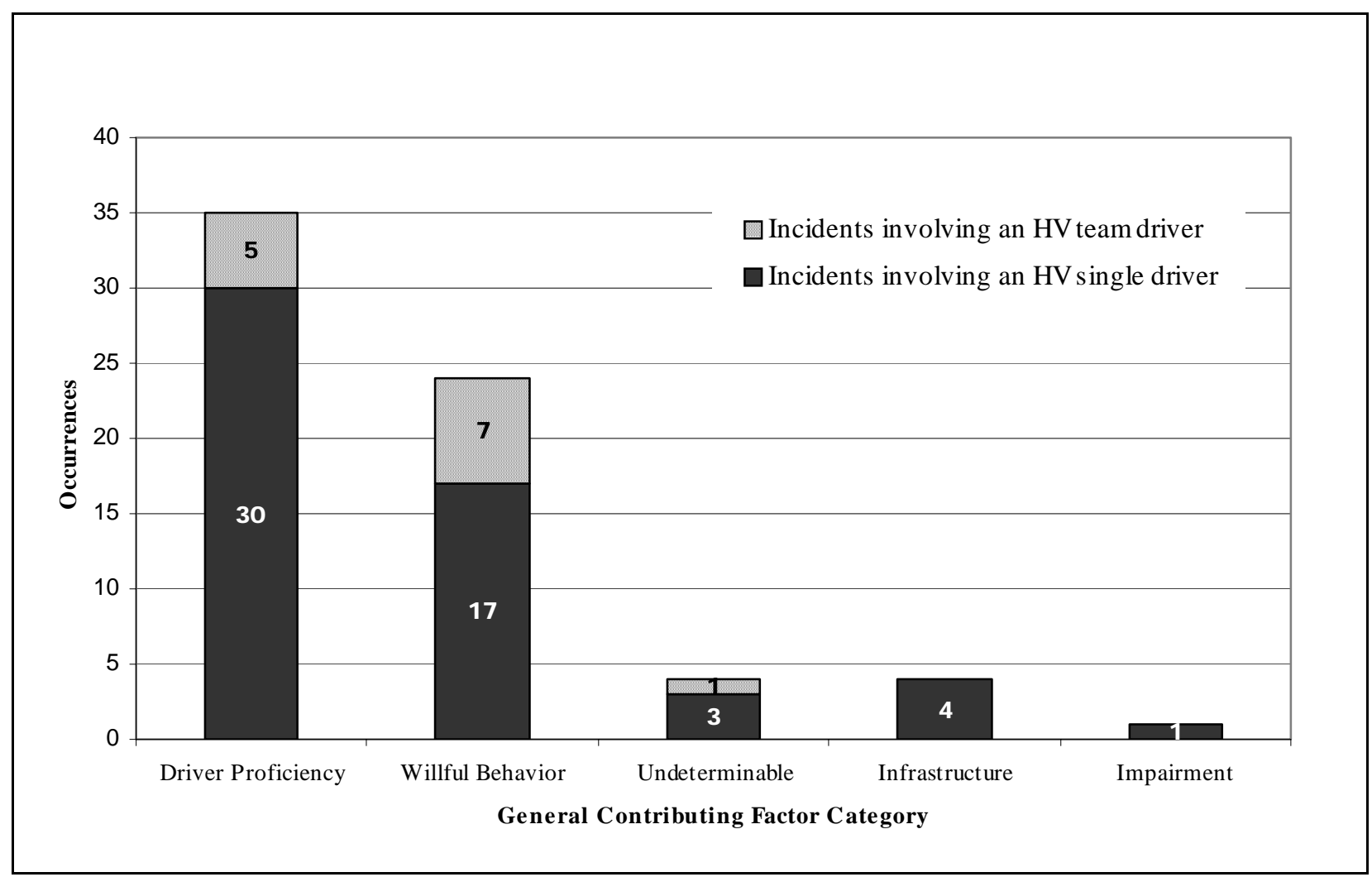

Figure 49. Frequency of General Contributing Factors as a function of Driver Type. 
Figure 50 outlines the General Contributing Factors for $\mathrm{HV}$ team and $\mathrm{HV}$ single drivers for the LV driver-initiated incidents. As shown in the previous figure, Driver Proficiency and Willful Behavior occurred most frequently for team and single drivers. In considering incidents initiated by SB drivers, Figure 51 indicates that HV single drivers were primarily involved, and Driver Proficiency was the most frequent factor.

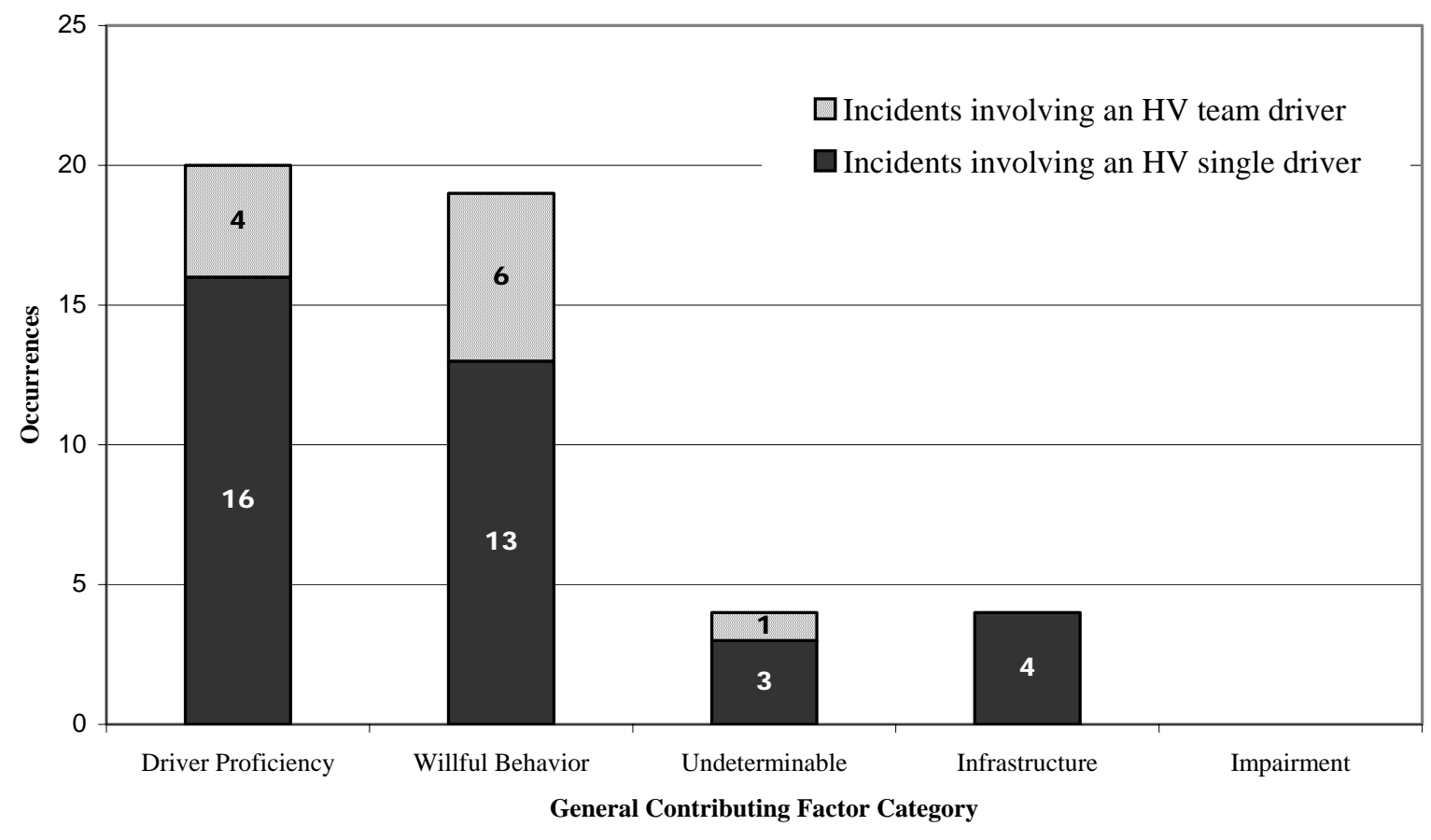

Figure 50. Frequency of General Contributing Factors involving team and single drivers for incidents initiated by a light vehicle driver. 


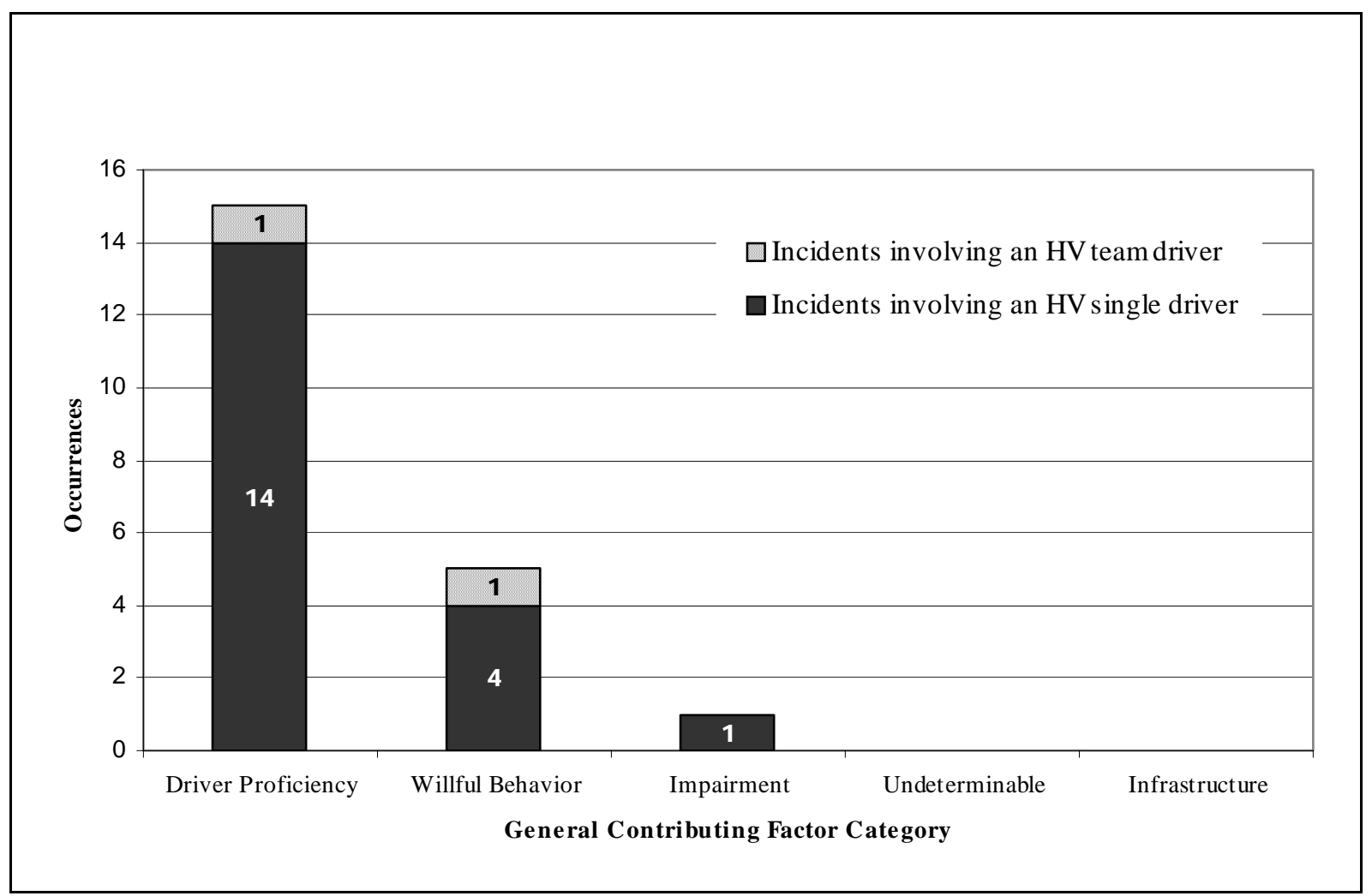

Figure 51. Frequency of General Contributing Factors involving team and single drivers for incidents initiated by a sleeper berth driver.

As indicated previously, the General Contributing Factors categories used in the present research were the same as those outlined in Wierwille et al. (2000). In the Wierwille et al. research, video cameras were mounted in stationary positions to capture incidents at various roadway sites (primarily intersections). The captured incidents were analyzed in a manner similar to the analysis conducted for the present effort. One of the analyses conducted by Wierwille et al. included an assessment of the General (or Principal) Contributing Factors for "serious" incidents (very close calls). Fifty-two serious incidents were captured and analyzed. Of these, 30 (57.7 percent) were attributed to Willful Behavior; 12 (23.1 percent) to Driver Proficiency; and 10 (19.2 percent) to Infrastructure. Figure 52 compares the General Contributing Factors data from Wierwille et al. to the data for the current effort. Note that to make a meaningful comparison with the Wierwille et al. data, the Undeterminable category used in the current effort was not included. As can be seen, the data from the two research efforts are similar. Figure 53 shows a comparison of the two studies when only the LV driver-initiated incidents from the current effort are included (incidents that were typical in the Wierwille et al. data). 


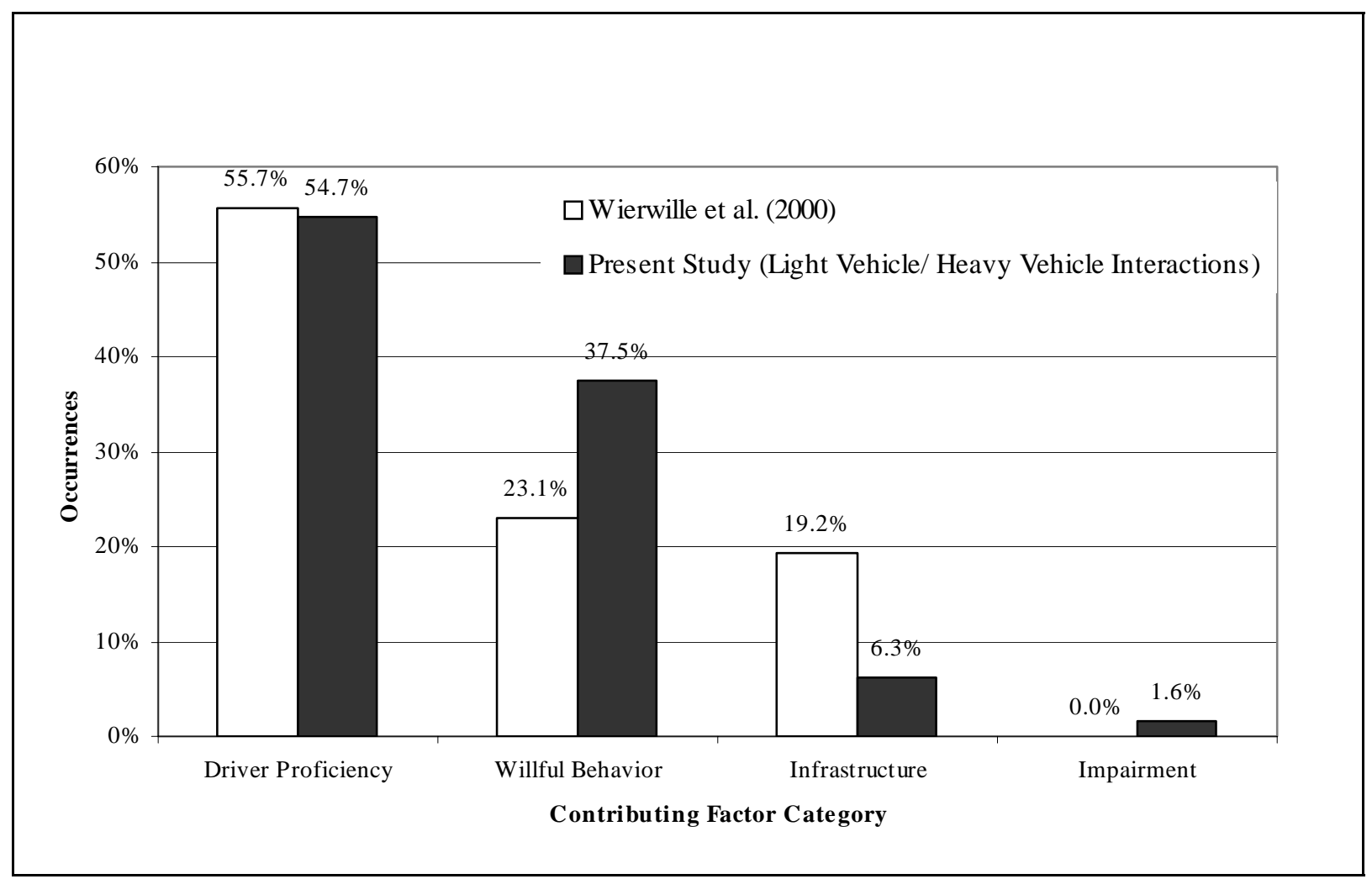

Figure 52. Comparison of General Contributing Factors Wierwille et al. (2000) and all determinable data from the current research. 


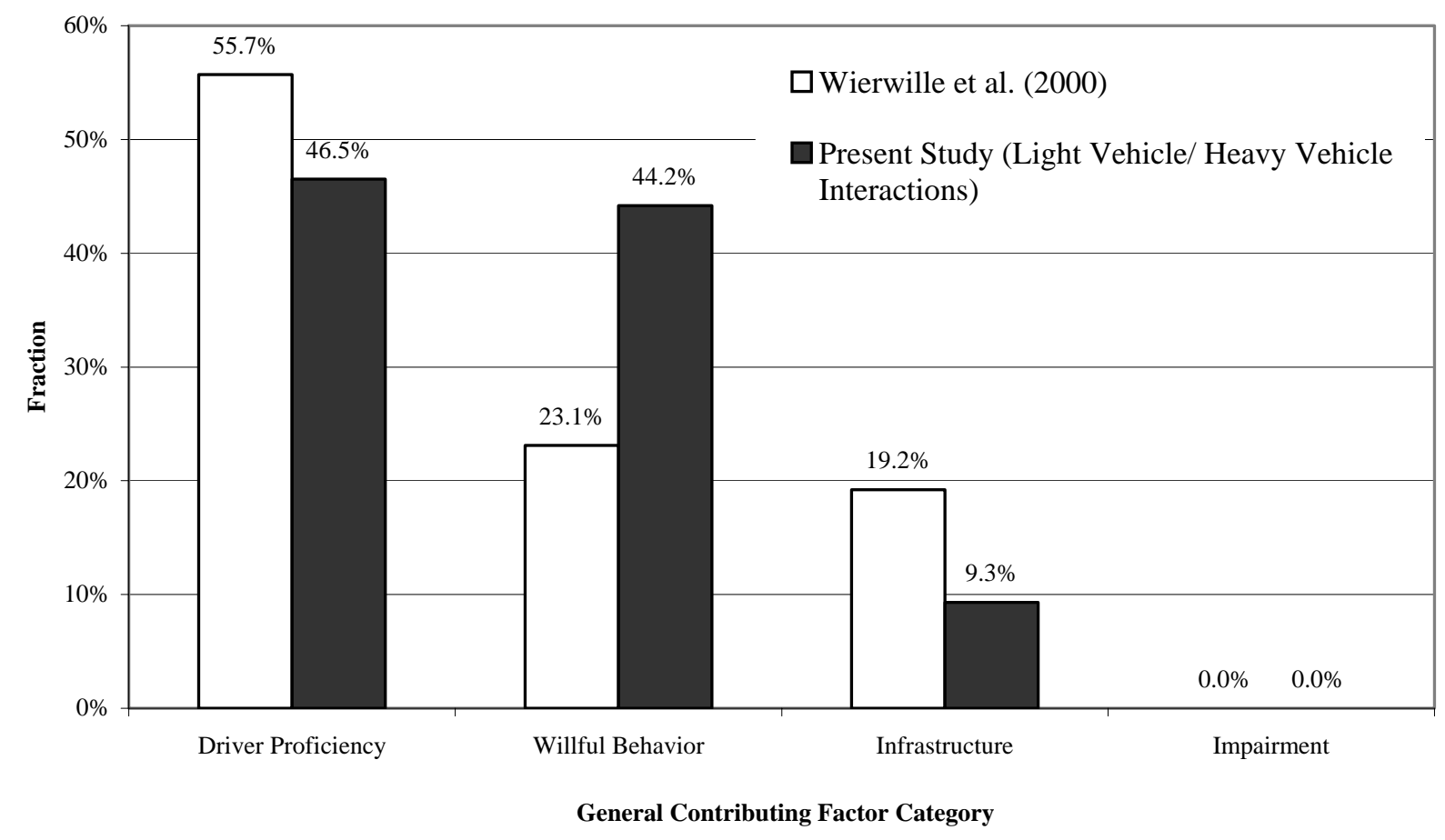

Figure 53. Comparison of General Contributing Factors Wierwille et al. (2000) and the determinable data from the light vehicle driver-initiated incidents captured in the current research.

\section{Specific Contributing Factors}

After a General Contributing Factor was identified for each incident, a more detailed assessment was made to determine the Specific Contributing Factors associated with the incident. Please refer back to Table 14 for the Specific Contributing Factors. Each General Contributing Factor is subdivided into several Specific Contributing Factors, which is similar to categorizations in Wierwille et al. (2000). In the same way as a single General Contributing Factor was assessed for each incident, the single most relevant Specific Contributing Factor was also determined for each incident. As can be seen by reading the definitions of the Specific Contributing Factors in Table 14, these factors help to provide a clear indication as to why the incident occurred.

It should be noted that other research efforts that have investigated LV-HV interactions have used similar, but not identical, factor categories. For example, Schafer (1999) reported the results of a study performed by Anacapa Sciences that looked at the "unsafe driving acts" of LV drivers. Considering the Anacapa study results in the context of the current effort, many of the unsafe driving acts that were identified in the Anacapa study, such as "Following Too Closely," "Unsafe Speed," and "Changing Lanes Abruptly in Front of a Truck," could be considered in the present categorization scheme as sub-categories of Aggressive Driving (Willful Behavior), 
Driving Techniques (Driver Proficiency), or one of the other Specific Contributing Factors listed in Table 14.

The frequency of occurrence data for the Specific Contributing Factors across all 68 incidents is shown in Tables 26 and 27. Table 26 shows the factors as a function of the Initiating Driver, while Table 27 shows the factors for the HV single and HV team drivers. A histogram of the combined data is presented in Figure 54. As can be seen across all incidents, Driving Techniques and Aggressive Driving are the Specific Contributing Factors that occur most frequently. 


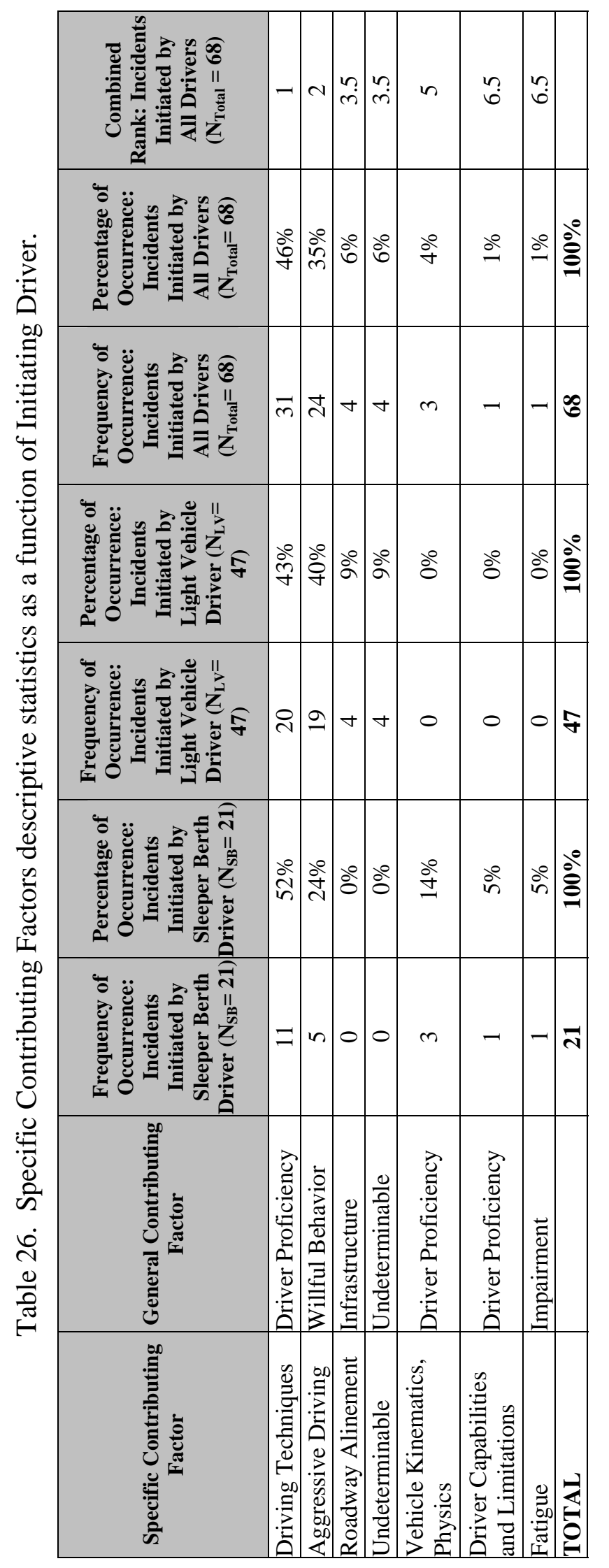




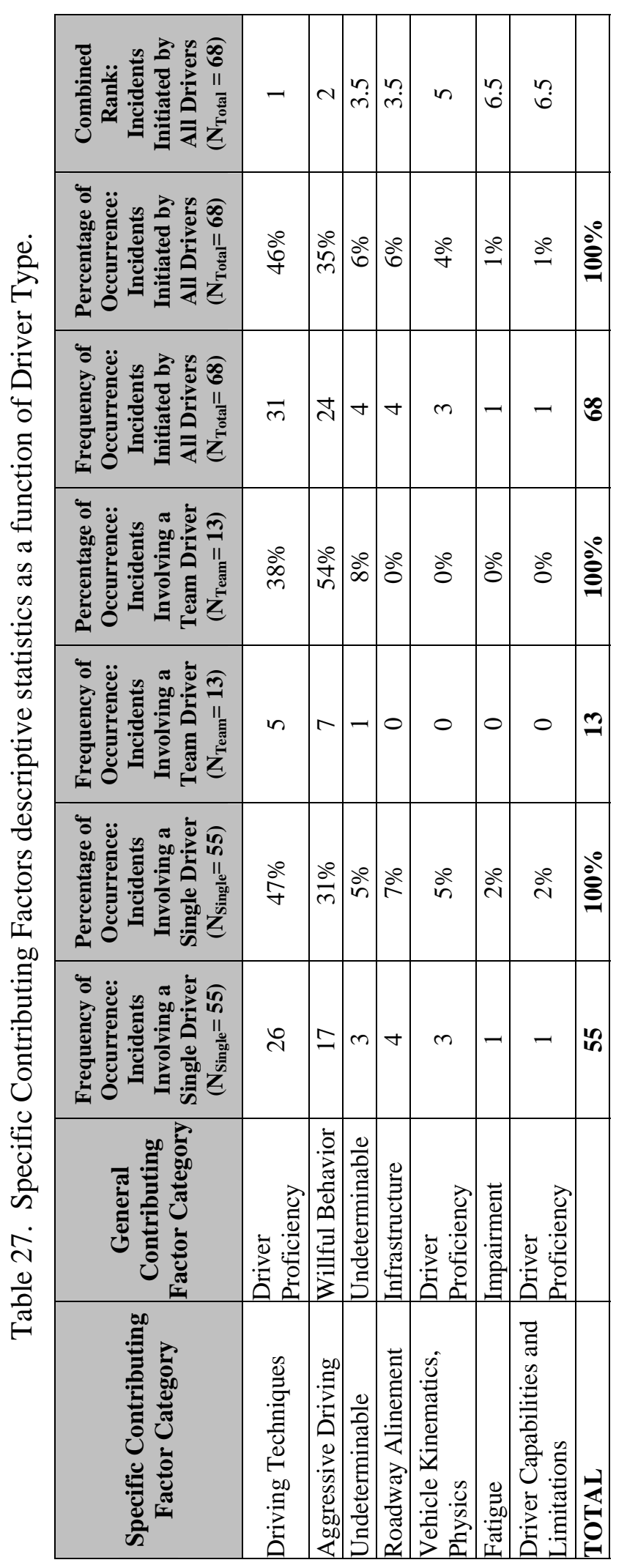




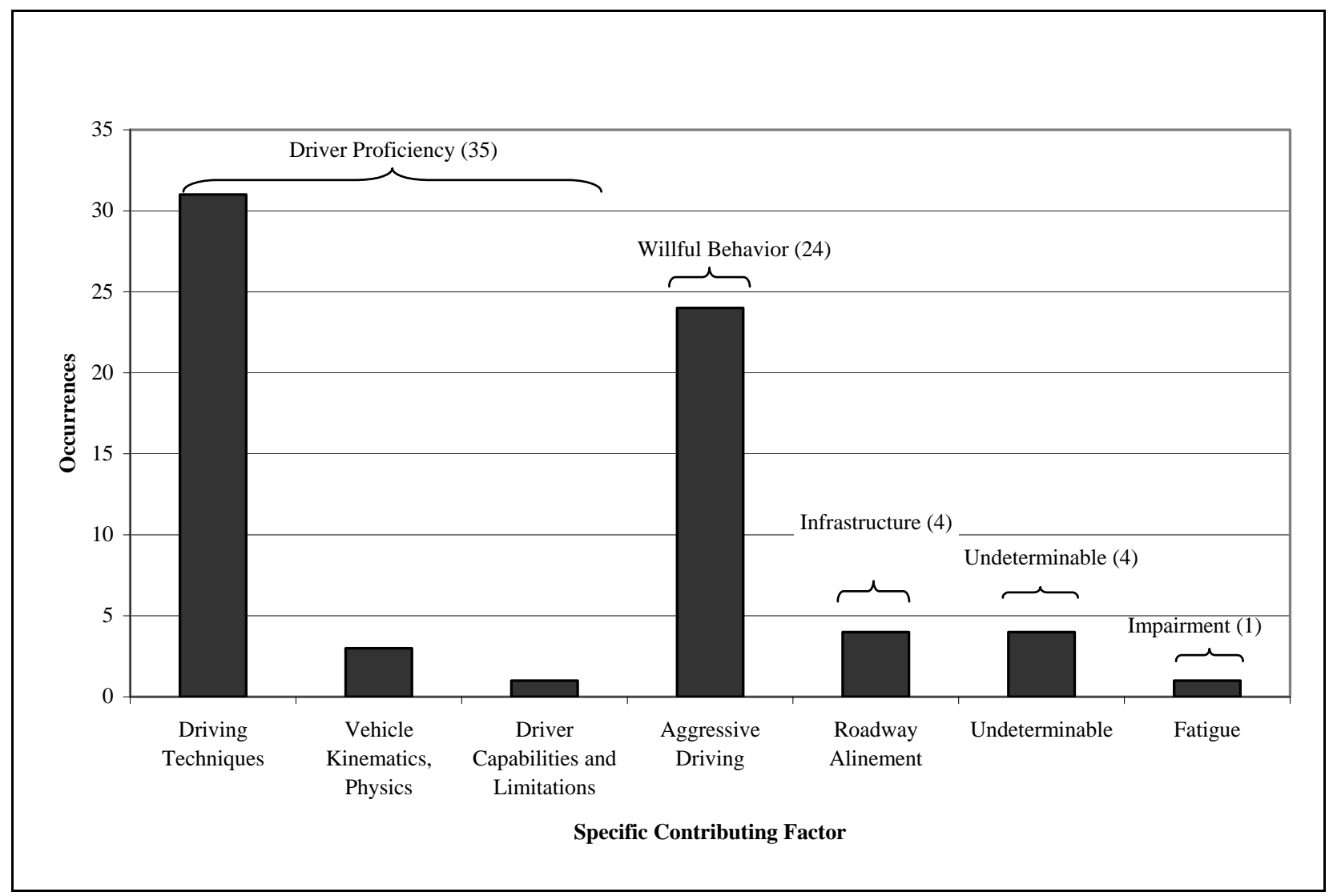

Figure 54. Frequency of Specific Contributing Factors for all incidents. 
A histogram outlining the frequency of Specific Contributing Factors for the 68 incidents, as a function of the Initiating Driver, is shown in Figure 55. Figure 56 shows the data for the LV driver initiated incidents, while Figure 57 shows the data for the SB driver initiated incidents. As can be seen from these figures, Driving Techniques and Aggressive Driving were the two most frequent factors for both groups of drivers. For LV driver initiated incidents, Driving Techniques (43 percent) and Aggressive Driving (40 percent) were the highest frequency factors. Driving Techniques was indicated as the Specific Contributing Factor in 52 percent of the incidents and Willful Behavior was the second most frequent factor (24 percent) for the SB driver initiated incidents.

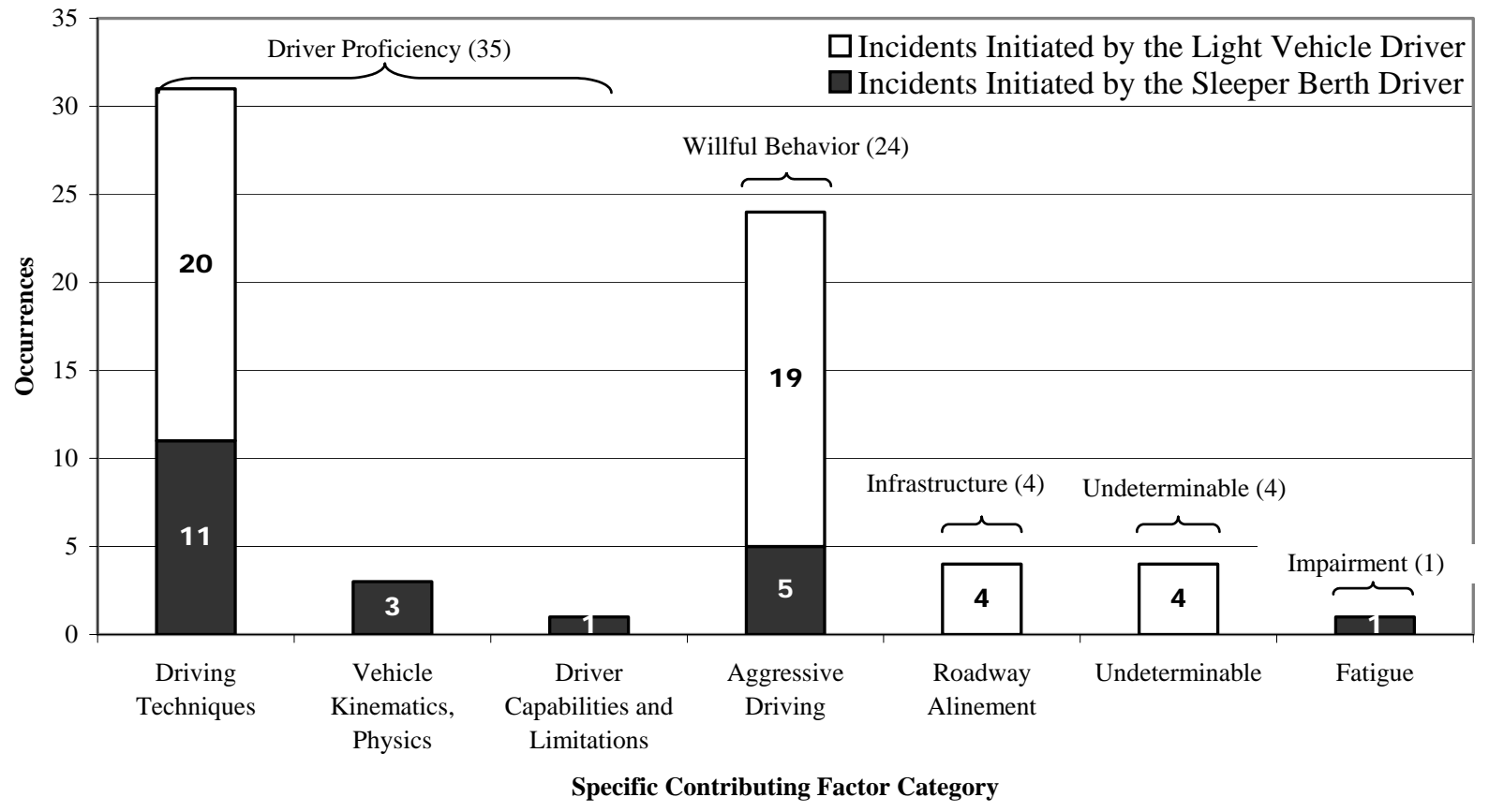

Figure 55. Frequency of Specific Contributing Factors as a function of Initiating Driver. 


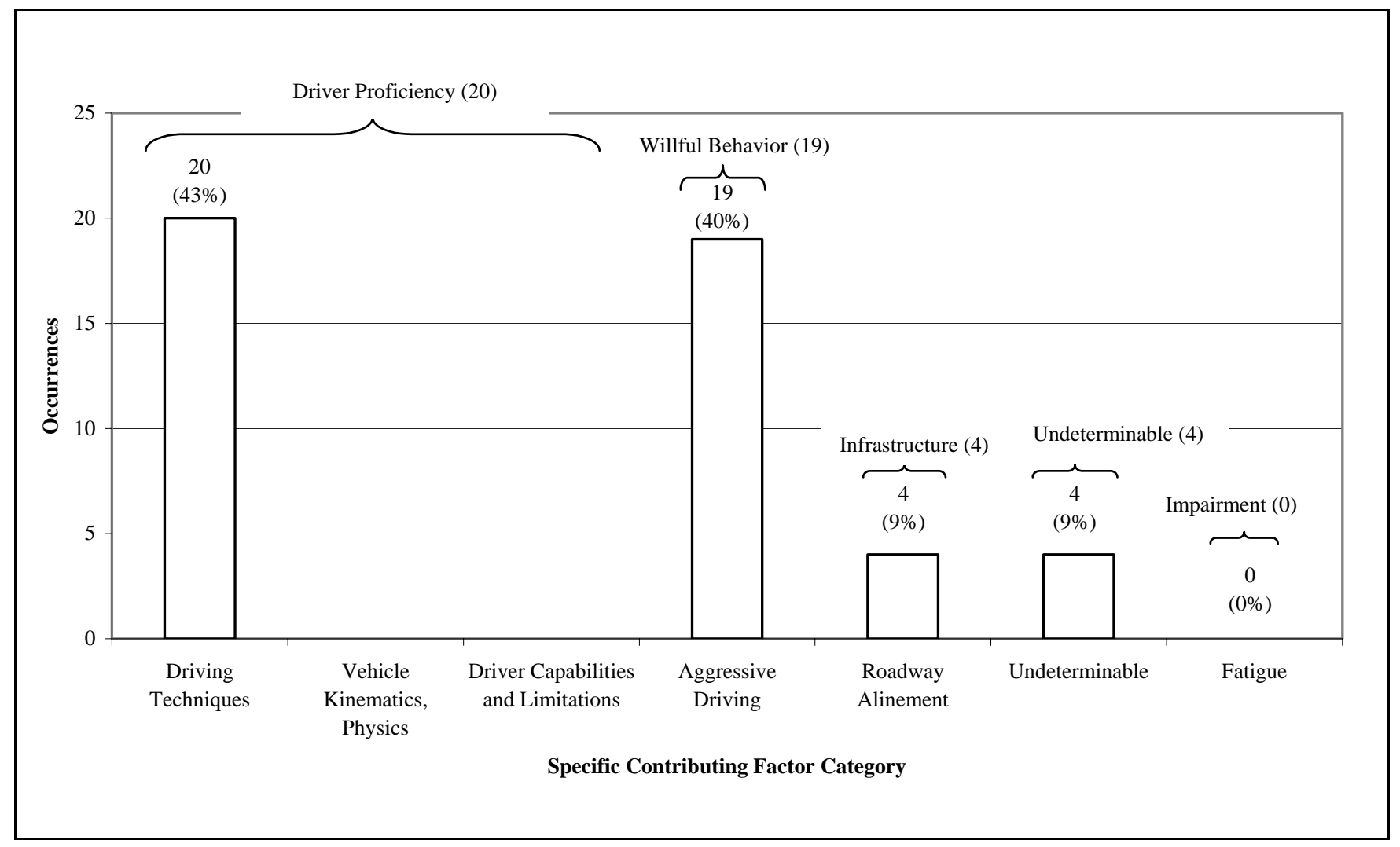

Figure 56. Frequency of Specific Contributing Factors for the light vehicle driver initiated incidents. 


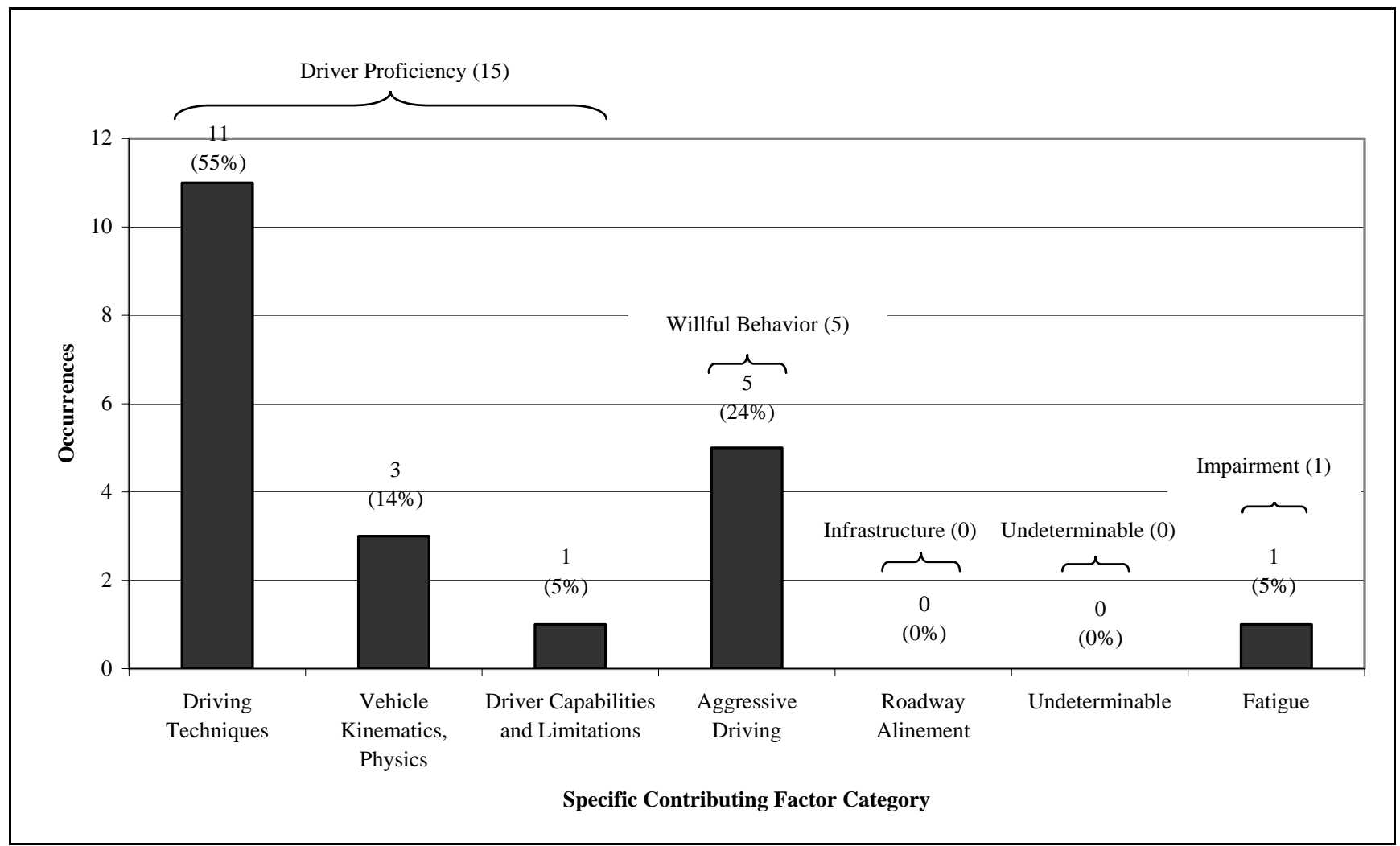

Figure 57. Frequency of Specific Contributing Factors for the sleeper berth driver initiated incidents. 
Figure 58 shows the frequency of Specific Contributing Factors as a function of the HV Driver Type, regardless of fault. The most frequent factors for both driver groups were Driving Techniques and Aggressive Driving. Of the 13 incidents involving team drivers, 7 were attributed to Aggressive Driving and 5 were attributed to Driving Techniques. Of the 55 incidents involving single drivers, 26 were attributed to Driving Techniques and 17 were attributed to Aggressive Driving.

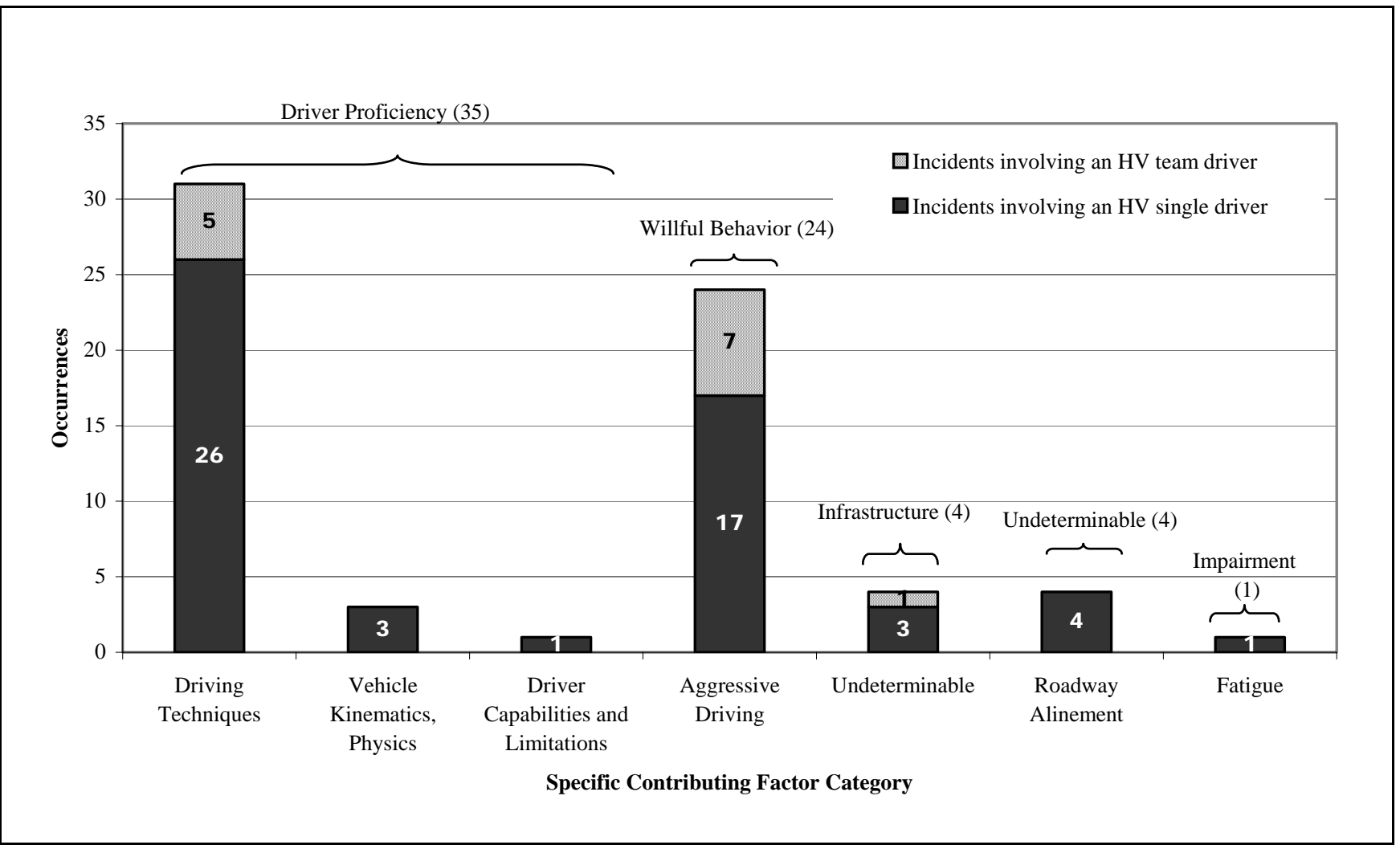

Figure 58. Frequency of Specific Contributing Factors as a function of HV Driver Type. 
Figures 59 and 60 present a break down of the Specific Contributing Factors for HV team and HV single drivers as a function of the Initiating Driver. As indicated in the previous figures, the relatively high frequency of occurrence of Driving Techniques and Aggressive Driving can be seen in both figures.

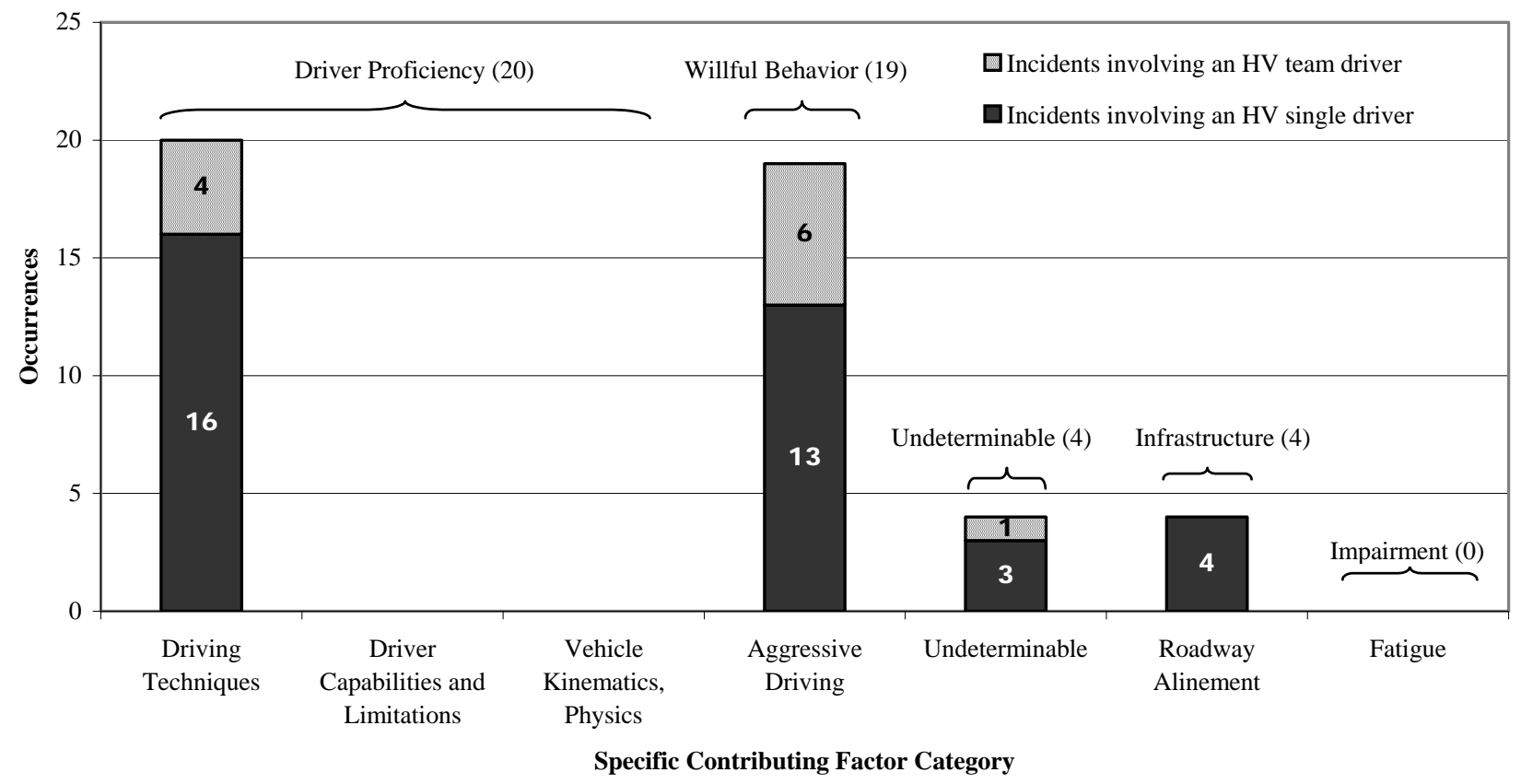

Figure 59. Frequency of Specific Contributing Factors involving HV team and HV single drivers for incidents initiated by a light vehicle driver. 


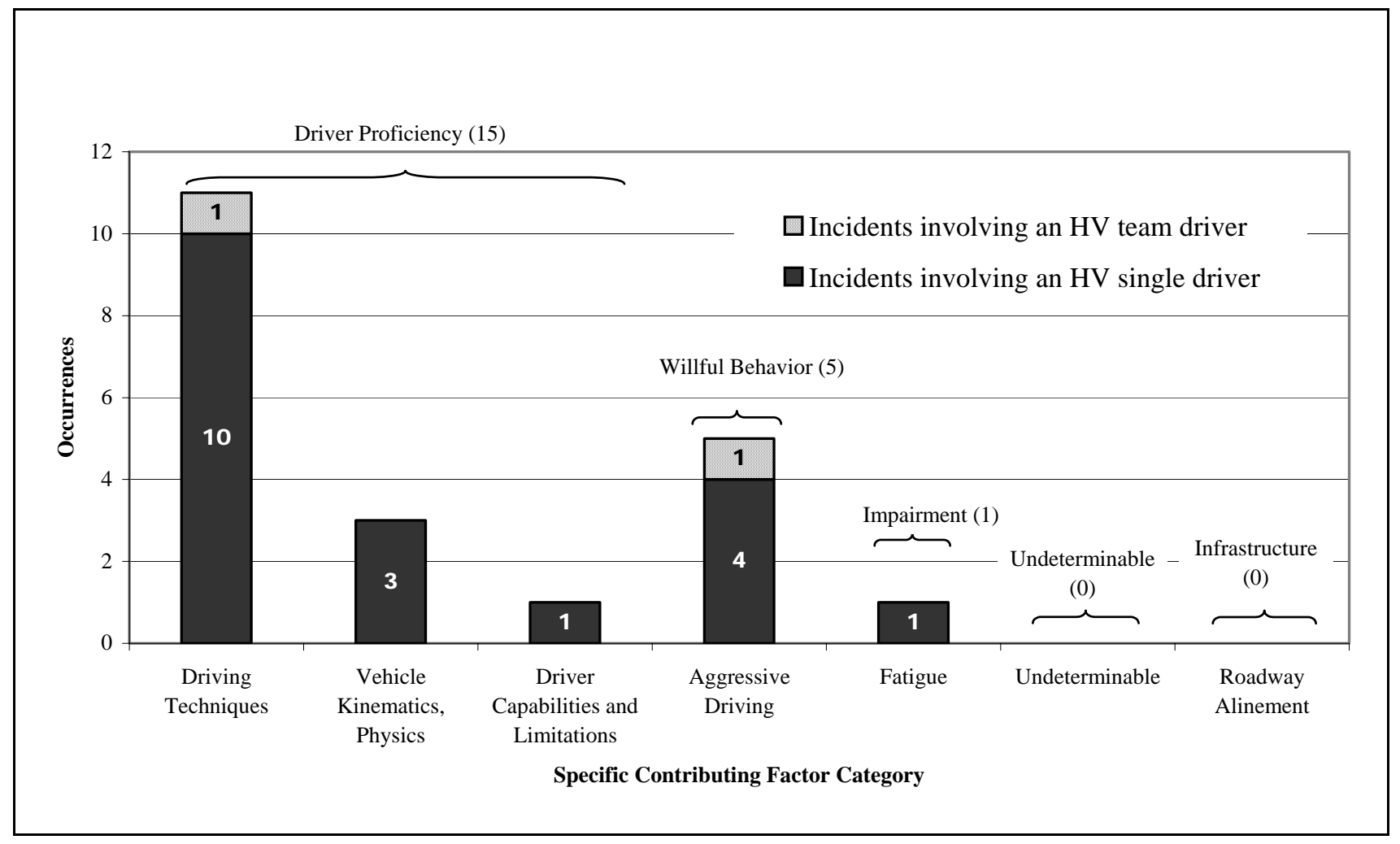

Figure 60. Frequency of Specific Contributing Factors involving HV team and HV single drivers for incidents initiated by a sleeper berth driver. 
Figure 61 provides an outline (tree) taxonomy of the General and Specific Contributing Factors for the 21 incidents initiated by the SB driver, while Figure 62 similarly provides an outline taxonomy of the contributing factors for the 47 incidents initiated by the LV driver. These figures are another way of viewing the data in Figures 55 and 56, but with emphasis on the taxonomic structure.

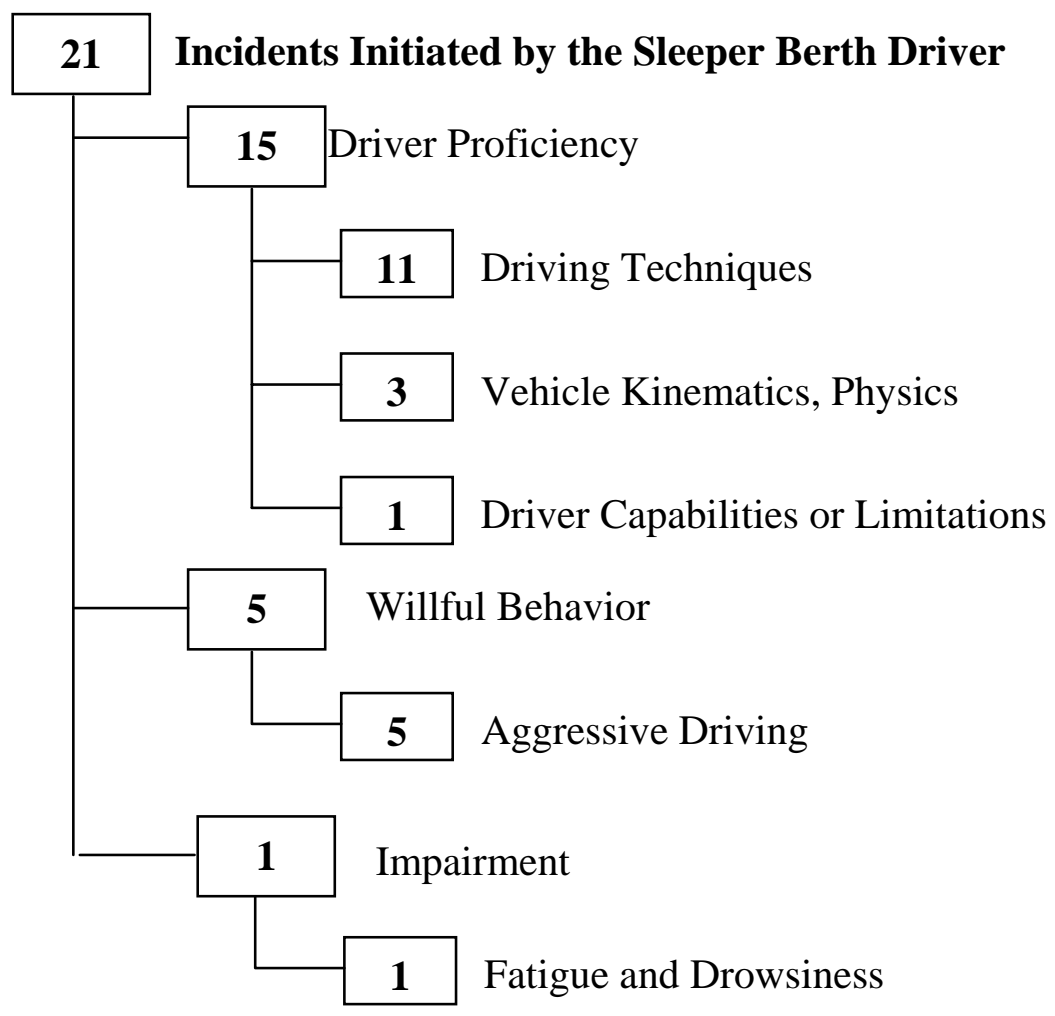

Figure 61. Outline taxonomy of the contributing factors for the incidents initiated by the sleeper berth driver. 


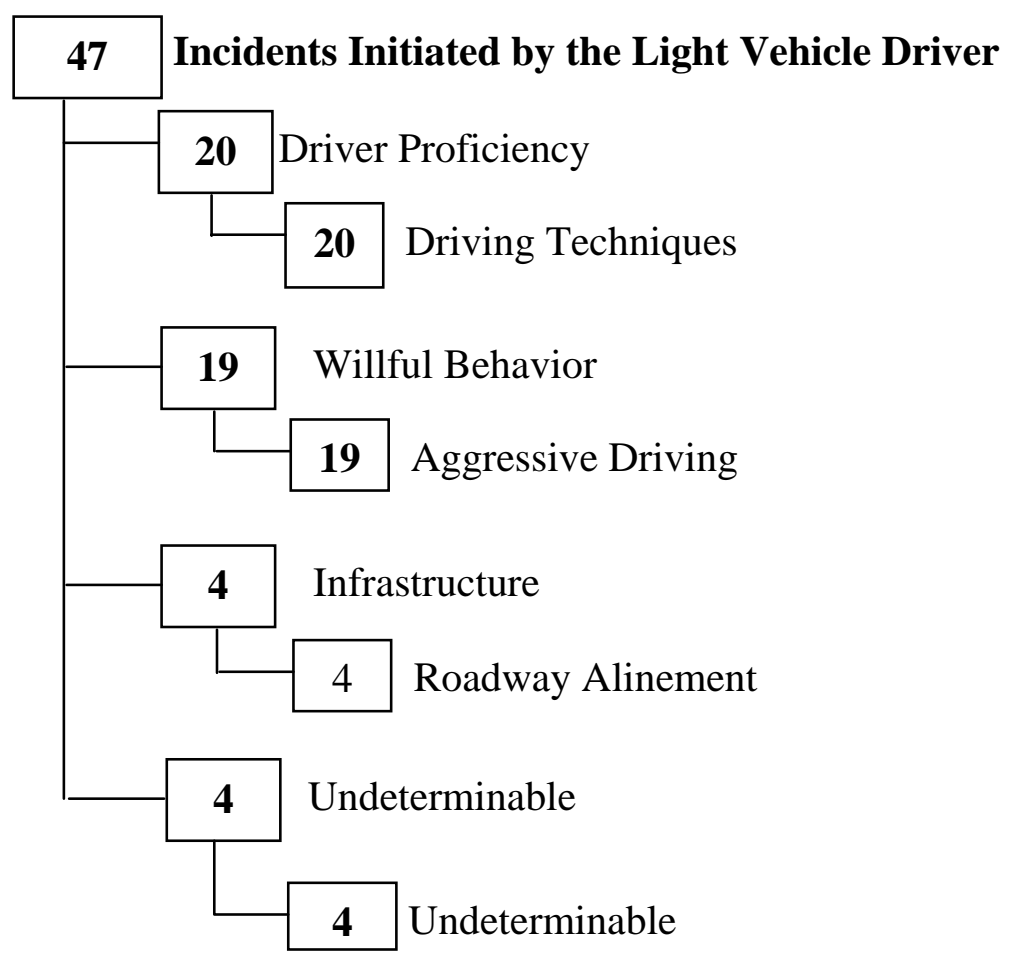

Figure 62. Outline taxonomy of the contributing factors for the incidents initiated by the light vehicle driver.

Hankey et al. (1999) conducted an accident database analysis using crash data from the state of Pennsylvania. One finding from the Pennsylvania database analysis that supports the data from the current effort is in regard to the Specific Contributing Factors associated with the incidents. Note that "incidents" in the current research refer to near-crashes while "incidents" in the Pennsylvania database analysis refer to crashes. It was found for the Pennsylvania database that 77 percent of crashes occurring in 1995 and 1996 had Human Error as a direct cause. To compare the results of the current research to this finding, the Specific Contributing Factors associated with Human Error in Figures 61 and 62 were grouped and tallied. (Summing over the categories of Driver Proficiency and Willful Behavior yields 59 such "error" incidents out of the total of 68.) The result of this was that 87 percent of the LV-HV interactions were determined to have Human Error as a direct cause, a result that is fairly consistent with the Pennsylvania database result.

Hankey et al. (1999) also conducted a database analysis using the 1996 Fatality Analysis Reporting System (FARS). In this analysis, Aggressive Driving was found to be a factor in 31.1 percent of the accidents in the FARS database. It is interesting, although perhaps coincidental, that in the current research, Aggressive Driving accounted for 35.3 percent of all incidents (a similar number to that found by Hankey et al.). Note that in the FARS database analysis, all fatal 
accidents were considered, while in the current study, only critical incidents involving LV and HV were included.

\section{Contributing Factor Taxonomy}

A taxonomy to highlight the characteristics of the incidents was developed. The Incident Types, Contributing Factor Categories, and brief incident descriptions were hierarchically arranged to create two taxonomies: one consisting of events initiated by the SB driver and another consisting of events initiated by the LV driver. At the highest level of the taxonomy, the events are grouped by the driver who initiated the event (i.e. SB driver or LV driver). The second highest level in the taxonomy is the Incident Type, followed by the General Contributing Factor Category, Specific Contributing Factor Category, and finally by the incident description. The incident descriptions outline the basic cause and result of the events. The taxonomy structure is shown in Figure 63.
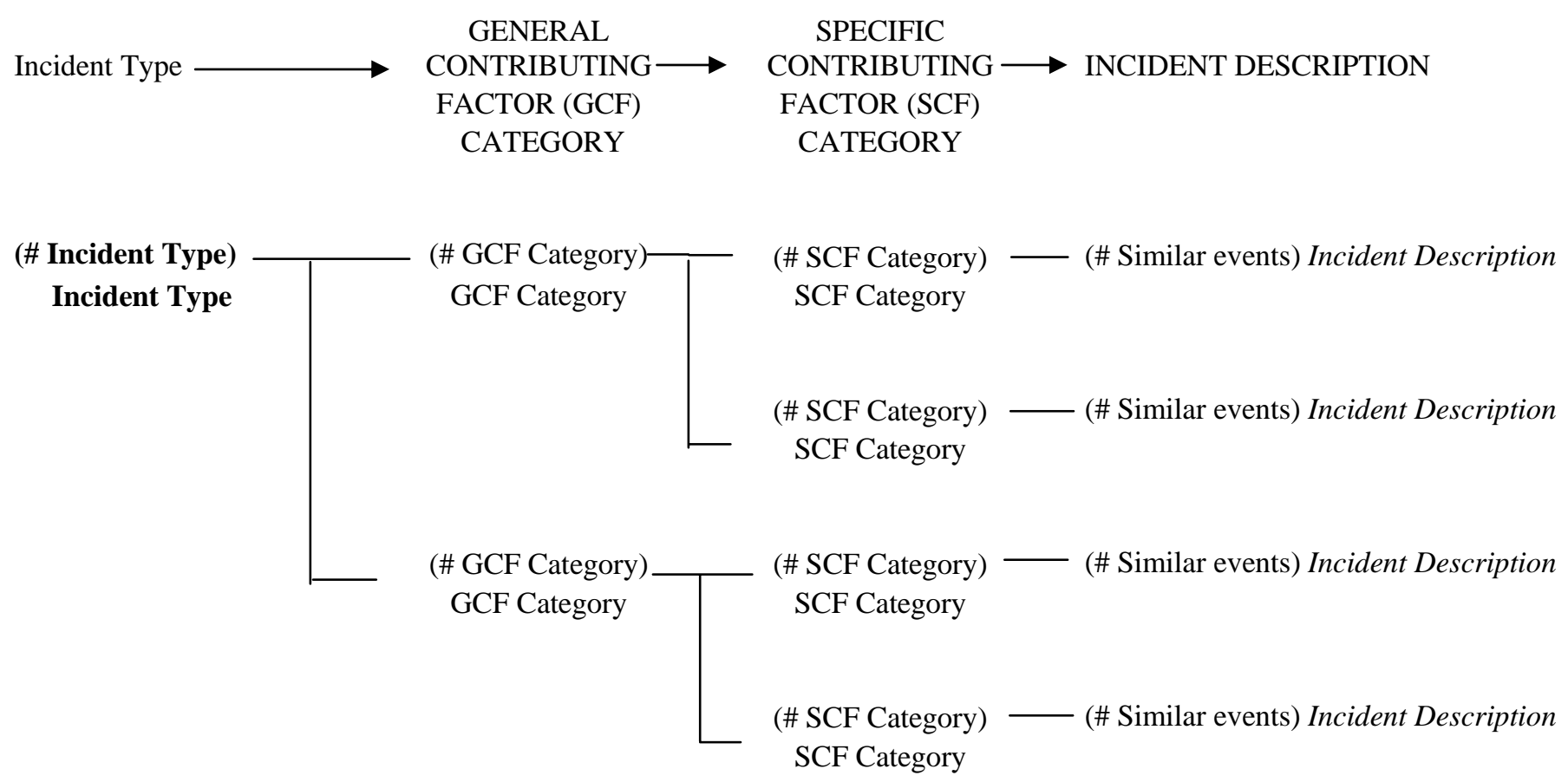

Figure 63. Taxonomy structure used to characterize the 68 interaction incidents.

Sleeper Berth Driver-Initiated Incidents

The taxonomy, which is several pages long, for the incidents initiated by the SB driver is presented in Figure 64. As indicated previously, the taxonomy describes what happened (Incident Type), why it happened (General and Specific Contributing Factors), and details of the incident (Incident Description). 


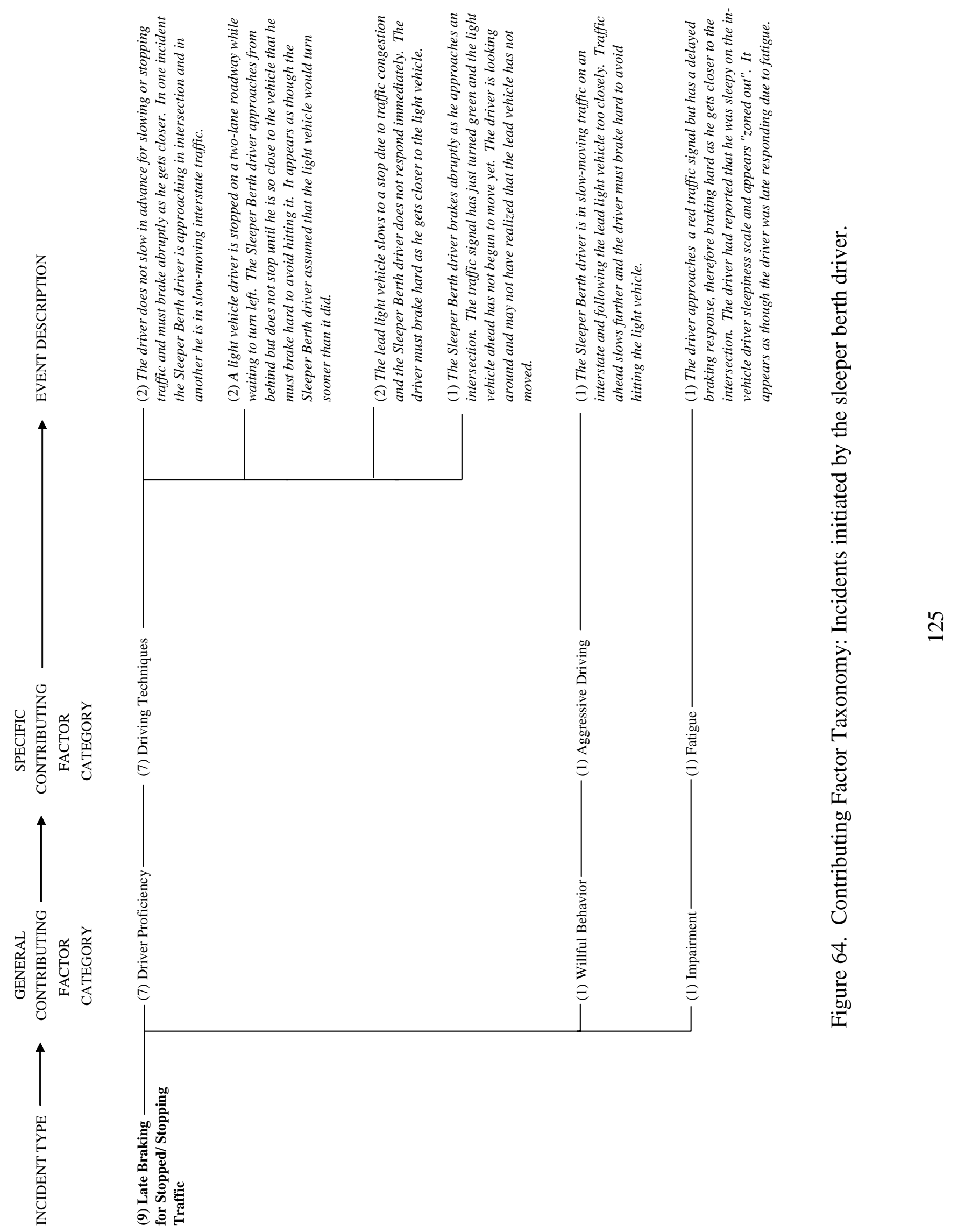




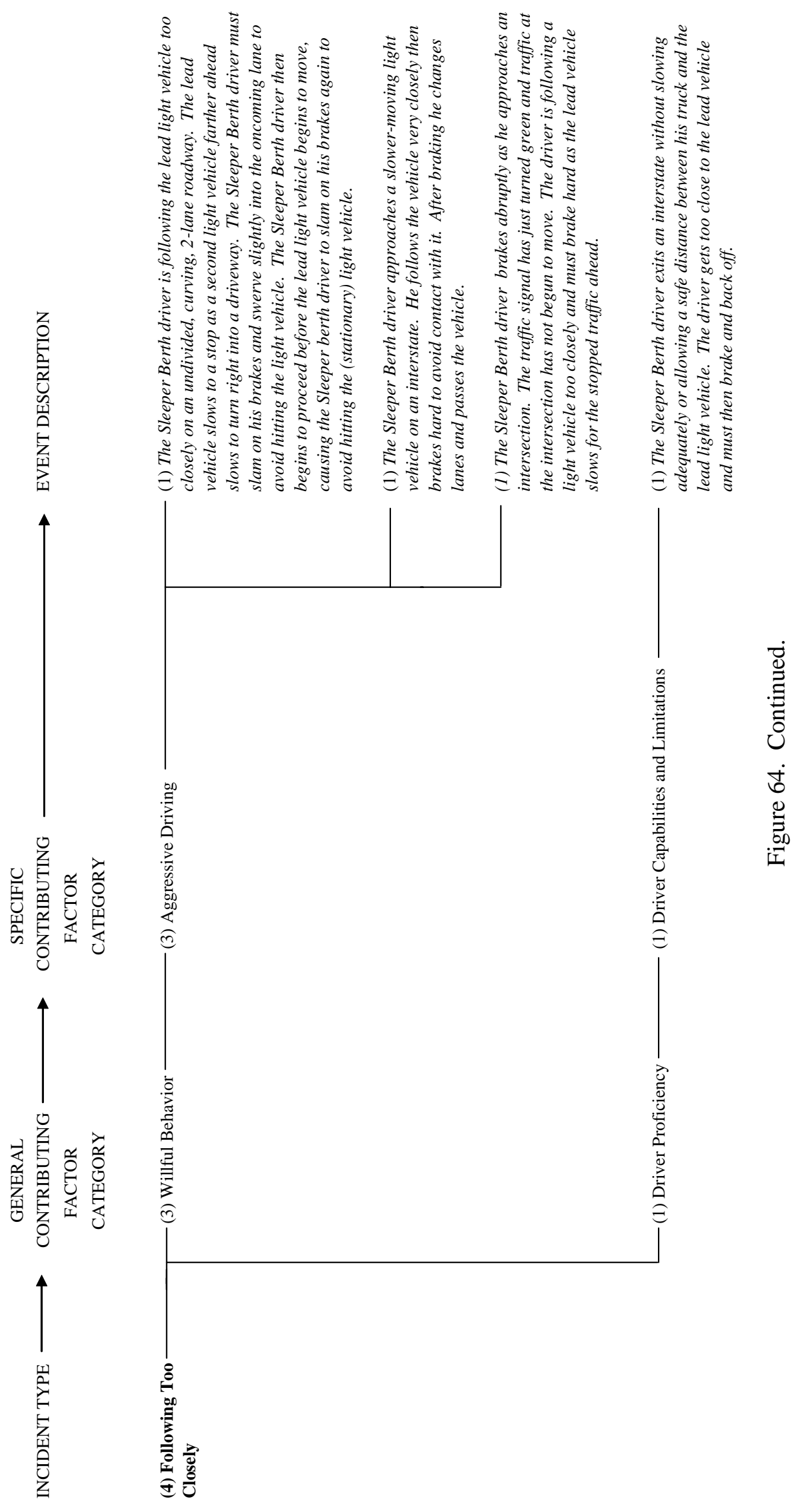




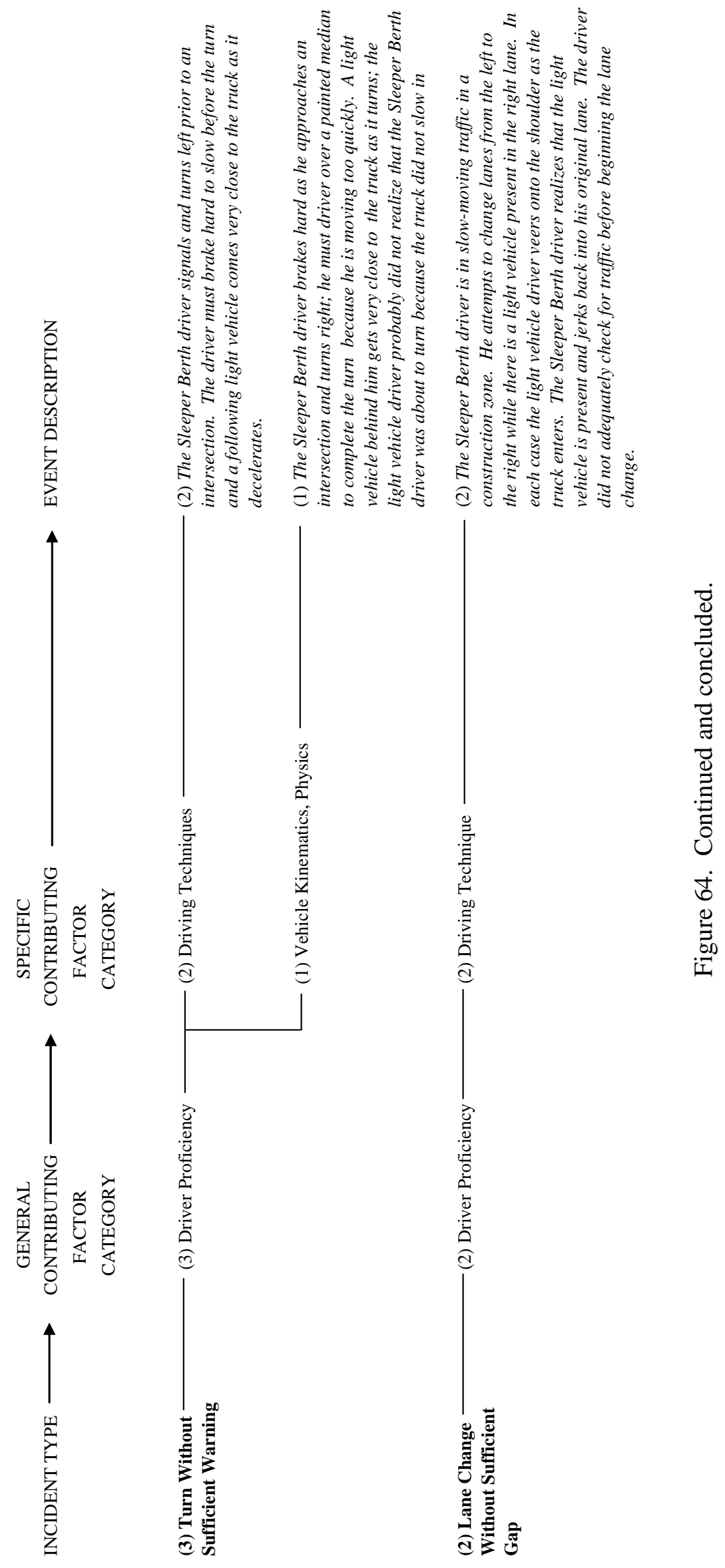




\section{Light Vehicle Driver-Initiated Incidents}

The contributing factor taxonomy for the LV driver-initiated incidents is presented in Figure 65 and continues over the next several pages. The taxonomy is identical in format to the SB driverinitiated incident taxonomy presented in the previous table. 


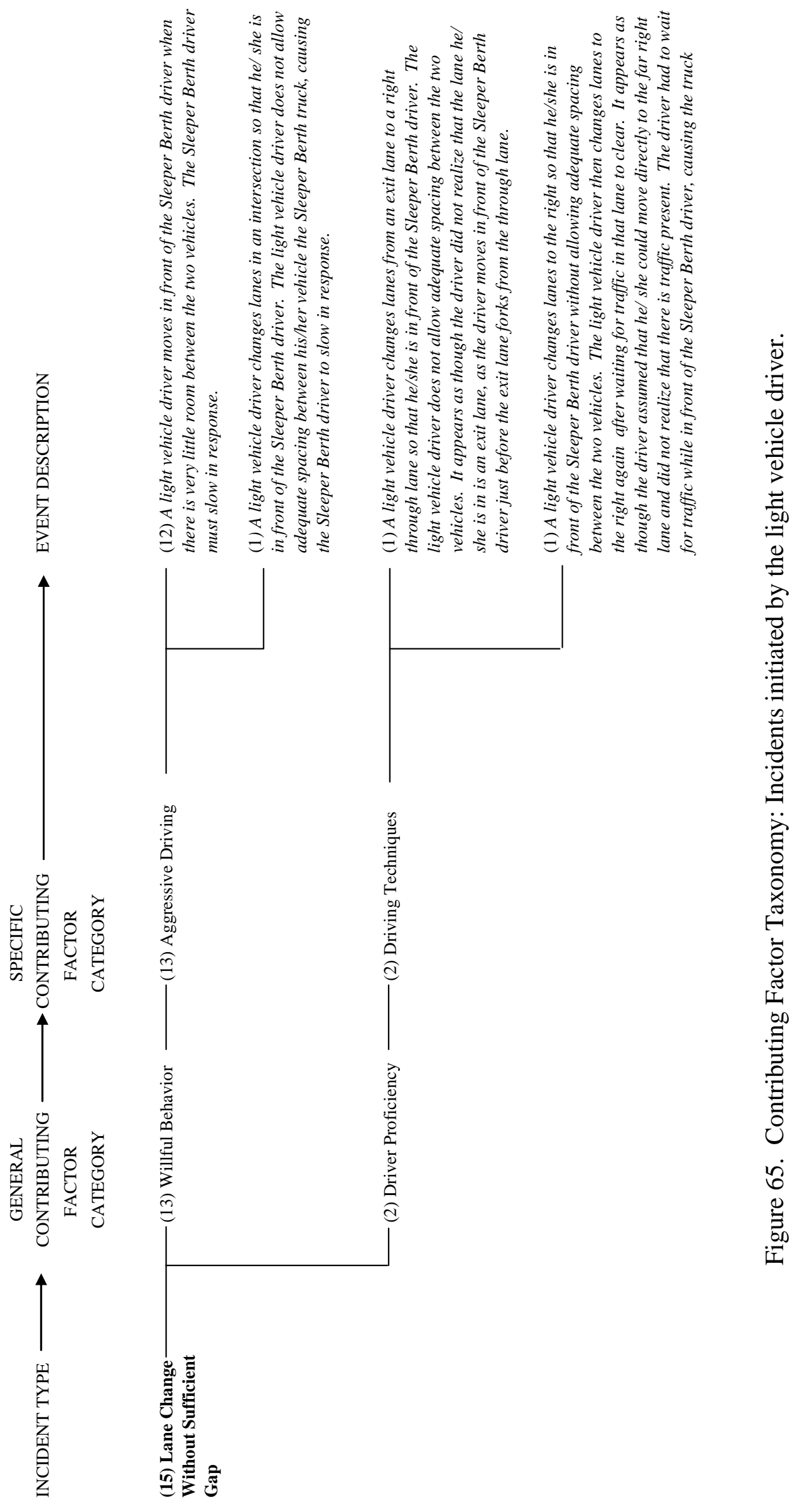




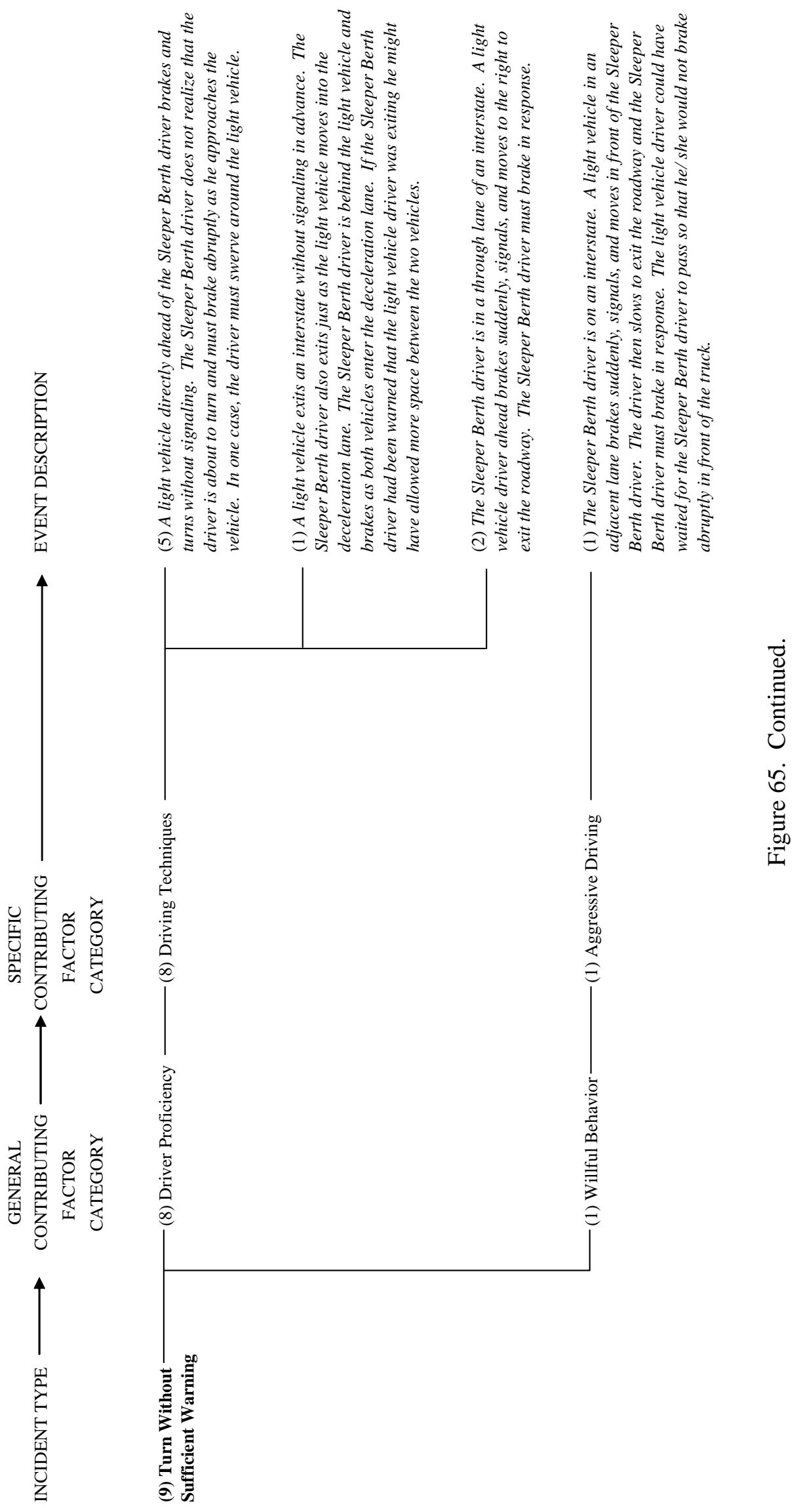




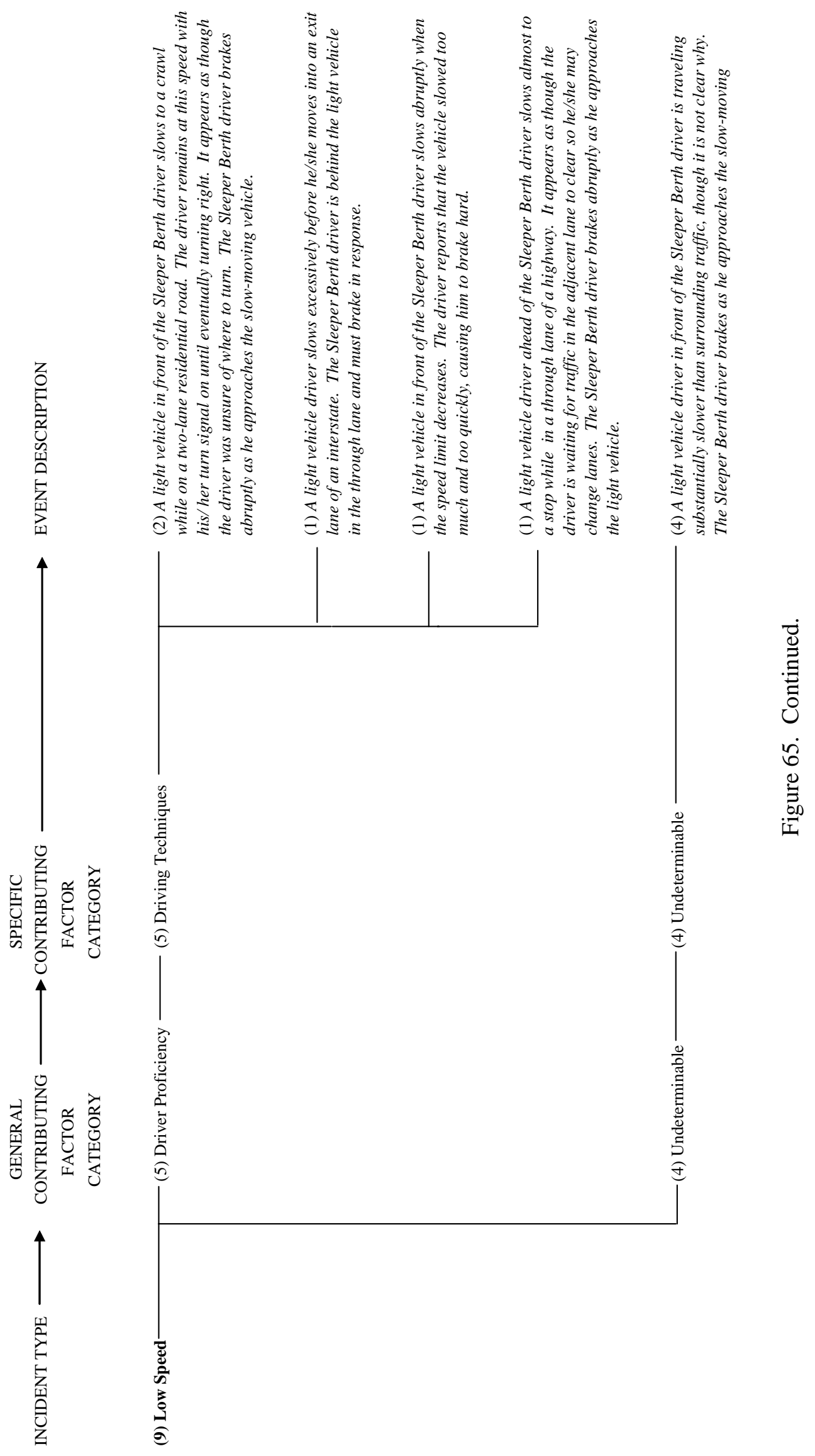




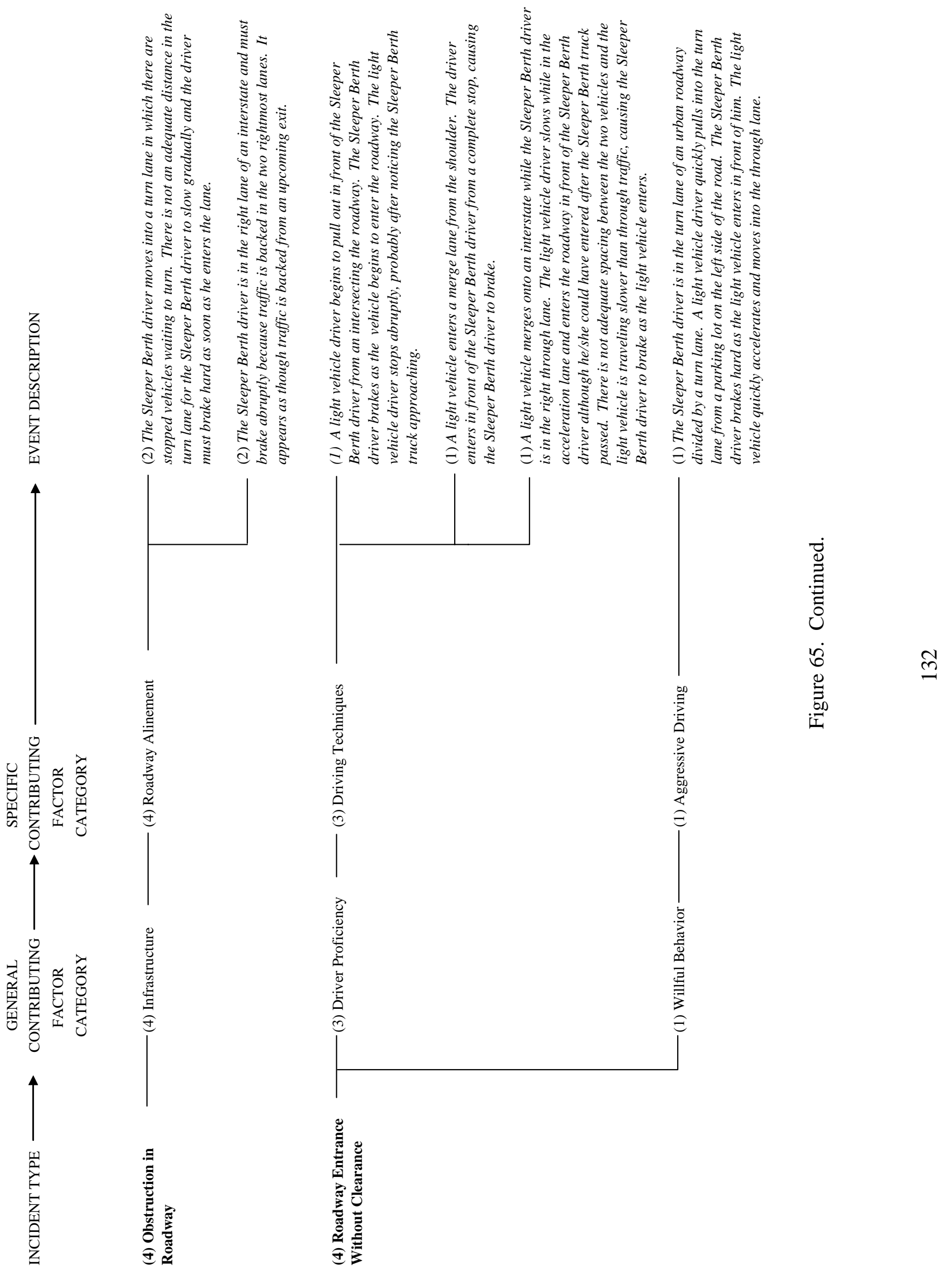




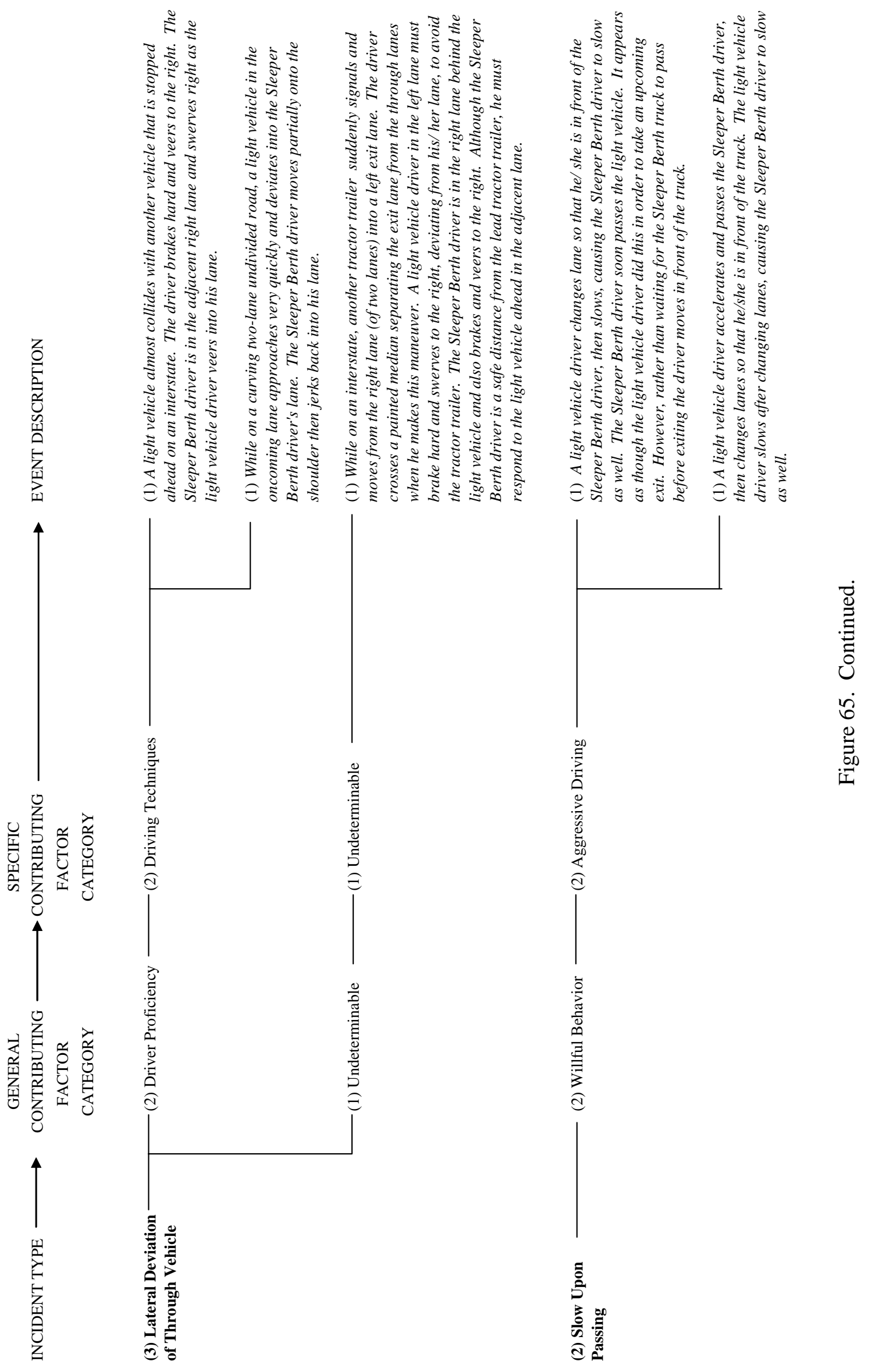




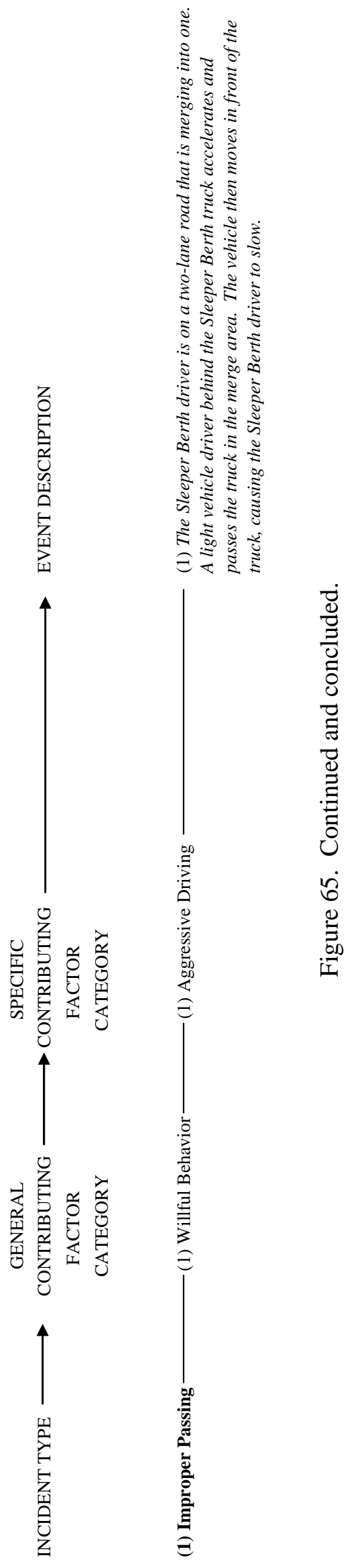




\section{DISCUSSION OF THE RESULTS FROM LIGHT VEHICLE-HEAVY VEHICLE ANALYSIS USING THE SLEEPER BERTH DATA SET}

The analyses presented in this report provide compelling evidence to support the contention that LV-HV interactions are a serious problem. Data analyses were conducted on 68 critical incidents involving an interaction between a LV and the SB truck. The analyses that were conducted focused on providing detailed descriptions of the Incident Types, Primary Maneuvers, Secondary Maneuvers, and Conflict Types associated with these 68 critical incidents.

Based on these analyses, there were several important findings. The first such finding is that of the 68 incidents, 47 (69.1 percent) were initiated by the driver of a LV and 21 (30.9 percent) were initiated by a SB driver. As highlighted previously, this finding equates to a 2.2:1 ratio of LV driver-initiated incidents to SB driver-initiated incidents. Results from database analyses (Craft, 1999; Wang et al. 1999) have also indicated that LV drivers are the initiator in most LV$\mathrm{HV}$ interactions. The finding of a disproportionate causal involvement for LV drivers is also consistent with the focus group results presented by Hanowski et al. (1998) demonstrating that truck drivers believed their most important safety concern was LV drivers. As indicated in the Phase A report, having the majority of LV-HV incidents initiated by LV drivers suggests that programs aimed at reducing LV-HV interactions should focus on LV drivers.

A second interesting finding from these analyses is in regard to the Incident Types that were most common for LV drivers and SB drivers. For LV driver-initiated incidents, Lane Change Without Sufficient Gap was the most common Incident Type (32 percent). For HV driverinitiated incidents, the most common incident type was Late Braking for Stopped/Stopping Traffic. It was suggested previously that Lane Change Without Sufficient Gap and Late Braking for Stopped/Stopping Traffic are similar in that they both refer to an event where an LV is in front of an HV (i.e., LV is the lead vehicle). The difference between the two Incident Types is in regard to which driver was deemed to be at fault. For the Lane Change Without Sufficient Gap incidents, the lead vehicle (often an LV) is judged to be at fault. When the following vehicle (often an HV) is judged to be at fault, the Incident Type that is noted tends to be Late Braking for Stopped/Stopping Traffic. These findings of the most common Incident Types for the two groups of drivers highlight truck drivers' concerns that they are often "cut-off" by LV drivers and that LV drivers do not respect HV drivers (Hanowski et al., 1998).

The analyses that were conducted on the Primary Maneuvers indicated that, across all incidents, the most common Primary Maneuvers were Through (40 percent) and Lane Change (32 percent). Looking at these data as a function of the initiating driver, it was found that LV drivers initiated 43 percent of their recorded incidents during a Lane Change maneuver and 26 percent during a Through maneuver. For HV drivers, Through maneuvers accounted for 71 percent of their initiated incidents. These findings correspond with the Incident Type data presented previously. That is, the most common LV driver-initiated Incident Type was Lane Change Without Sufficient Gap. Obviously, the Primary Maneuver for this Incident Type would be Lane Change. Similarly, the most common HV driver-initiated Incident Type was Late Braking for Stopped/Stopping Traffic, while the Primary Maneuver for this type was Through. These results provide further evidence to support the contention that many critical incidents are initiated by the action (maneuver) of an LV driver, which forces a reaction from an $\mathrm{HV}$ driver who may be maintaining a position within the lane (involved in a Through maneuver). 
In detailing the General Contributing Factors that were identified in the incidents, it was determined that Driver Proficiency accounted for 51 percent of all critical incidents. The second most common factor was Willful Behavior (35 percent). When examining the General Contributing Factors as a function of the initiating driver, it was found that both Driver Proficiency (43 percent) and Willful Behavior (40 percent) were common for LV driver-initiated incidents. In contrast, HV driver-initiated incidents had Driver Proficiency as the General Contributing Factor in the majority of cases (71 percent). Willful behavior accounted for 24 percent of the incidents.

The difference in the frequencies of the General Contributing Factors, as a function of the driver group that initiated the incident, suggests that there is a fundamental difference between incidents initiated by LV drivers and HV drivers. The analysis focused on the Specific Contributing Factors highlights these differences. Perhaps the most striking difference is in regard to Aggressive Driving. That is, 40 percent of the LV driver-initiated incidents were judged to be due to Aggressive Driving. This compares to 24 percent of the HV driver-initiated incidents. Driving Techniques was the most prominent Specific Contributing Factor for HV driver-initiated incidents and accounted for 52 percent of these incidents. Driving Techniques accounted for 43 percent of the LV driver-initiated incidents. Based on these findings, future efforts at reducing $\mathrm{LV}-\mathrm{HV}$ incidents might target the aggressive driving of $\mathrm{LV}$ drivers and the inadequate driving techniques demonstrated by HV drivers.

In addition to examining differences between LV and HV driver-initiated incidents, a second important area of exploration was with regard to the HV Driver Type used in the SB operations. Recall that teams drove a cumulative 867 hours while single drivers drove a cumulative 1,384 hours. If the occurrence of incidents is random in nature, then based on the time that each Driver Type spent on the road, one might expect that there would be an approximately equal ratio of incidents to driving time. The ratio of HV single drivers' cumulative driving time to HV team drivers' cumulative driving time was 1.60:1 (i.e., there were 1.60 hours logged by single drivers for every 1 hour logged by team drivers). However, the ratio of incidents involving single drivers as compared to those initiated by team drivers was 4.23:1, where HV single drivers were involved in 55 incidents and team drivers were involved in 13 incidents. When one looks at the ratio of incident initiation between the two groups, we see an even greater disparity. The ratio of single driver incident initiation to team driver incident initiation is 19:2 or 9.5:1. That is, for every incident that a team driver caused, there were 9.5 incidents that a single driver caused.

What conclusions can be drawn from these ratios? First, one would expect incident involvement to be comparable to participation. However, this was not the case. In fact, in terms of participation, a single driver was three-times more likely to be involved in an incident. More detailed analysis on this finding is expected for the Sleeper Berth project from which these data were taken, and two possible reasons for this discrepancy were presented previously (i.e., HV team drivers may be more likely to drive during off-peak hours and be less aggressive as compared to HV single drivers). One possible conclusion that can be made from this finding is that the single drivers who participated in this study were not as safe as the team drivers. 
As indicated previously, the analyses reported here address the Phase B effort for this project and examine the LV-HV incident data collected from the Sleeper Berth project. Phase A of this study conducted similar analyses on LV-HV interaction data collected from a research project that collected data from Local/Short Haul drivers. How do the results from Phase A and Phase B compare? What are the similarities and differences between the $\mathrm{LV}-\mathrm{HV}$ interactions collected in the L/SH study as compares to the Sleeper Berth study? The next section of this final report examines these questions. 
THIS PAGE INTENTIONALLY LEFT BLANK 


\section{CHAPTER 3: COMPARISON OF THE RESULTS FROM THE ANALYSES CONDUCTED WITH THE LOCAL/SHORT HAUL DATA AND THE SLEEPER BERTH DATA}

Recall that in Phase A of this project, analyses were conducted with critical incident data that were collected during a recent study of Local/Short Haul (L/SH) operations (Hanowski, Keisler, and Wierwille, 2001). The method of analysis that was used in Phase A was repeated in Phase B with data collected from the Sleeper Berth study. In this chapter, a comparison of the findings from these two investigative efforts is presented.

\section{INCIDENT TYPES}

Table 28 shows the Incident Type frequency and percentage of occurrence for the L/SH and Sleeper Berth data sets. The columns for percentages are presented in the histogram shown in Figure 66. As can be seen, in both the L/SH and Sleeper Berth data sets, the most common Incident Type was Lane Change Without Sufficient Gap. 
Table 28. Incident Type descriptive statistics for the L/SH and Sleeper Berth data sets.

\begin{tabular}{|c|c|c|c|c|c|c|}
\hline \multirow[b]{2}{*}{ Incident Type } & \multicolumn{6}{|c|}{ Local/ Short Haul } \\
\hline & $\begin{array}{c}\text { Frequency of } \\
\text { Occurrence: } \\
\text { Incidents } \\
\text { Initiated by } \\
\text { L/SH Driver } \\
\left(\mathrm{N}_{\mathrm{L} / \mathrm{SH}}=25\right)\end{array}$ & $\begin{array}{l}\text { Percentage of } \\
\text { Occurrence: } \\
\text { Incidents } \\
\text { Initiated by } \\
\text { L/SH Driver } \\
\left(\mathrm{N}_{\mathrm{L} / \mathrm{SH}}=25\right)\end{array}$ & $\begin{array}{c}\text { Frequency of } \\
\text { Occurrence: } \\
\text { Incidents } \\
\text { Initiated by } \\
\text { Light Vehicle } \\
\text { Driver } \\
\left(\mathbf{N}_{\mathrm{LV}}=117\right)\end{array}$ & \begin{tabular}{|c|} 
Percentage of \\
Occurrence: \\
Incidents \\
Initiated by \\
Light Vehicle \\
Driver \\
$\left(\mathbf{N}_{\mathrm{LV}}=117\right)$
\end{tabular} & $\begin{array}{l}\text { Frequency of } \\
\text { Occurrence: } \\
\text { Incidents } \\
\text { Initiated by } \\
\text { All Drivers } \\
\left(\mathbf{N}_{\text {Total }}=142\right)\end{array}$ & $\begin{array}{l}\text { Percentage of } \\
\text { Occurrence: } \\
\text { Incidents } \\
\text { Initiated by } \\
\text { All Drivers } \\
\left(\mathbf{N}_{\text {Total }}=142\right)\end{array}$ \\
\hline $\begin{array}{l}\text { Lane Change Without } \\
\text { Sufficient Gap }\end{array}$ & 1 & $4 \%$ & 29 & $25 \%$ & 30 & $21.1 \%$ \\
\hline \begin{tabular}{|l|} 
Roadway Entrance \\
Without Clearance \\
\end{tabular} & 5 & $20 \%$ & 21 & $18 \%$ & 26 & $18.3 \%$ \\
\hline $\begin{array}{l}\text { Left Turn Without } \\
\text { Clearance }\end{array}$ & 0 & $0 \%$ & 21 & $18 \%$ & 21 & $14.8 \%$ \\
\hline Low Speed & 2 & $8 \%$ & 4 & $3 \%$ & 6 & $4.2 \%$ \\
\hline $\begin{array}{l}\text { Turn Without } \\
\text { Sufficient Warning }\end{array}$ & 0 & $0 \%$ & 2 & $2 \%$ & 2 & $1.4 \%$ \\
\hline $\begin{array}{l}\text { Late Braking For } \\
\text { Stopped/ Stopping } \\
\text { Traffic }\end{array}$ & 3 & $12 \%$ & 0 & $0 \%$ & 3 & $2.1 \%$ \\
\hline Improper Passing & 1 & $4 \%$ & 6 & $5 \%$ & 7 & $4.9 \%$ \\
\hline $\begin{array}{l}\text { Wide Turn Into } \\
\text { Adjacent Lane }\end{array}$ & 3 & $12 \%$ & 5 & $4 \%$ & 8 & $5.6 \%$ \\
\hline \begin{tabular}{|l|} 
Obstruction In \\
Roadway
\end{tabular} & 1 & $4 \%$ & 3 & $3 \%$ & 4 & $2.8 \%$ \\
\hline Backing In Roadway & 3 & $12 \%$ & 4 & $3 \%$ & 7 & $4.9 \%$ \\
\hline Following Too Closely & 1 & $4 \%$ & 0 & $0 \%$ & 1 & $0.7 \%$ \\
\hline \begin{tabular}{|l}
$\begin{array}{l}\text { Merge Out Of Turn } \\
\text { (Before Lead Vehicle) }\end{array}$ \\
\end{tabular} & 1 & $4 \%$ & 4 & $3 \%$ & 5 & $3.5 \%$ \\
\hline $\begin{array}{l}\text { Through Traffic Does } \\
\text { Not Allow Merge }\end{array}$ & 0 & $0 \%$ & 5 & $4 \%$ & 5 & $3.5 \%$ \\
\hline Slow Upon Passing & 0 & $0 \%$ & 3 & $3 \%$ & 3 & $2.1 \%$ \\
\hline \begin{tabular}{|l} 
Lateral Deviation Of \\
Through Vehicle \\
\end{tabular} & 1 & $4 \%$ & 1 & $1 \%$ & 2 & $1.4 \%$ \\
\hline $\begin{array}{l}\text { Exit Then Re-Entrance } \\
\text { onto Roadway }\end{array}$ & 0 & $0 \%$ & 4 & $3 \%$ & 4 & $2.8 \%$ \\
\hline $\begin{array}{l}\text { Turn/ Exit From } \\
\text { Incorrect Lane }\end{array}$ & 1 & $4 \%$ & 3 & $3 \%$ & 4 & $2.8 \%$ \\
\hline $\begin{array}{l}\text { Conflict Between } \\
\text { Merging and Exiting } \\
\text { Traffic } \\
\end{array}$ & 0 & $0 \%$ & 2 & $2 \%$ & 2 & $1.4 \%$ \\
\hline \begin{tabular}{|l|} 
Obscene Gesture (To \\
Other Driver)
\end{tabular} & 1 & $4 \%$ & 0 & $0 \%$ & 1 & $0.7 \%$ \\
\hline $\begin{array}{l}\text { Proceeding Through } \\
\text { Red Traffic Signal }\end{array}$ & 1 & $4 \%$ & 0 & $0 \%$ & 1 & $0.7 \%$ \\
\hline Total & 25 & $100 \%$ & 117 & $100 \%$ & 142 & $100.0 \%$ \\
\hline
\end{tabular}


Table 28. Continued.

\begin{tabular}{|c|c|c|c|c|c|c|}
\hline \multirow[b]{2}{*}{ Incident Type } & \multicolumn{6}{|c|}{ Sleeper Berth } \\
\hline & $\begin{array}{c}\text { Frequency of } \\
\text { Occurrence: } \\
\text { Incidents } \\
\text { Initiated by } \\
\text { Sleeper Berth } \\
\text { Driver } \\
\left(\mathrm{N}_{\mathrm{SB}}=21\right)\end{array}$ & $\begin{array}{c}\text { Percentage of } \\
\text { Occurrence: } \\
\text { Incidents } \\
\text { Initiated by } \\
\text { Sleeper Berth } \\
\text { Driver ( } \mathbf{N}_{\mathrm{SB}}= \\
\text { 21) }\end{array}$ & $\begin{array}{c}\text { Frequency of } \\
\text { Occurrence: } \\
\text { Incidents } \\
\text { Initiated by } \\
\text { Light Vehicle } \\
\text { Driver }\left(\mathrm{N}_{\mathrm{LV}}=\right. \\
47)\end{array}$ & $\begin{array}{l}\text { Percentage of } \\
\text { Occurrence: } \\
\text { Incidents } \\
\text { Initiated by } \\
\text { Light Vehicle } \\
\text { Driver ( } \mathbf{N}_{\mathrm{LV}}= \\
47)\end{array}$ & $\begin{array}{l}\text { Frequency of } \\
\text { Occurrence: } \\
\text { Incidents } \\
\text { Initiated by } \\
\text { All Drivers } \\
\left(\mathbf{N}_{\text {Total }}=68\right)\end{array}$ & $\begin{array}{l}\text { Percentage of } \\
\text { Occurrence: } \\
\text { Incidents } \\
\text { Initiated by } \\
\text { All Drivers } \\
\left(\mathbf{N}_{\text {Total }}=68\right)\end{array}$ \\
\hline $\begin{array}{l}\text { Lane Change Without } \\
\text { Sufficient Gap }\end{array}$ & 2 & $10 \%$ & 15 & $32 \%$ & 17 & $25 \%$ \\
\hline $\begin{array}{l}\text { Roadway Entrance } \\
\text { Without Clearance }\end{array}$ & 0 & $0 \%$ & 4 & $9 \%$ & 4 & $6 \%$ \\
\hline $\begin{array}{l}\text { Left Turn Without } \\
\text { Clearance }\end{array}$ & 0 & $0 \%$ & 0 & $0 \%$ & 0 & $0 \%$ \\
\hline Low Speed & 1 & $5 \%$ & 8 & $17 \%$ & 9 & $13 \%$ \\
\hline $\begin{array}{l}\text { Turn Without } \\
\text { Sufficient Warning }\end{array}$ & 3 & $14 \%$ & 9 & $19 \%$ & 12 & $18 \%$ \\
\hline $\begin{array}{l}\text { Late Braking For } \\
\text { Stopped/ Stopping } \\
\text { Traffic }\end{array}$ & 10 & $48 \%$ & 0 & $0 \%$ & 10 & $15 \%$ \\
\hline Improper Passing & 0 & $0 \%$ & 2 & $4 \%$ & 2 & $3 \%$ \\
\hline $\begin{array}{l}\text { Wide Turn Into } \\
\text { Adjacent Lane }\end{array}$ & 0 & $0 \%$ & 0 & $0 \%$ & 0 & $0 \%$ \\
\hline $\begin{array}{l}\text { Obstruction In } \\
\text { Roadway }\end{array}$ & 0 & $0 \%$ & 4 & $9 \%$ & 4 & $6 \%$ \\
\hline Backing In Roadway & 0 & $0 \%$ & 0 & $0 \%$ & 0 & $0 \%$ \\
\hline Following Too Closely & 5 & $24 \%$ & 0 & $0 \%$ & 5 & $7 \%$ \\
\hline $\begin{array}{l}\text { Merge Out Of Turn } \\
\text { (Before Lead Vehicle) }\end{array}$ & 0 & $0 \%$ & 0 & $0 \%$ & 0 & $0 \%$ \\
\hline $\begin{array}{l}\text { Through Traffic Does } \\
\text { Not Allow Merge }\end{array}$ & 0 & $0 \%$ & 0 & $0 \%$ & 0 & $0 \%$ \\
\hline Slow Upon Passing & 0 & $0 \%$ & 2 & $4 \%$ & 2 & $3 \%$ \\
\hline $\begin{array}{l}\text { Lateral Deviation Of } \\
\text { Through Vehicle }\end{array}$ & 0 & $0 \%$ & 3 & $6 \%$ & 3 & $4 \%$ \\
\hline $\begin{array}{l}\text { Exit Then Re-Entrance } \\
\text { onto Roadway }\end{array}$ & 0 & $0 \%$ & 0 & $0 \%$ & 0 & $0 \%$ \\
\hline $\begin{array}{l}\text { Turn/ Exit From } \\
\text { Incorrect Lane }\end{array}$ & 0 & $0 \%$ & 0 & $0 \%$ & 0 & $0 \%$ \\
\hline $\begin{array}{l}\text { Conflict Between } \\
\text { Merging and Exiting } \\
\text { Traffic }\end{array}$ & 0 & $0 \%$ & 0 & $0 \%$ & 0 & $0 \%$ \\
\hline $\begin{array}{l}\text { Obscene Gesture (To } \\
\text { Other Driver) }\end{array}$ & 0 & $0 \%$ & 0 & $0 \%$ & 0 & $0 \%$ \\
\hline $\begin{array}{l}\text { Proceeding Through } \\
\text { Red Traffic Signal }\end{array}$ & 0 & $0 \%$ & 0 & $0 \%$ & 0 & $0 \%$ \\
\hline Total & 21 & $100 \%$ & 47 & $100 \%$ & 68 & $100 \%$ \\
\hline
\end{tabular}


Table 28. Continued and concluded.

\begin{tabular}{|c|c|c|}
\hline \multirow[b]{2}{*}{ Incident Type } & \multicolumn{2}{|r|}{ All } \\
\hline & $\begin{array}{c}\text { Frequency of } \\
\text { Occurrence: } \text { All } \\
\text { Incidents Included } \\
\left(\mathbf{N}_{\text {Total }}=210\right)\end{array}$ & $\begin{array}{l}\text { Percentage of Occurrence: } \\
\text { All Incidents Included } \\
\left(\mathbf{N}_{\text {Total }}=210\right)\end{array}$ \\
\hline $\begin{array}{l}\text { Lane Change Without } \\
\text { Sufficient Gap }\end{array}$ & 47 & $22 \%$ \\
\hline $\begin{array}{l}\text { Roadway Entrance Without } \\
\text { Clearance }\end{array}$ & 30 & $14 \%$ \\
\hline Left Turn Without Clearance & 21 & $10 \%$ \\
\hline Low Speed & 15 & $7 \%$ \\
\hline $\begin{array}{l}\text { Turn Without Sufficient } \\
\text { Warning }\end{array}$ & 14 & $7 \%$ \\
\hline $\begin{array}{l}\text { Late Braking For Stopped/ } \\
\text { Stopping Traffic }\end{array}$ & 13 & $6 \%$ \\
\hline Improper Passing & 9 & $4 \%$ \\
\hline Wide Turn Into Adjacent Lane & 8 & $4 \%$ \\
\hline Obstruction In Roadway & 8 & $4 \%$ \\
\hline Backing In Roadway & 7 & $3 \%$ \\
\hline Following Too Closely & 6 & $3 \%$ \\
\hline $\begin{array}{l}\text { Merge Out Of Turn (Before } \\
\text { Lead Vehicle) }\end{array}$ & 5 & $2 \%$ \\
\hline $\begin{array}{l}\text { Through Traffic Does Not } \\
\text { Allow Merge }\end{array}$ & 5 & $2 \%$ \\
\hline Slow Upon Passing & 5 & $2 \%$ \\
\hline $\begin{array}{l}\text { Lateral Deviation Of Through } \\
\text { Vehicle }\end{array}$ & 5 & $2 \%$ \\
\hline $\begin{array}{l}\text { Exit Then Re-Entrance onto } \\
\text { Roadway }\end{array}$ & 4 & $2 \%$ \\
\hline Turn/ Exit From Incorrect Lane & 4 & $2 \%$ \\
\hline $\begin{array}{l}\text { Conflict Between Merging and } \\
\text { Exiting Traffic }\end{array}$ & 2 & $1 \%$ \\
\hline $\begin{array}{l}\text { Obscene Gesture (To Other } \\
\text { Driver) }\end{array}$ & 1 & $0 \%$ \\
\hline $\begin{array}{l}\text { Proceeding Through Red } \\
\text { Traffic Signal }\end{array}$ & 1 & $0 \%$ \\
\hline Total & 210 & $100 \%$ \\
\hline
\end{tabular}




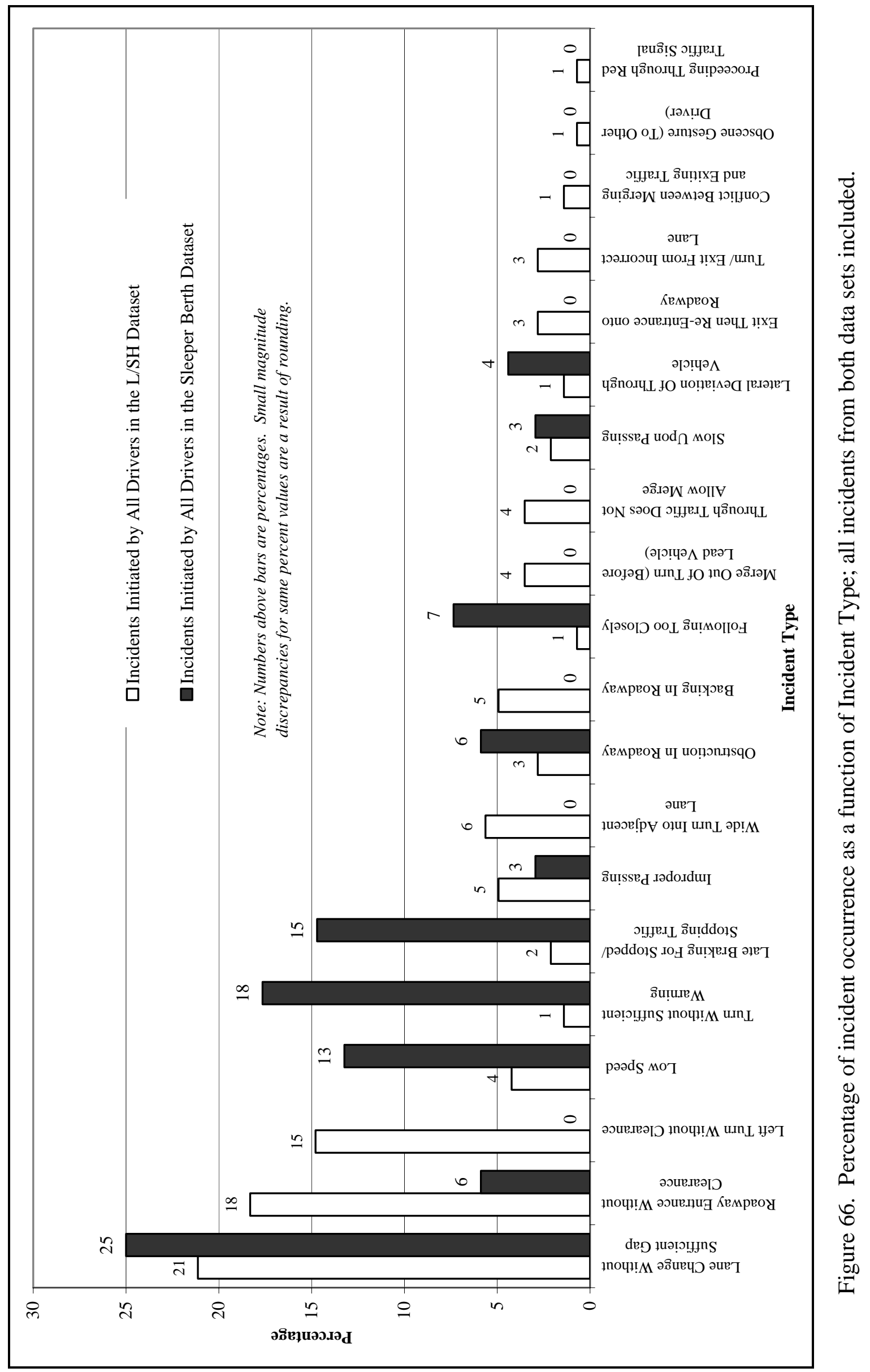


Figure 67 shows the percentage of occurrence data for incidents initiated by an HV driver. The white bars in Figure 67 represent incidents initiated by a local/short haul driver, while the dark bars represent incidents initiated by a sleeper berth driver. 


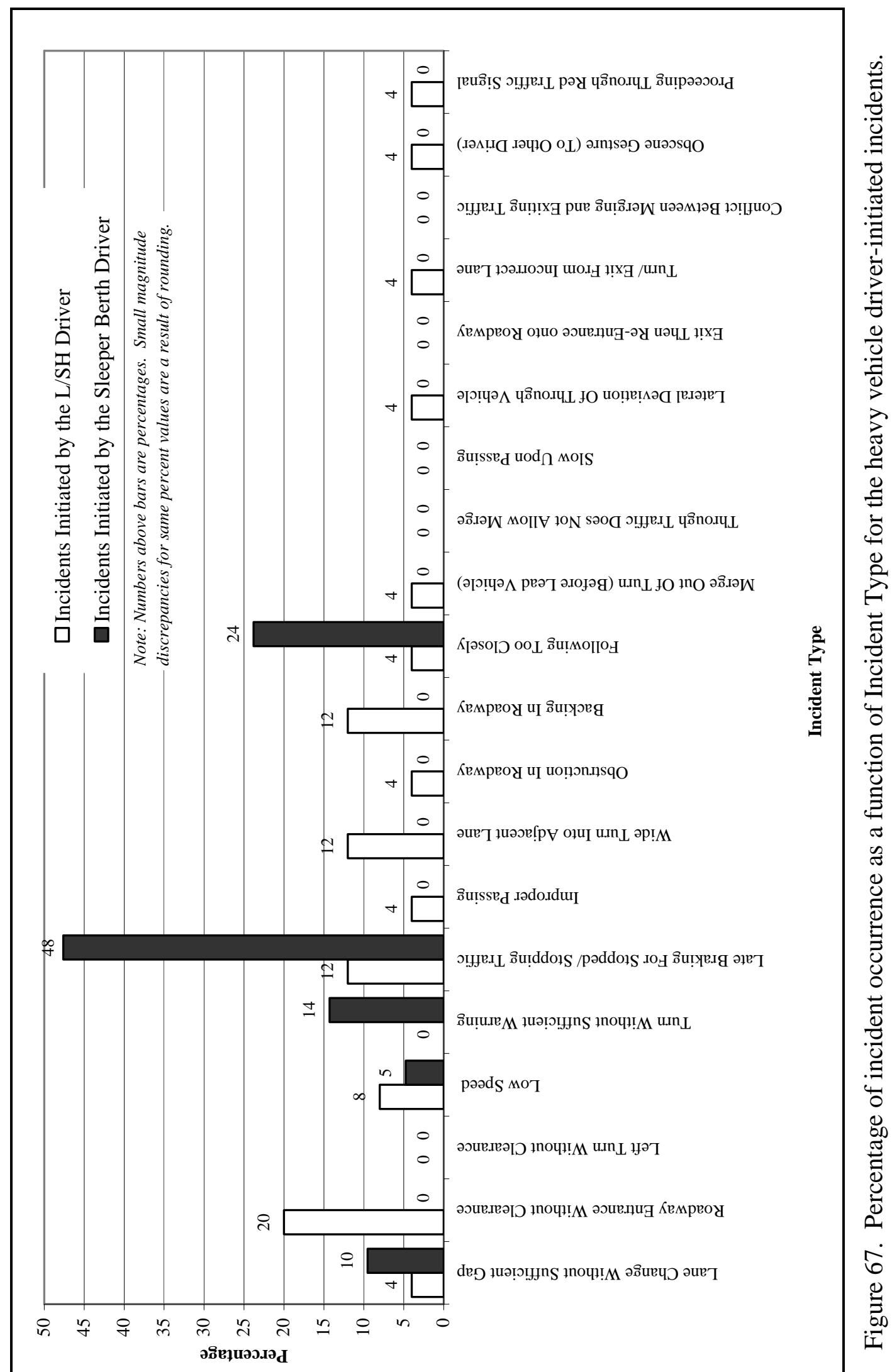


The percentage differences for the various Incident Types for the two truck driver groups are quite noticeable. How can these differences be explained? Because both the L/SH and Sleeper Berth studies were in situ data collection efforts using minimal experimental control, it is difficult to explain these differences with certainty. However, one can hypothesize reasons for the discrepancies. Consider the road type comparison data shown in Figure 68. The histograms show the percentage of occurrence of critical incidents for different road types as a function of the type of trucking operation. Not surprisingly, road types common to SB operations, such as interstate and highway, are where the majority of SB incidents occurred. That is, rural divided by median (i.e., interstate) and urban divided by median (i.e., highway) accounted for 74 percent of the SB incidents. Similarly, roadways common for L/SH trucks accounted for many of the $\mathrm{L} / \mathrm{SH}$ incidents. On a percentage basis, there were more incidents for $\mathrm{L} / \mathrm{SH}$ drivers in town settings (i.e., urban undivided, urban divided, one-way, and parking lot), which is where many $\mathrm{L} / \mathrm{SH}$ delivery routes are located. Looking generally at the driving environments of the two types of operations, it could be said that the majority of SB incidents occurred on highways where speeds are relatively high and traffic density is relatively low, as compared to L/SH incidents that tended to occur in and around town/urban areas (lower speeds and higher traffic density).

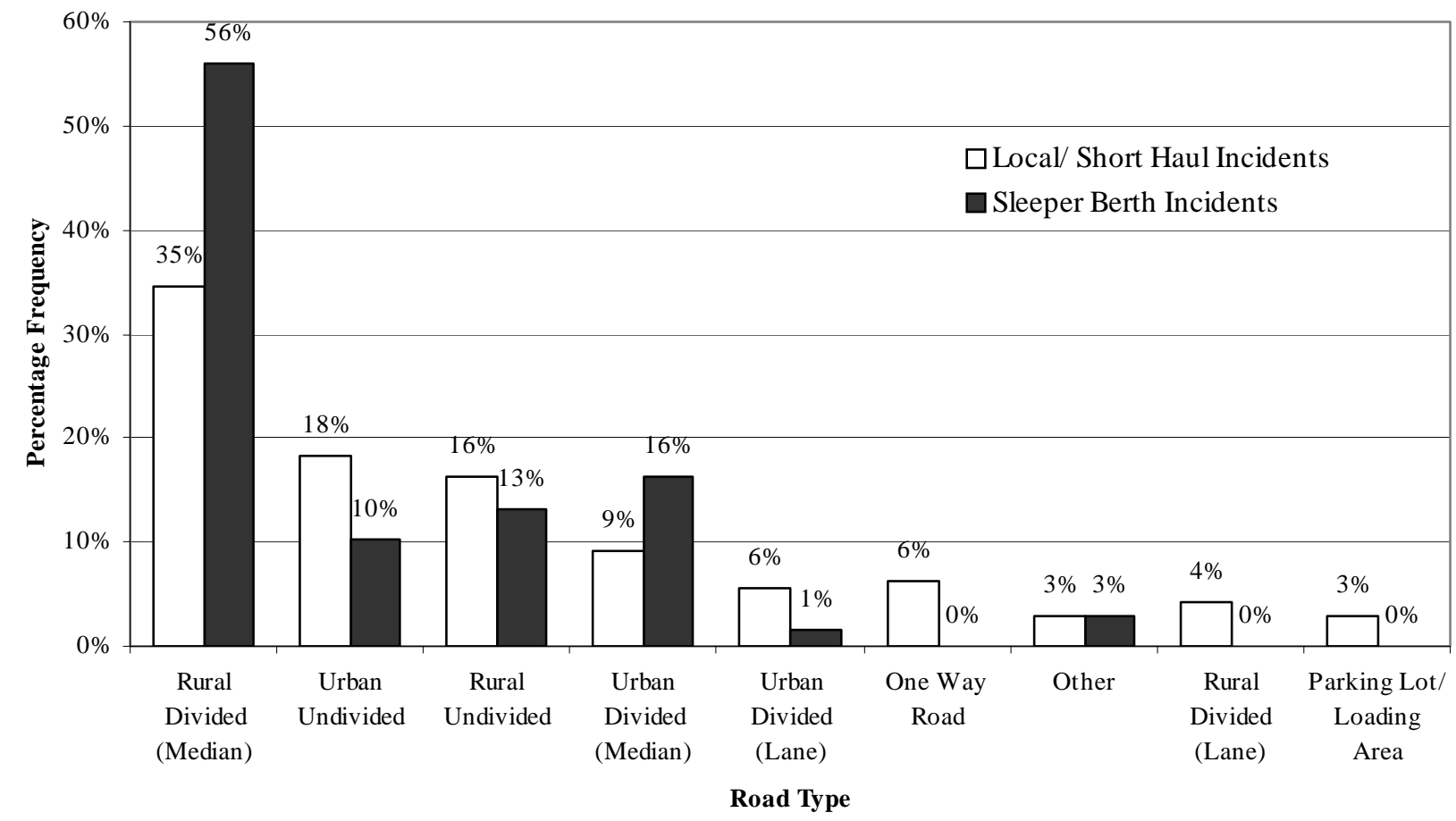

Figure 68. Percentage of incident occurrence as a function of Road Type and Trucking Operation. 
When one considers the Incident Type discrepancies in light of the road type characteristics, the variation in the Incident Type differences seems reasonable. For example, consider the Incident Type Late Braking for Stopped/Stopping Traffic. This Incident Type accounted for 48 percent of SB driver-initiated incidents, but only 12 percent of the L/SH driver-initiated incidents. One might expect this particular Incident Type to occur more frequently when vehicles are traveling at high speeds and traffic density is low. That is, a following driver reacting slowly to stopped/stopping traffic may be affected by a large speed discrepancy between his/her vehicle and a lead vehicle. This scenario would be more common on an interstate highway or U.S. state route as compared to bumper-to-bumper traffic in an urban area. A similar argument can be made for the percentage discrepancies with the other Incident Types as well. For example, Roadway Entrance Without Clearance accounted for a substantial portion of L/SH incidents (20 percent), but was not an Incident Type in any of the SB incidents. Once again, this result makes sense when one considers the driving environments of the two types of trucking operations. L/SH drivers have many deliveries during their workday and will, therefore, routinely exit parking lots onto roadways. This provides an opportunity for this particular Incident Type to occur, whereas this maneuver is not characteristic of SB operations. Much of the time, SB drivers were on limited-access highways having no intersecting side roads. The characteristics of the roadway environment that the two truck types operate can be used to explain many of the percentage discrepancies shown in Figure 67.

Figure 69 shows the percentage of incidents initiated by LV drivers. The white bars represent incidents captured in the L/SH study, while the dark bars represent incidents in the Sleeper Berth study. As shown, the most common Incident Type in both data sets was Lane Change Without Sufficient Gap. This particular Incident Type involves an LV driver cutting in front of (or cutting-off) an HV driver. This finding supports HV driver reports indicating that they are often "cut-off" by LV drivers (Hanowski et al. 1998). As in the previous discussion of HV driverinitiated incidents, the roadway characteristics common for the two trucking operations can be used to explain many of the discrepancies found with the other LV-initiated Incident Types. 


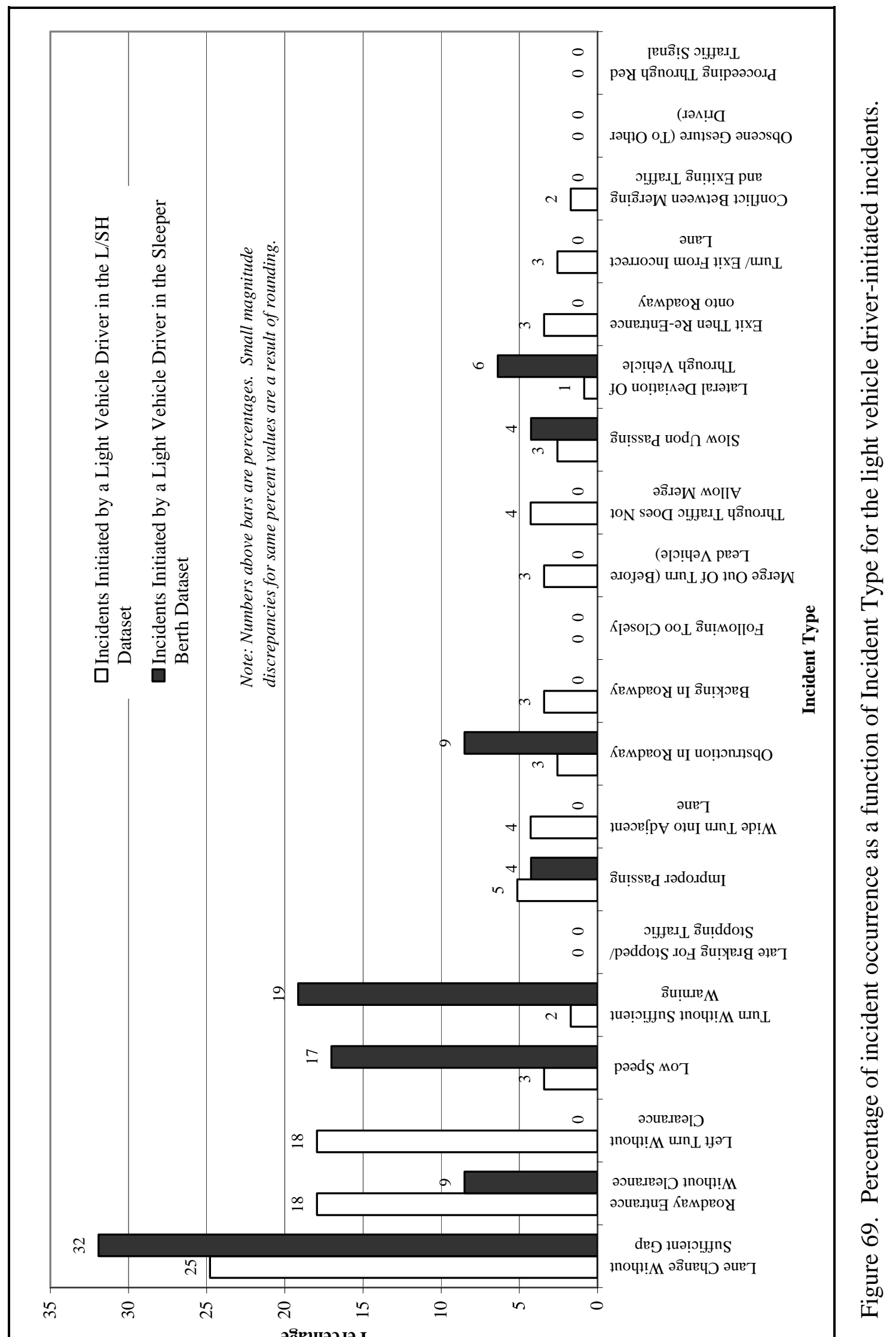




\section{Primary Maneuvers, General Contributing Factors, and Secondary Contributing Factors}

Table 29 shows the frequency and percentage of occurrence data for the Primary Maneuvers in both the L/SH and Sleeper Berth data sets. The percentage data from this table are shown in the histograms presented in Figures 70, 71, and 72. Figure 72 shows the percentage of primary maneuvers for all incidents in both data sets. These data are then broken out for HV driverinitiated incidents in Figure 71, and LV driver initiated incidents in Figure 72. While there are percentage discrepancies as a function of Primary Maneuver for each of the two data sets, it is suggested that these differences are likely attributable to the roadway environments common to the two trucking groups. For example, Through and Lane Change incidents were relatively more common for incidents in the sleeper berth data set. Because SB drivers tend to operate on open highways, it would be expected that many of the incidents that occurred would be of these two types. Primary Maneuvers typical of urban driving, such as making Left Turns at intersections, show up as commonly occurring incidents in the L/SH data set. Similarly, Right-turn, Merge Onto Roadway, U-turns, Roadway Entrance from Parking Space, and Backing maneuvers, all typical of urban driving, were relatively more common in the L/SH driver data set.

Table 29. Primary Maneuver descriptive statistics for L/SH and Sleeper Berth data sets.

\begin{tabular}{|c|c|c|c|c|c|c|}
\hline \multirow[b]{2}{*}{ Primary Maneuver } & \multicolumn{6}{|c|}{ Local/ Short Haul } \\
\hline & \begin{tabular}{|l} 
Frequency of \\
Occurrence: \\
Incidents \\
Initiated by \\
L/SH Driver \\
$\left(\mathrm{N}_{\mathrm{L} / \mathrm{SH}}=\mathbf{2 5 )}\right.$
\end{tabular} & \begin{tabular}{|} 
Percentage of \\
Occurrence: \\
Incidents \\
Initiated by \\
L/SH Driver \\
$\left(\mathrm{N}_{\mathrm{L} / \mathrm{SH}}=25\right)$
\end{tabular} & $\begin{array}{c}\text { Frequency of } \\
\text { Occurrence: } \\
\text { Incidents } \\
\text { Initiated by } \\
\text { Light Vehicle } \\
\text { Driver } \\
\left(\mathbf{N}_{\mathbf{L V}}=117\right)\end{array}$ & $\begin{array}{l}\text { Percentage of } \\
\text { Occurrence: } \\
\text { Incidents } \\
\text { Initiated by } \\
\text { Light Vehicle } \\
\text { Driver } \\
\left(\mathbf{N}_{\mathrm{LV}}=117\right)\end{array}$ & $\begin{array}{c}\text { Frequency of } \\
\text { Occurrence: } \\
\text { Incidents } \\
\text { Initiated by } \\
\text { All Drivers } \\
\left(\mathbf{N}_{\text {Total }}=142\right)\end{array}$ & \begin{tabular}{|c|} 
Percentage of \\
Occurrence: \\
Incidents \\
Initiated by All \\
Drivers \\
$\left(\mathbf{N}_{\text {Total }}=\mathbf{1 4 2}\right)$
\end{tabular} \\
\hline Through & 11 & $44 \%$ & 16 & $14 \%$ & 27 & $19 \%$ \\
\hline Lane Change & 1 & $4 \%$ & 31 & $26 \%$ & 32 & $23 \%$ \\
\hline Left Turn & 3 & $12 \%$ & 26 & $22 \%$ & 29 & $20 \%$ \\
\hline Right Turn & 6 & $24 \%$ & 12 & $10 \%$ & 18 & $13 \%$ \\
\hline Merge Onto Roadway & 1 & $4 \%$ & 14 & $12 \%$ & 15 & $11 \%$ \\
\hline Roadway Exit & 0 & $0 \%$ & 2 & $2 \%$ & 2 & $1 \%$ \\
\hline U-turn & 2 & $8 \%$ & 5 & $4 \%$ & 7 & $5 \%$ \\
\hline \begin{tabular}{|l|} 
Roadway Entrance From \\
Shoulder or Parking Space
\end{tabular} & 0 & $0 \%$ & 6 & $5 \%$ & 6 & $4 \%$ \\
\hline Backing & 1 & $4 \%$ & 4 & $3 \%$ & 5 & $4 \%$ \\
\hline Stopped in Roadway & 0 & $0 \%$ & 1 & $1 \%$ & 1 & $1 \%$ \\
\hline Total & 25 & $100 \%$ & 117 & $100 \%$ & 142 & $100 \%$ \\
\hline
\end{tabular}


Table 29. Continued and concluded.

\begin{tabular}{|c|c|c|c|c|c|c|}
\hline \multirow[b]{2}{*}{ Primary Maneuver } & \multicolumn{6}{|c|}{ Sleeper Berth } \\
\hline & $\begin{array}{l}\text { Frequency of } \\
\text { Occurrence: } \\
\text { Incidents } \\
\text { Initiated by } \\
\text { Sleeper Berth } \\
\text { Driver } \\
\left(\mathrm{N}_{\mathrm{SB}}=21\right)\end{array}$ & $\begin{array}{l}\text { Percentage of } \\
\text { Occurrence: } \\
\text { Incidents } \\
\text { Initiated by } \\
\text { Sleeper Berth } \\
\text { Driver } \\
\left(\mathrm{N}_{\mathrm{SB}}=21\right)\end{array}$ & $\begin{array}{l}\text { Frequency of } \\
\text { Occurrence: } \\
\text { Incidents } \\
\text { Initiated by } \\
\text { Light Vehicle } \\
\text { Driver } \\
\left(\mathbf{N}_{\mathrm{LV}}=47\right)\end{array}$ & $\begin{array}{c}\text { Percentage of } \\
\text { Occurrence: } \\
\text { Incidents } \\
\text { Initiated by } \\
\text { Light Vehicle } \\
\text { Driver } \\
\left(\mathbf{N}_{\mathrm{LV}}=47\right)\end{array}$ & $\begin{array}{l}\text { Frequency of } \\
\text { Occurrence: } \\
\text { Incidents } \\
\text { Initiated by } \\
\text { All Drivers } \\
\left.\mathbf{( N}_{\text {Total }}=68\right)\end{array}$ & $\begin{array}{l}\text { Percentage of } \\
\text { Occurrence: } \\
\text { Incidents } \\
\text { Initiated by } \\
\text { All Drivers } \\
\left(\mathbf{N}_{\text {Total }}=\mathbf{6 8}\right)\end{array}$ \\
\hline Through & 15 & $71 \%$ & 12 & $26 \%$ & 27 & $40 \%$ \\
\hline Lane Change & 2 & $10 \%$ & 20 & $43 \%$ & 22 & $32 \%$ \\
\hline Left Turn & 2 & $10 \%$ & 4 & $9 \%$ & 6 & $9 \%$ \\
\hline Right Turn & 1 & $5 \%$ & 1 & $2 \%$ & 2 & $3 \%$ \\
\hline Merge Onto Roadway & 0 & $0 \%$ & 4 & $9 \%$ & 4 & $6 \%$ \\
\hline Roadway Exit & 1 & $5 \%$ & 5 & $11 \%$ & 6 & $9 \%$ \\
\hline U-turn & 0 & $0 \%$ & 0 & $0 \%$ & 0 & $0 \%$ \\
\hline \begin{tabular}{|l|} 
Roadway Entrance \\
From Shoulder or \\
Parking Space
\end{tabular} & 0 & $0 \%$ & 0 & $0 \%$ & 0 & $0 \%$ \\
\hline Backing & 0 & $0 \%$ & 0 & $0 \%$ & 0 & $0 \%$ \\
\hline Stopped in Roadway & 0 & $0 \%$ & 1 & $2 \%$ & 1 & $1 \%$ \\
\hline Total & 21 & $100 \%$ & 47 & $100 \%$ & 68 & $100 \%$ \\
\hline
\end{tabular}

\begin{tabular}{|c|c|c|}
\hline \multirow[b]{2}{*}{$\begin{array}{l}\text { Primary } \\
\text { Maneuver }\end{array}$} & \multicolumn{2}{|c|}{ All } \\
\hline & $\begin{array}{l}\text { Frequency of Occurrence: } \\
\text { All Incidents Included } \\
\left(\mathbf{N}_{\text {Total }}=\mathbf{2 1 0}\right)\end{array}$ & $\begin{array}{c}\text { Percentage of Occurrence: } \\
\text { All Incidents Included } \\
\left(\mathbf{N}_{\text {Total }}=\mathbf{2 1 0}\right)\end{array}$ \\
\hline Through & 54 & $26 \%$ \\
\hline Lane Change & 54 & $26 \%$ \\
\hline Left Turn & 35 & $17 \%$ \\
\hline Right Turn & 20 & $10 \%$ \\
\hline $\begin{array}{l}\text { Merge Onto } \\
\text { Roadway }\end{array}$ & 19 & $9 \%$ \\
\hline Roadway Exit & 8 & $4 \%$ \\
\hline U-turn & 7 & $3 \%$ \\
\hline $\begin{array}{l}\text { Roadway Entrance } \\
\text { From Shoulder or } \\
\text { Parking Space }\end{array}$ & 6 & $3 \%$ \\
\hline Backing & 5 & $2 \%$ \\
\hline $\begin{array}{l}\text { Stopped in } \\
\text { Roadway }\end{array}$ & 2 & $1 \%$ \\
\hline Total & 210 & $100 \%$ \\
\hline
\end{tabular}




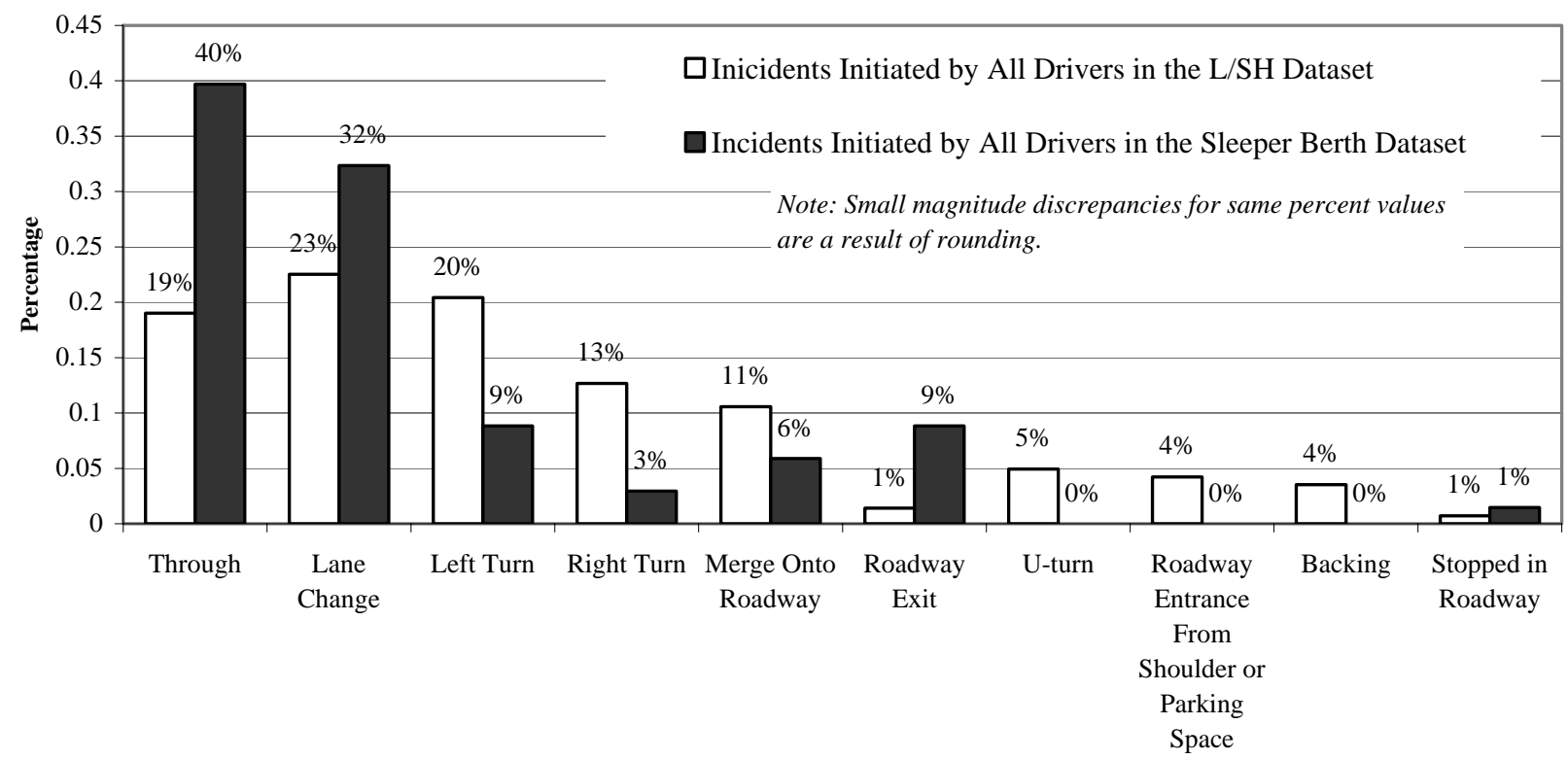

Primary Maneuver

Figure 70. Percentage of incident occurrence as a function of the Primary Maneuvers; all incidents from both data sets included. 


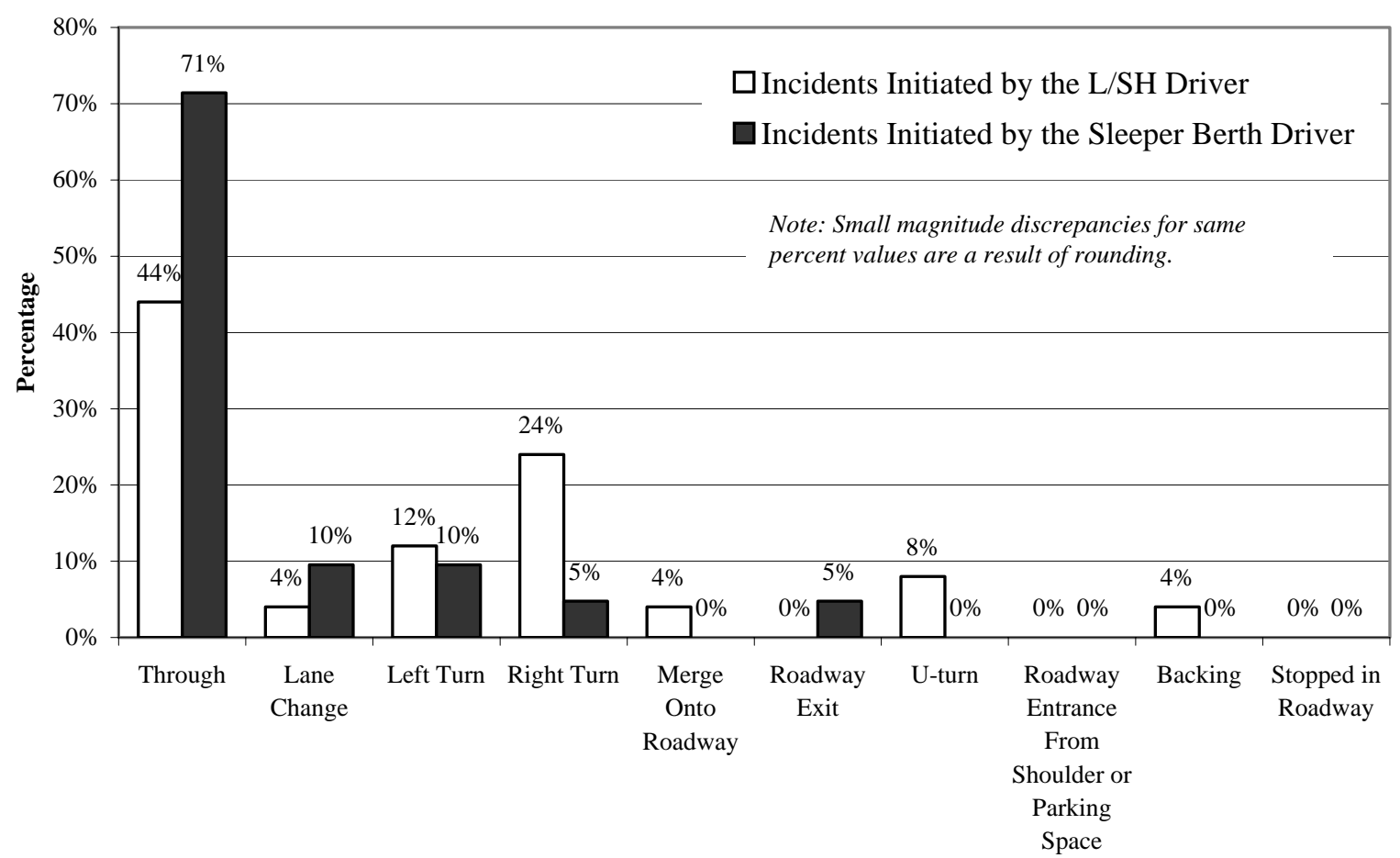

Primary Maneuver

Figure 71. Percentage of incident occurrence as a function of the Primary Maneuvers for heavy vehicle driver-initiated incidents. 


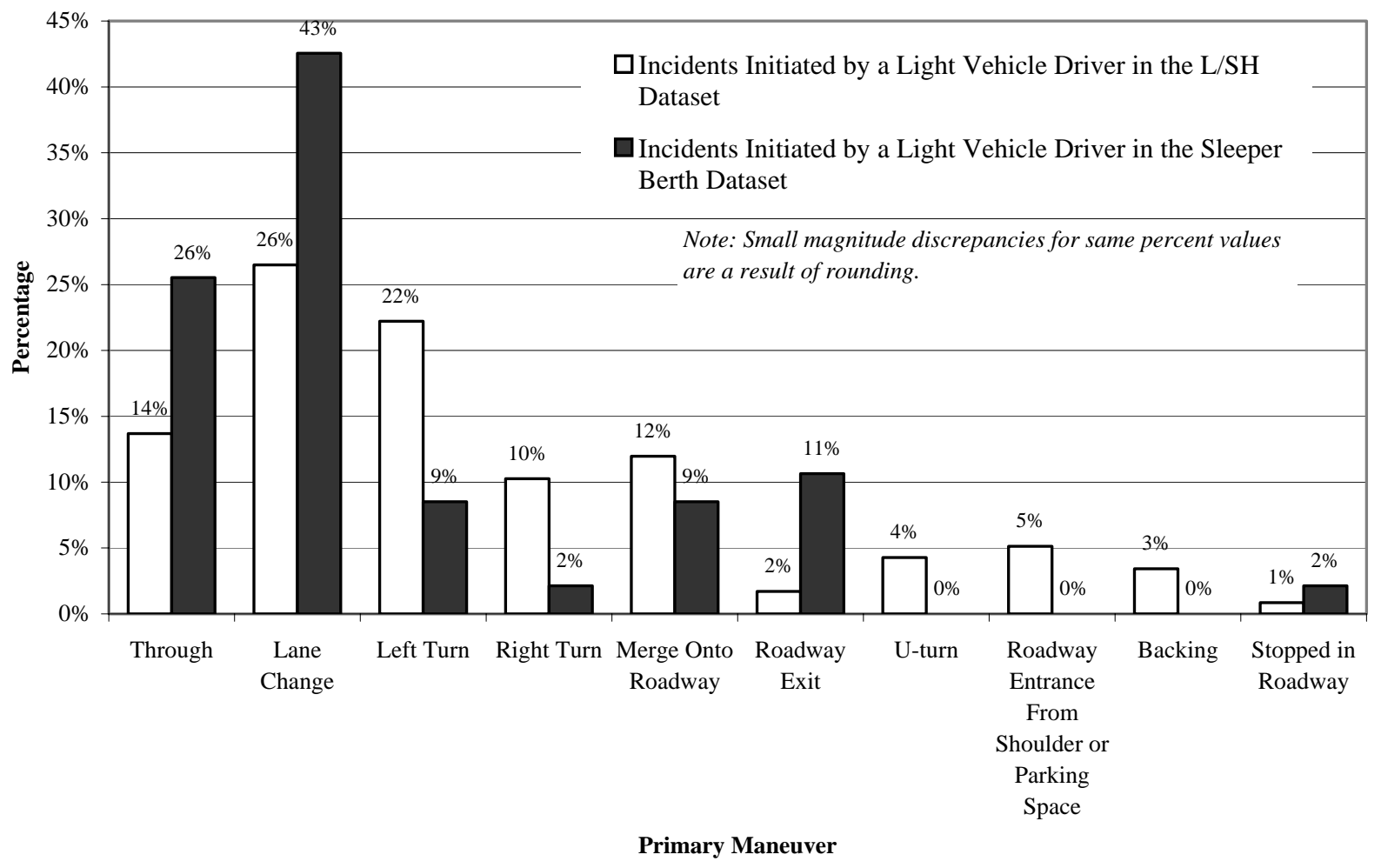

Figure 72. Percentage of incident occurrence as a function of the Primary Maneuvers for light vehicle driver-initiated incidents.

Table 30 shows the frequency and percentage of occurrence data for the incidents as a function of the General Contributing Factors. Figure 73 shows the percentage data for all incidents in the two data sets. Figures 74 and 75 show the percentage data as a function of the initiating driver; in Figure 74 the data are shown for the HV driver-initiated incidents, while Figure 75 shows the data for the LV driver-initiated incidents. 
Table 30. General Contributing Factor descriptive statistics for the L/SH and Sleeper Berth data sets.

\begin{tabular}{|c|c|c|c|c|c|c|}
\hline \multirow{2}{*}{\begin{tabular}{|c|} 
\\
General Contributing \\
Factor
\end{tabular}} & \multicolumn{6}{|c|}{ Local/ Short Haul } \\
\hline & $\begin{array}{l}\text { Frequency of } \\
\text { Occurrence: } \\
\text { Incidents } \\
\text { Initiated by } \\
\text { L/SH Driver } \\
\left(\mathrm{N}_{\mathrm{L} / \mathrm{SH}}=25\right)\end{array}$ & $\begin{array}{l}\text { Percentage of } \\
\text { Occurrence: } \\
\text { Incidents } \\
\text { Initiated by } \\
\text { L/SH Driver } \\
\left(\mathrm{N}_{\mathrm{L} / \mathrm{SH}}=25\right)\end{array}$ & $\begin{array}{c}\text { Frequency of } \\
\text { Occurrence: } \\
\text { Incidents } \\
\text { Initiated by } \\
\text { Light Vehicle } \\
\text { Driver } \\
\left(\mathbf{N}_{\mathbf{L V}}=117\right)\end{array}$ & \begin{tabular}{|c|} 
Percentage of \\
Occurrence: \\
Incidents \\
Initiated by \\
Light Vehicle \\
Driver \\
$\left(\mathbf{N}_{\mathrm{LV}}=117\right)$
\end{tabular} & $\begin{array}{c}\text { Frequency of } \\
\text { Occurrence: } \\
\text { Incidents } \\
\text { Initiated by } \\
\text { All Drivers } \\
\left(\mathbf{N}_{\text {Total }}=142\right)\end{array}$ & $\begin{array}{c}\text { Percentage of } \\
\text { Occurrence: } \\
\text { Incidents } \\
\text { Initiated by } \\
\text { All Drivers } \\
\left(\mathbf{N}_{\text {Total }}=142\right)\end{array}$ \\
\hline Driver Proficiency & 11 & $44 \%$ & 32 & $27 \%$ & 43 & $30 \%$ \\
\hline Willful Behavior & 6 & $24 \%$ & 55 & $47 \%$ & 61 & $43 \%$ \\
\hline Infrastructure & 7 & $28 \%$ & 15 & $13 \%$ & 22 & $15 \%$ \\
\hline Undeterminable & 0 & $0 \%$ & 15 & $13 \%$ & 15 & $11 \%$ \\
\hline Impairment & 1 & $4 \%$ & 0 & $0 \%$ & 1 & $1 \%$ \\
\hline Total & 25 & $100 \%$ & 117 & $100 \%$ & 142 & $100 \%$ \\
\hline
\end{tabular}

\begin{tabular}{|c|c|c|c|c|c|c|}
\hline \multirow[b]{2}{*}{$\begin{array}{l}\text { General } \\
\text { Contributing } \\
\text { Factor }\end{array}$} & \multicolumn{6}{|c|}{ Sleeper Berth } \\
\hline & $\begin{array}{c}\text { Frequency of } \\
\text { Occurrence: } \\
\text { Incidents } \\
\text { Initiated by } \\
\text { Sleeper Berth } \\
\text { Driver } \\
\left(\mathrm{N}_{\mathrm{SB}}=21\right)\end{array}$ & $\begin{array}{c}\text { Percentage of } \\
\text { Occurrence: } \\
\text { Incidents } \\
\text { Initiated by } \\
\text { Sleeper Berth } \\
\text { Driver } \\
\left(\mathrm{N}_{\mathrm{SB}}=21\right)\end{array}$ & $\begin{array}{c}\text { Frequency of } \\
\text { Occurrence: } \\
\text { Incidents } \\
\text { Initiated by } \\
\text { Light Vehicle } \\
\text { Driver } \\
\left(\mathrm{N}_{\mathrm{LV}}=47\right)\end{array}$ & $\begin{array}{c}\text { Percentage of } \\
\text { Occurrence: } \\
\text { Incidents } \\
\text { Initiated by } \\
\text { Light Vehicle } \\
\text { Driver } \\
\left(\mathrm{N}_{\mathrm{LV}}=47\right)\end{array}$ & $\begin{array}{l}\text { Frequency of } \\
\text { Occurrence: } \\
\text { Incidents } \\
\text { Initiated by } \\
\text { All Drivers } \\
\left(\mathbf{N}_{\text {Total }}=68\right)\end{array}$ & $\begin{array}{l}\text { Percentage of } \\
\text { Occurrence: } \\
\text { Incidents } \\
\text { Initiated by } \\
\text { All Drivers } \\
\left(\mathbf{N}_{\text {Total }}=68\right)\end{array}$ \\
\hline Driver Proficiency & 15 & $71 \%$ & 20 & $43 \%$ & 35 & $51 \%$ \\
\hline Willful Behavior & 5 & $24 \%$ & 19 & $40 \%$ & 24 & $35 \%$ \\
\hline Infrastructure & 0 & $0 \%$ & 4 & $9 \%$ & 4 & $6 \%$ \\
\hline Undeterminable & 0 & $0 \%$ & 4 & $9 \%$ & 4 & $6 \%$ \\
\hline Impairment & 1 & $5 \%$ & 0 & $0 \%$ & 1 & $1 \%$ \\
\hline Total & 21 & $100 \%$ & 47 & $100 \%$ & 68 & $100 \%$ \\
\hline
\end{tabular}

\begin{tabular}{|l|c|c|}
\hline & \multicolumn{2}{|c|}{ All } \\
$\begin{array}{c}\text { General } \\
\text { Contributing } \\
\text { Factor }\end{array}$ & $\begin{array}{c}\text { Frequency of } \\
\text { Occurrence: All } \\
\text { Incidents Included } \\
\left.\mathbf{( N}_{\text {Total }}=\mathbf{2 1 0}\right)\end{array}$ & $\begin{array}{c}\text { Percentage of } \\
\text { Occurrence: All } \\
\text { Incidents Included } \\
\text { ( }_{\text {Total }} \text { = 210) }\end{array}$ \\
\hline $\begin{array}{l}\text { Driver } \\
\text { Proficiency }\end{array}$ & 78 & $37 \%$ \\
\hline Willful Behavior & 85 & $40 \%$ \\
\hline Infrastructure & 26 & $12 \%$ \\
\hline Undeterminable & 19 & $9 \%$ \\
\hline Impairment & 2 & $1 \%$ \\
\hline Total & $\mathbf{2 1 0}$ & $\mathbf{1 0 0 \%}$ \\
\hline
\end{tabular}




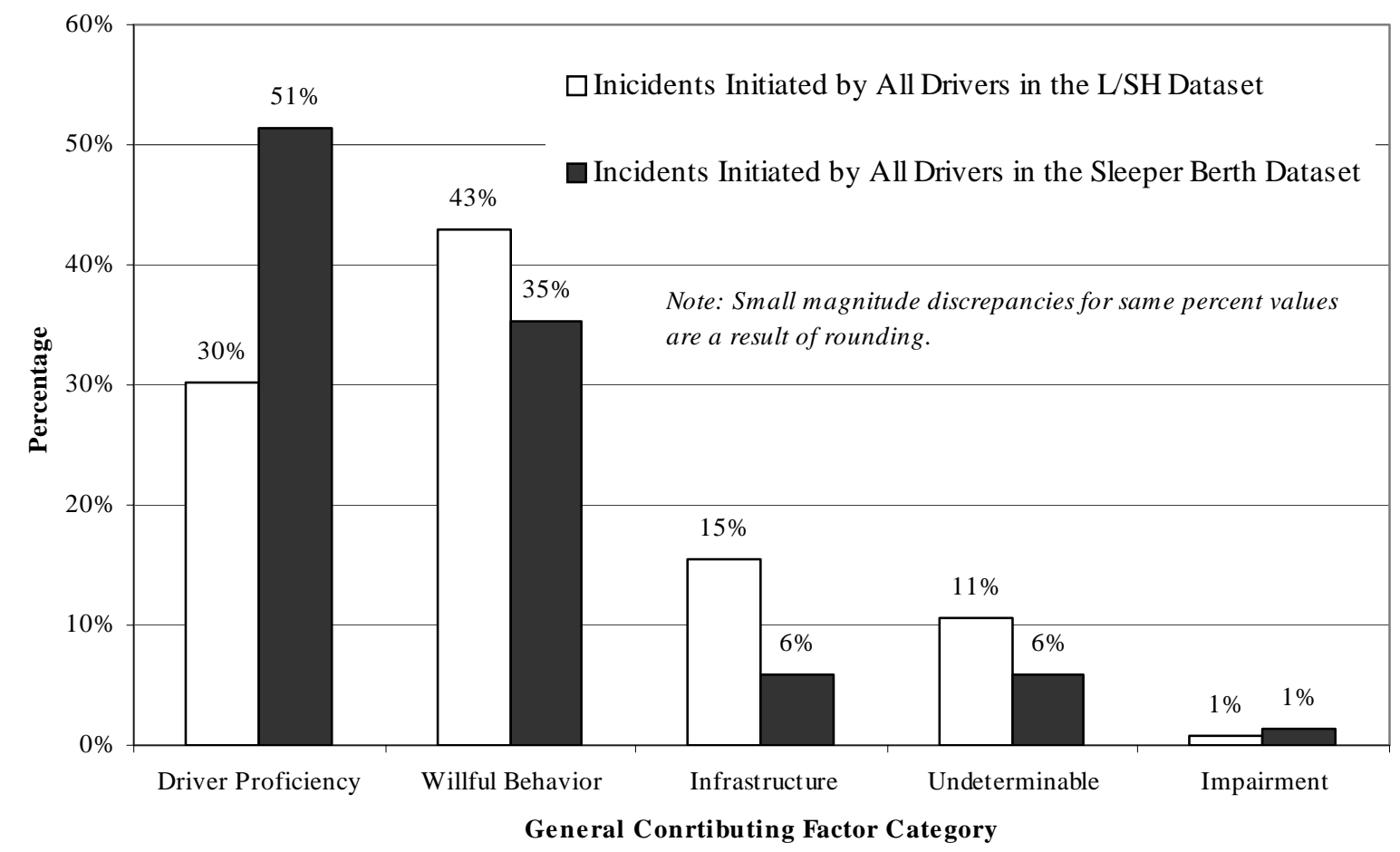

Figure 73. Percentage of incident occurrence as a function of the General Contributing Factors; all incidents from both data sets included. 


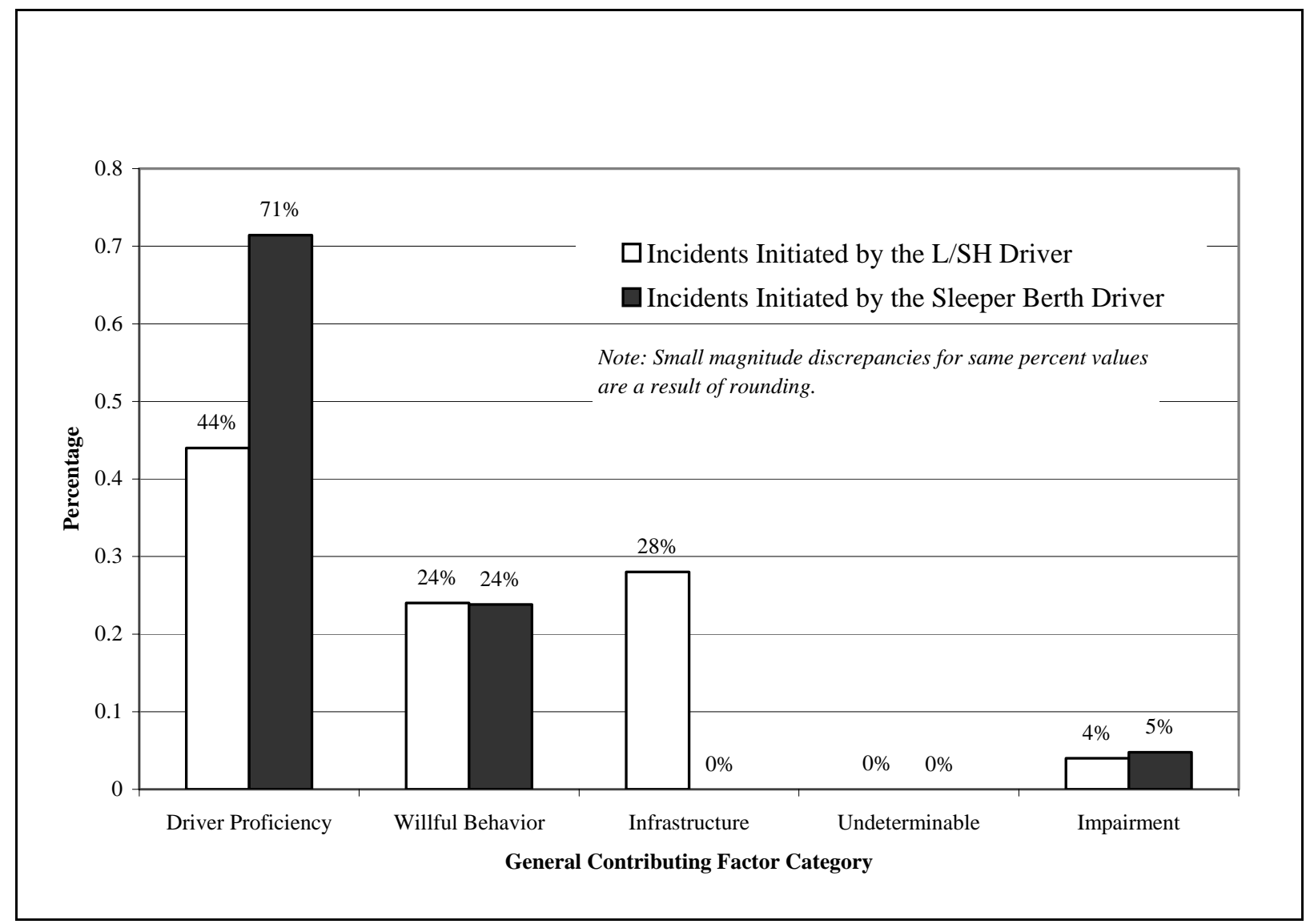

Figure 74. Percentage of incident occurrence as a function of the General Contributing Factors for heavy vehicle driver-initiated incidents. 


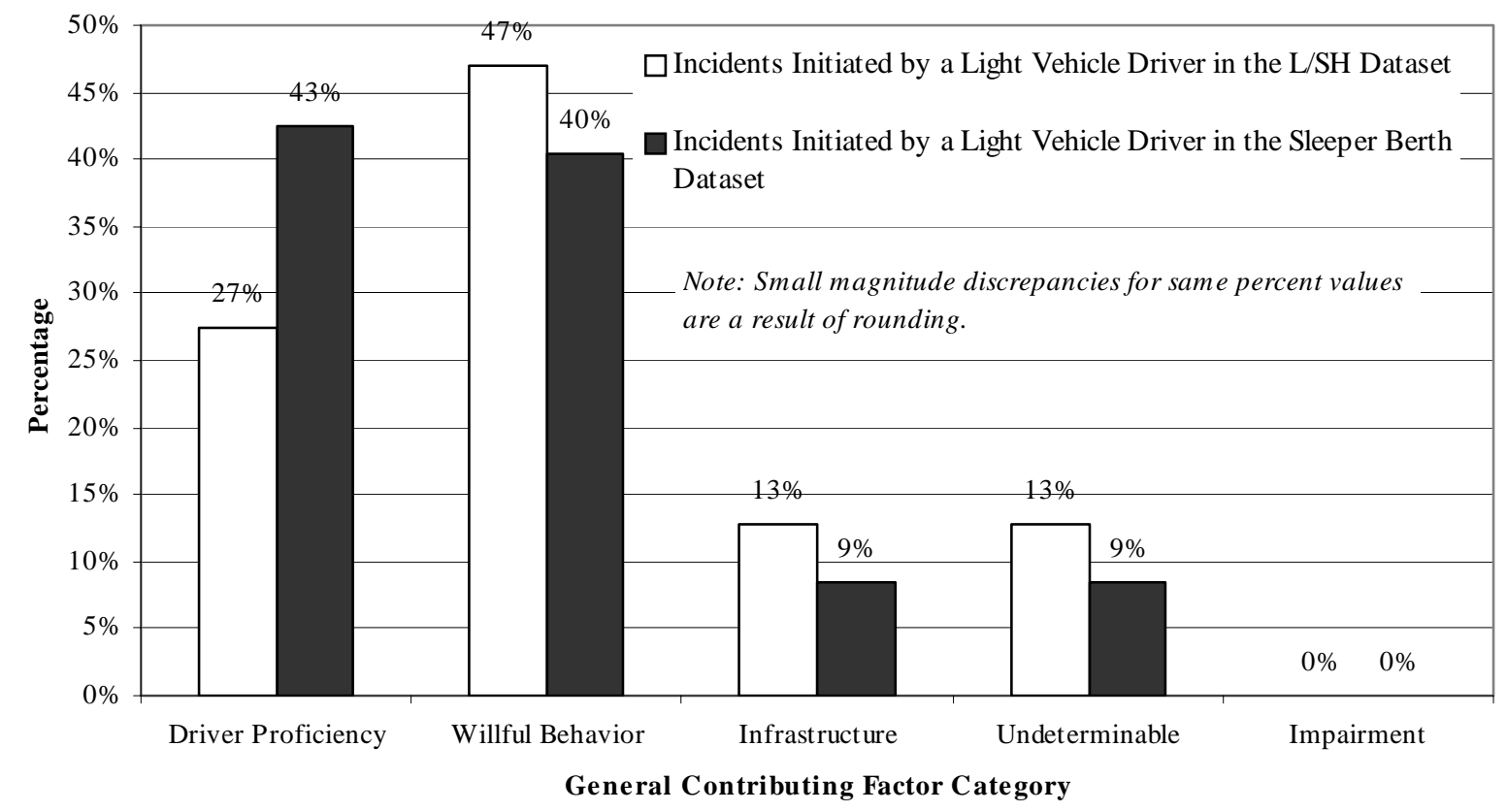

Figure 75. Percentage of incident occurrence as a function of the General Contributing Factors for heavy vehicle driver-initiated incidents.

As shown in Figure 73, across all incidents the General Contributing Factors with the highest percentages were Driver Proficiency and Willful Behavior. Looking at Figure 74, it can be seen that Driver Proficiency was the most common General Contributing Factor for HV driverinitiated incidents, while Figure 75 shows that Willful Behavior was, overall, most common for LV driver-initiated incidents. Infrastructure was found to play a greater role in the L/SH incidents, likely due to the urban driving environment more common in L/SH operations.

To more fully understand the General Contributing Factors associated with the incidents, one must examine the Specific Contributing Factors. Table 31 provides the descriptive statistics for the Specific Contributing Factors for both the L/SH and Sleeper Berth data sets. The frequency of occurrence data for all incidents is shown in Figure 76. As can be seen, the Specific Contributing Factor comprising the majority of incidents in the Driver Proficiency category was Driving Techniques. Driving Techniques accounted for 24 percent of the L/SH incidents and 46 percent of the SB incidents. Aggressive Driving was the most commonly indicated Specific Contributing Factor for the Willful Behavior category and accounted for 37 percent of the L/SH incidents and 35 percent of the SB incidents. For the Infrastructure General Contributing Factor, Roadway Alinement was the most commonly occurring Specific Contributing Factor across both data sets. 
Table 31. Specific Contributing Factor descriptive statistics for the L/SH and Sleeper Berth data sets.

\begin{tabular}{|c|c|c|c|c|c|c|c|}
\hline & \multicolumn{7}{|c|}{ Local/ Short Haul } \\
\hline $\begin{array}{c}\text { Specific } \\
\text { Contributing } \\
\text { Factor Category }\end{array}$ & $\begin{array}{c}\text { General } \\
\text { Contributing } \\
\text { Factor Category }\end{array}$ & \begin{tabular}{|c|}
$\begin{array}{c}\text { Frequency } \\
\text { of }\end{array}$ \\
Occurrence: \\
Incidents \\
Initiated by \\
$\mathrm{L} / \mathrm{SH}$ Driver \\
$\left(\mathrm{N}_{\mathrm{L} / \mathrm{SH}}=25\right)$
\end{tabular} & $\begin{array}{c}\begin{array}{c}\text { Percentage } \\
\text { of }\end{array} \\
\text { Occurrence: } \\
\text { Incidents } \\
\text { Initiated by } \\
\text { L/SH Driver } \\
\left(\mathrm{N}_{\mathrm{L} / \mathrm{SH}}=25\right) \\
\end{array}$ & $\begin{array}{c}\text { Frequency of } \\
\text { Occurrence: } \\
\text { Incidents } \\
\text { Initiated by } \\
\text { Light Vehicle } \\
\text { Driver } \\
\left(\mathrm{N}_{\mathrm{LV}}=117\right) \\
\end{array}$ & $\begin{array}{c}\text { Percentage of } \\
\text { Occurrence: } \\
\text { Incidents } \\
\text { Initiated by } \\
\text { Light Vehicle } \\
\text { Driver } \\
\left(\mathrm{N}_{\mathrm{LV}}=117\right) \\
\end{array}$ & \begin{tabular}{|c|} 
Frequency of \\
Occurrence: \\
Incidents \\
Initiated by All \\
Drivers \\
$\left(\mathbf{N}_{\text {total }}=142\right)$ \\
\end{tabular} & $\begin{array}{l}\text { Percentage of } \\
\text { Occurrence: } \\
\text { Incidents } \\
\text { Initiated by All } \\
\text { Drivers } \\
\left(\mathbf{N}_{\text {Total }}=142\right) \\
\end{array}$ \\
\hline Aggressive Driving & Willful Behavior & 3 & $12 \%$ & 50 & $43 \%$ & 53 & $37 \%$ \\
\hline Driving Techniques & Driver Proficiency & 8 & $32 \%$ & 26 & $22 \%$ & 34 & $24 \%$ \\
\hline $\begin{array}{l}\text { Roadway } \\
\text { Alinement }\end{array}$ & Infrastructure & 7 & $28 \%$ & 8 & $7 \%$ & 15 & $11 \%$ \\
\hline Undeterminable & Undeterminable & 0 & $0 \%$ & 15 & $13 \%$ & 15 & $11 \%$ \\
\hline \begin{tabular}{|l|} 
Purposeful \\
Violation of Traffic \\
Laws, Regulations \\
\end{tabular} & Willful Behavior & 2 & $8 \%$ & 5 & $4 \%$ & 7 & $5 \%$ \\
\hline $\begin{array}{l}\text { Roadway Sight } \\
\text { Distance }\end{array}$ & Infrastructure & 0 & $0 \%$ & 7 & $6 \%$ & 7 & $5 \%$ \\
\hline $\begin{array}{l}\text { Driver Capabilities } \\
\text { and Limitations }\end{array}$ & Driver Proficiency & 2 & $8 \%$ & 3 & $3 \%$ & 5 & $4 \%$ \\
\hline $\begin{array}{l}\text { Vehicle } \\
\text { Kinematics, } \\
\text { Physics }\end{array}$ & Driver Proficiency & 1 & $4 \%$ & 1 & $1 \%$ & 2 & $1 \%$ \\
\hline \begin{tabular}{|l|} 
Fatigue and \\
Drowsiness
\end{tabular} & Impairment & 1 & $4 \%$ & 0 & $0 \%$ & 1 & $1 \%$ \\
\hline $\begin{array}{l}\text { Unfamiliar With } \\
\text { Roadway/ Traffic } \\
\text { Pattern }\end{array}$ & Driver Proficiency & 0 & $0 \%$ & 2 & $2 \%$ & 2 & $1 \%$ \\
\hline $\begin{array}{l}\text { Use of Vehicle For } \\
\text { Improper Purposes } \\
\text { (Intimidation) }\end{array}$ & Willful Behavior & 1 & $4 \%$ & 0 & $0 \%$ & 1 & $1 \%$ \\
\hline TOTAL & & 25 & $100 \%$ & 117 & $100 \%$ & 142 & $100 \%$ \\
\hline
\end{tabular}


Table 31. Continued.

\begin{tabular}{|c|c|c|c|c|c|c|c|}
\hline & \multicolumn{7}{|c|}{ Sleeper Berth } \\
\hline $\begin{array}{c}\text { Specific } \\
\text { Contributing } \\
\text { Factor Category }\end{array}$ & $\begin{array}{c}\text { General } \\
\text { Contributing } \\
\text { Factor Category }\end{array}$ & \begin{tabular}{|c|}
$\begin{array}{c}\text { Frequency } \\
\text { of }\end{array}$ \\
Occurrence: \\
Incidents \\
Initiated by \\
Sleeper \\
Berth \\
Driver \\
$\left(\mathrm{N}_{\mathrm{SB}}=20\right)$ \\
\end{tabular} & \begin{tabular}{|c|}
$\begin{array}{c}\text { Percentage } \\
\text { of }\end{array}$ \\
Occurrence: \\
Incidents \\
Initiated by \\
Sleeper \\
Berth Driver \\
$\left(\mathrm{N}_{\mathrm{SB}}=20\right)$ \\
\end{tabular} & $\begin{array}{c}\text { Frequency of } \\
\text { Occurrence: } \\
\text { Incidents } \\
\text { Initiated by } \\
\text { Light Vehicle } \\
\text { Driver } \\
\left(\mathrm{N}_{\mathrm{LV}}=48\right)\end{array}$ & $\begin{array}{l}\text { Percentage of } \\
\text { Occurrence: } \\
\text { Incidents } \\
\text { Initiated by } \\
\text { Light Vehicle } \\
\text { Driver } \\
\left(\mathrm{N}_{\mathrm{LV}}=48\right)\end{array}$ & \begin{tabular}{|} 
Frequency of \\
Occurrence: \\
Incidents \\
Initiated by All \\
Drivers \\
$\left(\mathbf{N}_{\text {Total }}=68\right)$
\end{tabular} & $\begin{array}{c}\text { Percentage of } \\
\text { Occurrence: } \\
\text { Incidents } \\
\text { Initiated by } \\
\text { All Drivers } \\
\left(\mathbf{N}_{\text {Total }}=68\right)\end{array}$ \\
\hline Aggressive Driving & Willful Behavior & 5 & $24 \%$ & 19 & $40 \%$ & 24 & $35 \%$ \\
\hline Driving Techniques & Driver Proficiency & 11 & $52 \%$ & 20 & $43 \%$ & 31 & $46 \%$ \\
\hline \begin{tabular}{|l} 
Roadway \\
Alinement
\end{tabular} & Infrastructure & 0 & $0 \%$ & 4 & $9 \%$ & 4 & $6 \%$ \\
\hline Undeterminable & Undeterminable & 0 & $0 \%$ & 4 & $9 \%$ & 4 & $6 \%$ \\
\hline \begin{tabular}{|l} 
Purposeful \\
Violation of Traffic \\
Laws, Regulations \\
\end{tabular} & Willful Behavior & 0 & $0 \%$ & 0 & $0 \%$ & 0 & $0 \%$ \\
\hline \begin{tabular}{|l|} 
Roadway Sight \\
Distance
\end{tabular} & Infrastructure & 0 & $0 \%$ & 0 & $0 \%$ & 0 & $0 \%$ \\
\hline \begin{tabular}{|l|} 
Driver Capabilities \\
and Limitations \\
\end{tabular} & Driver Proficiency & 1 & $5 \%$ & 0 & $0 \%$ & 1 & $1 \%$ \\
\hline \begin{tabular}{|l|} 
Vehicle \\
Kinematics, \\
Physics \\
\end{tabular} & Driver Proficiency & 3 & $14 \%$ & 0 & $0 \%$ & 3 & $4 \%$ \\
\hline \begin{tabular}{|l|} 
Fatigue and \\
Drowsiness \\
\end{tabular} & Impairment & 1 & $5 \%$ & 0 & $0 \%$ & 1 & $1 \%$ \\
\hline $\begin{array}{l}\text { Unfamiliar With } \\
\text { Roadway/ Traffic } \\
\text { Pattern }\end{array}$ & Driver Proficiency & 0 & $0 \%$ & 0 & $0 \%$ & 0 & $0 \%$ \\
\hline $\begin{array}{l}\text { Use of Vehicle For } \\
\text { Improper Purposes } \\
\text { (Intimidation) }\end{array}$ & Willful Behavior & 0 & $0 \%$ & 0 & $0 \%$ & 0 & $0 \%$ \\
\hline TOTAL & & 21 & $100 \%$ & 47 & $100 \%$ & 68 & $94 \%$ \\
\hline
\end{tabular}


Table 31. Continued and concluded.

\begin{tabular}{|c|c|c|c|}
\hline \multirow{2}{*}{\begin{tabular}{|c|} 
Specific Contributing Factor \\
Category
\end{tabular}} & \multicolumn{3}{|c|}{ All } \\
\hline & $\begin{array}{l}\text { General Contributing Factor } \\
\text { Category }\end{array}$ & \begin{tabular}{|c} 
Frequency of Occurrence: All \\
Incidents Included \\
$\left(\mathrm{N}_{\text {Total }}=210\right)$
\end{tabular} & $\begin{array}{c}\text { Percentage of Occurrence: } \\
\text { All Incidents Included } \\
\left(\mathbf{N}_{\text {Total }}=210\right) \\
\end{array}$ \\
\hline Aggressive Driving & Willful Behavior & 77 & $37 \%$ \\
\hline Driving Techniques & Driver Proficiency & 65 & $31 \%$ \\
\hline Roadway Alinement & Infrastructure & 19 & $9 \%$ \\
\hline Undeterminable & Undeterminable & 19 & $9 \%$ \\
\hline \begin{tabular}{|l} 
Purposeful Violation of Traffic \\
Laws, Regulations
\end{tabular} & Willful Behavior & 7 & $3 \%$ \\
\hline Roadway Sight Distance & Infrastructure & 7 & $3 \%$ \\
\hline Driver Capabilities and Limitations & Driver Proficiency & 6 & $3 \%$ \\
\hline Vehicle Kinematics, Physics & Driver Proficiency & 5 & $2 \%$ \\
\hline Fatigue and Drowsiness & Impairment & 2 & $1 \%$ \\
\hline $\begin{array}{l}\text { Unfamiliar With Roadway/ Traffic } \\
\text { Pattern }\end{array}$ & Driver Proficiency & 2 & $1 \%$ \\
\hline \begin{tabular}{|l|} 
Use of Vehicle For Improper \\
Purposes (Intimidation)
\end{tabular} & Willful Behavior & 1 & $0 \%$ \\
\hline TOTAL & & 210 & $100 \%$ \\
\hline
\end{tabular}




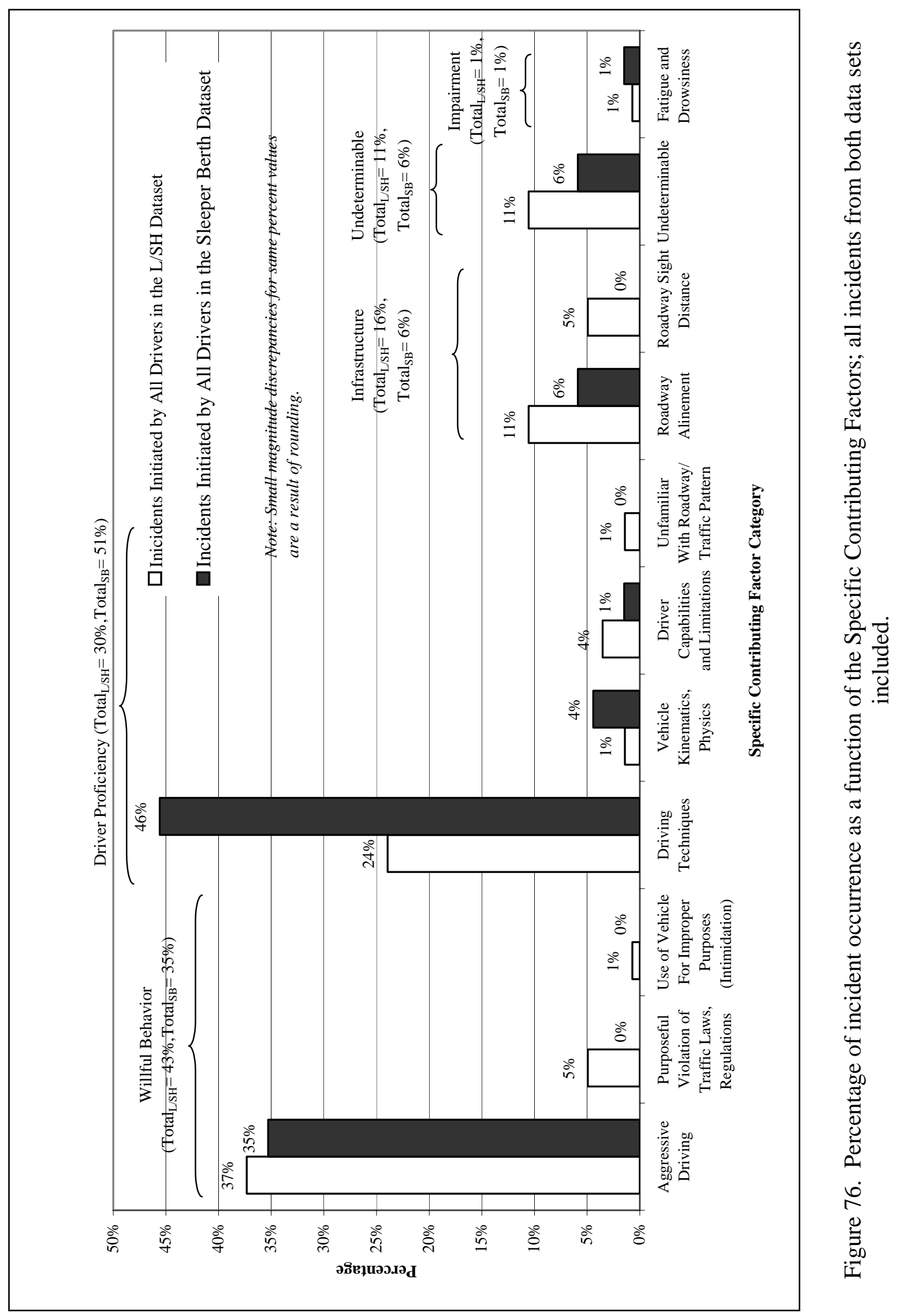


Figure 77 shows the Specific Contributing Factors for the HV driver-initiated incidents. For both the L/SH and SB drivers, the most frequent factor was Driving Techniques. The factor with the second highest frequency was Roadway Alinement for L/SH drivers (28 percent), and Aggressive Driving for SB drivers (24 percent). As indicated previously, there were no SB driver-initiated incidents attributed to Infrastructure, most likely due to the driving environments. Aggressive Driving was found as a factor for L/SH drivers, but to a lesser degree than for SB drivers (12 vs. 24 percent). However, across the entire Willful Behavior category, the percentage of incidents for $\mathrm{L} / \mathrm{SH}$ drivers was equal to the percentage for SB drivers (24 percent). 


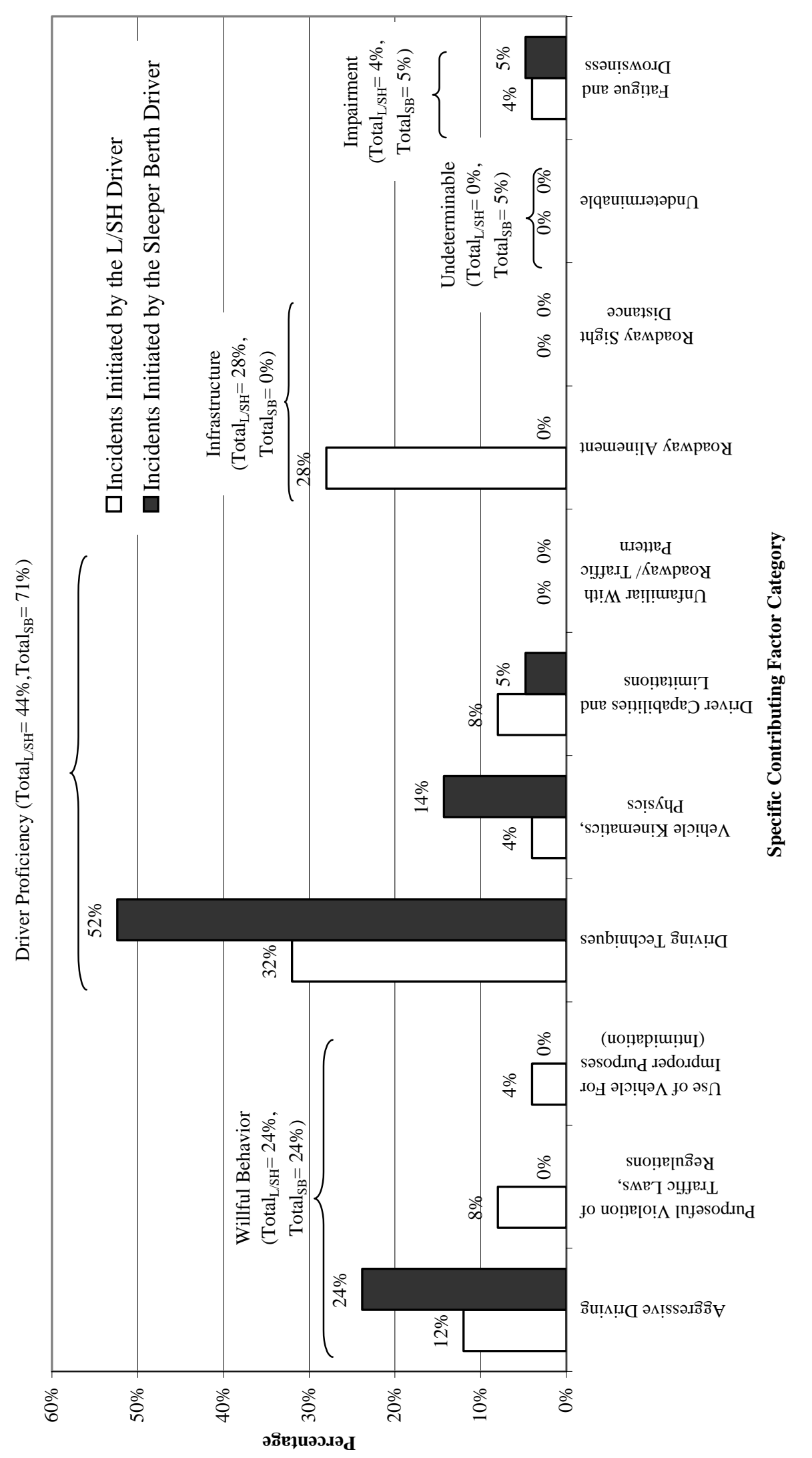

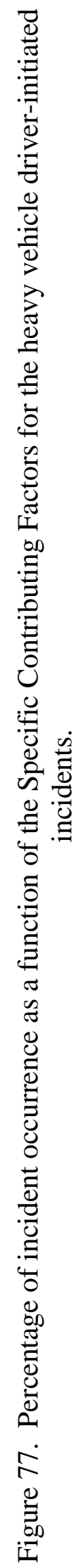


The breakdown of the Specific Contributing Factors for the incidents caused by LV drivers is shown in Figure 78. Perhaps the most noticeable result shown in the figure is that Aggressive Driving accounted for a large number of incidents across both data sets, 43 percent in the L/SH data set, and 40 percent in the Sleeper Berth data set. Driving Techniques had the second largest number of incidents for LV drivers in both data sets, 22 percent in the L/SH data set, and 43 percent in the Sleeper Berth data set. 


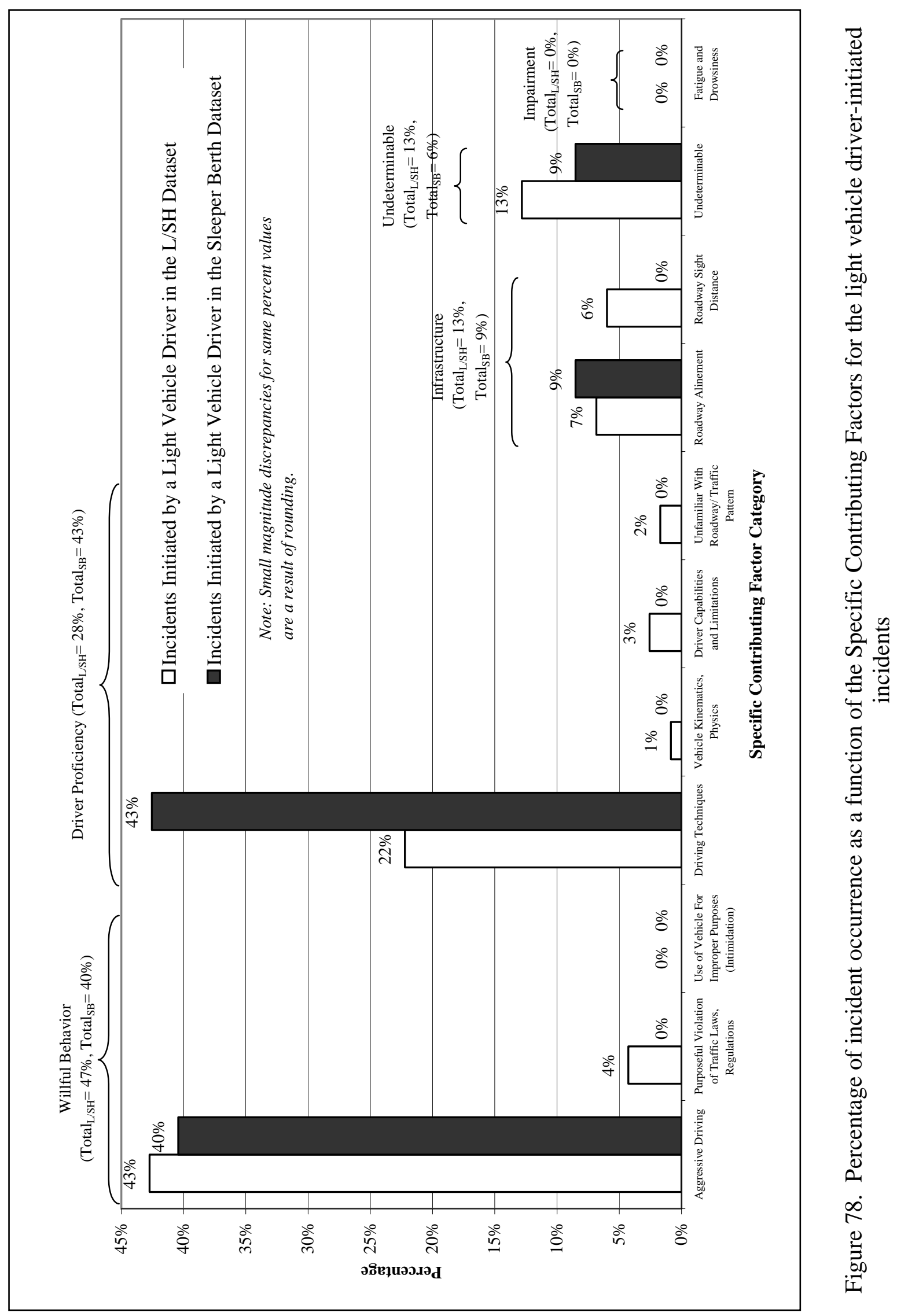




\section{Differences Due to Data Collection Methods}

Another important consideration in comparing the local/short haul and Sleeper Berth data sets is the different data collection methods used in the two studies. L/SH video was recorded continuously. When threshold levels for the pre-set triggers on the truck were met, such as hard braking or steering, a flag was inserted into the data set (and shown on the video). The purpose of these flags was to alert the video analyst that a critical incident may have occurred. The video analyst would use these flags to identify, or validate, incidents that occurred. However, analysts also watched for incidents that occurred without a flag. In the Sleeper Berth study, however, only the video surrounding these trigger events was recorded. That is, the video in the Sleeper Berth study was not recorded continuously. Therefore, only events resulting in a trigger could be analyzed, not non-triggered events as in the L/SH study. The Sleeper Berth data set may not fully reflect the complete set of critical incidents that occurred during the study.

This section examines possible differences in the two data sets that may have resulted from the data collection method used in each study. The six triggers utilized in the L/SH system are outlined in Table 32, and the 13 triggers utilized in the sleeper berth system are outlined in Table 33. As discussed in Hanowski et al. (2000), the trigger criteria used in the L/SH study were "tweaked" for each of the four trucks used depending on the characteristics of the truck. For example, steering angle rate was set differently for trucks that had substantial "play" in the steering wheel as compared to trucks with less play. As such, the criteria levels shown in Table 32 represent the approximate values used. In comparing Tables 32 and 33, the reader will notice that three of the triggers used in the Sleeper Berth study (the PERCLOS rating, Sleepiness rating 7, 8, or 9, and Sleep rating $=$ No Response) are associated with the drowsiness of the driver and not a specific driving behavior, per se. Drowsiness measures were also collected during the L/SH study; however, this did not occur real-time as in the Sleeper Berth study. Rather, drowsiness measures were collected off-line by analysts reviewing the videotapes and from the data collected from the paper-and-pencil questionnaires.

Table 32. Trigger types utilized in the Local/ Short Haul study.

\begin{tabular}{|l|l|}
\hline \multicolumn{1}{|c|}{ Trigger Type } & \multicolumn{1}{c|}{ Trigger Criteria } \\
\hline Steering & $\begin{array}{l}\text { Absolute steering angle rate above } 6.28 \mathrm{rad} / \mathrm{sec} \text { and } \\
\text { longitudinal speed above } 32.19 \mathrm{~km} / \mathrm{h}(20 \mathrm{mph}) \text { (intended to } \\
\text { pick up panic steering). }\end{array}$ \\
\hline Lateral acceleration & $\begin{array}{l}\text { Absolute lateral acceleration greater than } 0.25 \mathrm{~g} \text { and } \\
\text { longitudinal speed above } 32.19 \mathrm{~km} / \mathrm{h} \text { (20 mph) (intended to } \\
\text { pick up evasive maneuvers). }\end{array}$ \\
\hline $\begin{array}{l}\text { Zero-velocity limited lateral } \\
\text { acceleration }\end{array}$ & $\begin{array}{l}\text { Absolute lateral acceleration above } 0.5 \mathrm{~g} \text { (intended to pick up } \\
\text { side collisions). }\end{array}$ \\
\hline Longitudinal deceleration & $\begin{array}{l}\text { Longitudinal deceleration above } 0.5 \mathrm{~g} \text { (intended to sense panic } \\
\text { braking). }\end{array}$ \\
\hline Longitudinal acceleration & $\begin{array}{l}\text { Longitudinal acceleration above } 0.5 \mathrm{~g} \text { (intended to sense being } \\
\text { hit in the rear). }\end{array}$ \\
\hline Critical Incident push button & Actuation of a critical incident pushbutton by driver. \\
\hline
\end{tabular}


Table 33. Trigger types utilized in the Sleeper Berth study.

\begin{tabular}{|l|l|}
\hline \multicolumn{1}{|c|}{ Trigger Type } & \multicolumn{1}{c|}{ Trigger Criteria } \\
\hline Steering & $\begin{array}{l}\text { Steering wheel angular velocity above 3.64 radians/ second } \\
\text { (intended to pick up panic steering). }\end{array}$ \\
\hline Lateral acceleration & $\begin{array}{l}\text { Lateral acceleration above 0.30 g and longitudinal speed above } \\
\text { 20 mph (intended to pick up evasive maneuvers). }\end{array}$ \\
\hline $\begin{array}{l}\text { Zero-velocity limited lateral } \\
\text { acceleration }\end{array}$ & $\begin{array}{l}\text { Lateral Acceleration above 2.2 g and speed= 0mph (intended to } \\
\text { pick up side collisions). }\end{array}$ \\
\hline Longitudinal deceleration & $\begin{array}{l}\text { Longitudinal deceleration above 0.25 g and longitudinal speed } \\
\text { above 20 mph (intended to sense panic braking). }\end{array}$ \\
\hline Longitudinal acceleration & $\begin{array}{l}\text { Longitudinal acceleration above 2.5 g and speed= 0mph } \\
\text { (intended to sense being hit in the rear). }\end{array}$ \\
\hline Time to collision & $\begin{array}{l}\text { Closing distance from driver to lead vehicle is less than 4.0 } \\
\text { seconds. }\end{array}$ \\
\hline PERCLOS Rating & $\begin{array}{l}\text { Driver's eyes are closed 8.0 \% of any given minute as measured } \\
\text { by the PERCLOS sensor inside the truck. }\end{array}$ \\
\hline Sleepiness Rating 7, 8, or 9. & $\begin{array}{l}\text { Driver rates him/herself as a 7,8, or 9 on a 9-point drowsiness } \\
\text { scale, where 1= not drowsy and 9= extremely drowsy. Driver } \\
\text { prompted for a sleep rating at each Timed Trigger. }\end{array}$ \\
\hline Timed trigger & $\begin{array}{l}\text { Activated randomly in 90-minute intervals; allows baseline data } \\
\text { to be collected. }\end{array}$ \\
\hline Critical Incident push button & Actuation of a critical incident pushbutton by driver. \\
\hline $\begin{array}{l}\text { Sleepiness Rating = No } \\
\text { Response. }\end{array}$ & $\begin{array}{l}\text { No Response from the diver when queried for Sleepiness } \\
\text { Rating. }\end{array}$ \\
\hline Lane departure & Deviation from lane without complete lane change. \\
\hline $\begin{array}{l}\text { Lane departure with side } \\
\text { sensor active }\end{array}$ & $\begin{array}{l}\text { Simultaneous occurrence of lane departure and Steering } \\
\text { triggers. }\end{array}$ \\
\hline
\end{tabular}

In examining the methodology differences of the two approaches used to identify critical incidents, it is assumed that the occurrence ratio of triggered versus non-triggered events observed in the L/SH study may be generalized to the Sleeper Berth data set. If this is the case, one could predict the frequency of non-triggered events that may have occurred in the Sleeper Berth study based on the frequency of recorded triggered events. The ratio of triggered to nontriggered events in the L/SH data set was 18:124, or 1:6.89. That is, for every triggered event, there were almost seven non-triggered events. It is hypothesized that one might expect a similar ratio of triggered to non-triggered events in the Sleeper Berth data set. All 68 events recorded and analyzed in the Sleeper Berth data set were, as indicated, triggered events. However, as shown in Tables 32 and 33, there were seven trigger types utilized in the Sleeper Berth study that were not used in the L/SH study. Only one of these seven triggers, Time-to-Collision, flagged events that were analyzed in the present LV-HV study. Excluding events of this trigger type for comparison purposes, there were 52 events in the Sleeper Berth data set that were associated with the same triggers as those seen in the $\mathrm{L} / \mathrm{SH}$ data set. If the ratio mentioned above may be generalized to the Sleeper Berth study, 52 x 6.89, or 358 non-triggered events, potentially 
occurred during the study. Thus, the total number of events (triggered and non-triggered) expected to occur is $358+52$, or 410 events. As only 68 events were captured and analyzed in this study, there may have been approximately 342 events that occurred but were not recorded with the Sleeper Berth data collection method.

Another important consideration is whether triggered events differ in nature from non-triggered events. In other words, do the events recorded and analyzed in the Sleeper Berth data set represent the typical events drivers are involved in while driving? Figure 79 shows the percentage frequency of Incident Types of triggered and non-triggered events in the L/SH data set. Recall that data in the L/SH study were recorded continuously and thus virtually all events were analyzed. While most Incident Types occurred with roughly equal frequency in triggered and non-triggered events, Lane Change Without Sufficient Gap and Wide Turn Into Adjacent Lane are seen far more frequently in non-triggered events than triggered events. The reason for this may be that these particular Incident Types occurred subtly and did not have a direct trigger, per se. Thus, analyzing only triggered events in the Sleeper Berth data set may under-represent events of these Incident Types. 


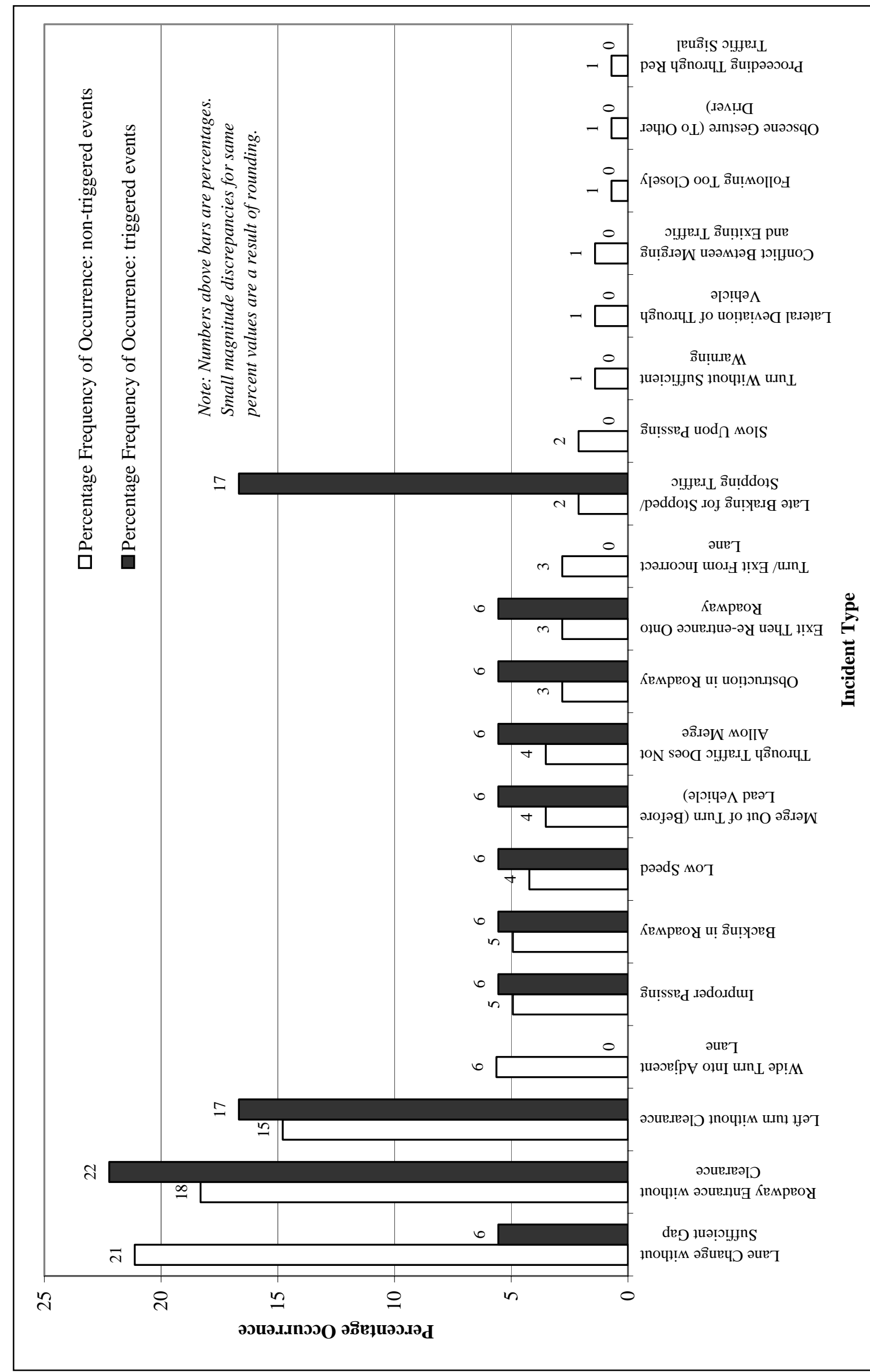

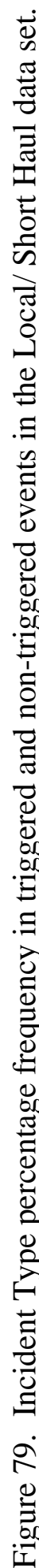


To account for the differences due to the data collection methods used in the two studies, let us compare only triggered events in both data sets. Again, this would include 18 of the 142 local/short haul events and 52 of the 68 sleeper berth events (discounting events associated with the Time-to-Collision trigger that was not used in the L/SH system). The percentage frequencies of these events are shown in Figure 80. It is worthwhile to revisit Figure 66, presented earlier, which included both triggered and non-triggered events. For convenience, the Figure 66 histogram of all events from both data sets is re-presented as Figure 81. 


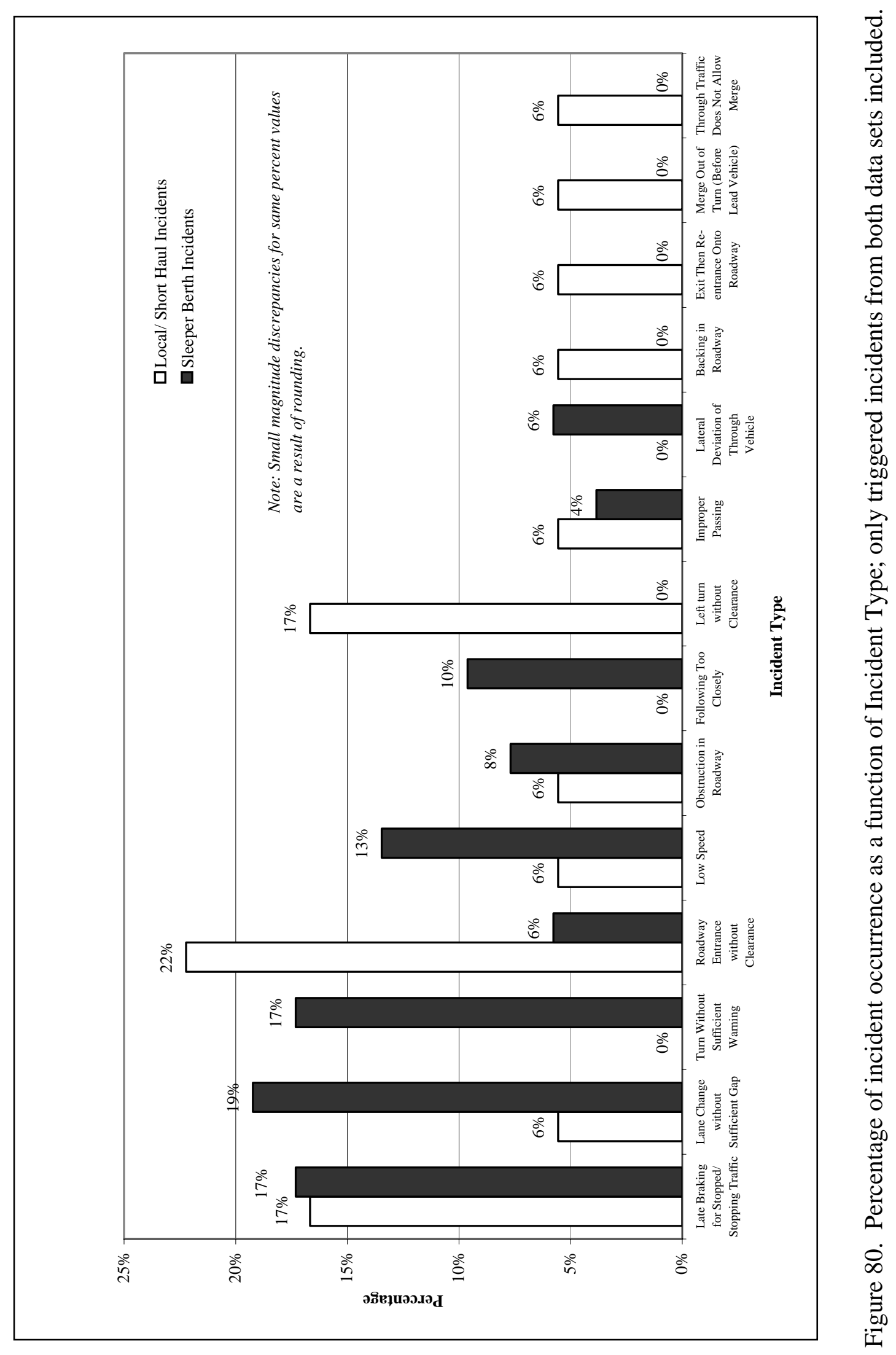




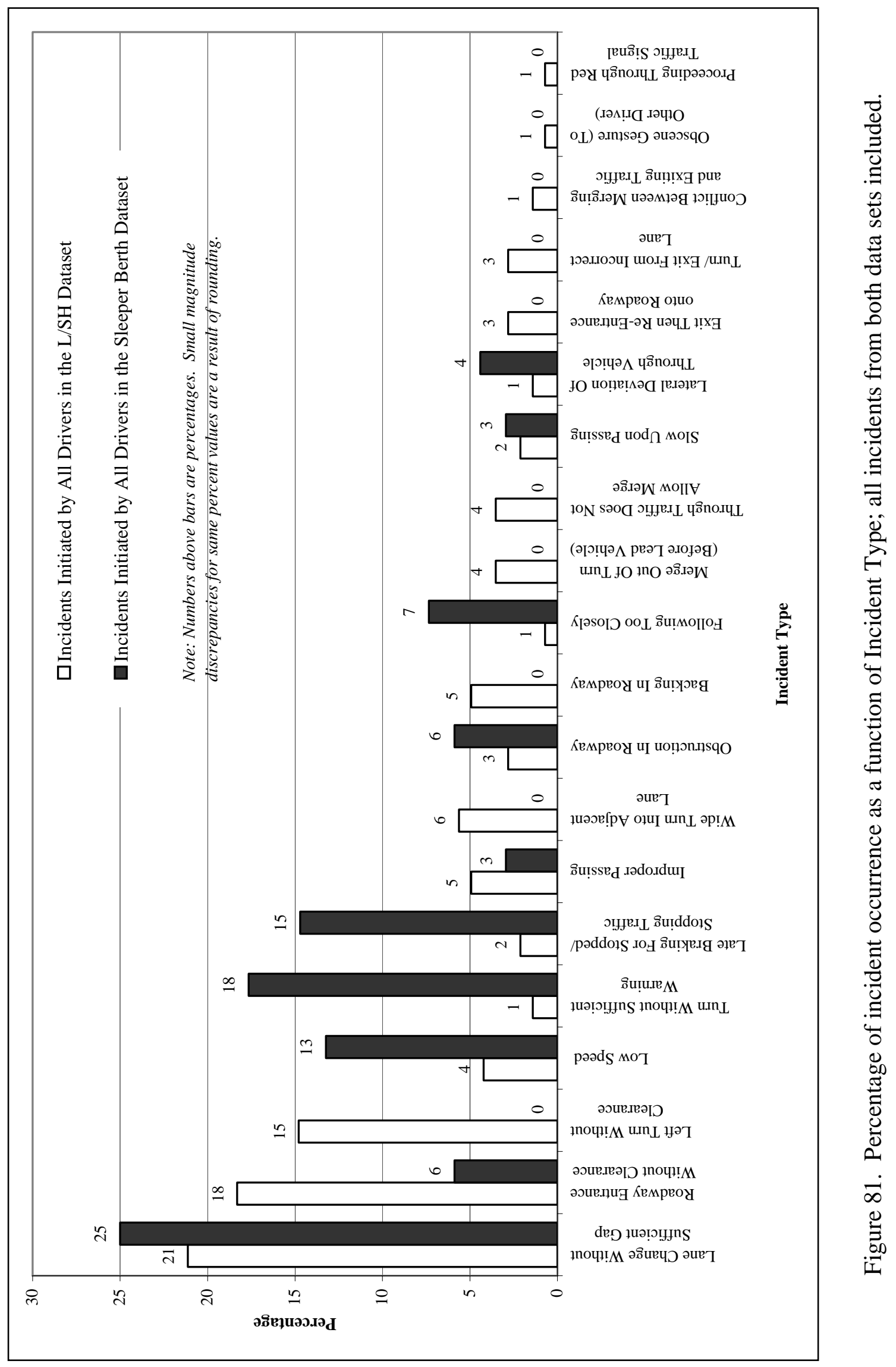


In comparing the results shown in Figures 80 and 81, the most striking result is the frequency of Late Braking for Stopped/Stopping Traffic in the two data sets. In the uncorrected analysis, this Incident Type accounted for far more events in the Sleeper Berth data set than in the L/SH data set; 15 percent of sleeper berth events versus 2 percent of L/SH events. However, when only triggered events are included, the percent frequencies of this Incident Type are approximately equal. This finding indicates that Late Braking for Stopped/Stopping Traffic more commonly resulted in a trigger, as would be expected considering the nature of the behavior (i.e., late braking). This Incident Type may, therefore, have been over-represented in the Sleeper Berth data set. The remaining Incident Types in the corrected analysis show little difference from the original results, indicating that the trigger method may accurately reflect the nature of critical incidents in which drivers were involved. It may be that this method is more likely to capture the most severe events; that is, incidents in which the driver engaged in an extreme action are probably more likely to activate a trigger.

The data sets may be further corrected for exposure time, or how much data were collected for each study. As previously mentioned, a total of 957 hours were collected for L/SH drivers, while 2,252 hours were collected for SB drivers. Figure 82 shows the Incident Type rate of occurrence among triggered events in the two data sets. This rate is expressed as the number of events that occurred per 1,000 hours of driving time. 


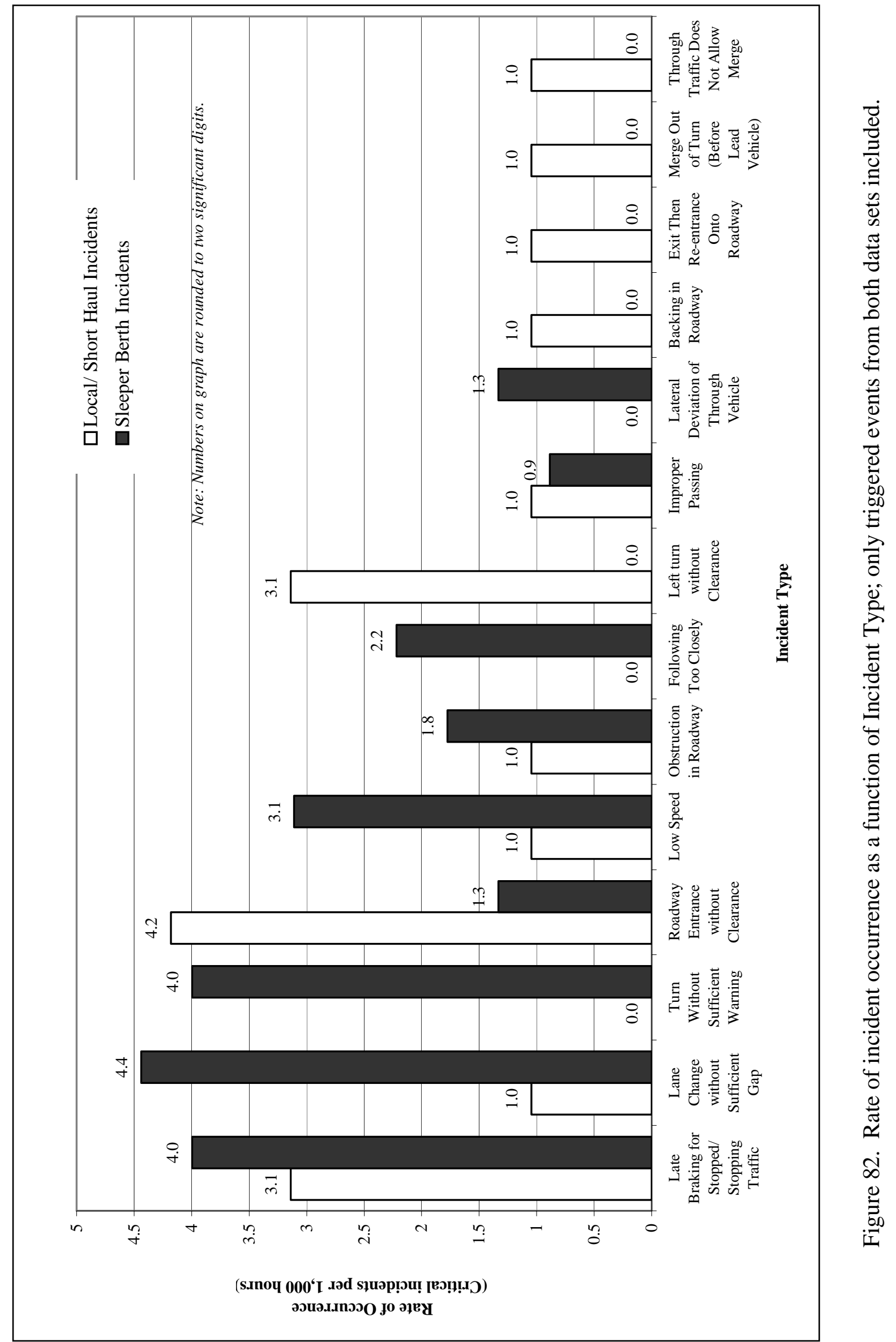


For the most part, the results in this histogram are comparable to those in Figure 81, which is uncorrected for time or trigger occurrence. However, note that while Lane Change Without Sufficient Gap occurs more frequently for sleeper berth drivers than local/short haul drivers in both figures, the difference is even more pronounced when corrected for driving time. This result is consistent with an observation stated earlier; that is, likely due to their driving environment, sleeper berth drivers are involved in far more lane change-related conflicts.

\section{DISCUSSION OF THE RESULTS COMPARING THE L/SH AND SLEEPER BERTH ANALYSES}

The purpose of this project was to investigate LV-HV interaction critical incidents that were captured during two on-road field data collection efforts conducted by VTTI. The project was divided into two phases. In Phase A, LV-HV interaction critical incidents from the recently completed L/SH study (Hanowski et al., 2000) were used. The results of Phase A were presented in Chapter 1. In Phase B, LV-HV interaction critical incidents from the on-going Sleeper Berth study were used. The results of Phase B were presented in Chapter 2. The analyses presented in the previous section compared the findings from the two research phases. The current section of this report presents a summary and discussion of the Phase A and Phase B results.

There were a number of interesting findings from the results comparison of the L/SH data (Phase A) and the Sleeper Berth data (Phase B). As was stated previously, a detailed examination of $\mathrm{LV}-\mathrm{HV}$ interaction incidents indicates that this is a serious problem on our nation's roadways. Across both data sets, $210 \mathrm{LV}$-HV interaction incidents were analyzed. Of these, 164 (78.1 percent) were initiated by a light vehicle driver. Put another way, nearly 8 out of every $10 \mathrm{LV}$ $\mathrm{HV}$ interaction incidents that were captured were caused by a light vehicle driver error. The ratio of light vehicle to heavy vehicle initiated incidents was 3.6:1. The high ratio presented here emphasizes the role that light vehicle drivers play in LV-HV interaction incidents.

Subsequently, future efforts aimed at addressing LV-HV interaction incidents should also focus on light vehicle drivers.

Comparisons between the findings from the L/SH analyses and the Sleeper Berth analyses were conducted for Incident Type, Primary Maneuver, General Contributing Factor, and Specific Contributing Factor. The Incident Type comparison indicated that Lane Change Without Sufficient Gap was the most common Incident Type in both data sets. A breakdown of incidents as a function of the initiating driver showed that Lane Change Without Sufficient Gap incidents were primarily attributed to light vehicle drivers. Critical incidents that involved a light vehicle driver changing lanes in front of a truck driver, leaving the truck driver with very little headway between vehicles, was a common incident type that was captured in both the L/SH and Sleeper Berth studies. In terms of heavy vehicle driver-initiated incidents, the most common types found were Late Braking for Stopped/Stopping Traffic (SB drivers) and Roadway Entrance Without Clearance (L/SH drivers). The comparisons of the contributing factors, discussed later, provided some insight into these Incident Types.

The Primary Maneuver associated with the incident was the next comparison that was made. For the Sleeper Berth data, Through (i.e., vehicle traveling forward on a roadway or straight through 
an intersection) and Lane Change maneuvers accounted for 72 percent of all incidents. The maneuvers associated with LV-HV interactions in the L/SH data set were more varied. Lane Change (23 percent), Left Turn (20 percent), Through (19 percent), Right Turn (13 percent), and Merge onto Roadway (11 percent) accounted for the majority of incidents recorded in the L/SH study. Further investigation of these maneuver types indicated that the Through maneuver was the primary type for both sleeper berth and L/SH driver-initiated incidents: 71 percent in SB and 44 percent in L/SH. Lane Change maneuvers were predominant for light vehicle drivers in both studies: 43 percent in SB and 26.5 percent in L/SH. Note that the predominant Primary Maneuvers for each group of drivers is consistent with the Incident Type classification presented in the previous paragraph. For example, one would expect that the Primary Maneuver for Late Braking for Stopped/Stopping Traffic would be Through. Indeed, as indicated by the SB driverinitiated incidents, this was the case.

Another expected finding regarding the Primary Maneuvers was that the maneuvers for each data set were consistent with the typical driving environment of the particular truck driving group. For example, it was expected that incidents in the L/SH data set would occur during Left Turn maneuvers and, in fact, 20 percent of the L/SH-related incidents occurred during Left Turns. On the other hand, because SB drivers operate primarily on the open highway, where there are few left turn maneuvers, Left Turn occurring incidents should be a small part of the incident data set. Indeed, this was the case. Left Turn maneuvers occurred in less than 10 percent of the SB incidents that were recorded. The important point of this discussion is that the incident data analyzed for this LV-HV interaction study involved a diverse set of driving characteristics, particularly with regard to the driving environment. The incident data that were analyzed included LV-HV interactions that were recorded on a variety of roadways and infrastructure types.

The contributing factors that were involved in the incidents were assessed at a high level (General Contributing Factors) and at a detailed level (Specific Contributing Factors). With regard to the General Contributing Factors, a comparison of the L/SH and SB incidents found that Driver Proficiency and Willful Behavior were the two most prevalent categories. These two categories accounted for 73 percent of all incidents in the L/SH data set and 86 percent of the incidents in the Sleeper Berth data set. A closer examination of these categories was conducted with the analysis of the Specific Contributing Factors. Across both data sets, it was found that Driving Techniques was the predominant Specific Contributing Factor in the Driver Proficiency category. This factor accounted for 24 percent of the L/SH incidents and 46 percent of the SB incidents. Aggressive Driving was the primary Specific Contributing Factor in the Willful Behavior category, accounting for 37 percent of the L/SH incidents and 35 percent of the SB incidents. Examining the Specific Contributing Factors as a function of the initiating driver proved quite interesting. Specifically, Driving Techniques was the predominant category for both L/SH and SB drivers, while Aggressive Driving was the primary Specific Contributing Factor category for light vehicle driver-initiated incidents. These findings support the results from the analysis of Incident Types presented previously. Recall, that Lane Change Without Sufficient Gap was the most common Incident Type for light vehicle driver-initiated incidents. The Aggressive Driving category fits this Incident Type well. Similarly, Late Braking for Stopped/Stopping Traffic (SB drivers) and Roadway Entrance Without Clearance (L/SH drivers) may be best represented by poor Driving Techniques. 
A final interesting finding with regard to the Specific Contributing Factors analysis was that Infrastructure was a factor in 28 percent of all $\mathrm{L} / \mathrm{SH}$ driver-initiated incidents. This finding suggests that drivers and/or companies should carefully consider the routes that drivers take when making their deliveries; sections of routes that are problematic for drivers should be avoided, if at all possible.

\section{Summary}

The results of the Phase A and Phase B analyses indicate that LV-HV interactions represent a serious problem. The detailed analyses that were conducted provide insight into how this problem might be addressed. The following are several concrete ideas that might be considered for reducing $\mathrm{LV}-\mathrm{HV}$ interactions:

- Addressing the LV-HV interaction problem must focus on the light vehicle driver. The light vehicle driver was the initiator in 78 percent of the LV-HV interaction incidents recorded.

- The primary area for light vehicle drivers that should be addressed involves Aggressive Driving. The majority of light vehicle driver-initiated critical incidents that were captured in both the L/SH and sleeper berth data collection efforts were due to Aggressive Driving.

- The primary area for heavy vehicle drivers that should be addressed involves Driving Techniques. Improved truck driver training programs should be implemented. Consideration should be given to ongoing (e.g., yearly) training courses. Given the high incidence of Aggressive Driving on the part of light vehicle drivers, one of the primary areas of focus for a truck driving training program should be on defensive driving.

- Infrastructure was found to play a role in L/SH driver-initiated incidents. Drivers and/or company dispatchers should be cognizant of problematic sections of routes, and avoid such locations to the greatest extent possible.

- In situ data collection is an effective way in which to study a wide range of safety-related issues in a naturalistic environment. The video and performance/behavior data collected from the L/SH and Sleeper Berth studies have been archived and provide a rich source of information that can be used for studying critical incidents, as was the case in the current effort, or other issues that might be identified at a later time. 
THIS PAGE INTENTIONALLY LEFT BLANK 


\section{REFERENCES}

Collins, D. J., Neale, V. L., and Dingus, T. A. (1999). Driver performance when using an invehicle signing information system considering adverse weather, visibility condition, and age. Proceedings of the Intelligent Transportation Society of America $9^{\text {th }}$ Annual Meeting and Exposition (CD-ROM). Washington, DC: Intelligent Transportation Society of America.

Craft, R. (1999, April). Driver-related factors in crashes between large trucks and passenger vehicles, analysis brief. Washington, DC: Federal Highway Administration, Office of Motor Carrier and Highway Safety.

Dingus, T. A., Hetrick, S., and Mollenhauer, M. (1999). Empirical methods in support of crash avoidance model building and benefits estimation. ITS Journal, 5, 93-125.

Dingus, T. A., Neale, V. L. Garness, S. A., Hanowski, R. J., Keisler, A. S., Lee, S. E., Perez, M. A., Robinson, G. S., Belz, S. M., Casali, J. G., Pace-Schott, E. F., Stickgold, R. A., and Hobson, J. A. (In press). Impact of sleeper berth usage on driver fatigue: Draft final project report. Contract No. DTFH61-96-00068. Washington, DC: Federal Motor Carrier Safety Administration

Federal Motor Carrier Safety Administration. The large truck crash fact 2000. Office of Data Analysis \& Information Systems, Federal Motor Carrier Safety Administration, U.S. Department of Transportation. FMCSA-RI-02-003, Washington, DC, August 2000.

Hankey, J. M., Wierwille, W. W., Cannell, W. J., Kieliszewski, C. A., Medina, A., Dingus, T. A., and Cooper, L. M. (1999, January). Identification and evaluation of driver errors: Task C report, driver error taxonomy development (Draft Technical Report). Project No. DTFH-61-97-C-00051. Blacksburg, VA: Virginia Tech, Center for Transportation Research.

Hanowski, R. J., Keisler, A. S., and Wierwille, W. W. (2001, February). Study of light vehicleheavy vehicle interaction: Phase A. study of light vehicle-local/short haul vehicle interaction. Contract No. DTFH61-96-C-00105. Blacksburg, VA: Virginia Tech Transportation Institute.

Hanowski, R. J., Wierwille, W. W., Garness, S. A., and Dingus, T. A. (2000, September). Impact of local/short haul operations on driver fatigue: Final report. Report No. DOTMC-00-203. Washington, DC: U.S. Department of Transportation, Federal Motor Carrier Safety Administration.

Hanowski, R. J., Wierwille, W. W., Gellatly, A. G., Early, N., and Dingus, T. A. (1998, August). Impact of local/short haul operations on driver fatigue: Focus group summary and analysis. Report No. FWHA-MC-98-029. Washington, DC: U.S. Department of Transportation, Federal Highway Administration.

Hanowski, R. J., Dingus, T. A., Gallagher, J. P., Kieliszewski, C. A., and Neale, V. L. (1999). Driver response to in-vehicle warnings. Transportation Human Factors Journal, 1(1), 91-106.

Massie, D. L., Blower, D., and Campbell, K. L. (1997). Short-haul trucks and driver fatigue (DTFH61-C-00038). Washington, DC: Office of Motor Carriers, Federal Highway Administration. 
Neale, V. L., Robinson, G. S., Belz, S. M., Christian, E. V., Casali, J. G., and Dingus, T. A. (1998, May). Impact of sleeper berth usage on driver fatigue, task 1: Analysis of trucker sleep quality. Report No. DOT-MC-00-204. Washington, DC: Office of Motor Carriers, Federal Highway Administration, U.S.D.O.T.

Robinson, G. S., Belz, S. M., Neale, V. L., Cooper, L. M., Dingus, T. A., Petersen, A., Bryson, M. J., Pace-Schott, E. F., Stickgold, R., and Casali, J. G. (1999, December). Impact of sleeper berth usage on long-haul driver fatigue: Task 4 \& 5, calibration and validation of data collection hardware \& data collection hardware installation. Contract No. DTFH61-96-C-00068. Blacksburg, VA: Virginia Tech Transportation Institute.

Schafer, A. (1999, November). The unsafe driving acts of motorists in the vicinity of large trucks, Analysis brief. Washington, DC: U.S. Department of Transportation, Office of Motor Carrier Safety

U.S. Department of Commerce. (1994, November). Truck inventory and use survey, 1992 census of transportation. Washington, DC: U.S. Government Printing Office.

Wang, J. S., Knipling, R. R., and Blincoe, L. J. (1999, April). The dimensions of motor vehicle crash risk. Journal of Transportation and Statistics. Vol. II, No. 1.

Wierwille, W. W. and Hanowski, R. J. (1998, July). Impact of local/short haul operations on driver fatigue: White paper addendum to task 2 report; recommended instrumentation and data to be collected for lane changing and backing. (DTFH61-96-C-00105). Blacksburg, VA: Center for Transportation Research, VPI \& SU.

Wierwille, W. W., Hankey, J. M., Kieliszewski, C. A., Hanowski, R. J., Medina, A., Lee, S. E., Keisler, A. S., and Dingus, T. A. (2001, April). Identification and evaluation of driver errors, task H report: Final project report. Contract No. DTFH61-97-C-00051. Blacksburg, VA: Virginia Tech Transportation Institute.

Wierwille, W. W., Kieliszewski, C. A., Hanowski, R. J., Keisler, A. S., and Olsen, E. C. B. (2000, July). Identification and evaluation of driver errors: Task E report, investigation of critical incidents (Draft Technical Report). Project No. DTFH-61-97-C-00051. Blacksburg, VA: Virginia Tech Transportation Institute.

Winters, J. J. (1998). An investigation of auditory icons and brake response times in a commercial truck-cab environment. Master's thesis, Virginia Polytechnic Institute and State University, Blacksburg, VA. 



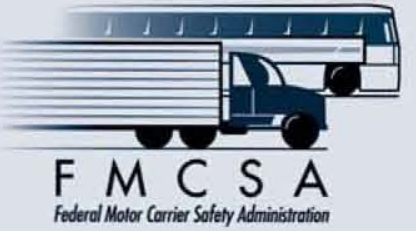

For more information on the Federal Motor Carrier Safety Administration and the Office of Research and Technology, check our website at www.fmcsa.dot.gov. 